UNIVERSIDADE DE SÃO PAULO

FACULDADE DE ECONOMIA, ADMINISTRAÇÃO E CONTABILIDADE DEPARTMENTO DE ADMINISTRAÇÃO PROGRAMA DE PÓS-GRADUAÇÃO EM ADMINISTRAÇÃO

TESE DE DOUTORADO

GESTÃO DE PROBLEMAS SOCIAIS COMPLEXOS E DESENVOLVIMENTO HUMANO

MANAGEMENT OF COMPLEX SOCIAL PROBLEMS AND HUMAN DEVELOPMENT

Hamilton Coimbra Carvalho

Advisor: Dr. José Afonso Mazzon

SÃO PAULO

2018 
Prof. Dr. Vahan Agopyan

Rector of University of São Paulo

Prof. Dr. Adalberto Américo Fischmann Director of School of Economics, Business and Accounting

Prof. Dr. Moacir de Miranda Oliveira Júnior

Chief of Business Administration Department

Prof. Dr. Moacir de Miranda Oliveira Júnior

Coordinator of the Post-Graduation Program in Business Administration 
HAMILTON COIMBRA CARVALHO

\title{
GESTÃO DE PROBLEMAS SOCIAIS COMPLEXOS E DESENVOLVIMENTO HUMANO
}

\section{MANAGEMENT OF COMPLEX SOCIAL PROBLEMS AND HUMAN DEVELOPMENT}

\begin{abstract}
Dissertation presented to the Business Administration Post-Graduate Program of the Business Administration Department of the School of Economics, Administration and Accounting, University of São Paulo, as a partial requirement for obtaining the title of Doctor of Science.
\end{abstract}

Advisor: Dr. José Afonso Mazzon

Versão original

SÃO PAULO

2018 
Autorizo a reprodução e divulgação total ou parcial deste trabalho, por qualquer meio convencional ou eletrônico, para fins de estudo e pesquisa, desde que citada a fonte.

FICHA CATALOGRÁFICA

Elaborada por Rafael Mielli Rodrigues - CRB-8/7286

Seção de Processamento Técnico do SBD/FEA/USP

Carvalho, Hamilton Coimbra

Management of complex social problems and human development /

Hamilton Coimbra Carvalho. - São Paulo, 2018.

$336 \mathrm{p}$.

Tese (Doutorado) - Universidade de São Paulo, 2018.

Orientador: José Affonso Mazzon.

1. Marketing social 2. Dinâmica de sistemas 3. Ciências da complexidade 4. Desenvolvimento humano 5. Pobreza I. Universidade de São

Paulo. Faculdade de Economia, Administração e Contabilidade. II. Título.

$$
\text { CDD }-658.8
$$


Mindware survives and spreads because of self-perpetuating properties of the mindware itself.

(Keith Stanovich) 
I dedicate this dissertation to my children, Eduardo and Cecilia; my wife, Amanda; my niece, Juliana; my nephew, Pedro; my brother, Christiano; my mother, Maria Aparecida; my father, Hamilton (in memoriam); and my grandfather, Navantino (in memoriam). 


\section{ACKNOWLEDGMENTS}

Words cannot express how grateful I am and always will be to Professor José Afonso Mazzon. From our first meeting, he has been the kindest human being and scholar one could hope to encounter in academic life. Everybody who has the privilege of knowing him and his work can easily understand what I am saying. He is characterized by rigor, high standards, thirst for knowledge, openness to new academic endeavors, honesty and an exceptional friendliness. Everybody knows that those traits, even in isolation, are rare in academia. Thus, it is clear how privileged I have been to be advised by Professor Mazzon. He has become my main role model in academia. I share with him a taste for integrative models that weave together different fields of knowledge to address relevant problems. Knowledge is too exciting and complex to be bounded by the artificial constraints of traditional academic disciplines. I still remember the day when I approached him to show him a chapter written by John Sterman, one of the giants in the field of system dynamics. I told him: "This is it! This kind of approach is what is missing in social marketing, and I would love to study it." Without any sign of doubt, and probably affected by my enthusiasm, he immediately gave me the green light to pursue that path. I also remember the enthusiasm in his voice every time I reported academic progress, no matter how slight (the first time I was invited to review a paper for a social marketing journal, the invitation to join the board of the International Social Marketing Association and many other events). I will never forget the support he gave me during very difficult times in my personal life. Only the sensation of accomplishment in finishing this work is stronger than the nostalgia and gratitude I feel while I write these words. I was one among many that have had the privilege of having their mindware shaped by Professor Mazzon's worldview and outstanding academic work. Now I am very happy to join the extensive but exclusive club that consists of his former advisees. For everything and a little more, thank you so much, Professor Mazzon!

I must also acknowledge all the support and friendship I have received from the great people who are integral to Professor Mazzon's professional and personal network: Jane Marques, Giuliana Isabella, Fabio Meletti, Adriana Cristo and Edson Oliveira.

I thank Professors Joaquim Santos and Silvia Koller for their valuable comments during the qualifying exam. I thank Professor Joaquim Santos twice over for being such a valuable mentor in the field of system dynamics. Among the lessons that I have taken to heart, I cite his advice to define clearly what problem a system dynamics model is addressing. Indeed, this is probably the most underrated skill in management.

I thank Professor Mike Radzicki at Worcester Polytechnic Institute for my short but precious stay at that institution.

Finally, I thank all the friends and colleagues who have contributed ideas, support and encouragement from the beginning of this project: Eduardo Franco, Kleber Oliveira, 
Alvaro Junqueira, Alexandro Afonso, Ângelo de Angelis, Gustavo Theodoro, Marcos Takahara, Vinicius Matsumoto and my work colleagues. 


\begin{abstract}
Complex social problems have multilevel roots and intricate webs of causation. They arise at the intersection of several of the spheres that comprise modern life: the physical, biological, cultural, political, social, economic, technological and environmental. They challenge the limited cognitive capacities of human beings, as delays, nonlinearities, policy resistance and complex interactions between the different parts of a system produce unforeseen consequences and patterns of systemic behaviors that are difficult to anticipate. Incentivized by the short-term focus of the political system, policy makers tend to act on the most visible parts of problems, which are often not causes but symptoms. They produce policies that often lead to worse conditions over time. Learning in complex systems, on the other hand, is hindered, because feedback from policies is typically opaque and amenable to distortion. This study draws on the complexity sciences, system dynamics, social marketing and related fields to address the issue of human development. We first explore the characteristics of complex social problems, showing that disciplines such as social marketing, based on individualistic mindware, are ill equipped to address them. The dissertation defends the need for a new interdisciplinary field (complex social problems management) capable of dealing with the challenging social problems of our times. In particular, we focus on the replication of low human development across generations, discussing the concepts of poverty, well-being and human development as well as the conditions that foster the development of essential psychobiological mechanisms in the first years of life. The discussion encompasses the social ecosystems that constrain opportunities for the poor and reinforce detrimental structures that produce toxic stress and low attention to human capital. A broad causal loop diagram summarizes the feedback loops that explain the persistence of this phenomenon. Based on the discussion in the first three chapters, we present three system dynamics models in the subsequent chapters, each one addressing an aspect of the problem. The first model, which we call the Caped model, focuses on parents' and children's essential capabilities and on the social environmental demands that deplete parents' psychological resources. The second model broadens the scope of the first and focuses on explaining why societies (in particular, Brazil) that are dominated by rent-seeking and extractive institutions produce detrimental social ecosystems. We uncover what seems to be a central mechanism, which is narrative (mindware) control. The third model deals with social change in general, and it aims to describe the channels and conditions by which that change occurs. It complements the analysis in the preceding chapters by identifying how a deep societal change toward the promotion of human development can occur. This dissertation contributes to the study of human development by employing a method that is suitable for modeling complex social problems. By identifying critical feedback loops and essential processes at the micro and macro levels, it provides integrative frameworks that complement research already conducted on the subject. From a practical perspective, the models can orient the design of better public policies and the design of adequate mindware for the discussion of human development.
\end{abstract}


Keywords: social marketing, system dynamics, complexity sciences, human development, poverty. 


\section{RESUMO}

Problemas sociais complexos possuem causas profundas e relações intrincadas de causalidade. Eles surgem na intersecção das diversas esferas que fazem parte da vida moderna: física, biológica, cultural, política, social, econômica, tecnológica e ambiental. Além disso, desafiam as capacidades cognitivas limitadas dos seres humanos, pois atrasos, não-linearidades, resistência a políticas e complexas interações entre as diferentes partes de um sistema produzem consequências não previstas e padrões de comportamentos sistêmicos que são difíceis de antecipar. Por sua vez, incentivados pelo foco de curto prazo do sistema político, gestores públicos tendem a atuar sobre as partes mais visíveis dos problemas, que frequentemente não são suas causas, mas seus sintomas. As políticas que são geradas com frequência levam à piora dos problemas no longo prazo. O aprendizado em sistemas complexos, por outro lado, é prejudicado porque o feedback das políticas é tipicamente opaco e sujeito a distorções. Esta tese busca inspiração nas ciências da complexidade, no campo da dinâmica de sistemas, no marketing social e em campos do conhecimento relacionados para tratar da questão do desenvolvimento humano. Inicialmente são discutidas as características dos problemas sociais complexos, argumentando-se que disciplinas como o marketing social, baseadas em modelos mentais (mindware) individualistas, são inadequadas para lidar com esse tipo de problema. Defende-se a necessidade de um novo campo interdisciplinar (gestão de problemas sociais complexos), capaz de lidar com os desafios das sociedades modernas. Em particular, foca-se na replicação intergeracional do baixo desenvolvimento humano, discutindo-se os conceitos de pobreza, bem-estar e desenvolvimento humano, bem como as condições que favorecem o desenvolvimento de mecanismos psicobiológicos essenciais nos primeiros anos de vida. A discussão abrange os ecossistemas sociais que limitam as oportunidades para os pobres e reforçam estruturas viciadas que produzem stress tóxico e uma baixa atenção ao capital humano. Na tese, um diagrama de malhas causais identifica as malhas de feedback que explicam a persistência do fenômeno. Com base na discussão nos três primeiros capítulos, apresentam-se três modelos de dinâmicas de sistemas nos capítulos seguintes, cada qual abordando um aspecto do problema. $\mathrm{O}$ primeiro modelo, chamado de modelo Caped, enfatiza as capacidades essenciais de pais e crianças, bem como as demandas do ambiente social que exaurem os recursos psicológicos dos pais. O segundo modelo amplia o escopo do primeiro e foca na explicação dos mecanismos pelos quais sociedades dominadas pela caça à renda (rentseeking) e por instituições extrativas (em particular, o Brasil) produzem ecossistemas sociais viciados. Identifica-se o que parece ser um mecanismo central, o controle de narrativas (mindware). $\mathrm{O}$ terceiro modelo trata de mudança social em geral e objetiva descrever os canais e condições pelos quais ela ocorre. O modelo complementa os capítulos anteriores ao identificar como uma profunda mudança social objetivando a promoção do desenvolvimento humano poderia ocorrer. A tese contribui com o estudo do desenvolvimento humano por meio do emprego de um método que é talhado para modelar problemas sociais complexos. Ao identificar malhas críticas de feedback e processos essenciais nos níveis micro e macro, apresentam-se modelos integrativos que complementam as pesquisas feitas sobre o tema. Sob uma perspectiva prática, os modelos 
podem auxiliar no desenho de melhores políticas públicas e no desenho de modelos mentais (mindware) adequados para a discussão do desenvolvimento humano.

Palavras-chave: marketing social, dinâmica de sistemas, ciências da complexidade, desenvolvimento humano, pobreza. 


\section{CONTENTS}

1. MANAGEMENT OF COMPLEX SOCIAL PROBLEMS AND HUMAN DEVELOPMENT ............21

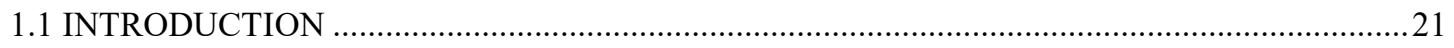

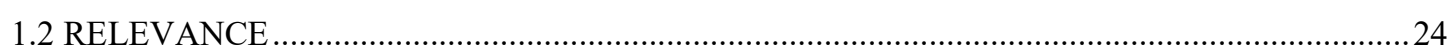

1.2.1 WHY DO WE NEED A NEW META-DISCIPLINE? ….......................................................24

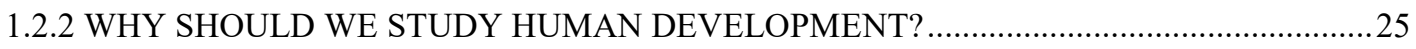

1.2.3 WHY SHOULD WE STUDY THE DYNAMICS OF THE BRAZILIAN STATE? .................25

1.2.4 WHY SHOULD WE USE SYSTEM DYNAMICS? ................................................................2.

1.2.5 WHY SHOULD WE STUDY MINDWARE AND SOCIAL CHANGE? .................................26

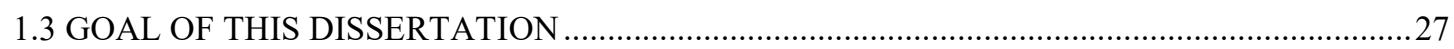

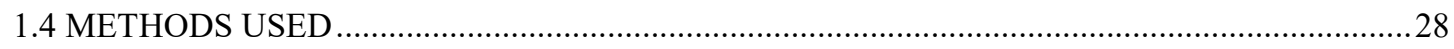

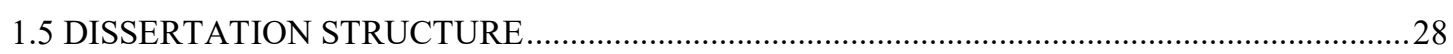

2. LEAVING SOCIAL MARKETING BEHIND TO EMBRACE COMPLEXITY ……..............................30

2.1 THE GAP BETWEEN SOCIAL MARKETING AND COMPLEX SOCIAL PROBLEMS ...........30

2.2 SOCIAL MARKETING: THE TRADITIONAL NARROW DOWNSTREAM APPROACH .......31

2.3. CRITICISM OF THE TRADITIONAL FOCUS OF SOCIAL MARKETING.................................33

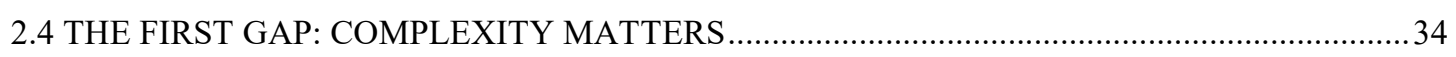

2.4.1 THERE HAS BEEN LITTLE CROSS-FERTILIZATION ………………………....................

2.4.2 AN EXAMPLE: ETHANOL, TORTILLA RIOTS AND THE ARAB SPRING .......................38

2.4.3 THE PLAGUE OF EVENT-ORIENTED WORLDVIEWS .......................................................

2.4.4 THE UNIVERSAL ACID OF COMPLEXITY SCIENCES..........................................................42

2.4.5 SYSTEMS THINKING AND SYSTEM DYNAMICS ………….............................................. 48

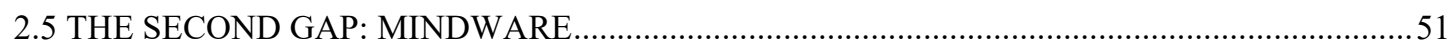

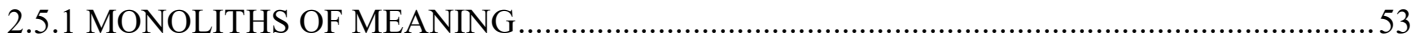

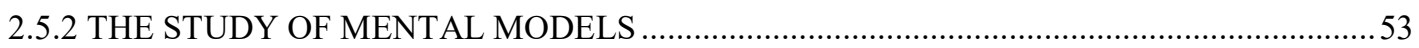

2.5.3 THROWING THE BABY OUT WITH THE BATHWATER: PROMOTION OF IDEAS IN

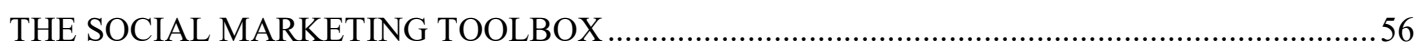

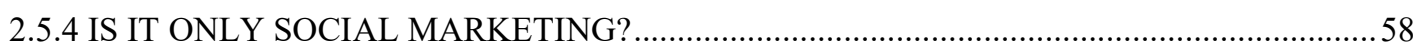

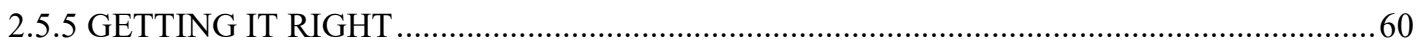

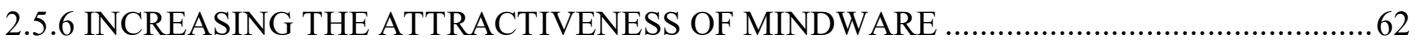

2.6 THE NEED FOR A META-DISCIPLINE: LEAVING SOCIAL MARKETING BEHIND............63

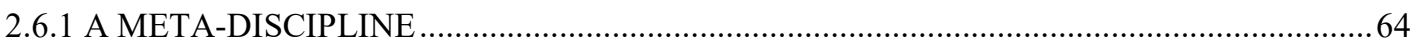

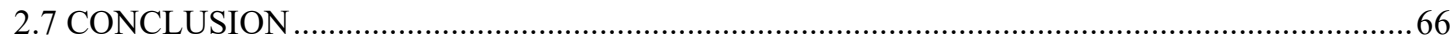

3. POVERTY, HUMAN DEVELOPMENT AND HIGH-ORDER CAPABILITIES ..................................6

3.1 AN AMBIDEXTROUS APPROACH TO HUMAN DEVELOPMENT ...........................................68

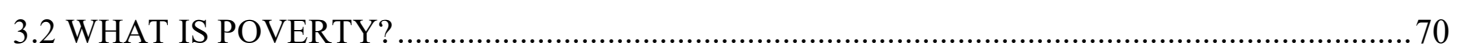

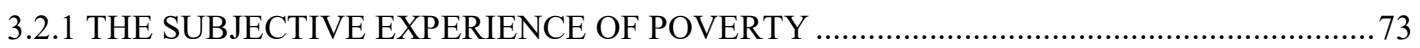


3.2.2 AGAIN, WHAT IS POVERTY?.

3.3 THE OTHER FACET OF HUMAN DEVELOPMENT: WELL-BEING AND FUNDAMENTAL

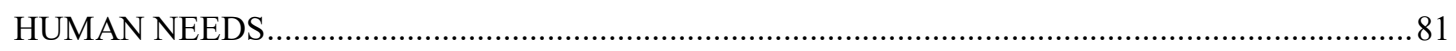

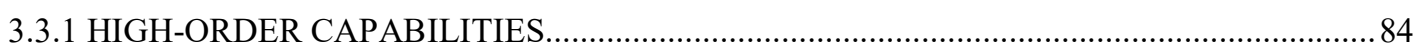

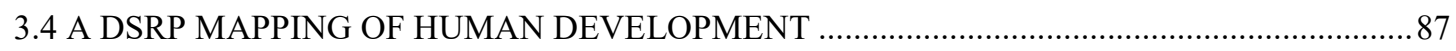

3.5 DISCUSSION AND CONCLUSION: SOCIAL ECOSYSTEMS MATTER ..............................89

4. THE SCOURGE OF WASTED LIVES: HOW SOCIAL ECOSYSTEMS HINDER HUMAN

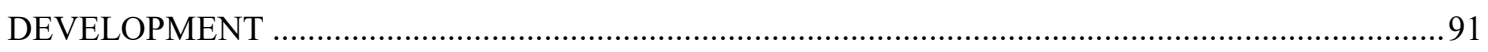

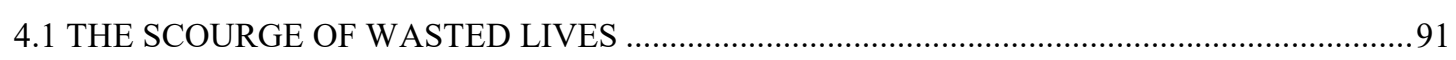

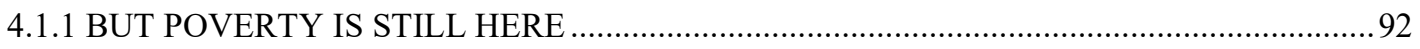

4.2 WHY IT IS IMPORTANT: CONSEQUENCES OF GROWING UP POOR, OR THE CURSE OF

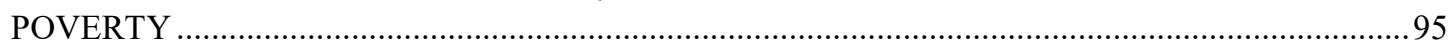

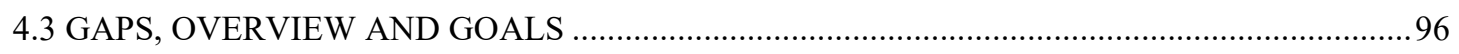

4.4 THEORETICAL PERSPECTIVES: A MULTILEVEL APPROACH ..........................................98

4.4.1 THE IMPORTANCE OF THE FIRST YEARS OF LIFE ............................................... 100

4.4.2 ENVIRONMENTAL INSTABILITY: THE EVOLUTIONARY PERSPECTIVE ................104

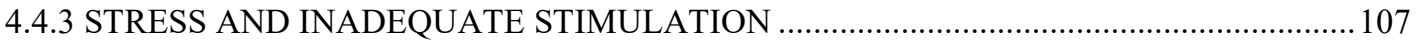

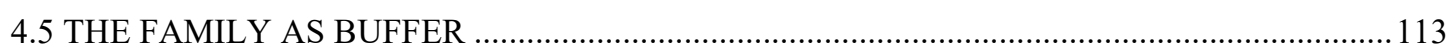

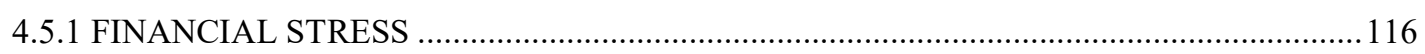

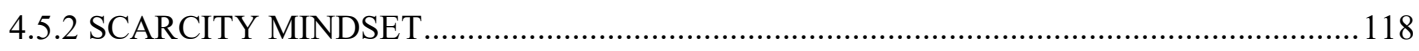

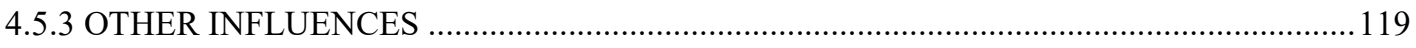

4.5.4 HOW SOCIETIES CREATE STRUCTURES THAT PERPETUATE LOW HUMAN

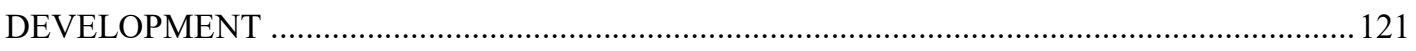

4.6 COMMON INTERVENTIONS TO BREAK THE CYCLE ...................................................... 124

4.6.1 CHILDCARE AND EARLY EDUCATION ............................................................... 125

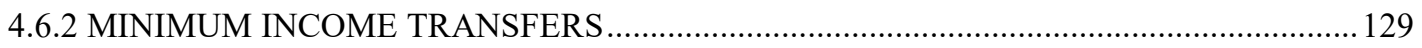

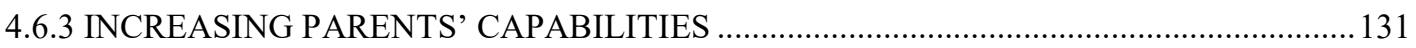

4.7 SYSTEM DYNAMICS: BUILDING A CAUSAL LOOP DIAGRAM ...................................... 132

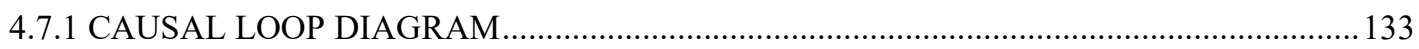

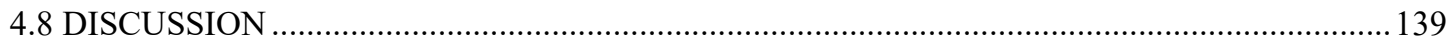

4.8.1 WHY INVESTMENT IN EARLY CHILDHOOD WILL (VERY PROBABLY) BE INSUFFICIENT IN THE COMING DECADES ............................................................... 139

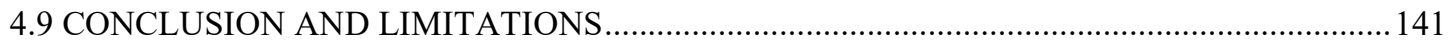

5. THE CAPED MODEL: INTERGENERATIONAL PERSISTENCE OF LOW HUMAN

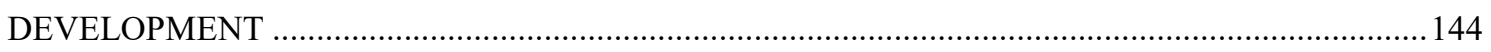

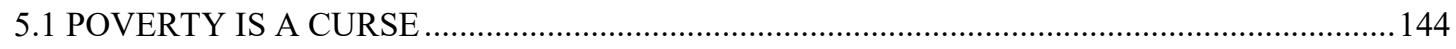

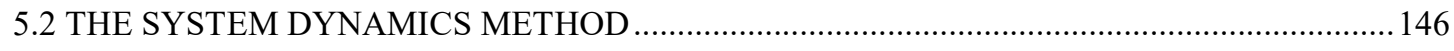

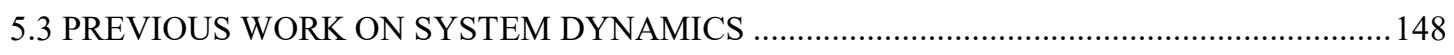

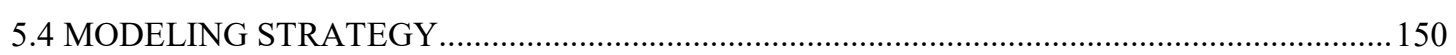

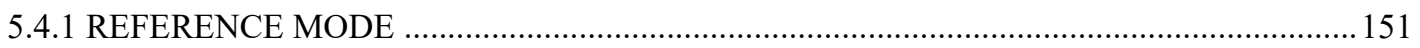




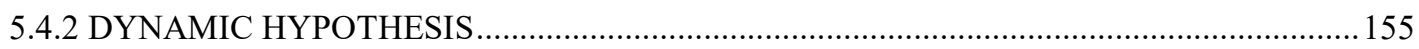

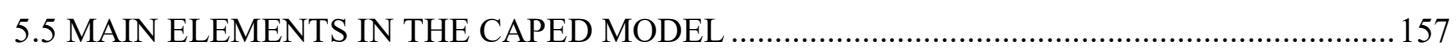

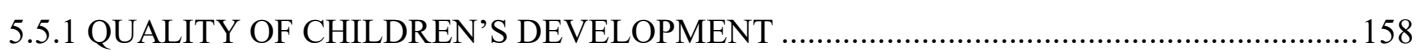

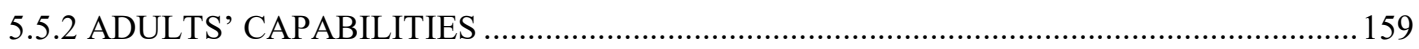

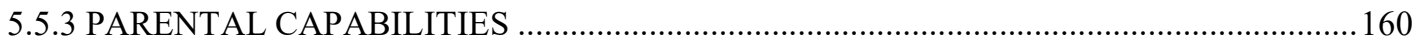

5.5.4 HARSHNESS OF ENVIRONMENTAL DEMANDS................................................................. 161

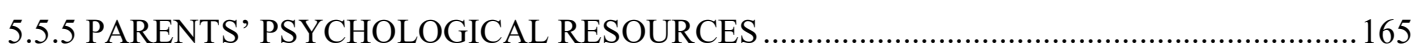

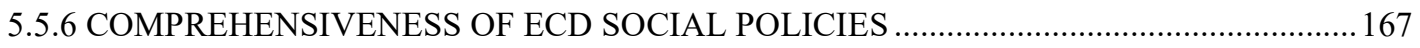

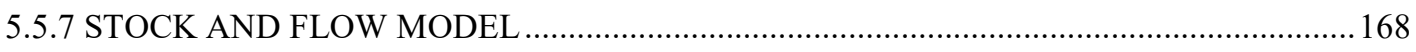

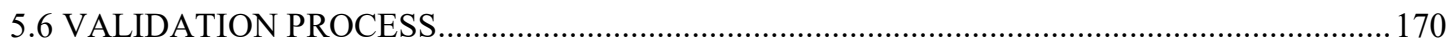

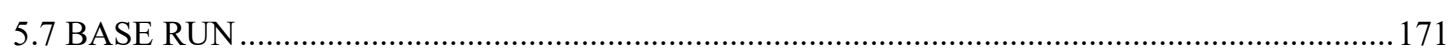

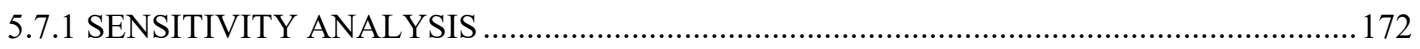

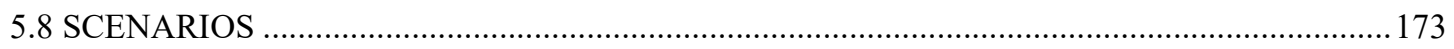

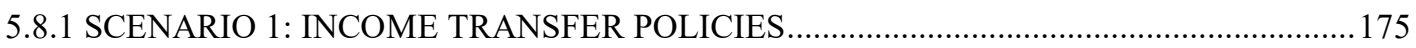

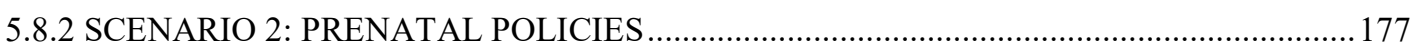

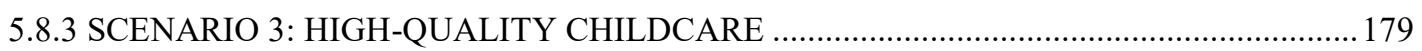

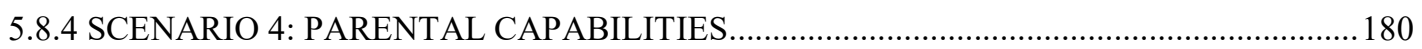

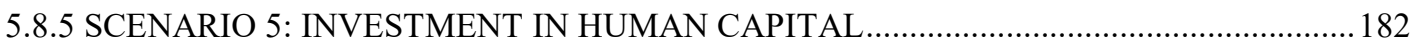

5.8.6 SCENARIO 6: ALLEVIATING ENVIRONMENTAL HARSHNESS.................................... 184

5.8.7 SCENARIO 7: COMPREHENSIVE POLICIES ……….......................................................... 186

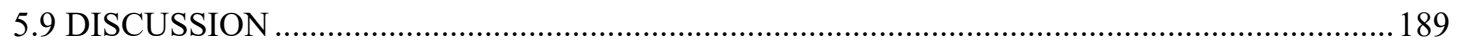

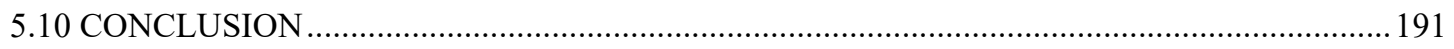

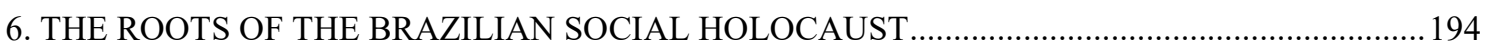

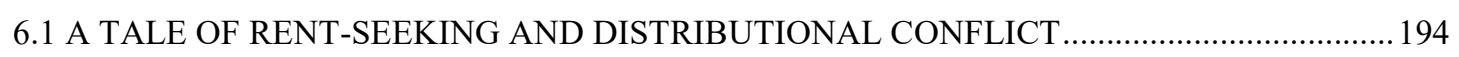

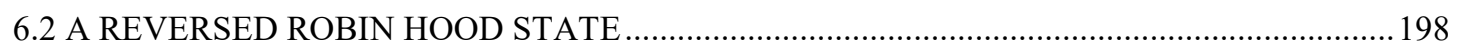

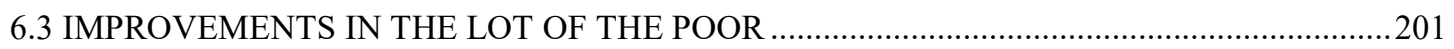

6.4 THERE IS NOWHERE TO HIDE: SOCIETAL DISCOMFORT ...............................................203

6.5 THE MINDWARE WAR: NARRATIVES AND POLITICAL DISCOURSE ................................206

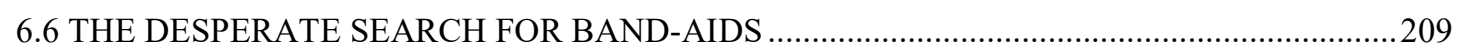

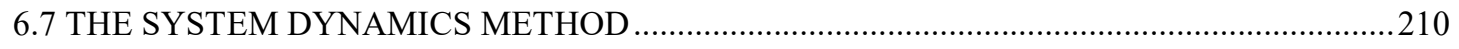

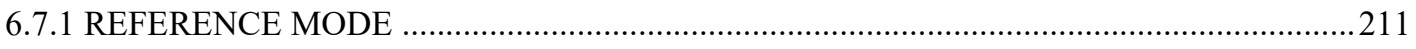

6.7.2 DIAGRAM OF SUBSECTORS AND MODEL BOUNDARY CHART ................................211

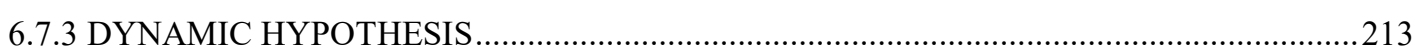

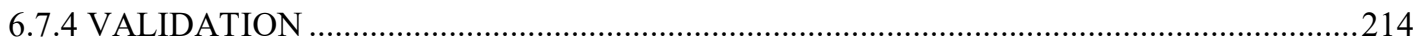

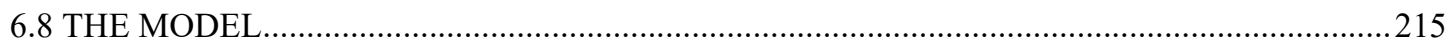

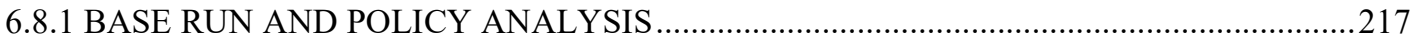

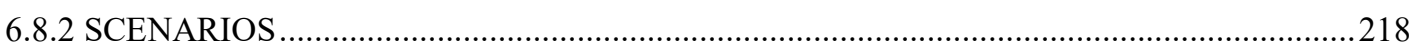

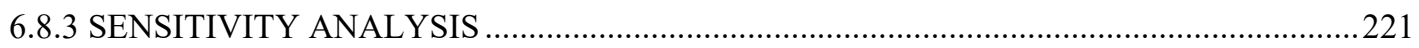




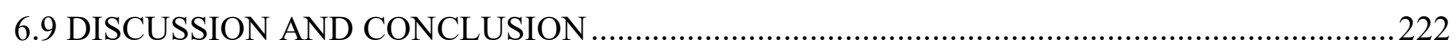

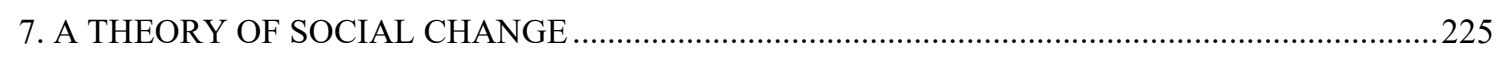

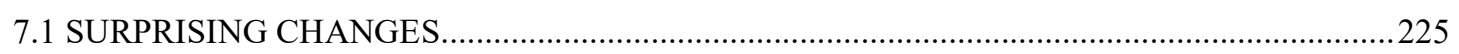

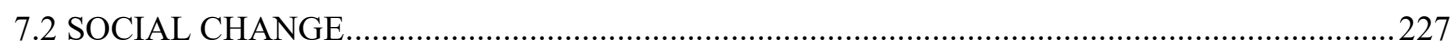

7.3 PREVIOUS WORK IN THE SYSTEM DYNAMICS LITERATURE.........................................228

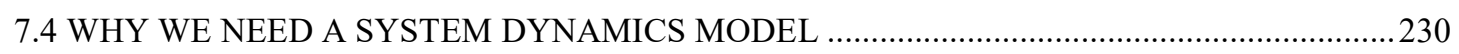

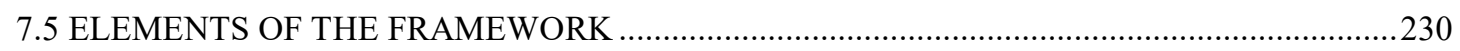

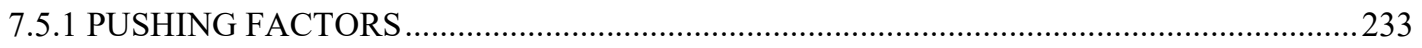

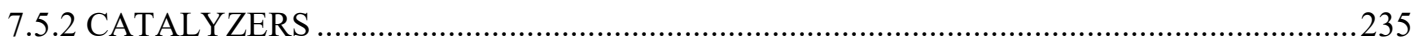

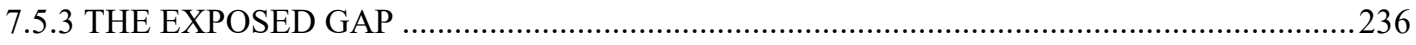

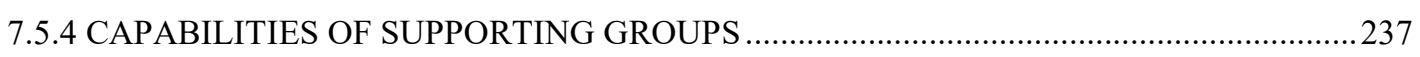

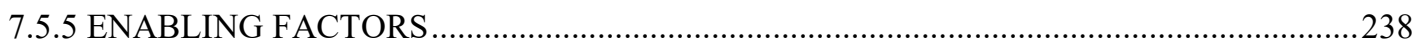

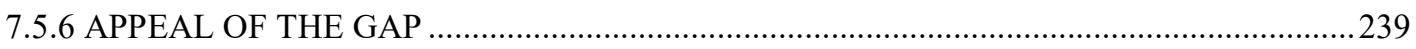

7.5.7 COUNTERPRESSURE FROM OPPOSING GROUPS, DISABLING FACTORS AND THE

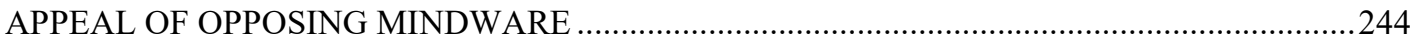

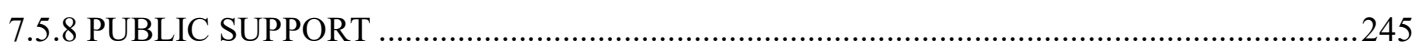

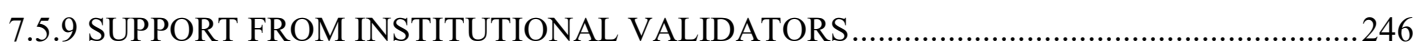

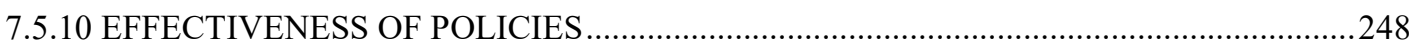

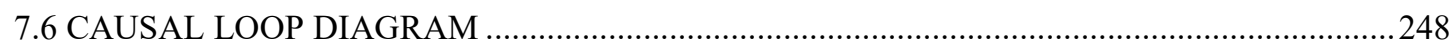

7.7 VALIDATION

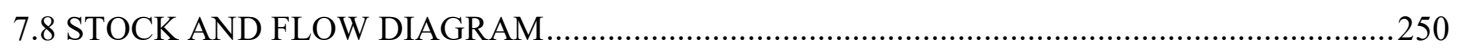

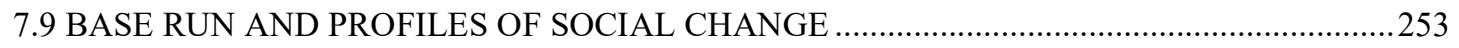

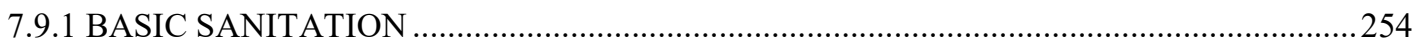

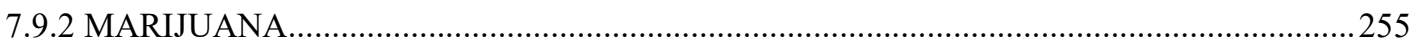

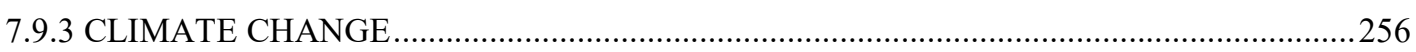

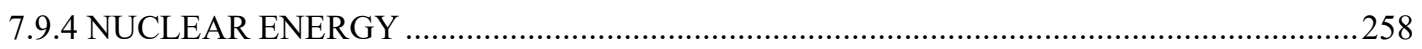

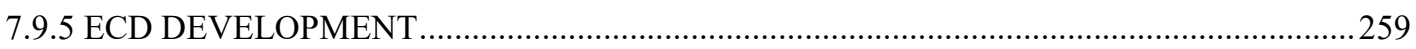

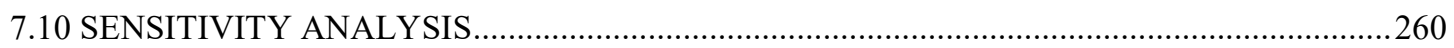

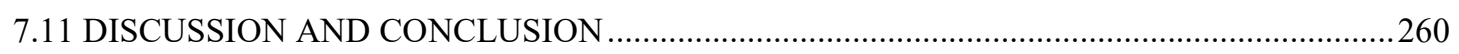

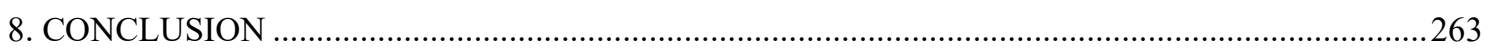

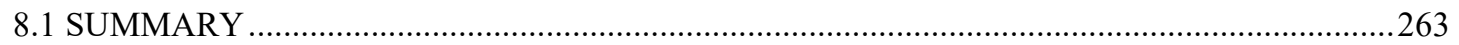

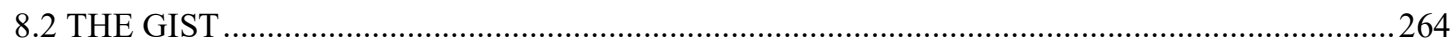

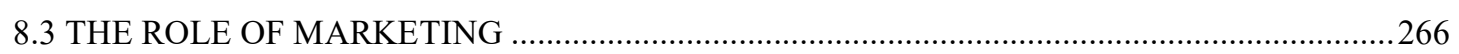

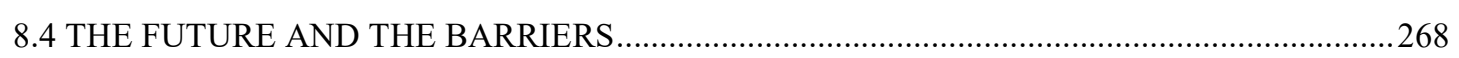

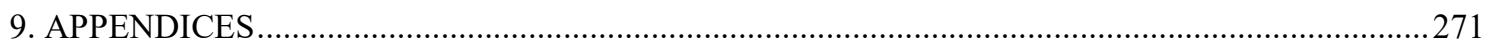

9.1 APPENDIX A: ADDITIONAL DISCUSSION OF MENTAL MODELS AND POLICIES TO

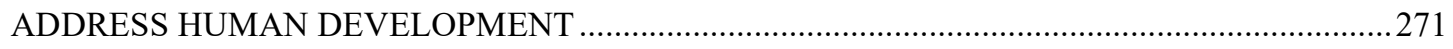

9.1.1 AN EXAMPLE CONTRASTING LINEAR MENTAL MODELS AND SYSTEMS THINKING 
9.1.2 THERE IS LITTLE GUIDANCE ON HOW TO ADDRESS POVERTY FROM A COMPLEXITY PERSPECTIVE

9.2 APPENDIX B: MORE DETAIL ON SYSTEM DYNAMICS AND ITS NOTATIONS.............280

9.3 APPENDIX C: WICKED PROBLEMS AND OUR CONTRIBUTION.....................................285

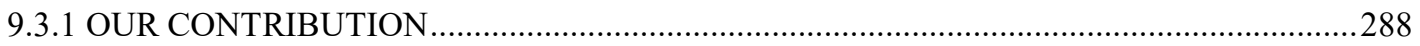

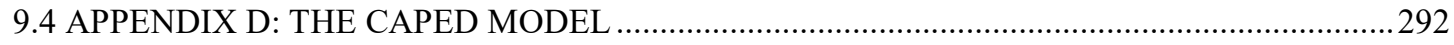

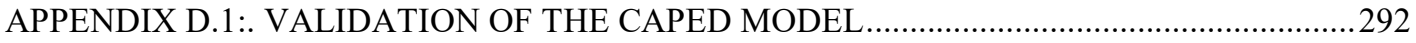

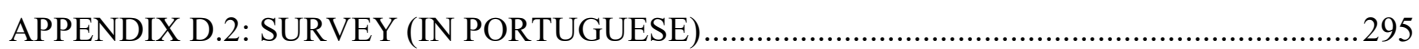

APPENDIX D.3: EQUATIONS FOR THE CAPED MODEL _..................................................297

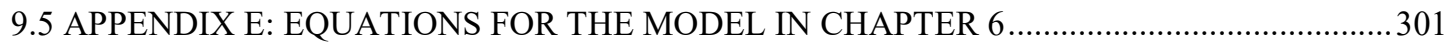

9.6 APPENDIX F: EQUATIONS FOR THE MODEL OF SOCIAL CHANGE ..............................304

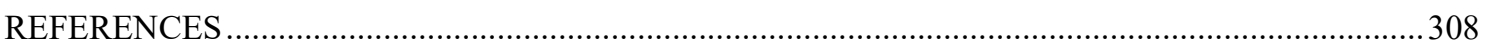




\section{LIST OF FIGURES}

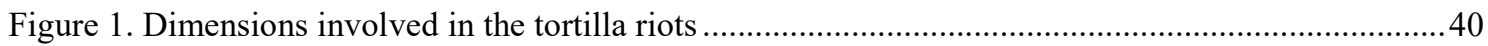

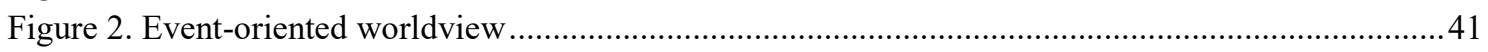

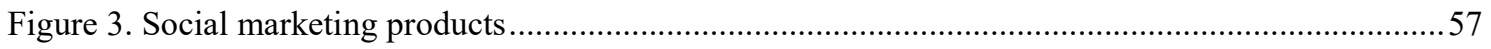

Figure 4. Disentangling individual generative capabilities from other stocks ..................................... 86

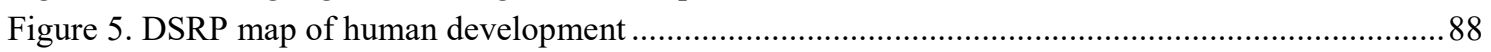

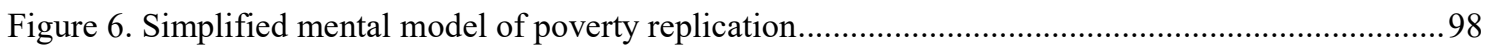

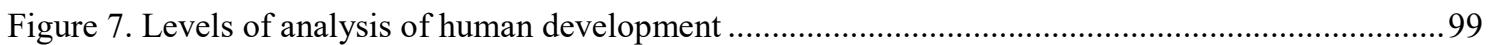

Figure 8. Sensitive periods for competences in early brain development ........................................... 103

Figure 9. Analytic model of how poverty affects black children in the United States .......................... 120

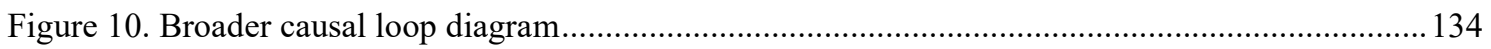

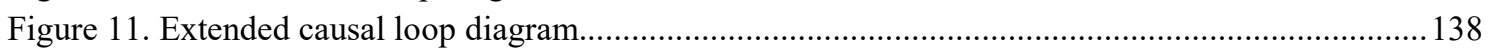

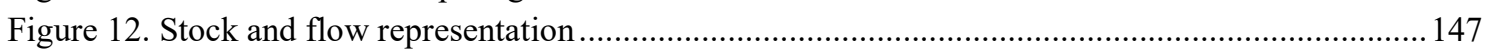

Figure 13. Example of feedback loops driving the evolution of a stock ............................................. 148

Figure 14. Reference mode for the Caped model .............................................................................. 152

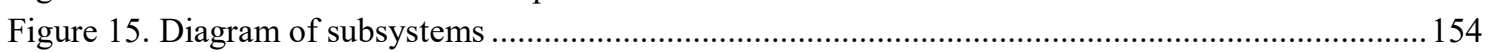

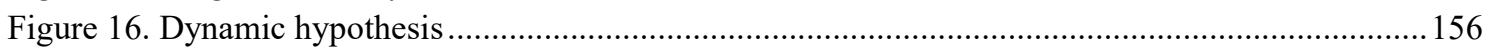

Figure 17. The role of neuroscience in addressing socioeconomic status-related disparities.................. 157

Figure 18. Average age at death across the 96 neighborhoods in the city of São Paulo (Brazil) .............. 162

Figure 19. Harshness of environmental demands and adults' capabilities ........................................... 164

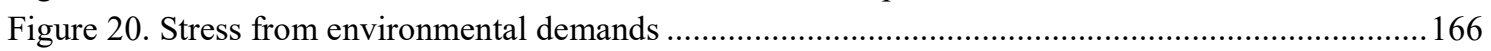

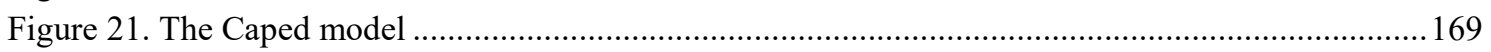

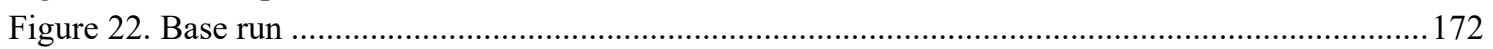

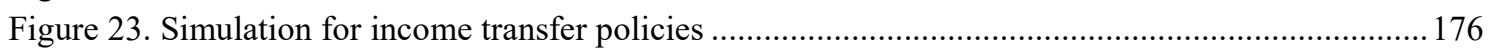

Figure 24. Sensitivity analysis for the efficacy of income transfer policies ......................................... 177

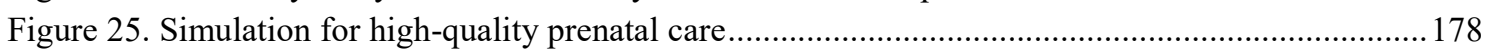

Figure 26. Sensitivity analysis for effects of prenatal care policies.................................................... 178

Figure 27. Simulation for high-quality childcare policies ............................................................. 179

Figure 28. Sensitivity analysis for effects of high-quality childcare policies ...................................... 180

Figure 29. Simulation for policies to increase parental capabilities ................................................... 181

Figure 30. Sensitivity analysis for effects of policies to increase parental capabilities ..........................182

Figure 31. Simulation for policies to increase human capital........................................................... 183

Figure 32. Sensitivity analysis for effects of policies to increase human capital ................................. 184

Figure 33. Simulation for policies to attenuate environmental demands.............................................. 185

Figure 34. Sensitivity analysis for the effects of policies to attenuate environmental demands..............186

Figure 35. Simulation results for four levels of comprehensive policies............................................ 188

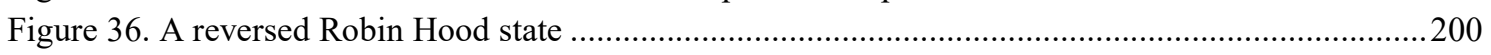

Figure 37. Evolution of Gini coefficient in Brazil (1976-2014) .............................................................202

Figure 38. Evolution of Human Development Index in Brazil..............................................................2202

Figure 39. Evolution of teen pregnancy in Brazil.............................................................................203

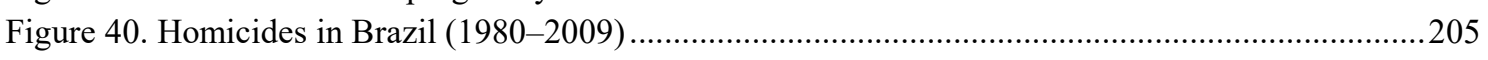

Figure 41. Evolution of worker productivity in Brazil ........................................................................206

Figure 42. A: warning in a high-income residential building in the city of São Paulo. B: A "cage" in a

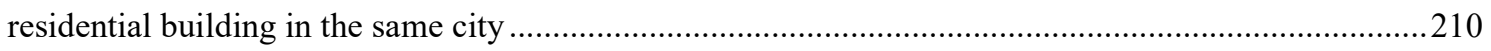

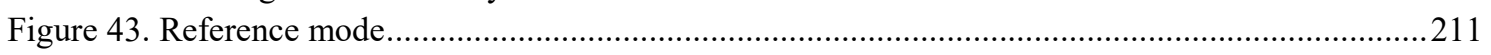

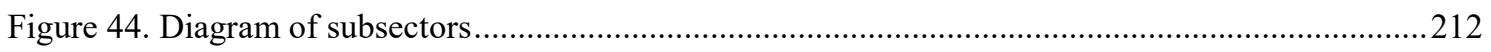

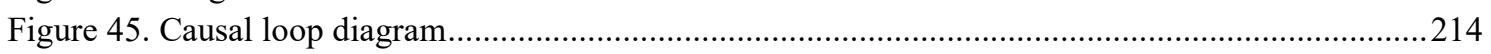

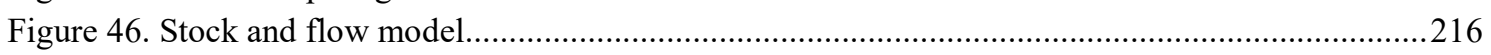

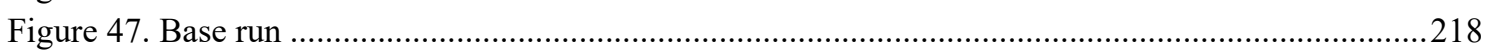

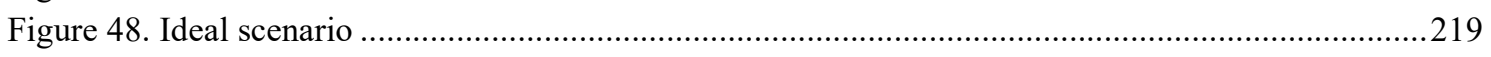




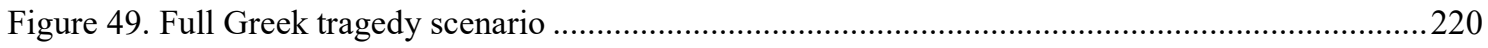

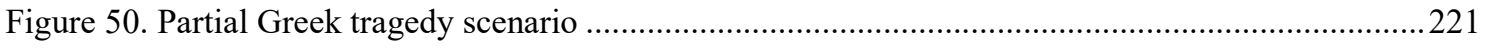

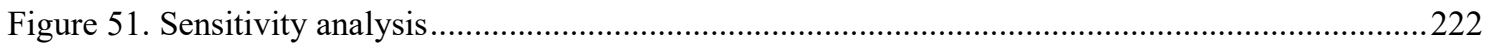

Figure 52. Sample of shifting attitudes in the United States..........................................................226

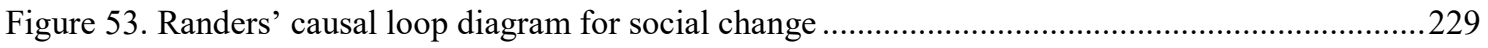

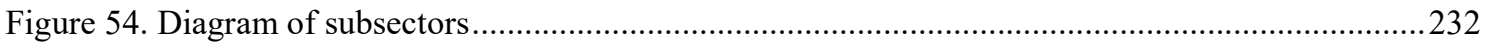

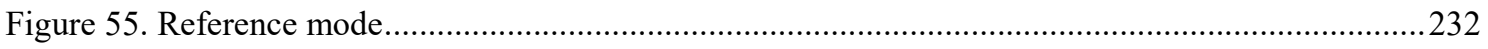

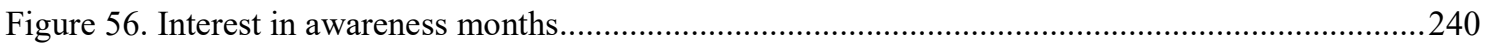

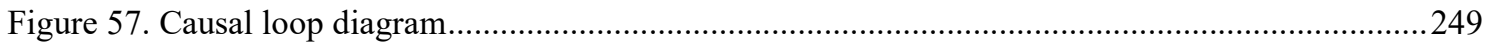

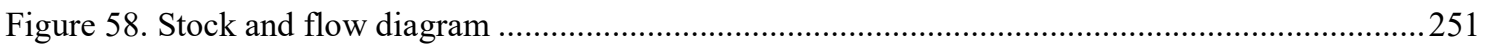

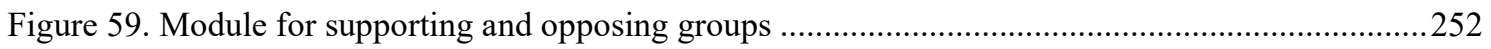

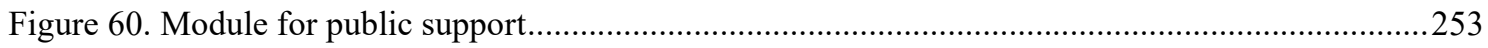

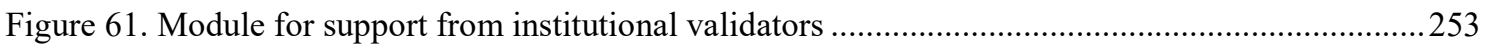

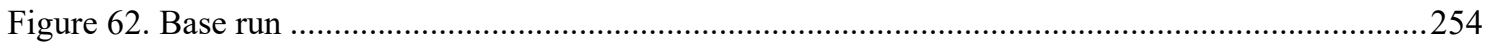

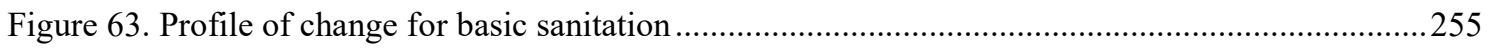

Figure 64. Profile for change: acceptance of marijuana ..................................................................256

Figure 65. Profile for change: climate change mindware ..................................................................257

Figure 66. Profile for change: climate change mindware with the presence of a catalyzer....................258

Figure 67. Profile for change: repealing nuclear energy ............................................................259

Figure 68. Profile for change: ECD development ........................................................................260

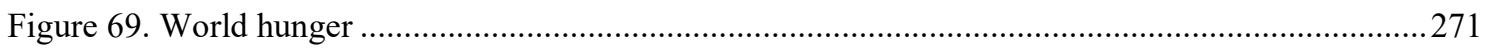

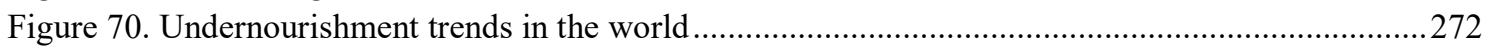

Figure 71. Usual mental model elicited to fight hunger ................................................................2 274

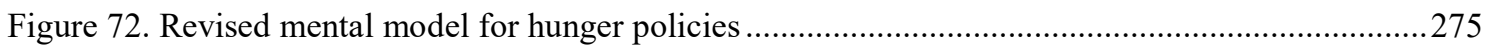

Figure 73. Revised causal loop diagram for hunger policies ...........................................................2276

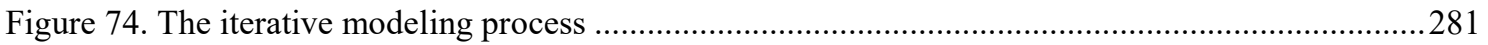




\section{LIST OF TABLES}

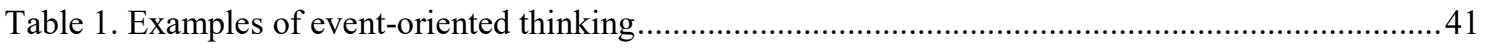

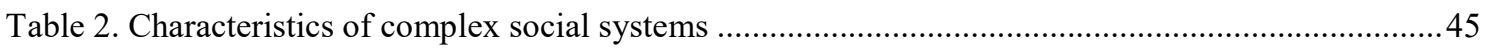

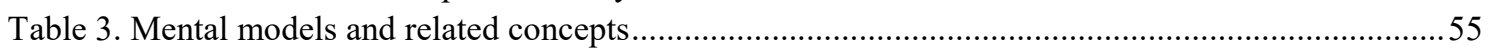

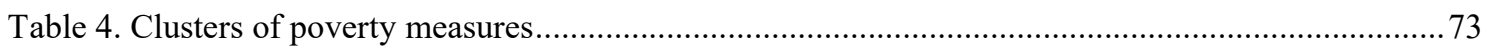

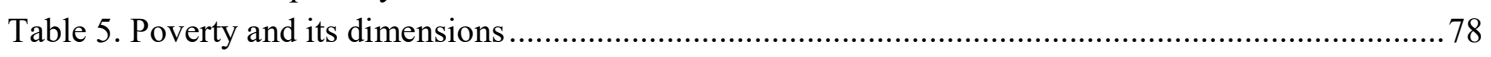

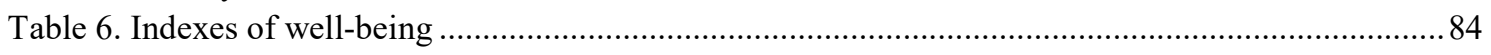

Table 7. Selected social indicators associated with poverty in childhood ................................................93

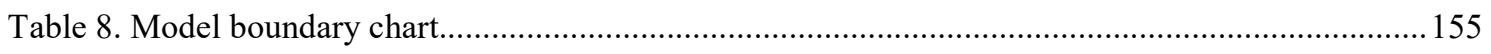

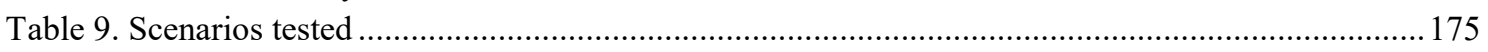

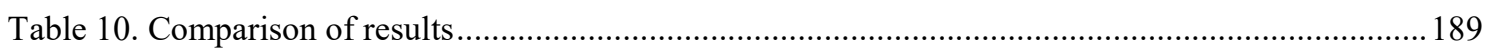

Table 11. Does the mindware of political parties incorporate rent-seeking?..........................................208

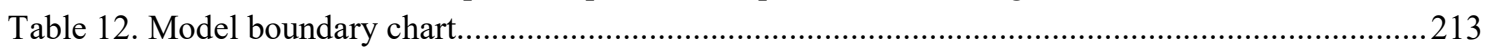

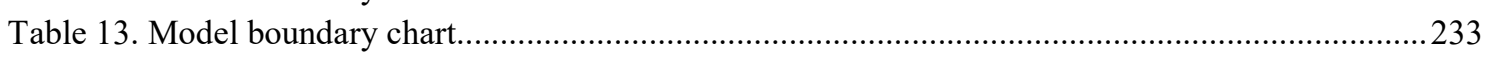

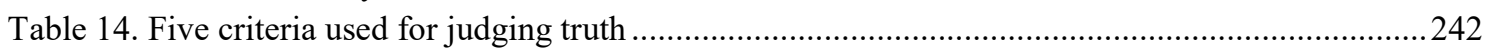

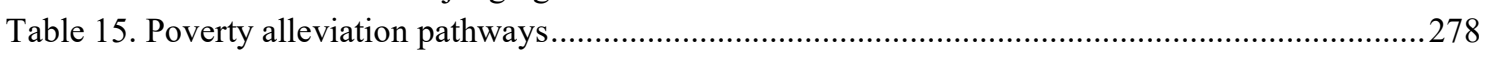

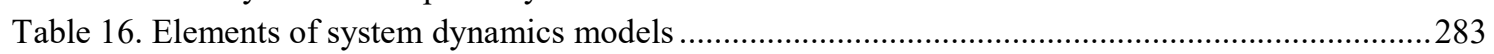




\section{MANAGEMENT OF COMPLEX SOCIAL PROBLEMS AND HUMAN DEVELOPMENT}

No society can surely be flourishing and happy, of which the far greater part of the members are poor and miserable. (Adam Smith)

\subsection{INTRODUCTION}

Progress over recent decades has significantly reduced poverty in most countries in the world. There are unprecedented levels of prosperity, health and education in our societies. On average, people live longer and better. However, there is a growing perception that this progress is not enough - average measures of human development does not capture either suffering or squandered opportunities for developing human potential. In other words, the distribution does not follow a normal curve; it is skewed. As the Nobel Prize winner Amartya Sen puts it, we live in a world of unprecedented opulence but also in a world with remarkable deprivation, destitution and oppression (Sen, 1999). Opulence and destitution, to different degrees, occur in most countries of the world, including, of course, Brazil.

Lifting people out of poverty is like treating a vulnerable individual for a disease. In such cases, getting better is different from having good health. Hence, as governments make progress in tackling poverty, they must cope with a different challenge: that of developing a social ecosystem conducive to the attainment of human potential. Moral concerns may be a powerful motivator behind this transformation, but economic interests usually carry more weight. In this sense, economic development in the twenty-first century will increasingly depend on knowledge workers and on the provision of complex products and services. Countries trapped in poverty, or trapped in the middle-income range, such as Brazil, will face higher barriers to continuing their development if they do not change the social structures that produce inadequate levels of human capital.

Poverty is one among several social problems whose nature has become more complex in recent decades. Corruption, environmental degradation, transit congestion and drug trafficking are other examples of problems that have been increasingly resistant to public policy. They are affected by the growing interrelationships among natural, social, 
economic, political, technological and cultural spheres in modern societies. In the case of poverty, for instance, the same structures and processes that have decreased its incidence have also contributed to climate change and increased pollution (Sterman, 2012). In the same vein, the evolution of technology for the detection of traffic violations has made speeding and other undesirable behaviors easier to detect, but technology has also empowered drivers to detect speed cameras and avoid fines. With the increasing intricacy of human-made domains, natural phenomena such as hurricanes can, in a short time, wreak havoc on the harmony of a society though unforeseen channels, as in the case of Hurricane Katrina and the subsequent tortilla riots in Mexico in 2007 (discussed in chapter 2). Globalization and technology weave together different systems on a scale unknown only three decades ago.

Whereas there is growing recognition among experts that social problems are caused by the complex interplay of variables from different spheres, this knowledge has not reached public policy makers, media pundits and influencers. It is still very common to witness politicians adopting simplistic narratives, blaming individuals for social problems or focusing on symptoms instead of root causes. Inspired by linear mental models, policies very often worsen the problems they are intended to address.

Nevertheless, there is hope. The growth of complexity sciences over recent decades has provided new conceptual and methodological tools to deal with complex social problems, overcoming some of the limitations of traditional disciplines. The challenge is to translate complexity frameworks into actual strategies. Above all, the challenge is to shape new mental models, or mindware, as we refer to them throughout this dissertation. These challenges also provide opportunities for new academic contributions.

Hence, this dissertation is about complexity, systems thinking, human development and behavior change. It is high time we overcame fragmented approaches, which often aim to change the points in social systems that have high visibility but low leverage for change, while the structures that produce the problems remain intact.

This dissertation makes explicit the need for a new (meta-) discipline with the goal of integrating knowledge from applied behavioral sciences and complexity sciences. We note that distinctions among disciplines are to varying degrees arbitrary (Meadows, 2002b). We also recognize that this is a strong proposal; nevertheless, it is a necessary one. All disciplines tend to fragment complex problems and validate propositions 
according to their narrow baseline assumptions (Davis, 1971). Integration is a necessary step in addressing the change in the nature of complex social problems.

To give another simple example, it is illusory to try to preserve a specific endangered species, such as the orangutan, while ignoring the systemic forces that endanger its habitats. These forces include deforestation for the production of palm oil, the state of poverty of the indigenous population, the lack of resilience of natural systems in which they live and macro forces such as global warming (Zolli \& Heally, 2012).

Moreover, tackling complex social problems demands the comprehension of how human beings make sense of their worlds. Changing behavior using traditional approaches is not enough. If we hope to move our systems in appropriate (and often counterintuitive) directions, we need to design new mental models endowed with two crucial features accuracy and appeal. Thus, it is necessary, first, to grasp the functioning of systems and, second, to market compelling mindware.

These premises are the foundation of this dissertation. Delving into different literatures and streams of research, the dissertation proposes a general model for human development, stressing the importance of the first years of life, on the one hand, and influences from the social ecosystem, on the other. It also discusses the case of low human development in Brazil, a country that has been relatively successful in reducing extreme poverty while facing limitations on its attempts to grow its human capital and develop its economy.

Brazil epitomizes a particular type of socioeconomic trap. Brazilian society suffers the consequences of having unequal structures, but it remains blind to the root causes of the ensuing problems. The country curbs the potential for human development of the majority of its population, paying a steep price in terms of low worker productivity, crime and other social maladies.

Indeed, a poor child's potential is crippled from the moment he or she is born. One hallmark of unequal societies where extractive institutions predominate is the placement of the inequality burden directly on the shoulders of poor children - if low human development has a face in Brazil, it is a child's face. Children that depend on educational and health services provided by the state have a disproportionate chance of becoming citizens endowed with low human capital, condemned to replicate the lives of their parents. However, poor children or their relatives typically do not protest on the streets. 
Their faint voice is suffocated, and public discourse instead reproduces the interests of rent-seekers. Children are the greatest victims of a distorted social system that, in the end, prevents Brazil from overcoming the middle-income trap. If a country could be compared to a garden, the Brazilian social ecosystem would be an arid soil that prevents the full development of human potential, thus sapping the country's economic potential. This dissertation dissects this ecosystem and models the underlying web of causes. In particular, it shows that the state is an agent in the intergenerational propagation of social inequity.

Development, in Sen's (1999) view, consists of removing the various types of "unfreedoms" that leave people with little choice and little opportunity to exercise their agency. In this dissertation, I argue that human development requires more than the removal of such restrictions. It encompasses the deliberate building of a more fertile social ecosystem.

\subsection{RELEVANCE}

\subsubsection{WHY DO WE NEED A NEW META-DISCIPLINE?}

At least three knowledge creation strategies fit the deductive-conceptual approach: bridging disciplines, challenging assumptions and introducing mediators and moderators (Janiszewski, Labroo, \& Rucker, 2016). This dissertation focuses on the first two strategies in particular, although the third is naturally encompassed by the system dynamics methodology that inspires most of this work. ${ }^{1}$ Nonetheless, the dissertation goes a step further than the traditional approach of bridging disciplines (e.g., using evolutionary theory to generate insights into consumer or organizational behavior). Instead of an interdisciplinary bridging, this dissertation proposes a meta-discipline to deal with complex social problems. As systems thinker Donella Meadows recognizes, "the right boundary about a problem rarely coincides with the boundaries of an academic discipline" (Meadows \& Wright, 2008, p. 98). As she also suggests, living in a world of systems requires, among other points, a celebration of complexity and a defiance of the disciplines. Interestingly, we are not the first to identify the need for a new integrative

\footnotetext{
${ }^{1}$ There is a lively discussion in the system dynamics literature about the epistemological nature of the approach, whether deductive or inductive (see, for instance, Groëßler, 2008). This dissertation does not delve into that discussion, assuming instead that the method can encompass both approaches.
} 
discipline to deal with complex modern problems (e.g., Bammer, 2017). However, our contribution reinforces calls for a new discipline by identifying gaps in traditional approaches while also advancing the need for certain elements that are absent from other proposals.

\subsubsection{WHY SHOULD WE STUDY HUMAN DEVELOPMENT?}

Human development concerns the expression of human potential, which has several consequences for modern societies. The most direct consequence is economic: a society with higher levels of human capital will create conditions for an increase in economic productivity and higher levels of development. In a world where knowledge workers and economic complexity are key to continuous development, no society can afford to squander human talent. From an ethical standpoint, understanding how societies can create social ecosystems conducive to human development is necessary to level the playing field for all citizens and avoid the suffering associated with poverty. This knowledge is also essential for producing better mental models to orient the design of public policies.

\subsubsection{WHY SHOULD WE STUDY THE DYNAMICS OF THE BRAZILIAN} STATE?

Like any national state, the Brazilian state is a major agent in allocating resources and enacting policies that ultimately define the state of human development in the country. The literature on institutions and rent-seeking shows that the allocation of resources may favor privileged segments, thereby reinforcing social inequality and limiting potential for economic development. However, there is little comprehension of why these processes remain unchallenged. Unequal societies such as Brazil seem to be blind to the root causes of the discomfort they necessarily feel in such a context, preferring instead to address symptoms. This dissertation explores these processes via a system dynamics model.

\subsubsection{WHY SHOULD WE USE SYSTEM DYNAMICS?}

System dynamics is one of the most powerful and flexible methods for representing complex systems. Since its birth almost six decades ago, it has been used to model a wide 
range of phenomena in several scientific disciplines, such as engineering, economics, business management, biology, ecology and social sciences. Remarkably, modern societies still struggle to understand and tackle complex social problems. As Jay Forrester, the founder of system dynamics, wrote, public policy keeps creating new problems by employing "obvious" solutions that do not work - and this seems truer today than ever. The method of system dynamics is particularly appropriate for dealing with important characteristics of complex social systems, such as nonlinearities, time delays, intricate webs of causation, stocks, flows and feedback loops. System dynamics allows the use of interdisciplinary lenses and the development of testable frameworks for addressing complex social phenomena.

\subsubsection{WHY SHOULD WE STUDY MINDWARE AND SOCIAL CHANGE?}

In social marketing, the discipline that gave birth to this project, the promotion of ideas to produce social change was once a legitimate goal, but that view has been modified in recent decades. We argue in this dissertation that ditching ideas from the repertoire of goals was a mistake. We live in an age of discord, to borrow a term from the cliodynamicist Peter Turchin. The marketplace of ideas is the arena where narratives, ideologies and mental models battle for one of the scarcest resources of the modern world - human attention. Prevailing mental models determine the lens through which societies see their problems and seek solutions to address them. In practice, they set the boundaries of the discussion of complex social problems. Moreover, social change is often preceded by change in narratives and ideologies. Therefore, how collective mental models are shaped by diverse interest groups or by individual agents of change, and how citizens draw their mental models from that collective cultural repertoire, is of central importance in the effort to change societies for the better.

Diverse social movements involved in issues such as marijuana use, gay rights, gender equality and promotion of ideologies (e.g., "the free market") have relied with considerable success on changing public attitudes. Consider the case of the gay rights movement, which has relied on pride parades and other initiatives to raise awareness and challenge prejudice. In many countries, these initiatives have changed societal attitudes toward gays from negative to neutral or positive. They have shaped public discourse. In the end, public support can provide the legitimization needed to garner political support, 
which is essential if laws and institutions are to change. For several kinds of major social cause, making social progress seems to require this kind of prior foundational work on building public support.

\subsection{GOAL OF THIS DISSERTATION}

In broader terms, this dissertation aims to explain the persistent state of low human development in countries such as Brazil through the lens of the complexity sciences and applied social sciences. In addition, it intends to push the boundaries of social marketing to the point of rupture. From the point of view of the academic and the practitioner, behavior change related to complex social problems demands an interdisciplinary stance. Individuals are parts of systems, and their behaviors are in most cases determined by the structures underlying these systems. Moreover, an adequate understanding of complex social systems is necessary to identify the points in the system with most potential for transformation, as well as relevant social actors whose behavior and mindware must be changed if one hopes to produce enduring social change.

Hence, the goals of this dissertation are:

1. the proposal of a new discipline capable of integrating the complexity sciences and applied behavior change sciences;

2. the conceptualization of human development;

3. the identification of mechanisms that lead to the replication of low human development;

4. the design, simulation and validation of system dynamics models that simulate that replication, from a micro and a macro perspective;

5. the design, simulation and validation of a system dynamics model of social change.

From a theoretical perspective, the present research contributes to the fields of applied social sciences, public policy and human development by developing integrative models that cut across the boundaries of several disciplines.

From a methodological perspective, this dissertation contributes to the diversification of methods for addressing human behavior and complex social problems, in particular through the use of simulations and scenarios. The integration between the complexity 
sciences and applied behavioral sciences, in particular, may help to end the "downstream curse" that still characterizes disciplines such as social marketing.

Finally, from a managerial perspective, this dissertation makes contributions that are useful to public policy makers and social actors tackling human development (and social change) by identifying channels for action and elements that must integrate practical interventions.

\subsection{METHODS USED}

The dissertation employs literature review, the distinction, systems, relationships and perspectives (DSRP) method (see chapter 3) and the system dynamics method.

\subsection{DISSERTATION STRUCTURE}

This dissertation is divided into eight parts: an introduction, six chapters (chapters 2, 3, 4, 5, 6 and 7) and a conclusion. The introduction presents an overview of the dissertation. The chapters 2, 3 and 4, which could be merged into a single unit, represent the foundation for the following chapters. Chapters 5, 6 and 7 were conceived as independent units (papers), reflecting different but complementary approaches to the overall theme of complex social problems and human development.

Chapter 2, "Leaving social marketing behind to embrace complexity," discusses the challenges and boundaries of social marketing as a discipline, and the need for systems and complexity thinking and for marketing mindware. It proposes a new discipline, which we call complex social problems management (CSP management).

Chapter 3, "Poverty, human development and high-order capabilities," discusses the concepts of poverty, well-being and human development. It also proposes the concept of individual generative capabilities and frames the discussion using the DSRP method.

Chapter 4, "The scourge of wasted lives: how social ecosystems hinder human development," discusses the major drivers of the replication of low human development, with a focus on the influences in the first years of life. It presents a causal loop diagram (CLD) to consolidate the review. 
Chapter 5, "The Caped model: intergenerational persistence of low human development," presents a system dynamics model of human development focusing on critical capabilities and on the influence of environmental demands.

Chapter 6, "The roots of the Brazilian social holocaust," advances a system dynamics model to explain the role of the Brazilian state in the perpetuation of low human development in the country. It highlights the importance of an often-overlooked mechanism for maintaining the status quo, namely narrative control by rent-seekers.

Chapter 7, "A theory of social change," proposes a system dynamics model to account for general processes of social change. If societies depend on the creation of new mindware and new policies to stimulate human development (among other causes), what are the channels? Why does change occur in certain circumstances? When is change virtually inevitable and when is it very difficult to induce?

Chapter 8, "Conclusion," ties the preceding chapters together, discussing implications for public policy makers, limitations and suggestions for future studies.

Finally, we present six appendices encompassing the model equations, system dynamics notation and additional discussions on complexity and systems thinking. 


\section{LEAVING SOCIAL MARKETING BEHIND TO EMBRACE COMPLEXITY}

There is an even more fundamental reason why simulation is essential. There is no learning without feedback, without knowledge of the results of our actions. Traditionally, scientists generated that feedback through experimentation. But experiments are impossible in many of the most important systems. When experimentation is too slow, too costly, unethical or just plain impossible, when the consequences of our decisions take months, years, or centuries to manifest, that is, for most of the important issues we face, simulation becomes the main-perhaps the only - way we can discover for ourselves how complex systems work, where the high leverage points may lie. (John Sterman)

\subsection{THE GAP BETWEEN SOCIAL MARKETING AND COMPLEX SOCIAL PROBLEMS}

This chapter deals with the gap between complex social problems and the mental models crystalized in the discipline of social marketing.

Complex social problems remain widespread in modern societies. It is astonishing to find that, almost five decades after the release of the classic book The Limits to Growth (Meadows, Meadows, Randers, \& Behrens III, 1972), the same complex problems mentioned in the book are still here. These problems include poverty in the midst of plenty, degradation of the environment, economic disruption, insecurity of employment, low trust in institutions and uncontrolled urban spread.

Complex social problems result from interactions among a myriad of social actors, each responding to different structures of incentives and each striving to maximize the attainment of his or her particular goals. Often, individuals behaving in response to the goals of their subsystems prevent the overall societal system from reaching its desirable goals. Consider how politicians sometimes resort to populist policies to increase their electoral capital through short political cycles. The public, on the other hand, tends to reward illusory policies that relieve the symptoms of social problems while not recognizing the long-term importance of policies such as basic sanitation or early childhood development (ECD). The media needs to sell information, but complex 
information does not sell well, so it often relies on pundits who oversimplify important issues. Nongovernmental organizations push their particular goals, competing in a crowded marketplace of ideas that overvalues "sexy" causes, and so it continues.

Another way to contemplate the issue is by considering that complex social problems arise at the intersection of the different spheres that encompass human life, as in the case of the tortilla riots described in section 2.4.2. These spheres comprise natural, cultural, social, technological, economic, demographic, political and historical forces, and they have been interacting at an accelerating pace, generating constant waves of unexpected problems for modern societies.

On the other hand, while the complexity of social problems keeps increasing, the design of public policies still adheres to inadequate mental models, leading to sequences of failed interventions that often aggravate the very problems they are intended to address. Public policy makers, of course, rely on collective mental models, which are products of cultural, historical and scientific developments.

Nevertheless, the increase in complexity of social problems has not been accompanied by an evolution in the disciplines or frameworks intended to address them. In this chapter, we focus on the discipline of social marketing, recognizing that the same criticisms could be applied to related disciplines that reflect linear paradigms, such as behavioral economics.

Our goal is twofold. First, we aim to expose the inadequacy of social marketing to tackle complex social problems. Second, we propose the need for a meta-discipline. Inspired by the complexity sciences, such a discipline would be able to integrate knowledge of human behavior from diverse disciplines to address the complex problems of our modern societies.

\subsection{SOCIAL MARKETING: THE TRADITIONAL NARROW DOWNSTREAM APPROACH}

The discipline of marketing was not immune to the social and cultural effervescence of the 1950s. Starting with Wiebe (1952), who asked why society could not sell brotherhood in the same way it sells soap (after all, the central concept of marketing is exchange), a progressive consensus started to form in support of the use of business concepts to tackle 
social issues. A hallmark of this moment was the successful family planning program delivering condoms in India during the 1960s (Lefebvre, 2011).

In a seminal paper in 1971, Philip Kotler and Gerald Zaltman christened the discipline of social marketing (Kotler \& Zaltman, 1971) as an organized approach to planning and implementing social change. The authors stressed that the vision of marketing was quite distinct from that of hard selling. Instead, they saw the new discipline as a "bridging mechanism that links the behavioral scientist's knowledge of human behavior with the socially useful implementation of what that knowledge allows" (p. 12). In other words, social marketing should concern the use of applied social science to bring about desired social change.

Most aspects of a social marketing intervention are similar to the familiar commercial approach. The presence of the following elements typically defines a social marketing program (Gordon, Carrigan, \& Hastings, 2011; Kotler \& Lee, 2016):

- Customer orientation: the offer has either to solve a problem the target audience has or to satisfy a want or need.

- Behavioral goals: interventions should have a clear focus on behavior.

- Exchange: the audience perceives benefits that are equal or exceed the perceived costs. Benefits can be tangible (e.g., rewards) or intangible (e.g., personal satisfaction, well-being or pride).

- Marketing research and pre-testing: a clear understanding of target audiences' perspectives is developed. Programs are insight driven, leading to a focus on gaining a deeper understanding of what motivates people.

- Full utilization of marketing mix: the famous four Ps (promotion, place, price and product) are used and, sometimes, other proposed "Ps" (people and policy change, for instance).

- Positioning: strategies that will position the desired behaviors more favorably than the competition are identified, understood and developed. Strategies may also be sought to remove barriers or minimize forces supporting the competition. The latter encompasses behaviors already in place as well as organizations and influential individuals promoting different behaviors.

- Judicious use of theory: interventions should draw on integrated theoretical frameworks. 
- Measurement of results and learning: feedback is used to improve current and future interventions.

Social marketing, like commercial marketing, is a discipline whose goal is to influence behaviors. However, as one of the most recent definitions implies, the discipline has focused on individuals and communities to the neglect of other levers in the social system. According to the International Social Marketing Association (International Social Marketing Association, 2013),

Social Marketing seeks to develop and integrate marketing concepts with other approaches to influence behaviors that benefit individuals and communities for the greater social good. Social Marketing practice is guided by ethical principles. It seeks to integrate research, best practice, theory, audience and partnership insight, to inform the delivery of competition sensitive and segmented social change programs that are effective, efficient, equitable and sustainable.

\subsection{CRITICISM OF THE TRADITIONAL FOCUS OF SOCIAL MARKETING}

Definitions of social marketing typically do not hint at mechanisms that influence upstream actors and bring about social change. Social marketing essentially is (or should be) about marketing social change (Gordon, Carrigan, \& Hastings, 2011). Even one of its founders recently acknowledged that a better name for the discipline would be "social cause marketing" (Kotler, 2017).

Nonetheless, with notable exceptions (e.g., French \& Gordon, 2015; Hastings \& Domegan, 2007) there is little attention in the literature to complex social systems and how they produce undesirable behaviors. Even in cases where attention is paid to broader influences on behavior, there is little comprehension of the structure and the dynamics of systems.

For instance, Kennedy, Kapitan, Bajaj, Bakonyi, and Sands (2017), using the fast fashion industry as a case study, propose an approach based on the analysis of stakeholders, networks, social mechanisms of interaction and cooperation, structures of governance and identification of shared narratives. While this makes a valuable contribution to the literature, the approach fails to take into account elements essential to the dynamics of complex problems, such as multilevel feedback loops, delays and nonlinearities. Because it lacks a "grammar" to analyze and simulate these dynamics, such as system dynamics 
(see section 5.2 for more information), the framework also fails to identify leverage points for change. Finally, although the approach emphasizes the importance of shared narratives, the authors do not to discuss at length the role social marketing could have in reshaping the predominant mental models of upstream and downstream actors.

The criticism levied here is not new. The strong focus on downstream and individualbased approaches is notorious in the social marketing literature (e.g., Corner \& Randall, 2011; Biroscak, 2014). There is an exaggerated focus on formulaic approaches to behavior change, which often prevents the use of interdisciplinary lenses (French \& Gordon, 2015).

Additionally, there is little guidance on how to effect change in societal systemic structures through upstream approaches (Andreasen, 2006). Biroscak (2014) offers the community-based prevention marketing (CBPM) framework as an upstream approach for social marketing. However, that framework, although it accounts for important courses of action to promote policy change, such as coalition building and advocacy, still seems insufficient in light of the gaps that will be discussed in sections 2.4 and 2.5.

We conclude this section by making a strong statement: social marketing has been flying blind for most of its history. By focusing on the visible parts of a system, especially the behavior of downstream individuals, by mostly ignoring complexity and systems thinking and by failing to adopt a true interdisciplinary stance, social marketing has produced results that are valuable but insufficient to address modern complex social problems.

We consider under two headings what we see as the major gaps preventing the discipline from producing relevant social change: the complexity gap and the mindware gap. We now discuss these in turn.

\subsection{THE FIRST GAP: COMPLEXITY MATTERS}

Most complex social problems have multilevel roots and a complex web of causation. Moreover, they exhibit a characteristic that politicians and public policy makers tend to ignore: the systems in which they are embedded are policy resistant (Sterman, 2000a). Interventions to improve the system often lead to worse conditions over time. Building roads to alleviate congestion is the classic example of this. The greater the number of roads, the more traffic over time. As Bandura (1997) remarks, some of the policies that 
cause harm were originally well intentioned - the harmful effects are typically unforeseen. Forrester (1971) insightfully acknowledges that evolution has not provided human beings with the necessary mental skills to interpret the dynamic properties of the systems we live in. Worse, social systems are far more complex than technological ones. As Forrester remarks, our prevailing mental models simply cannot anticipate the consequences of interactions between the parts of social systems.

Complex social problems are incongruous with mental models that rely on linear or single-cause explanations. However, in practice there are few frameworks to circumvent the prevalence of linear models. In discussing what they call the dawn of systems leadership, Senge, Hamilton, and Kania (2015) stress that self-sustaining changes in social systems are not the product of the volition of leaders. Instead, change depends on the creation of appropriate conditions, which, in turn, requires a proper visualization of the entire system. Most people in any complex system, they argue, tend to focus on the parts of the system most visible from their vantage point. One viable way out of this predictable trap is to engage stakeholders in the creation of a systems map that captures all the necessarily different perceptions of a given problem, but this is often not possible within our outdated policy venues.

Complex problems do not respect academic boundaries. Acemoglu and Robinson (2013, pp. 68-69) provide perhaps one of the best examples regarding the consequences of adopting limited viewpoints. Speaking of the income inequalities that characterize the modern world, they claim that

poor countries are poor because those who have power make choices that create poverty. They get it wrong not by mistake or ignorance but on purpose. To understand this, you have to go beyond economics and expert advice on the best thing to do and, instead, study how decisions actually get made, who gets to make them, and why those people decide to do what they do. This is the study of politics and political processes. Traditionally economics has ignored politics, but understanding politics is crucial for explaining world inequality. As the economist Abba Lerner noted in the 1970s, "Economics has gained the title Queen of the Social Sciences by choosing solved political problems as its domain." We will argue that achieving prosperity depends on solving some basic political problems. It is precisely because economics has assumed that political problems are solved that it has not been able to come up with a convincing explanation for world inequality. Explaining world inequality still needs economics to understand how different types of policies and social arrangements affect economic incentives and behavior. But it also needs politics. 


\subsubsection{THERE HAS BEEN LITTLE CROSS-FERTILIZATION}

Complexity matters, but there has been little cross-fertilization between social marketing and complexity sciences (including systems thinking). Most instances of use of complexity concepts in social marketing are qualitative and cursory. In addition, examples of rigorous systemic methods applied to social marketing are rare.

It is not the case, however, that marketing has been immune to concepts from other disciplines. For instance, the paths of systems thinking and the marketing discipline crossed when a particular instance of the former (general systems theory) was used as reference for the influential work of Fisk (1967). Their paths would cross again on other occasions (e.g., French \& Gordon, 2015, in the field of social marketing), but the crossfertilization did not bear much fruit besides a superficial understanding of how systems work. Fisk (1967), for instance, discusses (very briefly) hierarchies of goals, the role of interacting variables, negative feedback, delays and the classic elements of systems represented by inputs, constraints and outputs. He was mostly interested in the interrelationships among production, marketing and consumption. His work attests to the nature of "universal acid" that some few theoretical bodies occasionally acquire. The general systems framework was very popular at the time, especially because of novel theoretical developments in biology and information sciences (Richardson, 1999).

A few social marketers have, however, identified the need for systems thinking in the discipline. We now briefly discuss these exceptions.

Hastings and Domegan (2007) claim that social marketing should aim to realign market structures with wider societal values instead of just applying downstream formulaic solutions to social problems. This upstream approach entails the alignment of public policy decisions, corporate marketing decisions and civil society. They argue that social marketing's repertoire should encompass the identification of collective sources of problems, the use of coordinated approaches and long-term, strategic critical thinking. They also recognize (p. 269) that behavior change is inextricably linked to societal change, which requires a move from playing simple tunes (i.e., using standard commercial tools to influence individual behaviors) to running a complete symphony (i.e., addressing the problems in all their complexity): 
The need for systems thinking becomes even more apparent when we move from small decisions about shopping to large-scale problems with multiple stakeholders such as global warming. These sorts of problems are not only complex, but also typically conflicted because differing interests have to be accommodated. The oil industry will have one perspective, Friends of Earth another and car-owners a third-with politicians caught in the middle trying to please multiple constituencies while also hoping to get re-elected. These problems become so intractable they are sometimes termed "wicked" and the temptation is to ignore them. It is much easier and more pleasant to focus on simpler actions a bit of recycling here and litter-picking there. But, when, as with planetary degradation, the problems are systemic, the solutions have to be equally wide ranging. (emphasis added)

In turn, Kennedy and Parsons (2012) call positive social engineering the combination of macro-social marketing with other social technologies that facilitate social change. In explaining the government-sponsored anti-smoking campaign in Canada, they identified the critical factors of success as a coordinated combination of social marketing, legislation, regulation, education, funding, community mobilization and research. Finally, Biroscak (2014) provided a substantial contribution to the social marketing literature by employing system dynamics to model policy implementation in communitybased marketing programs (Biroscak, 2014).

Outside the social marketing field, but still under the marketing theoretical umbrella, macromarketing is the sole example of a marketing sub-discipline specifically concerned with systems. Its birth in 1965 was even influenced by the work of Jay Forrester, the founder of system dynamics (Layton \& Grossbart, 2006). Throughout its history, macromarketing has addressed a wide range of issues: the societal effects of marketing; the coordination of production, distribution and consumption activities; the effects of institutional factors and society on marketing; and the quality and quantity of life goals served by marketing. Notwithstanding the importance of those issues, and although understanding complex systems was one of the goals advocated by macromarketing scholars, the discipline has not so far been able to provide an integrated conceptual framework for dealing with complex social problems. It has dealt with the attributes of adaptive systems, the adaptiveness of marketing systems and with business ecologies, for instance, but little theoretical ground has been covered beyond those issues.

Nevertheless, the perceived gap between marketing and complex social problems has been recognized, albeit at a slow pace. No one epitomizes better this realization than 
Philip Kotler, the co-founder of the social marketing discipline. In his 2015 book Confronting Capitalism, Kotler discusses and presents a proposed solution to a wide range of social problems, from income inequality and poverty to environment exploitation, debt burden and societal well-being (Kotler, 2015). In the domain of poverty and inequality, for instance, he advocates the consideration by governments of minimum income programs. On the issue of how politics subverts the interests of the broader society, he recommends a set of measures, including higher taxes on luxury goods. This kind of recommendation represents a healthy departure from the narrow downstream focus present in the social marketing discipline. Other examples of complex problems addressed by social marketers (even if they do not adopt complexity approaches) are corruption and crime (Homel \& Carroll, 2009; Kindra \& Stapenhurst, 1998).

While the literatures on systems thinking and complexity often diverge, we have chosen to select common elements and propose a unified framework, which, we posit, should be incorporated into a discipline tackling complex social problems. However, before discussing that framework, and with the goal of illustrating how downstream social marketing interventions may entirely miss the point, we first present an example of a social problem that defies any discipline confined to its artificial, narrow academic boundaries.

\subsubsection{AN EXAMPLE: ETHANOL, TORTILLA RIOTS AND THE ARAB SPRING}

A practical example of the complexity gap comes from the unsuspected connections between the expansion of ethanol use in the United States, the tortilla riots in Mexico and the Arab Spring.

Zolli and Healy (2012) describe the mechanisms behind the tortilla riots that took place in Mexico, starting in January 2007, when the price of corn hit an all-time high of US $₫ 35$ a pound, hundreds of times more expensive than just a few months previously. Tortillas are a staple food for poor Mexicans, which means half of the population. A hypothetical social marketer working for the Mexican government would probably try to change the behavior of the poor with the goal of promoting the consumption of cheaper alternatives to tortillas. The social marketer could even work on upstream channels along with organizations involved in food production and distribution, in an attempt to broaden the 
offer of food alternatives. This approach could mitigate the problem, but it would never address its root causes.

The ultimate cause of the social unrest that followed the sharp increase in the price of tortillas was not, as the protesters assumed, the political party in power or Mexican businesses. In fact, the cause could be traced back to the passage of Hurricane Katrina in 2005. The hurricane closed $95 \%$ of oil production on the Gulf Coast for several months, leading to a spike in oil prices in the United States, followed by pressure to increase the production of biofuels. Ethanol in the United States is made from corn, and the fivefold increase in its production mandated by Congress resulted in a rush for new plants and the substitution in cultivation fields of inedible varieties of corn for edible ones. At the same time, due to the NAFTA agreement, US-produced corn was being sold in Mexico for $20 \%$ less than its production cost, since its production was (and still is) heavily subsidized. This had led many small-scale rural farmers in Mexico to abandon the cultivation of corn, making the country dependent on imports from its northern neighbor and pushing farmers toward the cities, where they swelled the ranks of the urban poor. The concentration in the distribution sector had also increased, with a few powerful economic actors, all headquartered in the United States, making all the relevant decisions. Katrina was thus the catalyzer of a perfect storm whose elements were already aligned.

Moreover, all the forces at work in these different systems had different time scales: fast in the case of Katrina, moderate for the coupling of oil and corn prices and slow for NAFTA and the concentration of market players. Hence, the interplay among the diverse systems amplified the effect of disruption (Katrina) to unprecedented levels. As Zolli and Healy (2012, p. 4) stress, this case made visible "the linkages between the energy system (the oil rigs) the ecological system (Katrina), the agricultural system (the corn harvest), the global trade system (NAFTA), social factors (urbanization and poverty) and the political systems of both Mexico and the United States."

Figure 1 is a graphical representation of those linkages, adding what we call the catalyzing factor of change, in this case, Hurricane Katrina (we discuss catalyzers in chapter 7). 


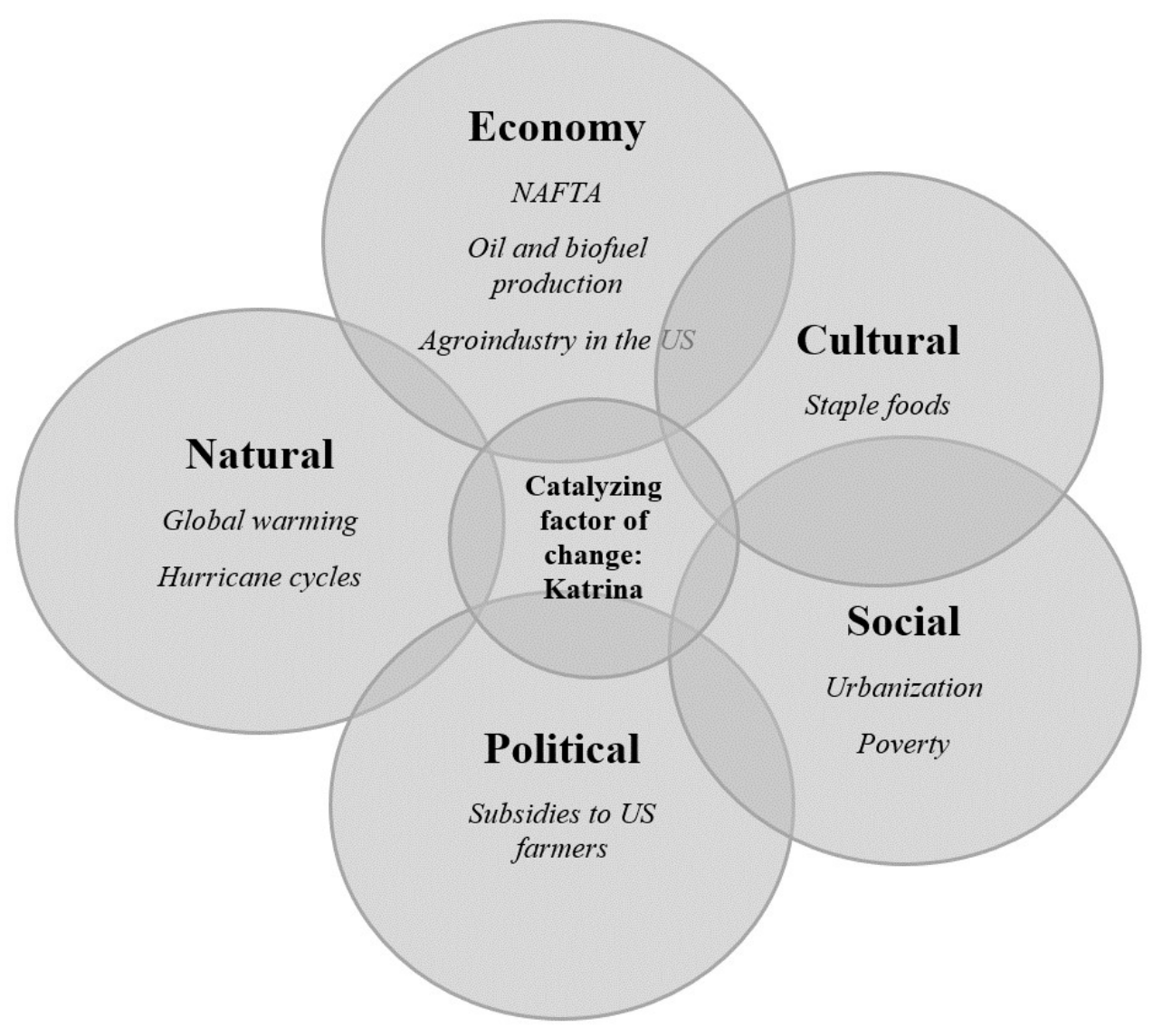

Source: Adapted from Zolli \& Healy (2012).

The Mexican government quickly struck a deal with tortilla producers while acting on NAFTA rules to increase imports. Luckily, international corn prices started to fall at the same time (Thomson, 2010). The crisis was mitigated. However, the same dynamics produced effects elsewhere, in a different context. Lagi, Bertrand, and Bar-Yam (2011) modeled the causal influence of the rise in international food prices, including corn, on pushing the social systems in some Arab countries past the tipping point of social unrest (leading to the Arab Spring).

Thus, the occurrence of food riots foretells a future of increasing interconnection in systems, with unanticipated consequences of policies in many sensitive social contexts. Appendix A presents the discussion of another example of the complexity gap not addressed by the traditional social marketing mindset (the case of world hunger). 


\subsubsection{THE PLAGUE OF EVENT-ORIENTED WORLDVIEWS}

As we have discussed, most public policy makers and influential social actors, including social marketers, tend to possess an event-oriented worldview (Sterman, 2000a).

Figure 2 depicts the event-oriented worldview and table 1 provides examples of common policies that inevitably backfire.

FIGURE 2. EVENT-ORIENTED WORLDVIEW

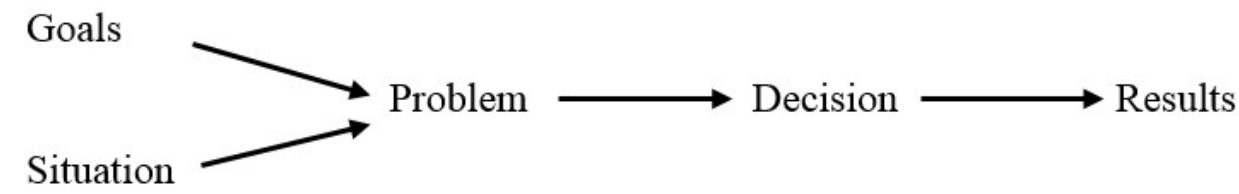

Source: Adapted from Sterman (2000a).

Table 1. Examples of event-oriented thinking

\begin{tabular}{ll} 
Problem as event & Solution as fix \\
Unruly binge drinkers & Deploy more police \\
Drug-related crime & Deploy more police \\
Congestion & Build new roads \\
Loss of market share & Launch new product \\
\hline Decline of fishing community &
\end{tabular}

Source: Morecroft (2015).

Events are visible manifestations of problems or the proverbial tip of the iceberg. They inevitably distract decision-makers from inquiring into the real underlying causes of phenomena. One characteristic of the prevalence of event-oriented worldviews among policy makers is the common ascription of undesirable effects following inadequate decisions to the category of "side effects." 
Event-oriented mindsets are the rule in public policy making and also in business settings. A recent example comes from a Harvard Business Review article written by Roger Martin, the famous strategy researcher. Discussing why mergers and acquisitions remain a dominant strategy in the business world, even when history and data show that most such transactions destroy value for the shareholders of the acquiring companies, ${ }^{2}$ Martin identifies two major structural factors explaining their prevalence (Martin, 2016). The first is stock-based compensation for CEOs and executives. The second is a remarkable example of an event-oriented worldview: a change in the depreciation rule of assets in the United States that had the unintended consequence of increasing the value of acquisitions, making them more attractive for CEOs.

Another example is the controversy over giving financial aid to poor countries. There is growing evidence that, rather than ameliorating poverty, aid increases corruption and limits economic growth (Swanson, 2015).

In sum, event-oriented thinking typically leads to decisions that make sense superficially but bring about negative consequences in the long term.

Hence, by accepting commonsensical approaches to tackling complex social problems, social marketers risk pulling the wrong levers, acting on symptoms instead of causes or, in a more benign scenario, acting on points of low leverage for change. Thus, any discipline concerned with social change must incorporate complexity and systems sciences into its toolbox. In the specific case of social marketing, this incorporation could also help in overcoming the discipline's "curse" of being associated with the negative aspects of commercial marketing.

\subsubsection{THE UNIVERSAL ACID OF COMPLEXITY SCIENCES}

We draw on the metaphor proposed by the philosopher Daniel Dennett, who compared evolutionary thinking to a universal acid that, since Darwin, has slowly corroded old ways of thinking, reaching all scientific fields (Dennett, 2013). We argue that the same metaphor applies to the expansion of the complexity sciences.

\footnotetext{
${ }^{2}$ Consider the case of the famous acquisition of Pixar by Disney Company. After 10 years, it was shown to be a huge mistake in financial terms: a very conservative analysis has shown that Disney's shareholders lost at least US\$5 billion until 2015. Yet this acquisition is usually touted as a perfect example of success.
} 
The initial academic discussion of complexity is usually traced back to Adam Smith's Wealth of Nations. However, the origins of the complexity sciences as formalized fields of inquiry can be attributed to information and computation theorists working in the first half of last century, such as the mathematician Stanislaw Ulam and the computational scientist John von Neumann (Miller, 2015). Ideas from biology and evolution (e.g., the role of simple rules in generating complex structures) were also progressively incorporated into the tenets of complexity thinking (Furtado \& Sakowski, 2014). Currently, the field of complexity has developed into several subfields and methods, such as agent-based modeling, network science, neural networks and genetic algorithms.

There are several definitions of complexity and complex systems. We cite two definitions from influential thinkers in this field. Complexity, according to Arthur (2013, p. 3), "is not a theory, but a movement in the sciences that studies how the interacting elements in a system create overall patterns, and how these overall patterns in turn cause the interacting elements to change or adapt." Mitchell (2011, p. 13), in turn, defines a complex system as "a system in which large networks of components with no central control and simple rules of operation give rise to complex collective behavior, sophisticated information processing and adaptation via learning or evolution." We note, however, that complex social problems often arise at the intersection of systems that do not necessarily fit Mitchell's definition (the political system, for instance).

We take a two-pronged approach to exploring the complexity gap. We first present the characteristics of complex systems that are most relevant to understanding the complex social problems of our times. Then, in the next section, we discuss the method of system dynamics, which, we think, is especially suited to identify the roots of those problems and to suggest adequate courses of action. System dynamics is able to deal with the interdomain complexity that underlies complex social phenomena and with situations of dynamic complexity. The latter is characterized by "subtle" links between causes and effects due to delays and multiple causation processes and the presence of multiple feedback loops fueled by nonlinear relationships (Martin, 2013; Nowotny, 2013).

We summarize the 14 main characteristics of complex social systems that are relevant for our purposes (table 2). We note that, as Mitchell (2011) warns, not all complex systems exhibit the characteristics shown in the table. In appendix $\mathrm{C}$, we expand the discussion of complex social problems, adopting a system dynamics perspective. 
The idea that complex systems from apparently disparate domains share abstract properties may come across as far-fetched. Nonetheless, consider two very different examples. First, this is how Arthur $(2013$, p. 5) describes the process of technological evolution:

Novel technologies call forth further novel technologies: when computers arrive, they call forth or "demand" the further technologies of data storage, computer languages, computational algorithms and solid-state switching devices. And novel technologies make possible other novel technologies: when the vacuum tubes arrives, it makes possible or "supplies" the further technologies of radio transmission and receiving, broadcasting, relay circuits, early computation and radar. And these novel technologies in turn demand and supply yet further technologies. It follows that a novel technology is not just a one-time disruption to equilibrium, it is a permanent ongoing generator and demander of further technologies that themselves generate and demand still further technologies. Notice again the self-reinforcing nature of this process. The result is not occasional disruption but ongoing waves of disruption causing disruptions, acting in parallel across the economy and at all scales within the economy. Technology change breeds further change endogenously and continually, and this throws the economy into a permanent state of disruption.

The description of how a technologic change (or how a general change in any system) sets in motion a complex cascade of events and changes is far from rare when it comes to complex systems. Now, consider how Trochim, Cabrera, Milstein, Gallagher, and Leischow (2006) describe the effects of a change in the area of tobacco control: 


\section{Table 2. Characteristics of complex social systems}

\section{Characteristic}

1. Presence of heterogeneous agents interacting within the confluence of several systems

\section{Emergence}

3. Endogeneity

4. Nonlinearity

5. Scaling

6. Different time scales

(continued)

\section{Implications}

Actors in the social ecosystem interact frequently with one another, within the confluence of several systems (natural, technological, cultural, social etc.). Communication among agents typically occur via sampling of available information.

Use of simple rules by agents leads to complex behaviors of the system. Hence, the behavior of the whole is different and emerges from the behavior of agents. Examples include bee hives, the brain, the immune system, the Internet and modern economies.

The dynamics of the system arise spontaneously from their internal structure. Self-reinforcing and balancing feedback loops define how the system behaves over time. Small, random perturbations can be amplified by the system's feedback structure, creating patterns in space and time.

Effects are rarely proportional to causes. Nonlinearities are the rule. What happens locally in a system, near the current operating point, often does not apply in other states of the system. The existence of tipping points and thresholds often leads to surprising behaviors.

Power laws (e.g., Pareto's law) are the rule in the natural world, and this may also be the case in the social world. Most social problems, for instance, are caused by a small percentage of groups or individuals.

Changes in systems occur on many time scales, and they sometimes interact among themselves, as in the case of the tortilla riots. 
Table 2 (continued)

\section{Characteristic}

7. Path dependence

8. Delays and accumulation of stocks

9. Adaptation, learning and exploitation

10. Presence of surprising and counterintuitive behaviors

11. Policy resistance

\section{Implications}

Decisions alter the state of the world, causing changes in the system and triggering others to act. The new situation then constrains the path for following courses of action. Hence, choosing a path often leads to irreversible consequences that determine the fate of the system, making it history-dependent. Public pension systems, public policies and decisions over standards are good examples of this.

Actions and policies usually require a long time horizon to manifest their results. Material (e.g., financial resources, people) and immaterial stocks (e.g., reputation, brand image) accumulate over the continuous passage of time. Often, systems are not in equilibrium.

Capabilities and decision-making rules employed by agents change over time. Adaptive systems may employ focused and unfocused processes (balancing exploitation and exploration). Agents strive to find points of exploitation in the system. In the end, all social systems will be gamed.

Causes and effects are distant in time and space. The natural tendency of human beings is to look for causes near the events they seek to explain. Attention is naturally drawn to symptoms instead of actual causes. Adequate policies are often not obvious. For instance, building more roads to alleviate car congestion leads to even more congestion over time.

The complexity of systems overwhelms our ability to understand them. Public policy makers employ event-oriented mental models in their attempt to solve complex problems. The result is that many seemingly obvious solutions fail or worsen the situation, since systems counterbalance the forces applied to them.

\section{(continued)}




\section{Table 2 (conclusion)}

\section{Characteristic}

12. Temporal trade-off

13. Resilience

14. Local rationality

\section{Implications}

The long-term response of a system is often different from its short-term response. High leverage policies often cause worse-before-better behavior, while superficial solutions tend to produce small improvements and then make the underlying problem worse over time.

Complex social systems have different degrees of resilience. They typically absorb most of the "normal" disturbance from the outside.

Bounded rational agents strive to reach the goals of their subsystems, which often are in contrast with the goals of the entire system. For instance, politicians work to maximize their electoral capital during shortterm cycles of the political system. Often, they resort to policies that have high popular appeal but lead to decreases in the collective well-being in the long term.

Source: Adapted from Arthur (2013); Ford (2010); Forrester (1961; 1969; 1971; 1973); Furtado \& Sakowski (2014); Mitchell (2011); Sterman (2000a; 2000b). 
At the policy level, it is reasonable to argue that the 1964 surgeon general's report on smoking has profound effects on the policy debate with consequences for smoking prevalence and consumption to this day. The report itself was the product of a complex series of events that led to its production. In turn, it set off a cascade of events and changes. It is virtually impossible to determine the effects of that important event in isolation, as a part that is separable from the whole.

For instance, the report was most likely an important catalyst in creating a public policy climate that enabled the litigation that led to the Tobacco Settlement Agreement several decades later, to increased taxation of cigarettes by states, to legal restrictions on smoking in public spaces, and to tobacco counteradvertising. By the same token, the report may have led to unanticipated "negative" consequences by spurring the tobacco industry to adapt its product, marketing, lobbying, and public relations, and perhaps indirectly contributed to the creation of front groups and covert efforts to undermine tobacco control research.

The complexity of social reality requires a grammar to understand how negative behaviors are produced by systems and how to prevent their occurrence. This grammar is provided by the field of system dynamics.

\subsubsection{SYSTEMS THINKING AND SYSTEM DYNAMICS}

The literature of systems thinking has a great deal of overlap with the complexity sciences. For instance, one point of overlap is the acknowledgment that a system is a functional whole in which different components produce an aggregate behavior that is not apparent from the performance of those components considered in isolation (Levine \& Fitzgerald, 1992).

In the broad literature on systems thinking, there are different lines of research and theorizing. Some authors, for instance, have focused on structural elements of systems. Trochim et al. (2006) discuss two elements: the parts that comprise a system and their relationships. Cabrera and Cabrera (2015) and Cabrera, Cabrera, and Powers (2015) expand that approach by proposing four universal rules subsuming systems thinking: distinctions, systems, relationships and perspectives (DSRP). According to this framework, distinctions are the vectors of difference among things and ideas. Parts and whole comprise systems - studying the former often uncovers important and neglected 
aspects of a problem. Relationships may be correlations, causation or feedback loops. Perspectives represent the vantage point from which a view is enabled, shaping how a system is perceived and how problems are addressed.

Although the comprehension of structures through frameworks such as DSRP may lead to a richer understanding of systems, it clearly falls short of the potential of systems thinking. This is where the field of system dynamics makes its major contribution.

System dynamics was pioneered by Jay Forrester at MIT (Forrester, 1961), and it is especially useful when one needs to understand a system marked by feedback loops, nonlinear relationships and delays. Forrester developed the method by applying concepts from feedback control theory to the study of industrial systems, urban systems and even the world system.

Ford (2010, p. 7) defines system dynamics as "a methodology for studying and managing complex systems that change over time." The method uses computer modeling to focus the modeler's attention on the feedback loops that give rise to dynamic behaviors. Indeed, the concept of feedback loops is considered the fundamental building block of system dynamics models (Richardson, 1999).

System dynamics is essential to understanding dynamic complexity. According to Ford (2010, p. xi),

Climate change, pandemics, and boom and bust in real estate are complex dynamics that challenge our understanding. We are unable to anticipate the dynamic consequences of policies adopted today, especially when there are long delays between our actions and the system's reactions. Our understanding is also limited by the complexity of the feedback processes that control system behavior. Our actions may be partially erased by the system's internal responses, and the system's apparent resistance to our interventions is confusing. Sorting out the effects of delays and multiple feedbacks is beyond our cognitive abilities, so we look to the past for lessons. But how are we to interpret past patterns in climate change, pandemics and boom-and-bust cycles? Our understanding of the dynamics of historical patterns is limited by the same complexities that make it difficult to think about the future. There are many interpretations of past behavior, and we are left with limited understanding of both past trends and current problems.

The origins of the fundamental concepts employed in system dynamics can be found in different theoretical bodies throughout the history of human thinking. Several landmark works in social sciences, biology and other fields have applied feedback-inspired ideas in 
previous centuries, leading to theoretical propositions such as the invisible hand and homeostasis (Richardson, 1999).

Systems dynamics overcomes the traditional concept of one-way causal chains found in many conceptual and methodological tools in the social sciences; instead, it deals with reciprocal chains of causality linking key variables through feedback loops. Feedback loops, in turn, are considered important units of analysis per se (Hirsch, Levine, \& Miller, 2007).

System dynamics is based on models. A model is a substitute for a real system (Ford, 2010). A system dynamics model uses equations to represent the interconnections in a system. In many real-world systems, it is impossible to represent the entire system. Therefore, one needs a simplified model that captures the essential structure producing the dynamic behaviors of interest. Thus, system dynamics models represent the real system from a "10,000 meter view," which means that structures but not details are the relevant elements.

They also allow the carrying out of experiments that would be virtually impossible, too expensive or ethically forbidden in actual systems. Experiments represent the effects of policies aiming at changing problematic situations and providing learning through rapid feedback. They are especially useful when there is a group of different stakeholders with different perspectives and expertise trying to improve the system. Experiments uncover diverse patterns of behavior produced by a system. For instance, some systems generate an unusually sluggish response. Other systems show unexpectedly rapid responses to external disturbances.

Another hallmark of system dynamics is its interdisciplinary focus. Social problems do not respect disciplinary boundaries. The discipline usually draws from several sources of data, such as empirical and theoretical literature, primary quantitative or qualitative data, secondary data and the experience and viewpoints of people closer to the problems. As Forrester (1961) stressed, since the goal of developing a system dynamics model is to obtain answers to the problem under consideration, model building cannot be limited to the narrow boundaries of intellectual disciplines. Most systems involve the interplay of historical, psychological, economic, organizational, monetary, legal, technical and social factors. Therefore, the ability of system dynamics to integrate different academic and practical perspectives is one of its major strengths (Hirsch, Levine, \& Miller, 2007). 
Finally, it is important to note a crucial distinction between so-called ecological approaches, which focus on delivering multiple strategies aimed at multiple levels, and actual systemic approaches, which consider the dynamic intricacies that characterize complex social systems (Hawe, Shiell, \& Riley, 2009). The employment of ecological approaches in interventions may not be sufficient to produce substantial social change.

In sum, system dynamics is a perfect fit with disciplines concerned with social change. Appendix B provides additional details on the system dynamics field and presents its notations.

\subsection{THE SECOND GAP: MINDWARE}

Not only has social marketing been operating within an individualistic paradigm, but also the extreme demands for measurability (by itself a reflection of US business culture) has been leading it to a focus only on observable behaviors. Nevertheless, there is another missing element in the social change equation, which speaks directly to how human beings make sense of the world: ideas or mental models.

Mental models are more than filters to interpret reality. They are a stock of interrelated beliefs and schemas that define the boundaries of problems and constrain the possible solutions. Ideas, as Keynes once recognized, rule the world. We employ the term mindware, coined by Harvard educator David Perkins (Perkins, 1995), to refer to that stock of beliefs and schemas. Mindware also comprises rules, procedures and other forms of knowledge that are stored in memory and can be retrieved in order to make decisions and solve problems (Stanovich, 2010).

According to Stanovich (2010), two problems regarding mindware are critical. The first is the mindware gap. This occurs when the tools of rationality (scientific thinking, probabilistic thinking and logic) are absent or not fully learned. The second problem is contaminated mindware, the presence of beliefs not grounded on evidence, harmful for the person and for society, although they are attractive and sticky or easily transmittable to others. The second problem appears to be more critical when it comes to mental models of complex social problems.

The repertoire of collective mindware in a society defines the lens applied to social problems and, importantly, what is ignored. Consider, for instance, the quest for 
continuous economic growth, which, in the end, reflects a goal that is impossible in a finite world. To preserve the environment and the future of our species, societies, especially developed ones, should have been moving to a mode of functioning based on equilibrium. However, all the conceptual infrastructure of our societies is engineered to promote growth. Societies demand increased services from governments, which play by electoral rules and depend on a growing economic substratum for the collection of taxes. Pressed by shareholders, firms strive to grow, incentivizing CEOs and workers with bonuses. Advertising, promotion and other tools are employed to induce families to keep consuming. Products are updated in increasingly short time spans. Luxury markets keep expanding throughout the world. Eventually, the limits to growth will be reached through pollution, food scarcity, limited resources or a population crisis. As Forrester (1973) emphasizes, human societies will face the consequences of physical or social stress caused by unsustainable growth, but they could choose the path of self-restraint to control growth and avoid collapse. This kind of self-restraint, we add, depends on the diffusion of a different type of mindware, which has not been marketed adequately.

Another example comes from Bales (2015), who argues that the cultural models available to make sense of complex problems such as climate change are simplistic and incomplete, leading to ineffective personal actions and support for ineffective policies, irrespective of the personal levels of involvement with such problems. In the case of human development, McLeroy, Bibeau, Steckler, and Glanz (1988) observe that the prevailing frameworks - both the models and the language - tend to put the focus (and the blame) on individual behaviors while ignoring the social and physical environments that maintain and reinforce inadequate behaviors.

Thus, mental models may hide important factors underlying a problem, leading to bias and ineffective policies. This is especially true when special interest groups and specialists with connections to powerful parties dominate the narrative on a complex issue, leading to what Baumgartner and Jones (2009) call a policy monopoly. Mindware competes in the several venues that constitute the marketplace of ideas (e.g., media, academia). This marketplace is a tough one: human attention is scarce; there is a myriad of causes and ideas competing for it, and powerful economic interests sell narratives that are hard to oppose. 


\subsubsection{MONOLITHS OF MEANING}

Words and associations matter. When the associations of ideas underlying mental models are very strong, the resulting schemas are difficult to change, leading, in some cases, to what we call monoliths of meaning - the associations are so entrenched in the public's minds that attempting to change them requires high levels of concerted effort. Wellestablished schemas, for instance, tend to dominate subsequent, inconsistent information (Fiske \& Taylor, 1991). Take the general concept of marketing. For decades, there has been resistance to its use in the nonprofit and governmental world. Hunt (1976), among others, pointed out a long time ago that the major challenge in expanding marketing to social uses involved marketing the idea of marketing to nonmarketers.

However, the issue is broader than merely convincing people that some repertoire of concepts could help them to achieve better results. It seems that the strong associations of marketing with the business world activate a conflict in schemas. The suggestive study of Heyman and Ariely (2004) identified that different norms apply to two markets that co-exist in our modern societies - the monetary market and the social one. They co-exist but they hardly mix. Elements strongly associated with the monetary market (such as financial incentives or the concept of marketing) may elicit resistance when applied in the context of a social market. Thus, broadening the concept of marketing means breaking the monolith of its meaning in the public's mind, something that seems to be very difficult considering the everyday reinforcement of its underlying associations in modern economies.

Monoliths of meaning are common in prevailing mindware regarding complex social issues, such as poverty, limits to growth and corruption. Tackling these problems necessarily requires changing mental models that are deeply ingrained.

\subsubsection{THE STUDY OF MENTAL MODELS}

Sterman (2002) argues that there are two concepts from the field of system dynamics that people find particularly difficult to grasp: first, that all decisions are based on models; and, second, that all models are wrong. Mental models, in turn, are rarely formalized. 
Accordingly, in the system dynamics literature, mental models have been defined as worldviews that represent information about the elements in a system, their connections and the rules that govern decision-making (Forrester, 1973; 1994). In other words, they are simplified knowledge structures concerning how some aspect of the world works (Gary \& Wood, 2016). As we saw above (section 2.5), they constrain individual and collective perception, information processing, evaluation and decision-making processes. Mental images of the world determine the making of public policy as well as the socially shared understandings that legitimize it. We refer to mindware and mental models interchangeably throughout the text, since their definitions tap into the same construct.

The assumptions underlying mental models often result from the interaction between a malleable social reality and mental processes operating in confirmatory mode. In this sense, they tend to be rife with incompleteness and internal contradiction. Thus, mental models about the world tend to be fuzzy, partial and malleable (in the sense that they can be adjusted to fit existent beliefs or values). In fact, every human being looks at reality through a worldview, an internally set of (apparently) consistent beliefs, attitudes and values that acts as a filter, directing attention to information that confirms previous (often subconscious) expectations and shunning information that may challenge those expectations (Meadows, Randers, \& Meadows, 2004).

Mental models have been studied within different disciplines, such as psychology, strategic management, organization theory, system dynamics and others. Table 3 presents a compilation found in Gary \& Wood (2016) of alternative labels for mental models found in the numerous disciplines that have researched the subject. Remarkably, there is no mention of mindware. 
Table 3. Mental models and related concepts

$\begin{array}{ll}\text { Cognitive maps } & \text { Dominant logic } \\ \text { Interpretative schemes } & \text { Mindscapes } \\ \text { Industry recipes } & \text { Worldview } \\ \text { Implicit theories } & \text { Managerial lenses } \\ \text { Corporate theory } & \text { Mental pictures } \\ \text { Screens } & \text { Organizing frameworks } \\ \text { Routines } & \text { Perception filters } \\ \text { Cognitive representations } & \text { Analogies } \\ \text { Frames/strategic frames } & \text { Knowledge structures } \\ \text { Mental templates } & \text { Heuristics } \\ \text { Causal maps } & \text { Decision biases } \\ \text { Belief structures } & \text { Schema } \\ \text { Source: Gary \& Wood (2016). } & \end{array}$

Very often, multiple mental models are employed to analyze an issue, depending on the perspective of the involved party. Stroh (2015) cites the example of efforts to curb smoking, showing how the perspectives of patients, doctors and politicians may hover around the lenses of defiance, fear, entitlement, ignorance and recognition (a common division also found in several other complex social problems, such as climate change). In such cases, the goal seems to be the promotion of the right mindware so that its perspective dominates the less favorable ones. Another possible approach is to map the intended set of associations into familiar schemas. For instance, Zolli and Healy (2012) report how the employment of a framework based on the familiar concept of financial portfolio helped in managing the complex challenge of natural ecosystem sustainability. Traditional frameworks often take those systems to the brink of collapse.

In sum, changing mental models or mindware is essential in the processes of social change. Changing them at the broader societal level, however, is difficult, timeconsuming and messy. Thus, this goal has been neglected in social marketing programs that depend on short-term, measurable results to meet funding requirements. Nonetheless, 
it was never neglected by businesses that comprehend the importance of mindware in selling culturally legitimized products such as cigarettes and guns (e.g., Brandt, 2007).

\subsubsection{THROWING THE BABY OUT WITH THE BATHWATER: PROMOTION OF IDEAS IN THE SOCIAL MARKETING TOOLBOX}

Ironically, for several years the promotion of ideas was part of a mainstream definition of social marketing. In the seminal paper that gave the discipline its name, Kotler and Zaltman (1971) describe social marketing as "the use of marketing principles and techniques to advance a social cause, idea or behavior." The inclusion of ideas (or social causes) as a legitimate object of social marketing persisted until the end of the 1980s. According to Kotler and Roberto (1989), the discipline is essentially a technology for social change management that involves the design, implementation and control of programs aimed at increasing the acceptability of a social idea or practice in one or more groups of target adopters.

As depicted in figure 3, a social idea can be a belief (e.g., "cigarette smoking is hazardous to one's health"), an attitude (negative or positive evaluations of people, objects, ideas or events, such as "planned babies are better cared for than babies from accidental pregnancies") or a value, such as "human rights." 
FIGURE 3. SOCIAL MARKETING PRODUCTS

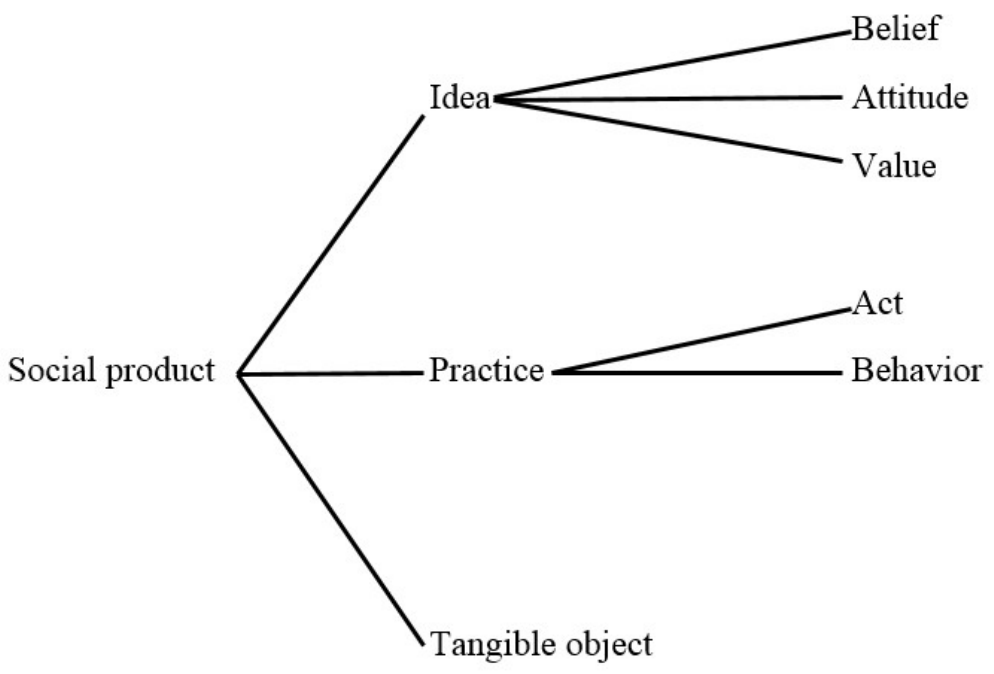

Source: Adapted from Kotler \& Roberto (1989).

Over time, however, the concept of idea as a legitimate social product under the influence of social marketing dwindled. In one of their subsequent textbooks, Kotler, Roberto, and Lee (2002) defined the focus on strict behavior change, relegating the role of ideas (knowledge, beliefs or attitudes) to a means of paving the way for behavior change, without specifying how this process could happen. On the one hand, the strict focus on behavior change seems a victory of the measurement paradigm so prevalent in businessinspired programs. Sponsors, grant providers and other social agents want concrete, shortterm, measurable results. Changes in attitudes in response to communication efforts, for instance, can easily dissipate and cannot substitute actual behavior change in many contexts. On the other hand, it seems that social marketing has thrown the baby out with the bathwater. Most complex social problems require a change in the prevalent mindware, and this requires a concerted effort to change collective ideas. Changing or shaping mental models may be a worthy goal per se in many cases, as industries selling cigarettes and guns have long known.

Some social marketing scholars have discussed possible channels for changing mental models, but they have not delved into detailed accounts of the underlying processes. Kotler and Roberto (1989) suggest mobilizing influence groups, such as governmental agencies, churches, consumer organizations, trade associations and educational institutions, classifying them as allies, opponents and neutrals. Then both marketing and 
political tactics could be employed to influence them. Andreasen (2006) recognizes the role of social norms in producing social change. One example he gives is the role that journalists, opinion leaders and scriptwriters have in promoting public will for change. He also recommends using the same basic approach from downstream social marketing (a combination of strategies to deal with perceived benefits, costs, social norms and selfefficacy) to influence upstream social actors, such as media gate keepers and politicians. He provides no detailed description, however, of the processes by which social change could occur in this manner.

Gordon, Carrigan, and Hastings (2011) recognize that several social marketing programs have sought to change values and attitudes as a prerequisite for behavior change. They advocate the publicizing of benefits and a shift in social norms. They also cite a "laundry list" that includes media advocacy, influencing policy change, regulation and law making, and building an evidence base for the intended change. Corner \& Randall (2011) propose that social marketing programs aiming at combating climate change should focus on value-based campaigns (avoiding the usual approach of emphasizing economic values), social networks and education. Educating citizens could lead to stronger proenvironmental identities, which, in turn, could lead to better acceptance of effective (but previously unpopular) policies.

Nonetheless, the focus on individual downstream behaviors has become a staple in social marketing. Gordon et al. (2011), for instance, emphasize that social marketing provides "a behavior change tool that stakeholders can use to target individual behavior change to promote specific causes." While this recommendation would also make sense when used to target key upstream social actors (such as politicians), the authors clearly have downstream approaches in mind. Other important authors in the field (e.g., Kotler and Lee, 2016), while recognizing that social marketing can target upstream actors (such as politicians and policy makers), tend to focus on downstream interventions. As Wymer (2011) stresses - and this is the conclusion to be drawn here - there is little guidance on how to implement upstream social marketing programs.

\subsubsection{IS IT ONLY SOCIAL MARKETING?}

The focus on downstream behaviors, the abandonment of ideas or mental models and the disregard of systemic factors causing problematic behaviors are the main limitations of 
the social marketing approach. According to Kotler and Lee (2009, p. 57) "perhaps the most challenging aspect of social marketing is that it relies heavily on voluntary compliance than legal, economic or coercive forms of influence." We, of course, disagree, but we also note that social marketing shares these drawbacks with similar disciplines interested in the promotion of social change.

Consider, for instance, behavioral economics. It has been (successfully) demonstrated that the main axioms of neoclassical economics are flawed, especially the homo economicus paradigm - the concept of human beings as cold, rational decision-makers (Carvalho \& Mazzon, 2013). By exposing the biases that guide actual decision-making and that are behind many social problems, and by proposing effective solutions that counter such biases, behavioral economists have gained the attention of businesses and governments throughout the world.

In this sense, Datta and Mullainathan (2014) propose a framework inspired by behavioral economics to orient the design of more effective public programs. Calling it behavioral design, they sketch an approach that includes the identification of "behavioral stress points," employs certain design principles (e.g., reducing the need for self-control and framing messages to match mental models) and uses prototyping and experimenting.

While that body of knowledge can easily be accommodated within the social marketing framework and vice versa - the disciplines are, after all, about changing human behavior - behavioral economics interventions also suffer from the same gaps discussed in this chapter. For instance, Datta and Mullainathan (2014) discuss how behavioral economics could help in incentivizing farmers from poor countries to employ fertilizers more effectively. The unstated assumption is that use of fertilizers is an adequate policy for addressing hunger in poor countries - something that Saeed (1994:2016a) convincingly rebuts by examining the long-term, systemic consequences of such well-meaning policies.

In other words, both behavioral economics and social marketing-inspired interventions may incur the non-negligible risk of addressing only symptoms or points of low leverage for change in complex social systems. They are linear frameworks that fail to account for the inter-domain complexity, nonlinear dynamics and long-term interplay of variables that define all complex social problems faced by modern societies. They typically ignore the role of mindware in preventing or promoting social change. 


\subsubsection{GETTING IT RIGHT}

A complexity approach to social problems must give birth to compelling mindware. The ensuing lenses and narratives may be promoted in the same way as industries market their products and services.

Susan Bales, founder of the prestigious FrameWorks Institute, ${ }^{3}$ gets it right when she discusses the role of cultural models on the perpetuation of social inequality (Bales, 2015). She states that the ability of social analysts to affect the world is constrained by the perceptions that regular people bring to that reality. This realization calls for a twosided approach: a science-based policy repertoire coupled with a science-based communication set of tools, with the aim of producing narrative solutions. People construct meaning and their mindware from associations, memories, parts of stories and near-fit hypotheses about how the world works. The corresponding collective blueprint (or collective mindware) is the main lens through which people interpret their social world.

An expert story requires a translated story if the agent of social change aims to really affect the world. In the case of inequality, for instance, a fatalistic worldview depresses engagement, obfuscates thinking about meaningful solutions, and frames small individual gestures as the only available solution. Other cultural models that tend to frame the issue are individualism, little-picture thinking (i.e., ignorance of the role of systems and structures that characterize complex systems) and small solutions (i.e., when people resort to individual behavior change in an attempt to "solve" complex problems).

Available but wrong cultural models then lead people to take ineffective personal actions and, importantly, to support ineffective policies, regardless of their level of commitment to the problem under consideration (Bales, 2015). Thus, understanding how people think about an issue and their mental repertoires is essential for the creation of productive mindware and coherent narratives and for the reframing of strategies (or, as Kotler and Roberto (1989) stated, dressing up the social idea through branding and symbolic packaging).

In the case of poverty, Bowles, Durlauf, and Hoff(2006) stress that the conventional view on poverty that still informs much of the public debate has an undeniable individualistic

\footnotetext{
${ }^{3}$ http://www.frameworksinstitute.org/
} 
flavor: the idea is that the mechanisms that determine an individual's socioeconomic prospects are under his or her control. This is the achievement model of income determination. It is clear nowadays that poverty traps arise from systemic mechanisms, but there has been no compelling narrative capable of changing the public's views on the issue.

In the case of child poverty, Raphael (2011) argues that in states such as Canada, the United Kingdom and the United States, governments tend to avoid interventions in the market economy, skewing the distribution of resources and inadvertently producing poverty. On the other hand, countries such as Norway, Sweden and France have a different worldview, with the practical consequence of having less poverty. It may come as a shock to many people that there are so many children living in poverty in countries such as the United States and Canada $-23 \%$ and $13 \%$, respectively, in relative poverty, according to a recent study (Innocenti Research Centre, 2012). Nations differ in how their institutions work to redistribute wealth and the extent to which governments invest in social infrastructure, factors that ultimately depend on the stock of beliefs that integrate the repertoire of collective mindware.

Banerjee and Duflo (2011) tackle the conflicting recipes for breaking enduring traps in poor countries. On the one hand, they argue, there are experts such as Jeffrey Sachs who claim that the key is to direct foreign aid toward malaria, infrastructure and other social problems to break the vicious circle of poverty. On the other hand, there are experts such as Willian Easterly who argue that aid does more bad than good, because it fosters corruption and undermines institutions. More than illustrating contrasting views, this battle of mindware exemplifies a set of typical characteristics in the discussion of complex problems: lack of consensus, presence of "heavyweight" thinkers behind the propositions, high-quality arguments and strong barriers to settling the disagreements empirically. These characteristics can be found in virtually any controversy related to complex modern social problems. Moreover, economic interests, as in the case of companies fighting the evidence in favor of climate change, or strongly entrenched ideological beliefs can support the propagation of misleading mindware (i.e.,, contrary to the bulk of scientific evidence), hindering the development of adequate policies.

Finally, promoting the right mindware is messy. It involves social advocacy and potentially dealing with political conflict. There are few indicators of progress in the short or medium term and no certainty of success, so financing this kind of intervention is more 
difficult. In a world obsessed with accountability and SMART indicators (specific, measurable, achievable, relevant, and time-bound), how can social actors justify efforts to change the system through the promotion of mindware? Promoting simple behaviors, on the other hand, is easier: indicators of progress are black or white; there is the reward accrued from the feeling of doing something about a complex problem; there is no need to face political conflict; and the focus remains conveniently on individuals.

\subsubsection{INCREASING THE ATTRACTIVENESS OF MINDWARE}

As we mentioned earlier, a promising strategy for fighting detrimental monoliths of meaning is to map the desired mindware onto a familiar schema. Framing is thus a common strategy for preventing the activation of strong mindware or for circumventing entrenched mindware. For instance, in the context of climate change, Baldwin and Lammers (2016) found that conservatives' attitudes and behaviors changed drastically when the messages compared the present environment with the past. In that case, the intervention piggybacked on the strong past-oriented inclination that characterizes conservative individuals.

Promotion of compelling ideas, dressed as attractive narratives, in an organized whole (the mindware), has the potential to change public discourse on relevant social topics. Commercial marketing has influenced public mindware for decades, resorting to what Carvalho and Mazzon (2015) call enabling factors. These factors of influence have been used as a powerful means to create acceptance of controversial products, such as cigarettes, alcohol and even marijuana. These products have been promoted in popular media for decades. In the case of cigarettes and alcohol, there is compelling evidence that exposure to them in cultural products (such as movies) explains subsequent adoption by teenagers (Pechmann, Biglan, Grube, \& Cody, 2012).

History is also full of examples of leaders who changed the prevailing mindware of a society (for better or worse), articulating new goals for the system, as was the case of Ronald Reagan and his anti-government discourse in the 1980s (Meadows, 1999).

At a more mundane level, the communicability of mindware may depend, among other factors, on its stickiness (how well it is retained in individuals' memories), its pitchiness (whether it is likely to be pitched in the public arena) and its catchiness (whether it is likely to be caught by those to whom it is pitched), according to the influential work of 
Conway and Schaller (2007). We briefly explore these factors, which seem to explain the strong appeal of inadequate mindware.

Stickiness reflects, for instance, the presence of counterintuitive narratives. Ontological violations may have an advantage in terms of memorability over intuitive beliefs. However, such violations must occur only to a modest degree. If a cultural unit violates the shared mindware too much, people will not be able to make sense of or remember it at all. Thus, minimally counterintuitive narratives may enjoy an advantage in recall and cultural transmission.

Another influence on the communicability of cultural elements is the degree to which they quench epistemic needs. Human beings are driven to know things, and especially to know them with confidence. Epistemic needs compel people to communicate with others, not only to obtain information, but also to validate their perceptions. Information bearing on basic human needs tends to be present in such exchanges, including threat-relevant information and concerns such as effective child-rearing. Other goals, such as impressionmanagement goals, can also influence the communicability of cultural elements. People tend to avoid the deliverance of bad news and prefer to communicate desirable information.

Catchiness, on the other hand, depends on several characteristics that influence the extent to which receivers attend to or ignore incoming information and the extent to which they are sufficiently persuaded by that information to the point of replicating it to others. Information that resolves disquieting feelings of uncertainty is one of those characteristics. Hence, in moments of crisis and heightened uncertainty among the population, there is greater opportunity for changes in mindware.

\subsection{THE NEED FOR A META-DISCIPLINE: LEAVING SOCIAL MARKETING BEHIND}

In defending social marketing's solution for fighting poverty, Kotler and Lee (2009) state that the purpose of the discipline is to develop constructive approaches to support desired behavior change. This can be achieved, according to them, by increasing the audience's perception that the benefits of the new behavior outweigh the costs of adopting it. The new behavior must be perceived as having higher value than the current one. In fact, as 
already discussed, this approach suffers from an intrinsically limited perspective. Not surprisingly, most of the examples cited in Kotler and Lee's book refer to small villages or poor communities adopting specific behaviors that do not change the root causes of poverty.

Social marketing as a discipline has simplified the problem of bringing about societal change by thinking that upstream social actors can be influenced in the same way as downstream individuals. However, this schematic approach ignores how social change actually occurs, how networks of economic interests crystalize into political power, shaping convenient narratives in defense of the status quo and how systems produce undesirable behaviors. One has only to consider why the proposal of cap-and-trade markets as a way to curb the emission of carbon - which piggybacks on "sacred" cultural linchpins like the concept of free market - did not get far. Meanwhile, social marketers have been promoting recycling and other feel-good behaviors.

There is a need for a discipline capable of identifying the systemic drivers of complex social problems and promoting solutions (including mindware) that address change at the correct points (or levers) of the systems. We could call this discipline social marketing, strategic social marketing or enhanced social marketing, but we think it is not a viable solution, for reasons we discuss next.

\subsubsection{A META-DISCIPLINE}

The late Donela Meadows called attention to the fact that all disciplinary boundaries are artificial (Meadows, 2002b). In fact, we think that an applied behavioral science must be able to integrate knowledge from all disciplines that study human behavior without allegiance to any specific tradition. In Meadows' own words:

Defy the disciplines. (...) follow a system wherever it leads. It will be sure to lead across traditional disciplinary lines. To understand that system, you will have to be able to learn from - while not being limited by - economists and chemists and psychologists and theologians. You will have to penetrate their jargons, integrate what they tell you, recognize what they can honestly see through their particular lenses, and discard the distortions that come from the narrowness and incompleteness of their lenses. They won't make it easy for you.

Seeing systems whole requires more than being "interdisciplinary" (...) Interdisciplinary communication works only if there is a real problem to be solved, and if the representatives from the various disciplines are more committed to solving the problem than to being academically correct. They will have to go into 
learning mode, to admit ignorance and be willing to be taught, by each other and by the system.

We are not the first ones to notice some problems discussed in this chapter. Others have perceived the gaps between existing disciplines and the complexity of modern social problems. Bammer (2017), for instance, proposes a new discipline, called integration and implementation science (I2S), to deal with complex societal problems. According to her proposal, the discipline would combine knowledge from different disciplines, assess which disciplines and stakeholders have relevant perspectives into the problem, identify the interconnections of elements driving the problem, decide how to address critical unknowns and, finally, use research to support change. In addition, we note a growing trend toward the creation of disciplines that integrate knowledge from fields that are traditionally separate, such as ecofinance (Zolli \& Heally, 2012) and ecological economics (Constanza et al., 1997).

Our proposition encompasses the incorporation of the conceptual tools of the complexity sciences (in particular, of system dynamics), the promotion of mindware and the full adoption of a transdisciplinary stance, allowing the integration of a vast repertoire of disciplinary toolboxes. We call this discipline CSP management.

CSP management has the following defining characteristics:

1. It adopts the concept of an integration and implementation science (Bammer, 2017). Complex problems do not respect academic boundaries. We need a discipline capable of integrating knowledge from a myriad of fields into actionable frameworks. The integration should overcome artificial boundaries (and tribal identity markers) between fields such as marketing, behavioral economics and social psychology, to name a few. In this sense, we may be talking about something like a meta-discipline.

2. It focuses on systems and complexity drivers, taking into account how complex problems emerge, how they are embedded in tangled social ecosystems and how structures contribute to their persistence. It uses system dynamics as a grammar to understand complex problems.

3. In the same vein, it never ignores upstream social actors, such as media gatekeepers, influencers and politicians. A discipline concerned with social change should 
account for the role of powerful social actors in legitimizing the institutional framework of a society.

\subsection{CONCLUSION}

In 2013, complexity was the organizing theme for the annual Peter Drucker Forum in Austria. One of the startling conclusions of the event was that management science lacked frameworks to deal with the complex phenomena challenging modern organizations.

In this chapter, we extend this conclusion from the Peter Drucker Forum to challenge the field of social marketing. When it comes to tame problems (e.g., organ donation, exercising), social marketing programs can produce consistent results. However, most problems that plague our modern societies have a distinctive complex nature that are not amenable to traditional social marketing interventions.

One could argue that social marketing should be concerned only with tame problems. However, this is not acknowledged within the discipline, which has been prone to making grandiose claims, as exemplified by books that promote the social marketing "solution" to poverty (Kotler \& Lee, 2009) or "how to change the world" (Roberto, 2012). Moreover, the (narrow) downstream approach that dominates the discipline leads to low levers being pulled in social systems while the structural determinants of problems continue to be ignored. Nowhere is this more clear than in Kotler and Lee's (2009, p. 5) assertion that "our relentless focus and attention is on those poor who want to help themselves. What do they want and need that will move them out of poverty, even keep them out in the first place?" This point, while reflecting an individualistic paradigm and ignoring macro and meso determinants of the phenomenon, assumes that poor people have a sufficient degree of agency, which is typically not the case.

Certainly, the proposal of a new discipline will face resistance. One could argue that it would be a simple matter of adapting the repertoire of social marketing to account for the gaps discussed in this chapter. Perhaps. However, this solution does not address the problem of negative associations evoked by the word "marketing," which, we feel, may be stronger in non-English countries. The monolith of meaning in this case may be too strong to change. 
Finally, if the call for a new meta-discipline truly reflects underlying tensions between existent disciplines and the increasing complexity of social problems, we can expect more people echoing the same tensions or supporting our proposal. This may in the end entail the need for promotion of this new mindware, a subject we will return to in chapter 6 , which deals with processes of social change. 


\section{POVERTY, HUMAN DEVELOPMENT AND HIGH-ORDER CAPABILITIES}

Poverty is a sociopolitical construct that perpetuates itself over generations, with the complicity of ruling powers - governments, business and institutions. (Christian Sarkar and Abhijeet De)

\subsection{AN AMBIDEXTROUS APPROACH TO HUMAN DEVELOPMENT}

The world has made remarkable progress in recent decades in reducing poverty. While in 1981 the poor accounted for 42\% of the world's population, by 2013 that figure had declined to 11\% (The Economist, 2017; World Bank, 2011a; World Bank, n.d.a). The reasons revolve around strong processes of economic growth, particularly in China, which accounted for $88 \%$ of the world's poor in 1981 . The same processes, on the other hand, explain why sub-Saharan Africa, which has not developed adequate market institutions (and hence has not been integrated into international markets), will probably account for the lion's share of poverty in the coming decades.

Although poverty has reached low levels in historical terms, few countries in the world provide social ecosystems conducive to the attainment of human potential for most of their citizens. In other words, there are many countries where most individuals are not poor by a given standard, but in these same countries the paths to human development are typically blocked. A country of cocoa farmers is not a country of software developers. In fact, the alleviation of poverty represents only part of what should be a two-pronged approach. Reducing poverty can be compared to fighting a disease in the body. Just as the absence of disease does not imply adequate health, the alleviation of poverty does not imply the existence of a social ecosystem conducive to societal well-being.

Indeed, countries will increasingly compete in markets that are knowledge-intensive in nature and whose contours are constantly challenged by technological development. Biotechnology, sophisticated services (such as branding), medicine, robotics, artificial intelligence, renewable energy and similar industries will be the source of differentiation and competitiveness for developed countries. In this arena, a well-prepared workforce is 
a necessary condition for success. The major challenge for modern societies, therefore, is how to tackle poverty while creating the basis (especially the human capital) for the development of a sophisticated economy.

Traditionally, poverty has been associated with material deprivation, but this is a narrow view. In public discourse, and even in the academic literature, one often finds disparate definitions of poverty, of human development and of how to alleviate the former and promote the latter. This is important, because defining the boundaries of a complex problem such as poverty or human development necessarily constrains the design of policies enacted to address them. Incomplete mental models lead to inefficacious policies, squandering of public resources and frustration of society's expectations.

In academia, a divergence in definitions is common and reflects different lenses of analysis. Employing a traditional focus, studies in economics tend to define poverty as financial deprivation (e.g., Bowles, Durlauf, \& Hoff, 2006). In the field of social marketing, Kotler and Lee (2009), who were the first social marketers to address poverty in a book, also accepted that definition. Behavioral economists such as Datta and Mullainathan (2014), in contrast, take a broader view, conceiving poverty as more than financial or material deprivation, encompassing psychological and cognitive scarcity as well. Social scientists researching poverty and well-being, on the other hand, tend to employ wider lenses to analyze the phenomenon, working with different dimensions, as we will see below.

To complicate matters, poverty is a highly sensitive issue in the political arena. For some political movements, poverty is caused not by social structures but by families with weak bonds, or even by governmental programs that foster dependency, a viewpoint epitomized by the former US president Ronald Reagan (The American Presidency Project, n.d.). Different political movements, on the other hand, tend to view poverty as influenced (and/or caused) by broader structures, a viewpoint often voiced by political parties on the left - and recently by another US president, Barack Obama (The White House, 2015).

Definitions and, above all, mental models matter. In the discourse of politicians in most countries, mention of poverty and social policies for addressing poverty (such as education) are commonplace. However, the reality is that few countries have been able to 
create social ecosystems favorable to the realization of human potential. There are still sizable segments of the population living in poverty in most developed countries.

Hence, the "technology" to address poverty - the mental models, the policies, the political choices - is clearly incomplete. Of course, poverty often results from the prevalence of extractive institutions (Acemoglu \& Robinson, 2013; North, 2005) and intricate political processes that maintain the status quo in most countries. In other words, we do not assume that incomprehension as to how to tackle poverty is the only explanation for poverty's permanence.

This chapter proceeds as follows. First, we tackle the various definitions of poverty and aspects of the phenomenon, such as its subjective experience. We propose a summary encompassing the major dimensions of deprivation, including one (intergenerational transmission of poverty) that is usually absent from most frameworks. Second, we discuss human development from a well-being perspective, emphasizing the importance of fundamental human needs in systemic approaches to the subject. We also advance the concept of individual generative capabilities. Finally, using the DSRP method (see section 3.4), we present an integrative framework for human development, taking into account both the dimensions of poverty and the drivers of well-being.

\subsection{WHAT IS POVERTY?}

When human beings started to live in cities and similar social structures, a new kind of social organization emerged, characterized, among other factors, by social inequality (Kamakura \& Mazzon, 2013). Moreover, slavery and unequal distribution of status were the hallmarks of most societies during most of human history (Diamond, 2013). In fact, until the nineteenth century, poverty was seen as inevitable, and the poor received little attention (Kotler \& Lee, 2009).

Poverty is a multidimensional phenomenon characterized by clusters of deficits, a complex social problem reflecting the prevalence of structural factors including extractive institutions and unequal power structures (Sarkar \& De, 2015). The usual definitions, however, tend to rely on lack or uncertainty of income, circumscribing the phenomenon to its economic dimension. On such views, the insufficiency of financial resources 
impairs the satisfaction of basic needs, such as food, shelter, education and health, undermining the development of human capital. Another common approach under the influence of economics is the modeling of poverty as economic traps (e.g., Bowles, Durlauf, \& Hoff, 2006).

There is an extensive discussion in the literature about the adequate measurement of poverty, depending on its conceptualization - is it deprivation, lack of capabilities and/or social exclusion? (Hick, 2012). Next, we provide a representative sample of that discussion.

Under the deprivation approach, a common treatment is the distinction between relative and absolute poverty (World Bank Institute, 2005). In the same vein, Sachs (2005) distinguishes three degrees of poverty: extreme, moderate and relative. People in extreme poverty are chronically hungry and have little or no access to health care, safe drinking water, sanitation, shelter and education for themselves and their children. Individuals in moderate poverty have their basic needs barely met and typically have little access to education and health care. They are always on the brink of extreme poverty. Extreme and moderate poverty represent conditions of absolute poverty (Leventhal \& Brooks-Gunn, 2002). Material deprivation - measuring whether people can afford to buy one or more of a set of necessities, such as shoes - is another approach to the issue from an absolute point of view (Hick, 2016).

Relative poverty, on the other hand, depends on the distribution of national levels of income. Individuals in relative poverty still lack access to high-quality health care and education, as well as to cultural goods, recreation, entertainment and other aspects of modern life. Moreover, they lack access to capabilities that could provide them with upward social mobility (Sachs, 2005). Internationally, a widely used measure for gauging relative poverty is the income threshold of US\$1.90 a day, adjusted for purchasing power parity (PPP) (World Bank, n.d.a).

Financial deprivation is the most visible facet of poverty, but it is far from being the only one. Barrett and Swallow (2006), for instance, define poverty as the combination of low levels of income or consumption, high vulnerability to shocks and lack of voice or power. The United Nations developed a Human Poverty Index (HPI) for measuring poverty in underdeveloped countries. The index combines three measures: probability at birth of not surviving to the age of 40 , adult illiteracy rate and a measure averaging the proportion of 
the population lacking access to improved water sources and the proportion of underweight children in the population. In 2010, the Multidimensional Poverty Index (MPI) replaced the HPI. The MPI is an improved measurement that combines 12 elements from three dimensions (health, education and standard of living) to identify the more vulnerable people in a region or country. Other indexes that have been employed to measure poverty or human development are the human development index (HDI), and the inequality-adjusted human development index (IHDI) (United Nations Development Programme, n.d.b).

The Nobel Prize winner Amartya Sen is the most famous proponent of the concept of capabilities in the study of poverty. Sen (1999) defines poverty in terms of deprivation of capability, especially of intrinsically important capabilities, which exclude financial resources (which in his view are only instrumentally important). Capabilities in Sen's conceptualization represent the substantive freedoms a person has to lead the kind of life he or she values. This point is important when one considers, for instance, that being relatively poor in a rich country can imply an absolute deprivation in terms of capabilities, since more income is needed to acquire the goods and services that promote adequate social functioning. Here we note the criticism of Warren (2008) regarding the typically loose definitions of capabilities in the literature of business strategy. We feel the same criticism can be applied to the usual definitions of capabilities found in the poverty literature. We will return to this point in section 3.3.1, in which we propose the concept of individual generative capabilities.

Comin, Bagolin, Avila, Júnior, and Picolotto (2006) also define poverty as a privation of basic capabilities. They propose a multidimensional index of poverty comprising the following dimensions: health, nutrition, education, knowledge, participation, trust and friendship, solidarity and freedom. In the same vein, Hick (2016) defines multiple deprivation in terms of seven dimensions: general health, mental health, housing deprivation, lack of autonomy, life satisfaction, financial stress and unemployment. Interestingly, Hick's research showed a high level of correlation for diverse vulnerable groups between measures in those dimensions and the general indicator of material poverty.

Table 4 presents a compilation of traditional measures of poverty, according to Comin and Bagolin (2002) and World Bank Institute (2005). 
Table 4. Clusters of poverty measures

$\begin{array}{ll}\text { Definition of poverty } & \text { Examples of indicators } \\ \text { 1. Insufficiency of income } & \mathrm{P}_{0} \text { (headcount index, or the proportion of } \\ & \text { poor individuals in the population) } \\ \bullet & \mathrm{P}_{1} \text { (poverty gap index, or the extent to } \\ & \text { which individuals fall below the poverty } \\ & \text { line) } \\ \bullet & \mathrm{P}_{2} \text { (squared poverty gap) } \\ \bullet & \text { The Sen-Shorrocks-Thon index, which } \\ & \text { measures the number of poor people, the } \\ & \text { extension of poverty and inequality } \\ & \text { among the poor }\end{array}$

2. Privation of basic needs (at the The Rowntree and Orshansky indexes, household level) which measure costs of food, clothing and housing and the provision of public goods

3. Social exclusion

Qualitative descriptors of insufficiency of resources to participate in regular social life

4. Privation of basic human capabilities Multidimensional measures of poverty Source: Comin \& Bagolin (2002); World Bank Institute (2005).

\subsubsection{THE SUBJECTIVE EXPERIENCE OF POVERTY}

We define the subjective experience of poverty as the combination of a scarcity mindset, prevalence of negative emotions and stress, low levels of agency (leading in some cases to learned helplessness) and social stigma.

One of the remarkable findings in the behavioral economics literature concerns the effect of poverty on cognitive capacity and executive control. The evidence shows that poverty leads to a scarcity mindset that affects how people think, what they notice, how they represent and deal with problems, how their attention is deployed and how they decide and behave (Mani, Mullainathan, Shafir, \& Zhao, 2013; Mullainathan \& Shafir, 2013). Under the pressure of a scarcity mindset, the mind orients automatically and powerfully toward unfulfilled needs. However, at the same time, by capturing the mind and leading 
it through a "tunneling" process, scarcity leads to the inhibition of fundamental capacities and the neglect of valued goals. Everything that is outside this tunnel tends to be ignored. The reduction in "bandwidth" capacity implies that an individual, even if he or she possesses the psychological resources to deal with environmental demands, can only employ part of them. Mani, Mullainathan, Shafir, and Zhao (2013) observed a reduction equivalent to 13 IQ points among poor participants who were experimentally induced to a scarcity mindset. The loss in cognitive competence was also equivalent to losing one full night of sleep. In addition, scarcity exacerbates the human tendency to focus on the short term, leading to processes of temporal hyperbolic discounting.

From a public policy perspective, bandwidth can be increased through interventions that reduce the cognitive burden on the poor, such as provision of free childcare to working mothers and a reduction in red tape in public programs. As Mullainathan and Shafir (2013, p. 178) state,

all this is a radical reconceptualization of poverty policy. It forces us to recognize the many ways in which different behaviors are linked. We understand that rent and food and school fees all form part of a household's budget. Now, rather than looking at education, health, finance and child care as separate problems, we must recognize that they all form part of a person's bandwidth capacity. And just as a financial tax can wreak havoc in one's budget, so can a bandwidth tax create failure in any of several domains to which a person must attend. Conversely, fixing some of those bottlenecks can have far-reaching consequences. Child care provides more than just child care, and the right financial product does much more than just creating savings for a rainy day. Each of these can liberate bandwidth, boost IQ, firm up self-control, enhance clarity of thinking and even improve sleep. Far-fetched? The data suggest not.

Poverty is also associated with a detrimental set of emotional states and low life evaluation. Evaluating a dataset of 450,000 responses to the Gallup-Healthways WellBeing Index in the United States, Kahneman and Deaton (2010) uncovered a "perfect storm" that strikes people and families living in the lower deciles of the income distribution: the prevalence of the lowest levels of positive emotions associated with the highest levels of stress and negative emotions. In addition, the study suggests that while emotional aspects of well-being (stress, positive and negative emotions) satiate with income, life evaluation does not. In the same sample, poor people reported several indicators of a difficult life: greater prevalence of sadness, worry, headache and asthma, as well as living alone and being divorced. 
Besides concentrating a high degree of negative emotional experiences, poverty creates other traps. As research conducted by Mead, Patrick, Gunadi, and Hofmann (2016) suggests, goal progress in daily life is helped when individuals can offset small annoyances against pleasant daily experiences, thus replenishing a healthy level of daily happiness. However, financial deprivation is associated with a preference for material goods over experiences (Tully, Hershfield, \& Meyvis, 2015). Poverty may thus prevent the construction of a buffer against daily annoyances, trapping individuals in the nonadaptive consequences of negative affect.

According to Berkowitz (2003), privations in life can lead to resentment, which, in turn, can generate antisocial behavior. The author cites evidence pointing to a causal link between continuing poverty and delinquency and crime. This would be the result of an aggressive urge caused by never-ending privation and the associated prevalence of negative affect.

Another aspect of the subjective life of the poor is the lack of voice or participation in public life. Lack of voice in poverty implies not only the usual absence of channels in public life but also a situation of internalized lack of voice and low levels of agency - or, in many cases, a situation of learned helplessness (Abramson, Seligman, \& Teasdale, 1978; Seligman, 1972). Learned helplessness imply that people attribute their state to an external cause, because they perceive noncontingency between their efforts and the results they experience. According to the traditional account of learned helplessness, people do not see themselves as capable of escaping the situation that produced their helplessness; they lack agency, and they think that outcomes are fully uncontrollable. (For a different perspective on learned helplessness, which attributes it to rarity of rewards for exploratory behavior, see Teodorescu \& Erev, 2014). Learned helplessness usually leads to deficits of three types: cognitive, motivational and emotional. Independently of the underlying mechanisms, its consequence is lack of effort to change the situation. This is more acute in the case of poverty, since it seems to induce a stable, chronic and generalized feeling of helplessness.

On the other hand, the poor can paradoxically exhibit a state of life satisfaction even when their objective living conditions are unsatisfactory, giving rise to a "satisfied poor" condition (Olson \& Schober, 1993). In the same vein, Neff (2009), studying two villages in India and drawing on learned helplessness and similar concepts, identified two processes that can explain adaptation to a situation of poverty: resignation and optimism. 
The former process, which the author calls resigned adaptation, occurs when people resign themselves to their fate by abandoning their wants, aspirations and expectations. The latter process occurs when individuals compare their current lot with past situations or have positive expectations regarding their future or the future of their children. In either case, there is adaptation to an uncontrollable situation and the absence of effort to change it. Moura Jr (2015) also identified the process of adaptation in contexts of poverty in Brazil.

Low social standing is associated with dysfunctional levels of cortisol (the hormone of stress), disease and poor health (Chandola, Rouxel, Marmot \& Kumari, 2017; Dickerson \& Kemeny, 2004; Kuzawa, 2010; Marmot, 2004). Social exclusion, perceptions of uncontrollability over one's fate and threats to social esteem, respect and acceptance which are typical of situations of poverty - can be a permanent trigger of cortisol release and a continuous source of allostatic load, a cumulative toll on the body's biological resources.

Finally, chronic poverty severely limits choices in all domains of life, such as choice of neighborhood, school and educational or recreational activities (McLoyd, 1990). It also renders the individual more subject to control by others and increases the probability of stigma. McLoyd (1990) reviews evidence showing that poor children tend to be viewed more negatively, receive more criticism and receive less positive attention from teachers. Poverty, in fact, defines the child's immediate environment. Worse, the longer an individual has been poor, the less likely it is that he or she will escape poverty. The poor can face a succession of negative life events (e.g., loss of jobs, eviction) that often produce tipping points in other domains of life (e.g., marriage), precipitating additional crisis and stress-inducing events and reinforcing stigma. Economic hardships also lead to more anxiety, irritability and depression among the poor. Severity and chronicity of stressors deplete emotional resources, perpetuating several causal chains (such as the quality of the parent-child relationship) that contribute to the permanence of low human development in a society.

\subsubsection{AGAIN, WHAT IS POVERTY?}

A society's well-being can be conceived in the same vein as Baron (2008) conceives utility: the degree to which desired goals are achieved. The goals, of course, are diverse 
and they require multifocal lenses that account for objective and subjective aspects of human experience. As we will see in the next section, thinking in terms of societal wellbeing is qualitatively different from thinking in terms of the alleviation of poverty. Of course, public policies to prevent or reduce poverty tend to have some degree of intersection with policies aimed at increasing well-being. The difference lies in the conceptual lenses and in the level of "energy" employed. Educational policies that eradicate illiteracy are very different from policies that prepare children to excel in life. Both goals, however, must be part of the repertoire of public policies in modern societies. For the sake of clarity, we summarize in table 5 the major dimensions associated with poverty reduction. The summary integrates propositions from a sample of relevant sources (Barrett \& Swallow, 2006; Berry et al., 2014; Blair, 2010; Bowles et al., 2006; Claro, Paunesku, \& Dweck, 2016; Comin et al., 2006; Evans et al., 2005; Kamakura \& Mazzon, 2013; McLoyd, 1990; Moura Jr. 2015; Mullainathan \& Shafir, 2013; Sachs, 2005; Sen, 1999).

We also propose a new dimension - intergenerational channels for poverty transmission. An alternative way to conceptualize the vicious circle of poverty is through the intergenerational transmission of key deficits in assets and resources (Blanden \& Gibbons, 2006; Bird, 2011). These assets include not only physical assets, but also health, education, cultural and social capital and worldviews. The idea that low human development propagates over generations is consistent with the defining characteristics of the phenomenon: multidimensional causes, path dependence, irreversibility, distorted social structures, extractive institutions and the low priority of the issue in the public agenda. We return to this subject in chapters 4 and 5 . 
Table 5. Poverty and its dimensions

\begin{tabular}{|c|c|}
\hline Dimension & Sub-dimensions \\
\hline \multirow{3}{*}{ Financial } & Insufficiency of resources \\
\hline & Vulnerability to shocks \\
\hline & Low consumption of goods and services \\
\hline \multirow{10}{*}{ Psychological } & Low levels of self-regulation \\
\hline & Low levels of agency and self-efficacy \\
\hline & Low levels of cognitive and emotional resources \\
\hline & Affective misery, including low levels of positive emotions \\
\hline & Low self-esteem \\
\hline & Scarcity mindset \\
\hline & Fixed mindset \\
\hline & Prevalence of stress \\
\hline & Low resilience \\
\hline & Single parenting \\
\hline \multirow{4}{*}{$\begin{array}{l}\text { Family and family } \\
\text { environment }\end{array}$} & Chaos and stress-inducing conditions \\
\hline & Low level of attention and stimulation from relatives \\
\hline & Conflict between parents \\
\hline & House crowding \\
\hline
\end{tabular}

(continued) 
Table 5 (continued)

\section{Work}

Dimension

Health

Education

Social

(continued)
Sub-dimensions

Meaningless work

Job-related stress

Lack of opportunities to develop one's competences

Inadequate access to clean water and basic sanitation

Inadequate nutrition

Obesity

Incidence of preventable diseases

Low-quality health system

Consumption of cigarettes and other detrimental products

Low-quality educational system

Prevalence of simple skills and abilities

Low occupational prestige and low social status

Stigma and social isolation

Dysfunctional neighborhoods

Inadequate levels of leisure

Low quality of friendship

Weak feelings of belonging to valued social groups 
Table 5 (conclusion)

$\begin{array}{ll}\text { Dimension } & \text { Sub-dimensions } \\ & \text { Lack of trust } \\ & \text { Lack of community vitality } \\ \text { Social } & \text { Low levels of perceived fairness in social mechanisms of } \\ & \text { justice and social outcomes }\end{array}$

No voice

Political Absence of channels for participation in social affairs

Absence of democratic and participatory institutions

Cultural Lack of access to cultural goods and services

Lack of access to social services (prenatal care, health care, Intergenerational childcare, education) that provide equality of opportunities for children

Naturally, in any specific social setting only a subset of the sub-dimensions displayed in table 5 will be more prominent. Additionally, a repertoire of well-developed resources from those listed in the table can help to protect or buffer the environmental risks associated with poverty. For instance, Cecconello and Koller (2000) present evidence showing how adequate emotional and instrumental resources can increase the capabilities of children to adapt and deal with the demands of their social environment. This is critical in transitions among ecologic microsystems, such as from family to school and neighborhood, in which new roles have to be enacted and new competencies (such as emotional regulation) are required. 


\subsection{THE OTHER FACET OF HUMAN DEVELOPMENT: WELL-BEING AND FUNDAMENTAL HUMAN NEEDS}

The period after World War II witnessed an unprecedented social and economic development in several countries. It is no exaggeration to say that a new paradigm was born, marked by increasing social participation, expanding empathy toward different social groups and very low levels of human violence (Pinker, 2012). The zeitgeist changed progressively, and new worldviews of more humane societies started to spread. However, it took some decades for the academic field of well-being to develop and start asking different questions from those typically asked by poverty researchers. Instead of inquiring into what should be done to alleviate poverty, well-being researchers started investigating what makes a life worth living and what social dimensions contribute to this (Kahneman, Diener, \& Schwarz, 1999; Seligman, 2011). Reaching one's potential in life means tapping into the two major, interrelated aspects of well-being: hedonia (subjective well-being), and eudemonia, or the different dimensions that comprise a virtuous life (Biswar-Diener, n.d.).

Moving from alleviating poverty to providing conditions for the full realization of human potential involves the identification of drivers of a flourishing life. Some theoretical paradigms suggest answers to this question. According to the fathers of SelfDetermination Theory, Edward Deci and Richard Ryan, all individuals have natural, innate and constructive tendencies toward a more elaborated sense of self (Ryan \& Deci, 2002). Their theory presents a dialectical view in which there is interaction between an active, integrating human nature and social contexts that either nurture or hinder the full development of human potential. Such potential, in turn, depends on the full activation of three basic innate psychological needs: autonomy, competence and relatedness. Autonomy refers to being the perceived source of one's own behavior, acting from interest and integrated values. Competence refers to feeling effective in one's ongoing interactions with the social environment and having opportunities to express and exercise one's capacities. In modern societies, individual competences need to have channels for their development in increasingly complex structures of organizations and social networks - in other words, what we can call ecosystems of socioeconomic complexity (Hidalgo, 2017). Finally, relatedness refers to feeling connected to others, to caring for and being cared for, and to having a sense of belongingness both with other individuals 
and with one's community - what Baumeister and Leary (1995) call the fundamental need to belong. Ryan and Deci (2002) present evidence linking the fulfillment of these three basic needs to general well-being.

Within the same theoretical current, Little, Hawley, Heinrich, and Marsland (2002) emphasize the role of agency in human development. Personal agency, according to them, is a sense of personal empowerment, which involves both knowledge and having the means to achieve one's goals. They see a well-adapted agentic individual as one who perceives herself as the origin of her actions, has high aspirations, perseveres in the face of obstacles, learns from failures, considers different alternatives of action and has a greater sense of well-being. In contrast, a non-agentic individual often feels helpless, has a greater sense of ill-being and perceives herself as a pawn to exterior influences.

The emergence of positive psychology and the field of well-being studies provided a more sophisticated view of the drivers of human development. Seligman (2011) identified five dimensions in which individuals pursue goals out of intrinsic motivation: positive emotions, engagement - including the concept of flow (Csikszentmihalyi, 1990) accomplishment, meaning and social relationships. A global concept of well-being should comprise the drivers that promote life satisfaction, positive emotions and a small but adequate degree of negative emotions. On a small scale, emotions such as frustration, guilt or anger are associated with striving for one's goals and with noticing relevant aspects of the environment, including the social injustice that motivates people and movements to fight for better conditions (Seligman, 2011).

Loewenstein (2009) argues that a worthwhile life is one that comprises the activation of dimensions including meaning, wisdom, values and capabilities, such as health, freedom from assault, political voice, property rights, equal employment and access to education. A worthwhile life is also one with high levels of social trust and strong ties to families, neighborhoods and communities (Helliwell \& Putnam, 2004). Other research emphasizes complementary dimensions, such as belonging to higher-order social organisms (Haidt, Seder, \& Kesebir, 2008), having opportunities for developing one's capabilities (Forgeard, Jayawickreme, Kern, \& Seligman, 2011), perceiving fairness in the word (Starmans, Sheskin, \& Bloom 2017) and having channels to express one's distinctiveness (Vignoles, 2009). 
The greater concern toward societal well-being over recent years has led to the development of several national well-being indexes. Helliwell, Layard, and Sachs (2012) discuss the dimensions that such indexes should integrate, including factors such as income, quality of work, use of time, ecology, social capital, physical and mental health, family experience, subjective well-being, civic engagement and education (see OECD, 2017a, for an adequate implementation).

Indeed, the development of such indexes represents a healthy evolution from traditional measures. Once, GDP per capita or GDP growth were the sole measures of a country's well-being. GDP is, of course, a very imperfect measure of progress toward societal goals, since it increases when several detrimental activities increase, such as polluting industries, construction of prisons and military spending.

Table 6 presents popular indexes or reports of well-being and their dimensions. We note that they mix subjective aspects of well-being (e.g., emotional experiences) and objective aspects (e.g., basic sanitation). 
Table 6. Indexes of well-being

\begin{tabular}{|c|c|c|}
\hline Index & Dimensions & Sponsor \\
\hline $\begin{array}{l}\text { World Happiness } \\
\text { Report }\end{array}$ & $\begin{array}{l}\text { Life satisfaction, emotional experience } \\
\text { (happiness, worry and depression), life } \\
\text { purpose and diverse indicators on objective } \\
\text { and subjective well-being employed by } \\
\text { different countries, such as education, } \\
\text { health, trust, housing, jobs and security, } \\
\text { water and sanitation, inequality, } \\
\text { biodiversity, obesity and crime }\end{array}$ & $\begin{array}{l}\text { The Global Happiness } \\
\text { Council }\end{array}$ \\
\hline $\begin{array}{l}\text { Gross National } \\
\text { Happiness Index }\end{array}$ & $\begin{array}{l}\text { Psychological well-being, health, education, } \\
\text { use of time, cultural diversity and resilience, } \\
\text { good governance, community vitality, } \\
\text { ecological diversity and resilience, and } \\
\text { living standards }\end{array}$ & Government of Bhutan \\
\hline Prosperity Index & $\begin{array}{l}\text { Governance, personal freedom, social } \\
\text { capital, safety and security, education, } \\
\text { health, environment, economic quality and } \\
\text { business environment }\end{array}$ & Legatum Institute \\
\hline $\begin{array}{l}\text { Happy Planet } \\
\text { Index }\end{array}$ & $\begin{array}{l}\text { Life satisfaction, life expectancy, inequality } \\
\text { of outcomes and ecological footprint }\end{array}$ & $\begin{array}{l}\text { New Economics } \\
\text { Foundation }\end{array}$ \\
\hline
\end{tabular}

Thus far, we have sampled the literature on poverty and well-being, and the reader may be justified in feeling confused about the myriad of measures and their diverse dimensions. Some dimensions, such as physical and mental health, financial sufficiency to meet basic needs, work satisfaction, subjective well-being and a feeling of belonging to social groups seem to be essential characteristics of a good life. Sufficiency requirements, on the other hand, seem to be open to discussion.

To organize the subjects discussed in this chapter, we present in section 3.4 an integrated framework. However, there is one remaining piece of the puzzle that needs to be addressed: the concept of generative capabilities.

\subsubsection{HIGH-ORDER CAPABILITIES}

Social phenomena often display the same fractal characteristics found in natural systems. A fractal is a self-similar structure occurring in objects and systems at different scales 
(Mitchell, 2011). We can draw a parallel between individuals and organizations. Both are prone to the phenomenon of path dependence: some paths chosen (or imposed) constrain their future development in a manner that it is often impossible to revert. Like individuals, organizations must strive to develop the right set of resources to assure their survival in the market. Resource-based theory (Barney \& Clark, 2007) and other similar theoretical frameworks deal with organizational resources and capabilities. The combination of rare tangible and intangible resources deserves special attention in the literature, inasmuch as it enables a firm to achieve a competitive advantage in the market. We borrow the concepts of assets, resources and capabilities, which are common in those frameworks, for the discussion of human development.

We note that we are not the first to borrow organizational resource-based approaches to address phenomena at the individual level. For instance, Dorsch, Törnblom, and Kazemi (2017) provide a thorough review of the resources theories typically applied in organizational studies, drawing several implications for the understanding of consumer behavior. One important implication they draw is the idea that an individual's resource reservoir can help in absorbing daily stress. This point is especially relevant in the discussion of the role parents have in the first years of their children's lives (see chapter 4).

Families in poverty have a signature set of resources and capabilities. Due to their focus on immediate concerns and the prevalence of a scarcity mindset, they often have low levels of crucial resources - money, energy and time - to employ in the development of important capabilities in their offspring. In addition, education and professional skills are assets that typically have low levels in such contexts. However, there are two fundamental intangible capabilities associated with better outcomes in life that are fundamental in efforts to lift people from poverty and promote well-being. The first is self-regulation: the capacity to delay gratification, make plans, persist and endure setbacks (Baumeister, 2002; Blair \& Ursache, 2011). The other is self-efficacy: the capacity to employ one's resources to achieve desired results (Bandura, 1997).

Nevertheless, to avoid the common misunderstanding of assets, resources and capabilities found in the management literature (e.g., Teece, 2009), we adapt the conceptualization found in Warren (2008) that disentangles capabilities from other assets in an organizational context. In addition, considering the striking parallels between the role of self-efficacy and self-regulation in an individual's life and the role ascribed in the 
management literature to dynamic capabilities (Teece, 2009), we adopt the term generative capabilities to aggregate the two factors. They represent for individuals what dynamic capabilities represent for organizations.

In both the individual and the organizational contexts, dynamic capabilities refer to the development of a meta-capability to use existent resources and generate further resources and capabilities in order to manage well-being (or progress) in the social (or business) environment. They include the flexibility to adapt to changes in the environment, based on a "learning to learn" capacity. At the individual level, there is a growing body of evidence linking non-cognitive skills to essential outcomes in life (Heckman, 2013).

Figure 4 presents a schematic representation of individual generative capabilities, which, we propose, are essential for the promotion of well-being.

FIGURE 4. DISENTANGLING INDIVIDUAL GENERATIVE CAPABILITIES FROM OTHER STOCKS

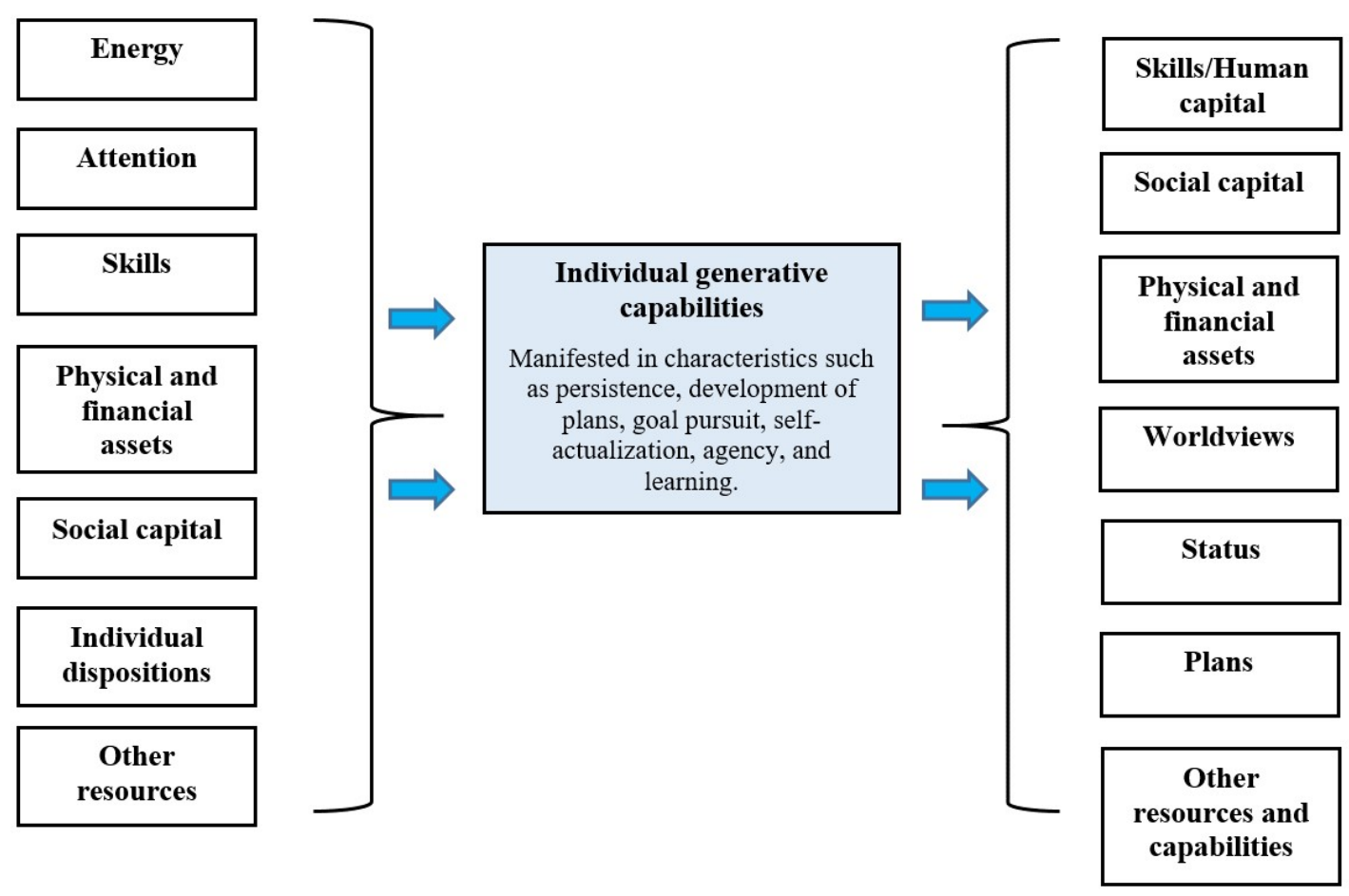

Source: Elaborated by the author. 
An important aspect of these second-order capabilities is their social determination. Selfefficacy and agency beliefs seem to be dependent on social class. Kamakura \& Mazzon (2013), for instance, found in a sample of respondents from the city of São Paulo that the poorest social class perceived themselves as having little control over their own lives. Social classes, particularly in hierarchical countries (such as Brazil) seem to open specific "social avenues" for individuals. They constrain the opportunities and the access to social networks - what Kurt Lewin summarized under the concept of life spaces (Lewin, 1948:2010).

In chapter 5, we employ the concept of individual generative capabilities in a system dynamics model to study the intergenerational replication of low human development.

\subsection{A DSRP MAPPING OF HUMAN DEVELOPMENT}

To integrate the concepts discussed in this chapter, we employ the DSRP framework proposed by Cabrera and Cabrera (2015). DSRP comprises what the authors claim to be the four universal rules subsuming systems thinking: distinctions, systems, relationships and perspectives. Distinctions are the vectors of difference among concepts or real objects. Parts and whole represent the elements that integrate any system. Relationships - typically, correlations, causation or feedback loops - link elements in a system. Perspectives are viewpoints determining how a system is perceived.

Figure 5 displays the DSRP map (created using the Plectica platform) that summarizes the discussion on human development presented in this chapter. 
FIGURE 5. DSRP MAP OF HUMAN DEVELOPMENT

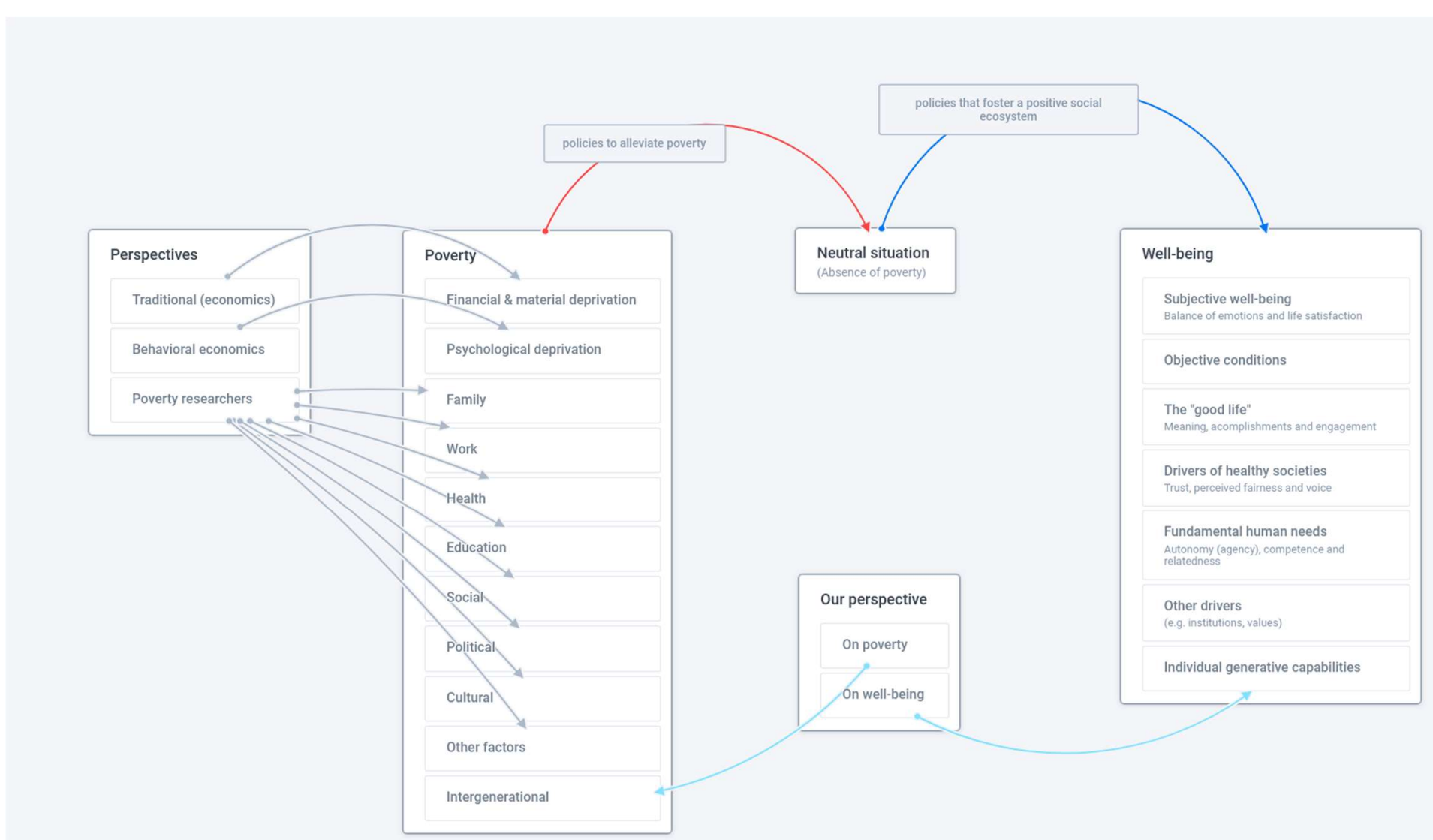

Source: Elaborated by the author. 


\subsection{DISCUSSION AND CONCLUSION: SOCIAL ECOSYSTEMS MATTER}

Standard economic thinking tends to attribute the behavior of the poor (for instance, in failing to take up social programs that would benefit them) to variants of a rational costbenefit analysis, while ignoring the powerful influence of psychological factors (Bertrand, Mullainathan, \& Shafir, 2004). Poverty, however, makes economic decisionmaking more difficult, depleting cognitive control, while also being associated with limited attentional resources and self-control (Spears, 2011).

Poverty is a multidimensional phenomenon, having multiple causes and diverse consequences. The risk of associating poverty with its economic dimension is, of course, the design of policies that address only the most visible facets of the phenomenon (Comin $\&$ Bagolin, 2002). For instance, that narrow definition may lead to the development of income transfer programs while ignoring all other relevant dimensions, such as real channels for social mobility and the need for social programs for proper early childhood development (see chapter 4).

Overcoming poverty requires the development of individual and societal capabilities. The capabilities approach is congruent with the system dynamics view of phenomena: there are several, interrelated stocks that need to reach sufficient levels to activate desirable feedback loops (see chapters 4 and 5). However, most conceptualizations of capabilities are diffuse, and they do not account for the dynamics of sociopolitical processes that lead to different levels of capabilities across population segments.

Nowadays, alleviating poverty in our societies is unsatisfactory from a viewpoint that takes full human potential into account. Such a focus is equivalent to trying to reduce psychological suffering in individuals without stimulating the drivers of human growth (such as meaning and accomplishment). The acknowledgment of this limitation is behind the birth of positive psychology. Hence, well-being management requires an ambidextrous approach by public policy makers that includes all the nuances of human development, from poverty alleviation to the stimulation of flourishing and satisfying lives.

Of course, many policies may act simultaneously on poverty and well-being. Nevertheless, a clear conceptual framework can provide better mental models and inspire better decision-making in the public arena. For instance, it is not sufficient for an educational policy to eliminate illiteracy (a feature of extreme poverty); it should also aim 
to provide the best educational experience for children, so they can accumulate the right resources to fulfill their potential in life. In this sense, the systems map we present in section 3.4 may help in clarifying conceptual differences by providing a better understanding of elements that ambidextrous policies need to integrate.

Policies, in some cases, may prompt concerns about their legitimacy. Indeed, processes of human development depend on objective and subjective conditions of life. One important aspect regarding the subjective experience of being poor is the possibility of adaptation to detrimental conditions of life in contexts of poverty. Subjective assessments may not reflect actual deficits in basic sanitation, health services and so on. This poses a problem for anyone proposing a specific equation (or index) for human development, since it may be argued that people know best what is good for them. To deflect such charges (which may assume an ethnocentric flavor when the analysis is done at the level of countries), one may appeal to the metaphor of Neurath's boat (Stanovich, 2005) - most assumptions are based on firm scientific ground (planks, in the metaphor), but some of them may be based on rotten planks. The latter planks, according to the metaphor, must be fixed while the boat is still in motion. By being predisposed to constantly reexamine and fix the rotten planks, one may reduce the risk of imposing standards that are not valued (in the long-term) by some populations.

Finally, the societal consequences of poverty are broader than those observed at the family level, as we discuss in chapter 6. Low levels of labor productivity, deficits in natural capital (for instance, through overexploitation of natural resources), the existence of dysfunctional neighborhoods and the prevalence of extractive institutions are more than consequences; they are also causes that reinforce the phenomenon (Acemoglu \& Robinson, 2013; Bowles et al., 2006; Sachs, 2005). Even processes of economic development are compromised, as they require a transition to market structures that depend on impersonal mechanisms of exchange, economic institutions that organize specialized knowledge, and entities (businesses, families) operating above the subsistence level (North, 2005). Moreover, as industries and international markets undergo transformations toward the intense incorporation of knowledge, societies will have to have ambitions greater than merely enacting policies to tackle poverty. They will need huge stocks of well-prepared individuals endowed with high-order capabilities and living in social ecosystems who are prepared to foster the attainment of full human potential. 


\section{THE SCOURGE OF WASTED LIVES: HOW SOCIAL ECOSYSTEMS HINDER HUMAN DEVELOPMENT}

No society can surely be flourishing and happy, of which the far greater part of the members are poor and miserable. (Adam Smith)

Life is not a matter of holding good cards, but of playing a poor hand well. (Robert Louis Stevenson)

\subsection{THE SCOURGE OF WASTED LIVES}

How can societies trap their youngest citizens into a path to low human development that will result in the perpetuation of social maladies?

One of the most disturbing assertions in the field of human development is the one voiced by Blair \& Ursache (2011): poverty gets under the skin of children very early. The poor children of today have a disproportionate chance of becoming poor adults and being underachievers in the future. The evidence is sufficiently strong to assert the importance of contexts in the prenatal period and in the first years of life to set in motion trajectories for lifelong health, learning and behavior (Council for Early Child Development, 2010; McEwen, 2012). In addition, the consequences of children growing up in unfavorable social ecosystems are extremely negative and go beyond the levels of the individual or the family, generating consequences at broader levels. Subpar economic productivity, crime and deepening of social inequalities are among the main effects of social policies that fail to provide equality of opportunities to vulnerable poor children (Brooks-Gunn, Duncan, \& Maritato, 1997; Conger, Conger, \& Elder Jr., 1997; Werner \& Smith, 2001). In other words, the costs of poverty are borne not only by children living in inadequate conditions but also by the broader society.

We live in a world very different from that of a century ago, when extreme poverty and child labor were still part of the landscape in most countries and when children used to labor as adults, having, in the words of the writer Upton Sinclair, "no hope but the grave" (Sinclair, 1906/2014). However, the twentieth century witnessed a turning point in human history, with significant improvements in several social problems, such as violence, extreme poverty and widespread diseases (IBGE, 2006; Pinker, 2012). Urbanization removed children from backbreaking work in rural areas; laws prohibited child labor, 
families decreased in size and education became a viable way to improve a family's lot. The median income of families more than doubled in the first decades after World War II in the United States, raising patterns of consumption and redefining standards of relative poverty (Hernandez, 1997). Brazil and several other developing countries were not immune to that overall trend. For instance, a male Brazilian child born in 1910 had a life expectancy of only 33 years; in 2015, that had risen to 72 years (IBGE, 2006; 2015c).

\subsubsection{BUT POVERTY IS STILL HERE}

On the other hand, we still live in a world where children are twice as likely as adults to live in extreme poverty, and the youngest children (those under the age of five) are most at risk (UNICEF, 2016). We live in a world where, every year, almost 6,000,000 children die before their fifth birthday (United Nations, 2015). Even in some developed countries such as the United States, there has been little progress in lifting children out of poverty (Hernandez, 1997). In middle-income countries such as Brazil, a hallmark of poverty is its disproportionate prevalence among children compared to adults and seniors (IPEA, 2008).

Table 7 displays social indicators associated with poverty in childhood for a sample of countries with different levels of socioeconomic development as measured by the Inequality-adjusted Human Development Index (IHDI) (United Nations Development Programme, n.d.b). 
Table 7. Selected social indicators associated with poverty in childhood

\begin{tabular}{|c|c|c|c|c|}
\hline Country (IHDI) & $\begin{array}{l}\text { Prevalence of } \\
\text { child malnutrition } \\
\text { (percentage of } \\
\text { children under } \\
\text { five, 2010-2016) }\end{array}$ & $\begin{array}{l}\text { Maternal } \\
\text { mortality ratio } \\
\text { (per } 100,000 \text { live } \\
\text { births, 2015) }\end{array}$ & $\begin{array}{l}\text { Mortality rate per } \\
1,000 \text { live births, } \\
2015)\end{array}$ & $\begin{array}{l}\text { Primary } \\
\text { completion rate } \\
\text { (percentage of } \\
\text { relevant age } \\
\text { group, 2015) }\end{array}$ \\
\hline Argentina $(0.698)$ & - & 52 & 13 & 102 \\
\hline Australia (0.861) & - & 6 & 4 & $\mathrm{~N} / \mathrm{A}$ \\
\hline Brazil (0.561) & - & 44 & 16 & $\mathrm{~N} / \mathrm{A}$ \\
\hline Cabo Verde (0.518) & - & 42 & 25 & 102 \\
\hline Canada (0.839) & - & 7 & 5 & $\mathrm{~N} / \mathrm{A}$ \\
\hline $\begin{array}{l}\text { Central African } \\
\text { Republic (0.199) }\end{array}$ & 40.7 & 882 & 130 & 44 \\
\hline China (-) & 9.4 & 27 & 11 & 92 \\
\hline Denmark (0.858) & - & 6 & 4 & 99 \\
\hline $\begin{array}{l}\text { Dominican } \\
\text { Republic }(0.565)\end{array}$ & 7.1 & 92 & 31 & 94 \\
\hline $\begin{array}{l}\text { Guinea-Bissau } \\
(0.257)\end{array}$ & 27.6 & 549 & 93 & $\mathrm{~N} / \mathrm{A}$ \\
\hline Haiti (0.298) & 21.9 & 359 & 69 & $\mathrm{~N} / \mathrm{A}$ \\
\hline Indonesia (0.563) & 36.4 & 126 & 27 & 102 \\
\hline Norway (0.898) & - & 5 & 3 & 98 \\
\hline Saudi Arabia (-) & - & 12 & 15 & 108 \\
\hline Sweden $(0.851)$ & 0 & 4 & 3 & 104 \\
\hline USA (0.796) & 2.1 & 14 & 7 & $\mathrm{~N} / \mathrm{A}$ \\
\hline
\end{tabular}

Source: United Nations Development Programme (n.d.b); World Bank (n.d.b).

The panorama illustrated in table 7 suggests that developed countries have minimized the main problems associated with poverty in childhood. However, relieving hunger is not 
the same as providing adequate and delicious nutrition. In the same vein, low human development manifests itself to different degrees, but the appropriate approach toward softening the burden of poverty is not necessarily the same when the goal is to develop human potential in a society.

The fact is that modern societies have not been able to eradicate poverty, which keeps replicating itself across generations. In addition, even in the successful cases of elimination of extreme poverty (such as in the Nordic countries), a sizable share of the young population still lives under conditions that are detrimental to full human development (Werner \& Smith, 2001; Zachrisson \& Dearing, 2015).

Thus, considering that the main victims of the social dynamics that replicate low human development are children, and if the goal is to avoid the replication of poverty and to develop full human potential, it seems desirable to understand how societies can reorient their structures to create positive social ecosystems. The literature on human development strongly suggests that there is an optimal time in a child's life to create the roots for societal well-being: the most critical window of time for human development starts in the womb and closes in approximately the first five years of life. Breaking the cycle of low human development requires energetic and adequate action from society in that crucial period.

At the beginning of life, the formation of essential neural structures requires adequate levels of environmental stability and stimulation that are typically absent (or deficient) in situations of poverty and social deprivation. In addition, the amount of time spent in poverty (i.e., whether poverty is short term or persistent) influences the quality of later human development, affecting outcomes such as IQ in a dose-dependent manner (BrooksGunn, Duncan, \& Maritato, 1997). In other words, the causes of low human development result from diverse interacting factors, as we will discuss below. Such factors reflect a range of influences from different levels of the social tissue, including dysfunctional families, misguided public policies and, on a broader level, uneven income distribution and extractive economic institutions. They are tangled in social ecosystems that display all the features of complexity: policy resistance, unexpected side effects of interventions, nonlinearities and feedback loops (Sterman, 2000).

Governments throughout the world have not been immune to the knowledge that children replicate poverty by virtue of their family's socioeconomic circumstances. The provision 
of childcare and early educational interventions has been integrated into the repertoire of public interventions aimed at early childhood, with mixed results so far. In addition, economic development over recent decades has produced societies that are more inclusive and more attentive to the needs of the socially disadvantaged. Nonetheless, the repertoire of interventions still seems insufficient. As Raphael (2011, p. 23) emphasizes, "public policy decisions in many wealthy developed nations have done little to reduce child poverty rates and in many instances have served to increase them." Major social problems persist, despite the best intentions and efforts, when they are more complex than the narrow conceptual frameworks employed to understand them (Sterman, 2006). Narrow perspectives are usual in governments facing complex problems, which points to a problem of shared mindware among public decision-makers and their influencers. In addition, public organizations typically lack agility and adequate levels of capabilities to deal with the complexity found in social ecosystems (Rieckhoff \& Maxwell, 2017).

\subsection{WHY IT IS IMPORTANT: CONSEQUENCES OF GROWING UP POOR, OR THE CURSE OF POVERTY}

As indicated above (section 4.1.1), evidence shows that poverty gets under children's skin very early and continues to blight lives independently of later circumstances. Developmental delays or insufficiency of key competences or capabilities shut several doors in life, blocking, in practice, the fulfillment of human potential. As expected, the effects are stronger for families living in longer-term poverty (Haveman, Wolfe, \& Wilson, 1997; Teachman, Paasch, Day, \& Carver, 1997).

In fact, children raised in poverty are more likely to drop out of school, to have a baby as a teenager, to earn lower wages and to become single parents in the future. They have more psychosocial difficulties, more mental problems and lower levels of physical development and self-control (Hanson, McLanahan, \& Thomson, 1997; Lipman \& Offord, 1997; Mayer, 1997). Family poverty affects the cognitive abilities of children as measured through IQ, verbal ability and achievement tests - and the effects appear as early as the age of two (Smith, Brooks-Gunn, \& Klebanov, 1997).

In addition, living in poverty during childhood is associated with several detrimental health effects through middle and late adulthood. Stunting, cardiovascular disease, metabolic syndrome, type II diabetes, hypertension, some cancers and psychiatric 
disorders are among the most common health problems among those who experienced poverty in childhood. Furthermore, people who were poor during childhood die earlier than comparable individuals who were raised in better conditions. Importantly, later improved life circumstances have only a modest effect in preventing or ameliorating such problems, confirming the path dependence that characterizes the curse of poverty (Kuzawa, 2010; Raphael, 2011). Instead of accumulating social advantage over time, people who were poor during childhood have an enormous chance of accumulating the opposite (i.e., social disadvantage). The poor also consume more tobacco and alcohol and have a greater prevalence of inadequate diet. Growing up poor may also lead to less interest in health care coverage in adult life, independently of the adult's socioeconomic status (Mittal \& Griskevicius, 2016).

Hence, health inequalities start in the initial years of life, creating the basis for inequalities that continue to worsen over time. As Shonkoff et al. (2012) summarize, development, which begins prenatally and continues through life, is driven by an ongoing, inextricable interaction between biology and ecology - the latter determined by the social and physical environment. Environmental influences and early experiences affect when, how and to what extent different genes are actually expressed.

In essence, the complex processes and structures that expose children to social vulnerability at a tender age create path dependence in their lives - a true curse. The effect of adverse conditions is cumulative, and thus calls for social interventions at the critical, earlier periods of life. Therefore, from a public policy perspective, it is necessary to map the drivers that create hostile social ecosystems and to identify leverage points for intervention in those systems. Moreover, as social and political actors seem to lack adequate mental models, it is critical to understand how prevailing conceptual frameworks may hinder the proper design of public policies to break the cycle of low human development.

\subsection{GAPS, OVERVIEW AND GOALS}

Practical and theoretical gaps warrant the proposition of an integrative model. Practical gaps are incomplete interventions that aim to change one piece or a few pieces of the system. For instance, in Brazil, the three most important programs - the pioneer Primeira Infância Melhor (Rio Grande do Sul state), the São Paulo Pela Primeiríssima Infância 
(São Paulo state) and the federal Criança Feliz - have as their primary goal an increase in parents' capabilities to stimulate development in the first years of life (Brasil, n.d.; Rio Grande Do Sul, n.d.; São Paulo, n.d.). A hallmark of such programs is imperfect integration with other governmental branches, resulting in imperfect coverage of all aspects involved in child development. For instance, the two state-level programs previously mentioned are under the management of the respective secretariats of health, leading to an inevitable bias in their conception (i.e., by neglecting non-health aspects of possible interventions).

The literature on poverty and human development is vast. There is no shortage of models (e.g., the institutionalist field in economics) to explain the persistence of poverty in nations or in segments of populations and to orient interventions in early childhood; nor is there a shortage of ecological models describing the layers of influence on poverty. Nevertheless, we found no model integrating key individual and social variables into the critical feedback loops that characterize the replication of low human development.

Therefore, this chapter integrates findings from several lines of research with the goal of explaining the replication of low human development across generations. We review the findings of different streams of research to build a causal loop diagram (CLD) encompassing the major feedback loops driving the phenomenon.

This chapter proceeds as follows. Firstly, we review the literature with the goal of identifying common themes and fundamental processes. We are especially concerned with a child's first years of life and the processes that lead to (or prevent) a flourishing life. We also review common interventions that have been applied to break the cycle of low human development, in particular increasing parents' repertoire of behaviors, adopting minimum income transfer programs and strengthening public childcare. Secondly, we present the method of system dynamics that guides the development of the qualitative model presented in the chapter - a broad CLD that subsumes the theoretical discussion. Finally, we conclude by discussing the implications of the model, pointing out limitations and suggestions for future research. 


\subsection{THEORETICAL PERSPECTIVES: A MULTILEVEL APPROACH}

Theoretical approaches to poverty developed in the last century used to put the blame for the replication of poverty on genetics or cultural traits (Peters, 1998). However, most people would probably agree upon further reflection that poverty and low human development involve more than such simplistic explanations.

When considering poverty or low human development, one of the first mental models that springs to mind is the one depicted in figure 6. It shows a reinforcing loop that links parental investment, quality of assets in infancy and quality of assets in adulthood. Assets, in the representation, are a bundle that includes financial, educational, cognitive, emotional, social and cultural resources.

\section{FIGURE 6. SIMPLIFIED MENTAL MODEL OF POVERTY REPLICATION}

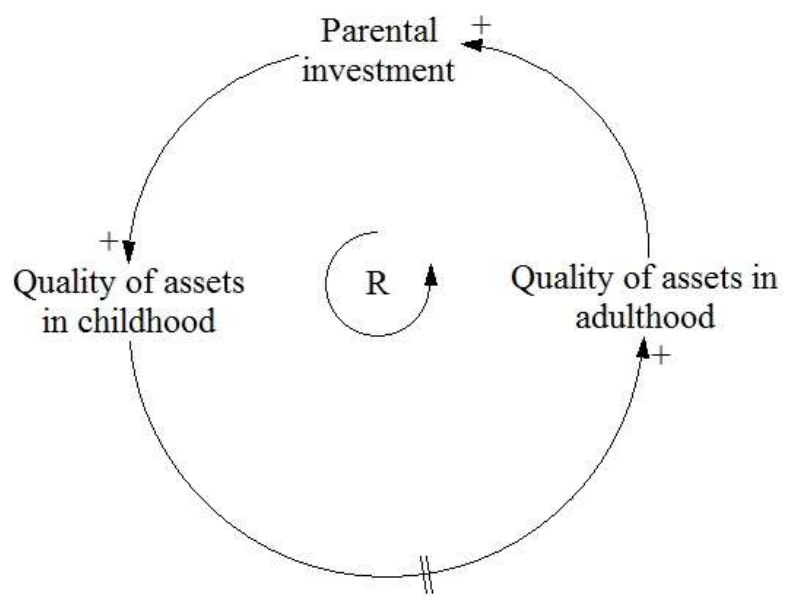

Source: Elaborated by the author.

However, the mental model depicted in figure 6 is too simplistic to be useful. More nuance is needed for theoretical and practical purposes.

Hence, figure 7 presents the multilevel approach adopted in this chapter. It integrates the major theoretical perspectives applied to the study of poverty. Although they may come across as static and limited by boundaries, in reality there is a continuous interplay of among the several layers illustrated in the figure. The evolutionary apparatus of human beings, for instance, determines the expression of genes and hormones under certain 
circumstances, while being influenced by immediate and distant forces. Social institutions shape the social and parental immediate environment, creating constraints or freeing resources that will affect the expression of children's innate repertoire of needs and potentialities. Therefore, in the following review of the literature, we strive to adopt a perspective that moves from the inner to the outer layers of influence, while recognizing, whenever necessary, the interplay of influences and the somewhat artificial boundaries between them.

This approach resembles the well-known ecological system model (Bronfenbrenner, 1989), which identifies five relevant contexts for children development: microsystems (e.g., family), mesosystems (e.g., linkages between family and school), ecosystems (e.g., linkages between a parent's workplace and the quality of the marital relationship), macrosystems (e.g., culture) and chronosystems (temporal change in individuals and environments). However, our approach differs by considering two inner lenses to human behavior (the evolutionary and biological/psychological levels) while embedding the concept of chronosystems into the dynamical interplay over time of the variables of interest. Similar to the extension that Bronfenbrenner and Morris (2007) named the bioecological model of human development, we also adopt an interdisciplinary and integrative focus, as well as an explicit interest in applications of the framework to public policy.

\section{FIGURE 7. LEVELS OF ANALYSIS OF HUMAN DEVELOPMENT}

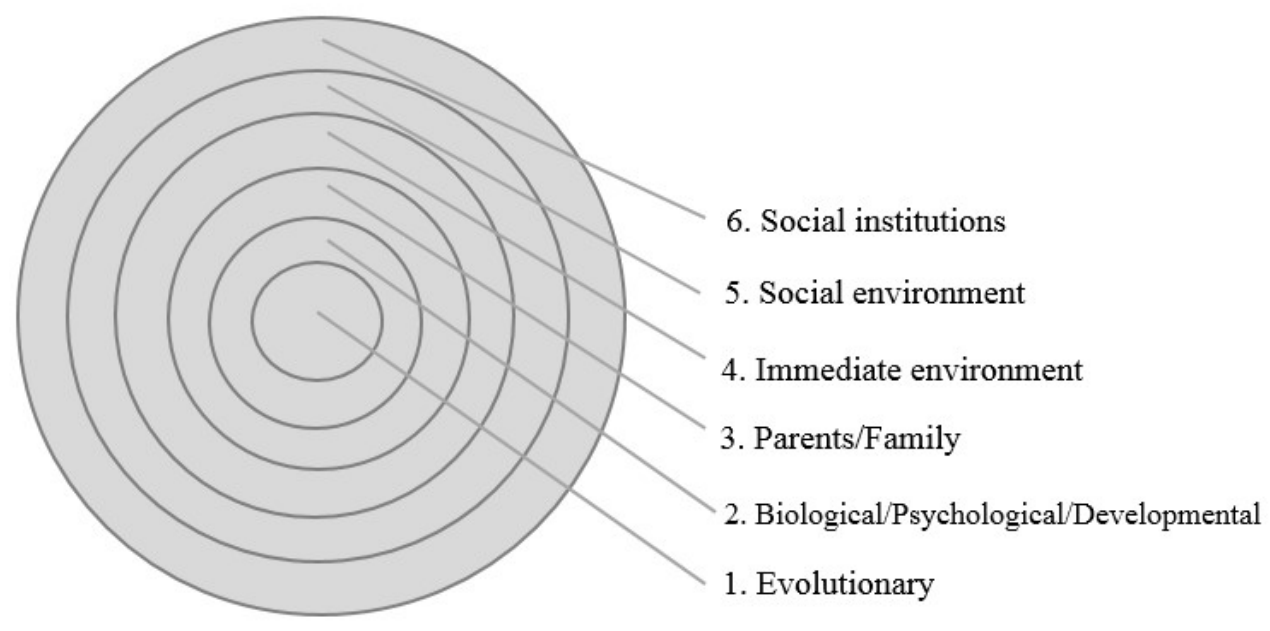

Source: Elaborated by the author. 
The lenses illustrated in figure 7 orient the literature review and the development of the qualitative model. Of course, there is an implicit trade-off between the depth and breadth of the subjects covered by the review. As Williams and Poehlman (2017) demonstrate in the case of consumer research literature, researchers in that field could benefit from studies in disciplines such as neuroendocrinology and psychophysiology to understand how unconscious or preconscious processes ultimately influence consumer behavior. The point is that calls for multidisciplinary approaches are not new in several fields of social science. Nonetheless, when it comes to understanding complex social problems, they are a necessity, although the choice always comes with a price (the trade-off). Thus, applying multidisciplinary lenses to the subject of human development provides a richer and more complete understanding of causes and processes, notwithstanding the underlying tension between depth and breadth of coverage of the selected fields of inquiry.

\subsubsection{THE IMPORTANCE OF THE FIRST YEARS OF LIFE}

Especially in the first years of life, human development occurs through processes of increasingly complex relationships between the individual and the human and non-human (e.g., symbolic) elements in his or her immediate environment. Those relationships require consistency over extended periods of time (Bronfenbrenner \& Morris, 2007).

The effects of poverty are more negative for younger children, because the first three years of life are critical for the development of brain cells and key psychological mechanisms, as well as for the capacity to form trusting human relationships (Lipman \& Offord, 1997; Smith, Brooks-Gunn, \& Klebanov, 1997). Neurological evidence shows that the synapses (connections between neurons) develop rapidly during the first years of a child's life, forming the basis for cognitive and emotional functioning for the rest of life (Mustard \& Young, 2007). As Noble (2017) summarizes, children who live in poverty tend to perform worse on IQ, reading and other tests. Their lower probability of graduating from high school or going to college are well attested in the literature, as is their higher probability of being poor and underemployed as adults. What recent evidence indicates is a sober reality: low socioeconomic status is associated with significant differences in size, shape and functioning of children's brains. It is also associated with earlier brain maturation, and therefore reduced brain plasticity, compared to children in more advantaged social conditions. Critically, Noble et al. (2015) show that poor children 
have less cortical surface area, with the effects of this being more pronounced in areas that process language and command self-regulation processes; this replicates previous studies that showed an association between socioeconomic status and those abilities (e.g., Noble, McCandliss, and Farah, 2007). In their study, the most disadvantaged children displayed the most detrimental relationship between income and brain structure.

Indeed, the first years of a child's life are crucial from a foundational perspective: the proper formation of executive functions and self-regulation mechanisms depends on a range of adequate interactions between infants and their caregivers. Those interactions depend also, of course, on the elements brought to the encounter - the genes and temperament of the child, the sociopsychological resources of the parents and the immediate social environment. Hence, the "nature versus nurture" debate is no longer relevant, as there is a virtual consensus that the interaction between genes and environment (epigenetics) commands the process. In other words, environmental factors, ranging from noise, light and changes in temperature and nutrition to the touch, voice and smell of caregivers, among others, affect genetic activation and expression (Council for Early Child Development, 2010).

The proper development of critical assets in early childhood requires that basic foundational conditions exist, especially health, hygiene and adequate nutrition (Naudeau, Kataoka, Valerio, Neuman, \& Elder, 2011). Children born to poor families are more likely to have low birth weight, and they are at increased risks of mortality, hospitalization, stunting and general health problems. Even during pregnancy, there is increased risk of damage to the integrity of some organs. Undernutrition, which includes deficient maternal conditions and untreated health problems, may lead to impaired brain development, sapping a child's potential even before she is born. Poor children typically have prenatal and postnatal nutritional deficits (Korenman \& Miller, 1997), which will affect their future earnings potential: there is a direct relationship between proper nutrition at these stages and later annual income (Banerjee \& Duflo, 2011).

Other detrimental conditions that may be critical in contexts of poverty include the consumption of alcohol during pregnancy, which often leads to mental retardation. Problems associated with low-quality prenatal care also include low birth weight, risks for preterm birth, intrauterine growth restriction, fetal undernutrition, neonatal and infant death, and slow growth in the first two years of life (Larson, 2007; Duncan, Ziol-Guest, $\&$ Kalil, 2010). Furthermore, moderate to severe perinatal stress is a powerful predictor 
of psychiatric, behavioral and social problems later in life, especially in the absence of adequate family buffers (Werner \& Smith, 2001).

Besides poor maternal and early nutrition issues, additional vulnerabilities in the first years of life include acute susceptibility to disease and infection, poor access to health services, exposure to hazardous environments, risk of losing a parent and, in some countries, neglect of or discrimination against girls (Cain, 2009).

Figure 8 summarizes the critical time windows for the development of crucial capabilities in a child's life. Brain development depends on the successful completion of sequences of circuit formation - which requires proper stimulation during sensitive periods - in a cascade of hierarchical development. Each circuit is associated with specific abilities, and the quality of higher-order circuits depends on the development of earlier, lower-level stages. Repeated use of brain connections leads to their permanence, while infrequent use leads to losses. Wiring and sculpting of the brain in response to early experiences is very active, as new neural connections shape the respective neural circuitries, making them stable and resistant to posterior change (Council for Early Child Development, 2010). Months can make a huge difference, as the well-known case of Romanian orphans adopted by Canadian families exemplifies: those adopted after the age of eight months exhibited persistent cognitive, social and behavioral deficits, while those adopted before the age of four months had fewer developmental problems (Moore, 2014; Morison, Ames, \& Chisholm, 1995).

In sum, brain plasticity is at its peak in early childhood, offering a precious window of time for proper interventions, and it decreases rapidly with age (National Scientific Council on the Developing Child, 2007). 
FIGURE 8. SENSITIVE PERIODS FOR COMPETENCES IN EARLY BRAIN DEVELOPMENT

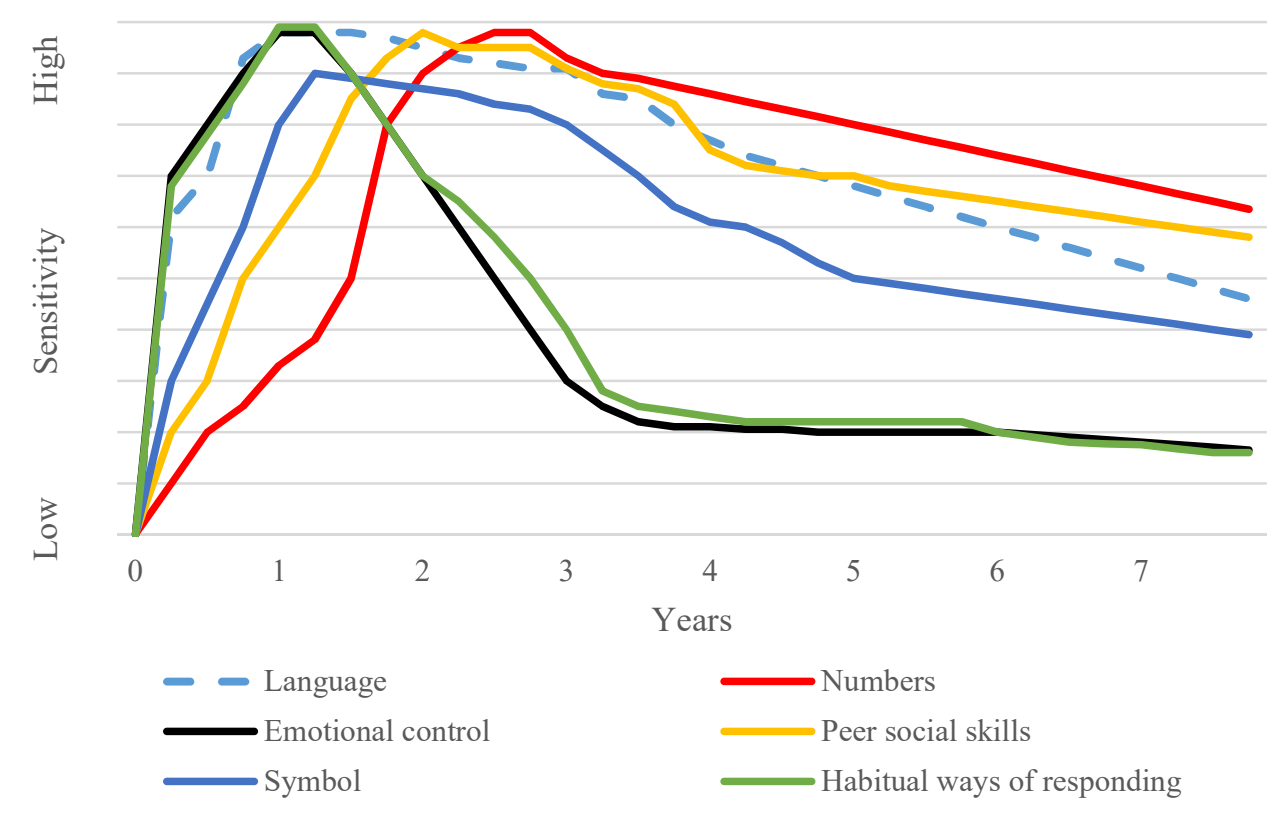

Source: Adapted from Council for Early Child Development (2010).

When adequate rearing conditions are lacking during the first years of life, one consequence with long-term potential effects is that children are insufficiently ready for school, a readiness that depends not only on previous cognitive skills but also on physical, social, emotional and motivational capabilities (Hair et al., 2006; Heckman, 2013). In this case, the most common development is the setting of an educational path of low levels of learning, undermining public investment in education in later years.

Studies that follow individuals through life are useful to illuminate the consequences of living a childhood in adverse conditions. For instance, in the well-known Kauai study (Werner \& Smith, 2001), two-thirds of the individuals who survived the high-risk combination of perinatal stress, poverty in early childhood, parents with little formal education and dysfunctional families, had a difficult life, one marked by health or behavioral problems. It is worth stressing that difficult conditions in childhood do not necessarily prevent the development of resilience in an individual; the same study found that the remaining individuals at high risk developed resilience in the face of adversity. However, consistent with the discussion presented in this chapter, their resilience came from a combination of favorable temperament and an environment in the first years of life that was characterized by minimally adequate levels of attention from caregivers. 
Nonetheless, those resilient individuals reported several stress-related health problems (such as depression and frequent headaches) during midlife at a rate more than twice as high as that reported by the other high-risk group, suggesting that poverty in early childhood may had left enduring scars, even in a context marked by attenuating circumstances.

While the first childhood years have an extraordinary importance in laying the foundations for resilience, the existence of an early favorable environment, although necessary, is not sufficient per se. The critical competences developed in the first years of life provide the foundations for a full life, but complementary capabilities need to be developed through a combination of individual and societal efforts. The institutional setting in a country is of special importance, given its role for socioeconomic development and income distribution (Acemoglu \& Robinson, 2013; North, 2005). In essence, it creates the repertoire of opportunities available to individuals and families through their lives. In other words, there must exist an entire social ecosystem favorable to the development of human potential if the goal is to create equitable and harmonious societies.

Before discussing how self-regulation - a critical competence for life - develops in the first years of life, we first tackle the evolutionary perspective, which is usually absent from mainstream analysis of human development.

\subsubsection{ENVIRONMENTAL INSTABILITY: THE EVOLUTIONARY PERSPECTIVE}

Life history theory (LHT) is a growing body of inquiry in the literatures of evolutionary biology and evolutionary psychology. According to LHT, individuals across species are very sensitive to unpredictability in their ecological environment. Accentuated unpredictability in aspects such as scarcity of resources triggers the development of specific traits and behaviors to cope with that condition in the environment (Ellis, Figueredo, Brumbach, \& Schlomer, 2009). From an evolutionary perspective, (human) individuals tend to adapt to or select two kinds of life story strategies, which lie on a continuum. A slow life history strategy (known as k-selected in the jargon of the evolutionary literature) is preferred when the environment is stable, with low risk and relative consistency (Pianka, 1970). On the other hand, environments with the opposite 
characteristics - unstable and with high risk and inconsistency - elicit fast life history strategies (r-selected) from individuals (Figueredo, Vásquez, Brumbach, \& Schneider, 2004). Stable environments, from an evolutionary viewpoint, have a low degree of risk of death from predation, homicide, disease and accidents. These risks influence the allocation of individual resources and life history strategies, leading to a trade-off between quantity and quality or between mating effort versus parental effort. However, human environments carry more risks than these physical ones. According to Chisholm (1993), psychosocial stress may function as cue to local mortality risk, favoring the development of psychological phenotypes consistent with a fast life history strategy. Furthermore, life history strategy development may continue in older adulthood, responding to ongoing risks and incentives.

Therefore, a slow strategy results in later reproduction and higher priority to existing progeny through parental investment focused on their growth and development. A stable environment - which is typically absent in situations of poverty and low human development, at least in urban settings - tends to increase parental investment and support, which translates into responsiveness, reliability and sensitivity to children's needs. On the other hand, faster strategies lead men to reproduce with more women, resulting in children more likely to be raised in single-parent families or in the homes of step-parents. In such contexts, quantity prevails over quality, and both men and women tend to reproduce at younger ages.

While evidence suggests that men tend to have faster life strategies than women at all ages (Kubinski, Chopik, \& Grimm, 2017), the effects of unstable environments seem more prejudicial for women. Blanden and Gibbons (2006), for instance, in their study of teenage poverty, found a link between poverty in childhood and later lone motherhood, after controlling for teenage family characteristics. Dinh, Pinsof, Gangestad, and Haselton (2017) found that women from adverse childhood backgrounds reported higher in-pair sexual motivation and behavior during the high fertility phase of the menstrual cycle, compared to women from low adversity backgrounds, predisposing them to higher probability of pregnancy. Van Brummen-Girigori and Buunk (2016), in turn, found in a sample of Curaçao female teenagers that, consistent with a fast life history strategy, those reared without a father reported stronger intrasexual competitiveness and a diverse repertoire of non-verbal seduction strategies. There is also substantial evidence linking father absence to earlier age at menarche (e.g., Schlomer \& Cho, 2017), which is 
associated with early onset of sexual behaviors and with diverse health and psychosocial problems. In addition, an evolutionary perspective helps explain why women abandon or kill their children under conditions of environmental stress - a common occurrence in human history, in which relevant fitness trade-offs were common for mothers (Liesen, 2011).

Hence, there seems to exist an inescapable feedback loop linking unstable parental environments to the development of psychological phenotypes that will reproduce the cycle over time. In addition, the probable consequence of an unstable environment - low levels of development of children's self-regulation - contributes to making the parental environment even more unstable, creating another reinforcing loop. Thus, the effects of the environment (stable versus unstable) influence the development of infants, who have to make their own trade-offs between life history strategies, impacting in turn their attachment strategies and their emotional and social competencies (Chisholm, 1996; Ellis, Figueredo, Brumbach, \& Schlomer, 2009; van Brummen-Girigori \& Buunk, 2016).

In fact, the bundle of cognitive, emotional and social competences (and mindsets) is of the utmost importance in carrying the effects of poverty experienced at earlier ages over the entire life of an individual. Consequently, it is unsurprising that life history strategies affect more than early age development. They increase the risks of psychopathologies throughout life, including risks for developing social, emotional (e.g., depression, anger), cognitive and health problems as well as problematic behaviors such as self-harm and substance abuse (Ellis et al., 2012; Hurst \& Kavanagh, 2017).

Critically, evidence presented by Simpson, Griskevicius, Kuo, Sung, and Collins (2012) suggests that unpredictability in the first five years of life - rather than in later periods and rather than simply harsh child environments - explains a faster life history strategy at the age of 23. This includes engaging in aggressive, delinquent and criminal behaviors, as well as having an increased number of sexual partners at that age.

However, not all consequences are straightforward; some seem to be dormant, depending on environmental triggers for their activation. For instance, evidence suggests that people who lived under scarcity of resources during their childhoods exhibit a preference for having children sooner when primed with mortality cues (Griskevicius et al., 2011) and are more prone to take risks and succumb to temptation when primed with resource scarcity (Griskevicius et al., 2012). 
Additionally, individuals adopting a fast life history strategy - consider a scenario of parents reared and living in poverty - tend to have lower scores in personality traits associated with positive outcomes in life, such as consciousness, agreeableness and emotional stability (Figueredo, Vásquez, Brumbach, \& Schneider, 2007; Manson, 2017), which aggravates unpredictability in the family environment.

Evolutionary pressures also have other pathways to influence human development. The evidence suggests that stress and undernutrition affecting prenatal development predisposes the infant's body to metabolic syndrome and diabetes in adulthood, reflecting the evolutionarily implicit strategy of always prioritizing the brain, which depends on glucose for proper functioning. Under stress in the first periods of life, the body will induce insulin resistance in the peripheral organs to protect the brain's need for energy (Kuzawa, 2010). Thus, negative early-life events activate evolutionary responses to unpredictable environments, leading to several detrimental health effects throughout life (Gluckman, Hanson, \& Beedle, 2007). In the evolutionary game, survival trumps quality of life over longer time spans.

Unpredictability and harshness in the lives of families, therefore, seem to be a major transmission chain in the replication of low human development across generations. There is a key pathway through which stable (as opposed to unstable) environments lead to parental investment and support, leading, in turn, to a higher probability of adequate children development and vice versa. However, understanding the replication of high or low human development in social ecosystems still requires the integration of other perspectives and streams of research, in order to gain nuance in the analysis and identify the main leverage points to change the system.

\subsubsection{STRESS AND INADEQUATE STIMULATION}

Hardwired evolutionary pressures lead to decisions that ultimately affect children through multilevel processes that channel the instability of the environment to influence the mechanisms of children's development. In turn, the literature on developmental psychology uses the critical roles of stress, chaos, environmental risks and cortisol levels to explain the consequent underdevelopment of key resources in individuals and the perpetuation of the vicious cycle of low human development across generations. We also 
draw on recent evidence from neuroscience to underscore how the instability associated with poverty may alter the brain's volume and function.

Typically, there are five developmental age groups prone to suffer the effects of poverty: prenatal to two years; early childhood (three to six years); late childhood (seven to 10 years); early adolescence (11 to 15 years); and late adolescence (16 to 19 years). Poverty strongly influences children's physical, cognitive and emotional development, and the influence is more severe in the first developmental age groups (Leventhal \& BrooksGunn, 2002).

As Evans and Kim (2013) summarize, children in poverty have less cognitively stimulating environments, with fewer age-appropriate toys, fewer educational materials and more exposure to television. They also live in impoverished language environments where fewer words are spoken and parents read less to them (Hoff, Laursen, \& Tardif, 2002). Their parents tend to engage in harsher and less responsive interactions. Children in poverty have deficits in motor skills, emotional regulation, generalized brain development and, critically - because of stress regulation (see next section) - deficits in hypothalamic-pituitary-adrenal (HPA) function. The prevalence of a wide array of physical and psychosocial stressors during childhood leads to damage in biological and regulatory systems (Loman \& Gunnar, 2010; Evans \& Kim, 2013).

\subsubsection{SELF-REGULATION AND THE EFFECTS OF CHRONIC STRESS}

Elevated chronic stress is an important pathway between childhood poverty and human well-being (Loman \& Gunnar, 2010; Evans \& Kim, 2013). Chronic stress compromises the multiple processes involved in self-regulation, coping and executive functions, such as attention control, working memory, inhibitory control and delay of gratifications and planning (Blair, 2010; Blair \& Ursache, 2011; McEwen, 2012).

According to Blair and Ursache (2011), there is a conceptual difference between executive functions, on the one hand, and self-regulation and self-control, on the other. Executive functions consist of interrelated cognitive abilities that are required when one must intentionally hold information in mind, manage and integrate information, and resolve conflict between stimulus representation and response alternatives. They are like a higher-level layer guiding behavior and responses to stimuli. Executive functions include working memory, inhibitory control and cognitive flexibility. This set of 
functions facilitates planning, future-directed thinking and monitoring of behavior. Executive functions, especially inhibitory control, are critical for overriding habitual or well-established responses in order to achieve one's goals. In turn, lower-order, more automatic response systems (emotion, attention and stress systems), commonly referred to as self-regulation or self-control mechanisms, influence and are influenced by executive functions. Executive functions typically predict school achievement above and beyond measured intelligence.

Notwithstanding the technical differences, we broadly refer to executive functions and self-control mechanisms as self-regulation, whose development depends especially on the proper maturation of stress physiologic processes in the first years of life. Self-regulation has also been referred to as self-control or "the capacity of the self to alter dominant responses and to regulate behavior, thoughts, and emotions" (de Ridder, LensveltMulders, Finkenauer, Stok, \& Baumeister, 2012). There is plenty of evidence linking poor self-regulation to a myriad of social problems, such as crime, teenage pregnancy, domestic violence and unstructured families (Baumeister \& Tierney, 2011; de Ridder, Lensvelt-Mulders, Finkenauer, Stok, \& Baumeister, 2012).

Evidence shows that the prevalence of high levels of adrenaline and of the stress hormone cortisol leads to malfunction in the endocrine, metabolic and immune systems, negatively influencing their development. Children in poverty have more sympathetic nervous activity (e.g., elevated blood pressure), more dysregulated metabolic activity, more elevated HPA activity (e.g., dysregulated cortisol) and more compromised immune systems (Evans \& Kim, 2013). A useful measure of chronic stress, allostatic load, reflects the constant mobilization of several biological systems in response to strong environmental demands; allostatic load is elevated among poor children, who also tend to have reduced hippocampal volume, exaggerated amygdala responses to adverse stimuli, altered pre-frontal cortical activity and other adverse maladjustments in the brain (McEwen \& Gianaros, 2010). In an epidemiological cohort group followed from birth, Holz et al. (2015) found that, after controlling for several confounding factors, life in poverty during early childhood predicted lower volume of the orbitofrontal cortex (OFC) and increased conduct disorders 25 years later. One specific area in the OFC, the medial orbitofrontal cortex, is critical for intertemporal choice, in particular the ability to forgo earlier gratification in favor of delayed rewards (Sellitto, Ciaramelli, \& di Pellegrino, 2011). 
The proper development of the HPA axis is vital for supporting normal physiological functions and for regulating other systems (Dickerson \& Kemeny, 2004; Negriff, Saxbe $\&$ Trickett, 2015). From an evolutionary perspective, cortisol is a hormone essential for survival. It plays a critical role in metabolism by mobilizing energy for the body. This is primarily accomplished by the elevation of blood glucose levels, which facilitates adequate metabolic function. Cortisol also influences other systems, such as the immune and the cardiovascular systems (e.g., by elevating heart rate). However, prolonged cortisol activation is associated with several negative health effects, including suppression of relevant aspects of the immune system, damage to hippocampal neurons, diabetes and hypertension.

Low-income households are systems especially suited to damaging the HPA axis in children. They tend to be chaotic living environments characterized by high levels of ambient stimulation (such as noise and crowding), minimal structure and routine, inconsistent parental behavior and considerable unpredictability and confusion in daily activities (Evans, Gonnella, Marcynyszyn, Gentile, \& Salpekar, 2005).

According to evidence reviewed by Blair and Ursache (2011), conditions of poverty, especially low levels of sensitive and responsive maternal caregiving behavior (which, at adequate levels, can function as a buffer against the effects of environmental risks), are associated with elevated levels of stress physiology in early childhood. Adverse experiences detrimentally affect cognitive development and executive functions through processes involving attention, emotions and stress physiology. In low-resource, unpredictable environments, the stress response system and pre-frontal cortex connectivity develop in a way that promotes reactive rather than adequate self-regulation.

The crucial point is that early experiences shape or program the developing person to meet the demands of the expected environment. Stress reactivity shapes processes of selfregulation to optimize the functioning of the individual within that environment. It is not the case that stress should be completely avoided: stress-physiological reactivity is expected to be high in any kind of environment, advantageous or disadvantageous. Stress can be positive when it is associated with normal early childhood experiences such as receiving an immunization, meeting new people or coping with adult limit-setting (National Scientific Council on the Developing Child, 2007). 
However, there is an inverted $U$ relation between stress levels and the development of executive function (Blair \& Ursache, 2011). In advantageous environments, in which resources and support are high and predictable, a high level of demand that stays within adequate boundaries produces tolerable stress (National Scientific Council on the Developing Child, 2007) and is conducive to the development of adequate self-regulation. In contrast, disadvantageous environments, such as contexts of poverty, are more likely to be excessively and unpredictably understimulating or overstimulating. They also tend to lack the presence of the maternal buffer (described in section 4.5) or adult support. Therefore, they lead to high, low or unregulated levels of stress hormones and, consequently, to poor development of executive function. The continuous stimulation of the stress response system, which produces toxic stress, can harm the immune system and other metabolic regulatory mechanisms, leading to lower threshold levels for their activation, with effects for the rest of an individual's life (Banerjee \& Duflo, 2011; National Scientific Council on the Developing Child, 2007; Shonkoff et al., 2012).

In the same vein, Gunnar and Donzella (2002) assert that novelty induces increases in cortisol in infants. However, when novel events elicit positive affect and occur in the mother's presence, they lead to decreases in cortisol. In contexts of poverty, maternal caregiving behavior is usually deficient. In addition, psychological distress associated with poverty contexts can also lead to punitive and coercive patterns of parenting behavior, worsening the quality of their relationship with offspring (McLoyd, 1990). Finally, typical patterns of stress in contexts of poverty can lead to amygdala hypertrophy, resulting in chronic activation of fear, anxiety and stress biological systems (Tottenham et al., 2010).

Thus, the effects of toxic stress induced by excessive environmental demands are dual: it creates a permanent effect on children's biological systems, and it saps the only buffer that could eliminate or attenuate its effects, namely, sensitive caregiving at home. In other words, such mechanisms explain how poverty gets under children's skin very early, creating a curse that is very difficult to escape. Thus, it is not surprising that children in poverty have deficits in cognition, display learning disabilities, have little sense of agency (predisposing them to learned helplessness) and present social maladjustment and emotional problems. They also tend to have less resilience and to adopt ill-adjusted coping strategies (Leventhal \& Brooks-Gunn, 2002; Raphael, 2011). 


\subsubsection{THE ROLE OF SELF-EFFICACY}

After briefly reviewing biological and evolutionary drivers of development, we now move toward the outer layers of figure 7 . Drawing a parallel with the literature on dynamic capabilities (Teece, 2009), which deals with organizational abilities to orchestrate assets and resources in order to adapt to changing environments, we consider two higher-order capabilities as essential to human development: self-regulation (reviewed in section 4.4.3.1) and self-efficacy. The latter, which has similarities to the concepts of agency and internal locus of control, can be conceived as the "beliefs in one's capabilities to organize and execute the courses of action required to produce given attainments" (Bandura, 1997, p. 3).

Bandura conceives self-efficacy as similar to a dynamic capability, inasmuch as it is a generative capability in which cognitive, social, emotional and behavioral subskills are organized and effectively orchestrated to serve innumerable purposes. Skills are necessary but not sufficient to achieve results; efficacy beliefs in using skills well in different and ever-changing circumstances complement the conceptual domain of the construct. The literature on self-efficacy stresses the importance of agency and efficacy beliefs, which regulate aspirations, choice of behavioral courses and processes of selfregulation. Bronfenbrenner \& Morris (2007), in turn, stress the importance of extending the idea of self-efficacy to encompass the synergistic interactions between an individual and particular features of his or her environment. These interactions have the potential to generate successive levels of developmental progress. Thus, self-efficacy in childhood is a protective, resilience-enhancing factor for dealing with life pressures. It also transcends the child. Maternal self-efficacy is a protective factor that encompasses caregiving competence, including emotional skills (Werner \& Smith, 2001).

Parents living in poverty tend to possess low levels of energy and a weak repertoire of nurturing behaviors (Morris, Robinson, Hays-Grudo, Claussen, Hartwig, \& Treat, 2017). Bandura (1997) reviews evidence showing that teaching parents a repertoire of masteryinducing experiences may help in building a sense of agency in their offspring. That sense, in turn, is conducive to cognitive development. According to Bandura, it is not the possession of socioeconomic advantage per se that leads to a cognitive stimulating home environment; what parents do with their advantages is what makes the difference. In other 
words, the existence and enactment of a parent's competences are essential for developing a sense of agency or, broadly, self-efficacy in children.

The process of development of self-efficacy in early childhood has a reciprocal causation nature. Parents who use their repertoire of mastery-inducing activities bring about increases in their children's competences, which may then elicit greater parental investment (Bradley, Caldwell, \& Elardo, 1979). The first causal link, from parents to children, is stronger (Bradley et al., 1989). However, as we will see in section 4.6, there is scant evidence that public programs aimed at increasing parental competences work.

Bandura (1997) stresses the role of mastery experiences in early childhood as a source of self-efficacy, especially concerning cognitive, linguistic, physical and social competences. Hence, parents are important not only as a source of mastery-inducing activities; they also influence the richness of experiences through the design of the immediate familial environment. That environment can lead to the development of selfefficacy through the presence of an enriched physical environment, freedom for exploration and varied mastery experiences.

Next, we look at the influence of factors affecting families, particularly one (the effects of a scarcity mindset) that has not been accounted for in previous integrative frameworks, before expanding the analysis to account for the effects of broader factors.

\subsection{THE FAMILY AS BUFFER}

Tremblay (1999) compares the development of children to plants growing in a garden. When the soil is barren, only stronger seeds will flourish. On the other hand, all seeds will meet their different potential when the soil is fertile. In this metaphor, families (or the state, in critical cases) are the main gardener.

Corroborating this view, in the cohort of Americans that took part in the Kauai study and replicating findings from other studies - Werner and Smith (2001) found that temperament, intellectual competence, internal locus of control, positive self-concept and the ability to plan ahead were among the main protective factors against adversities in life. These elements, which reflect the interplay between innate proclivities and the immediate environment, typically depend on the protective role performed by a competent and loving mother and other caregivers, often from the same family. 
After controlling for the quality and quantity of care received outside the home, familyrelated variables, particularly maternal education, are among the strongest predictors of children's cognitive, social and emotional development (Downer \& Pianta, 2006). Families in poverty often lack a father figure, but, even when the family is "complete", parents are less likely to have steady jobs and more likely to have low levels of education (Blanden \& Gibbons, 2006), configuring a background context of social disadvantage.

To the developing child, parents are the main providers of the structural complementary elements of Bronfenbrenner and Morris's (2007) bioecological model: process (or the different interactions between an organism and the environment), context and time. Parents - mothers in particular - help to foster a sense of attachment and social competence that, by being internalized as an implicit working model, guides the ensuing interactions with other social actors as the child matures (Bowlby, 1969).

Hence, parents are, at the same time, critical actors in the process of child development and a source of assets, resources and competences. These competences can accentuate, ameliorate or buffer the effects of poverty channeled through immediate and mediate environments. While income is essential for making material resources available to children, parents' educational attainment, for instance, seems to be a critical resource in shaping parent-child interactions - in fact, it is associated with a child's brain surface area (Noble et al., 2015). In any case, the quality of mother-child interaction seems to be crucial in attenuating (acting as a buffer against) the strong negative effects associated with lower socioeconomic status (Bronfenbrenner \& Morris, 2007).

Although there is controversy regarding how parents' assets or competences influence the life chances of their children - either by increasing economic investment in offspring or through adequate family values and constructive interactions (Mayer, 1997) - the role of the family is crucial, as it may provide structure, opportunities for growth and resilience against environmental shocks. Heckman (2013) argues that the scarcest resource in the first years of life is love and attention from parents. In fact, successful development seems to require parents acting as coaches instead of merely cohabiting the same space.

Nevertheless, there is more to the issue than simply parenting styles. In a famous study, Hart and Risley (2003) found a striking difference in vocabulary and patterns of interaction between young children (aged from zero to three years old) from families living on welfare, compared to working-class and professional families. By the age of 
three, a child from a poor family had accumulated a gap amounting to 30,000,000 words in terms of word exposure compared to a child from the upper social class, while also being socialized to a pattern of overwhelming negative feedback, compared to the opposite in families from the upper social class. Worse yet, the authors report evidence showing a strong correlation between the vocabulary gap at the age of three and later educational achievement. In other words, initial gaps widen over time, reinforcing the cycle of low family capabilities and poor human development.

Noble, McCandliss, and Farah (2007) also found that the home literacy environment and physical punishment might be significant mediators between socioeconomic status and academic achievement. There is also an association between physical and psychological violence from parents in childhood and the probability of obesity in adulthood (Greenfield \& Marks, 2009). Evans and Kim (2013) assert that parental investment and parental responsiveness and warmth are important pathways linking childhood poverty to adverse outcomes. Maccoby and Martin (1983) classify parents along two orthogonal dimensions of responsiveness (support and emotional warmth) and demandingness (i.e., provision of structure, order, predictability and restraining of potentially disruptive behavior). Parents low in responsiveness and/or low in demandingness (e.g., neglectful or authoritarian parents) do not foster appropriate child development, for instance, through insufficient school involvement (Darling \& Steinberg, 1993). Parental warmth, involvement and moderate control are conductive to children's proper development, because they provide a sense of security, trust and direction (Hanson, McLanahan, \& Thomson, 1997). One attractive representation of the importance of healthy interactions between children and their caregivers is the "serve and return" sports metaphor (National Scientific Council on the Developing Child, 2007). Children start developing when they reach out for interaction (even through babbling and crying), and adults respond appropriately. This process keeps going back and forth, embedded in a continuous relationship. It works best when the adult is the person responsible for catering to the child's unique individuality. As McLanahan (1997) points out, parents' education, the number of siblings and the presence or absence of both parents in the household influence the quality and quantity of parental resources. (For a different perspective on the effect of large families, see Banerjee \& Duflo, 2011). Families that remain intact during childhood and adolescence may be a protective factor against the risk of later delinquency (Werner \& Smith, 2001). Consistent with the evolutionary perspective, families living in poverty often lack the 
presence of a father. Single-parent households have lower incomes and less adult supervision, leading to long-term detrimental effects in children's development, in particular to behavioral and psychological problems.

Analyzing longitudinal data from Canadian families, Lipman and Offord (1997) found that low levels of maternal education and living in a family with a female head were risk factors for poor academic performance, social impairment and behavioral problems. In particular, the predictive power of maternal education remained consistent in their regression analysis, with or without economic status variables. Accordingly, there seems to exist some degree of independence between the effects of economic deprivation and the effects of family structure on children's development, even when income traditionally accounts for a substantial portion of the variance (Smith, Brooks-Gunn, \& Klebanov, 1997).

On the other hand, there is suggestive evidence that a supportive extended-family network may mitigate the negative effects of harsh socioeconomic environments. Strong support from other adults living in the home or in a close relationship with the single parent may be sufficient for that mitigation (Bronfenbrenner \& Morris, 2007). Attention to the child and performance of supportive roles are key to providing what these authors call a general immunizing factor for children of single-parent mothers, even in favorable socioeconomic circumstances.

\subsubsection{FINANCIAL STRESS}

Parental income is typically associated with the intergenerational persistence of poverty. Using data from a panel of US families, Corcoran and Adams (1997) found that children raised in poor or low-income families had much lower income-to-needs ratios as adults than children raised in better conditions, controlling for other influences such as schooling. Moreover, they found a nonlinear effect: children from families with average to high incomes were only slightly better off as adults than were children from moderateincome families. On the other hand, a recent study based on tax data and other administrative sources in the United States found significant differences in intergenerational transmission of income among all brackets of family incomes (Mitnik \& Grusky, 2015). This may reflect the availability of better data (tax data are usually considered of higher quality) and/or the deepening of income inequality in that country. 
The study, which found that on average half of the parental income advantage passes on to the children, presented a portrait of a stratified society (in the United States). The expected income of children raised in families occupying the 90th percentile of the distribution was $200 \%$ higher than the income of children from poor families (the 10th percentile). Intergenerational transmission of income was also $75 \%$ greater in the case of richer families than in families occupying the $50^{\text {th }}$ percentile.

Duncan and Brooks-Gunn (1997) reviewed the effects of family income, finding them to be particularly important for children's ability and achievement, especially in early and middle childhood. Income matters because of its effects (among other influences) on the quality of the home environment, which is taken as encompassing a richer learning environment for children, the warmth of mother-child interactions, and the physical conditions of the home. Importantly for the model developed in this chapter, Duncan and Brooks-Gunn, using data from a large panel of US families, found that the only stage at which parents' income significantly predicted completed schooling was early childhood (zero to five years of age in their classification). However, the effect of income decreased significantly in the studies reviewed by the authors when other measures of socioeconomic status (SES) were entered in the regressions - typically the level of the parents' education and the occupational prestige of their jobs. In sum, parental income negatively affects human development, but its effects seem to be especially relevant for low levels of income; in complex social systems, thresholds matter.

We define financial stress as the insufficiency and volatility of monetary resources to meet a family's needs. While economic hardships may reduce parents' ability to provide food and other basic needs, economic growth provides jobs and opportunities. On the other hand, inflation and recessions may create powerful, enduring shocks in the lives of poor families (Bird, 2011).

Inadequate economic conditions can also obstruct a family's access to important social resources, such as safe neighborhoods, good schools, health services and recreational facilities. They may undermine effective interactions between parents and their offspring, reducing parental responsiveness, warmth and supervision (Hanson, McLanahan, \& Thomson, 1997). 


\subsubsection{SCARCITY MINDSET}

The evidence reviewed so far points to the critical roles of low socioeconomic status (SES) and unstable environments in the replication of poverty across generations. Nonetheless, there are more nuances to explore.

As Banerjee and Duflo (2011) cleverly stated, the poor are often trapped in the same problems that affect the non-poor, including inadequate beliefs and procrastination. However, the non-poor have an incommensurable advantage over the poor, in that they are free from basic worries. They have clean water, sewage treatment, private health insurance, certainty of meals and so on. The poor, on the other hand, constantly have to draw upon their reservoirs of self-control and mental space to address the most basic needs of modern life.

In this sense, Mani, Mullainathan, Shafir, and Zhao (2013) and Mullainathan and Shaffir (2013) uncovered a fundamental process that saps parents' energy and attention: the scarcity mindset brought about by perceptions of financial scarcity among the poor. Scarcity is a mindset that consistently drains working memory and other crucial psychological resources, leading the human mind to orient itself automatically and powerfully toward unfulfilled needs.

The result is a decrease in bandwidth, or the broad mental capacity encompassing fluid intelligence and self-regulation, implying that a scarcity mindset creates a process of "tunneling" that leaves out of consideration everything unrelated to unfulfilled needs while also impairing cognitive capacity. The greater the scarcity, the stronger the reduction in bandwidth. Hence, the tunneling process under conditions of scarcity drains what system dynamicists would call the stock of parents' energy. Parenting requires complex decisions, which are impaired under scarcity, but it also requires patience and sacrifice, which depends on energy levels.

Research on self-control and self-regulation shows how demanding or distressing events drain people's energy levels (Finkenauer, Buyukcan-Tetik, Baumeister, Schoemaker, Bartels, \& Vohs, 2015). Mullainathan and Shaffir (2013) summarize the conclusions of decades of research on parenting under poverty: poor parents are harsher and inconsistent with their children, they fail to engage with their children in substantive ways, they appear less loving and they let the children watch TV instead of reading to them. Moreover, the 
poor, in general, display ill-adjusted health behaviors, failing, for instance, to get proper prenatal care or to eat properly.

The concept of scarcity mindset is a valuable contribution to the study of poverty, because it provides an overarching mechanism to explain several strong effects of poverty on parents and their children. It also overcomes the common prejudice against the poor, based on the idea that they are essentially "different" people possessing an innate tendency toward myopic behaviors (Banerjee \& Duflo, 2011).

Hence, several behaviors associated with poverty can be better understood with the use of the scarcity lens. Those include preventative behaviors that could help in breaking the cycle, such as avoiding unwanted pregnancies or increasing one's skills through formal learning, and behaviors that typically are manifested in situations of financial deprivation, such as alcohol consumption, drug use and harsh, inconsistent parenting. Moreover, not only do the poor have a narrow bandwidth and lower levels of self-control, but they also lack a margin in which they may make mistakes with impunity. In their case, every mistake tends to be strongly consequential.

\subsubsection{OTHER INFLUENCES}

So far, we have looked at individual and family factors that explain the effects of poverty in the crucial development stages of children. However, children and their families are integrated into other, broader social structures (figure 7), which exert their influence through distinct channels.

There is a great confluence of cumulative risk factors that occur across multiple domains of life (home, school, workplaces, neighborhood, etc.), and such stressors also affect parents, who tend to navigate unhealthy and stressful environments. The quality of social institutions, including health and educational structures, may change or moderate the effects observed at the family level. Dysfunctional educational systems, for instance, can add stressors to parents and children's lives by failing to provide adequate psychological structure or by failing to fulfill their mission. On the other hand, public policies can act as buffers, attenuating the effects of dysfunctional families or immediate environments. Families also suffer the influence of macro policies and events such as economic cycles, job opportunities, habitational policies and political disruptions. 
Some authors do consider the effects of macro factors on poverty, but their models typically encompass few factors beyond the individual level of analysis. McLoyd (1990), for instance, provides a partial representation of cumulative risk factors affecting black children in the United States (figure 9).

FIGURE 9. ANALYTIC MODEL OF HOW POVERTY AFFECTS BLACK CHILDREN IN THE UNITED STATES

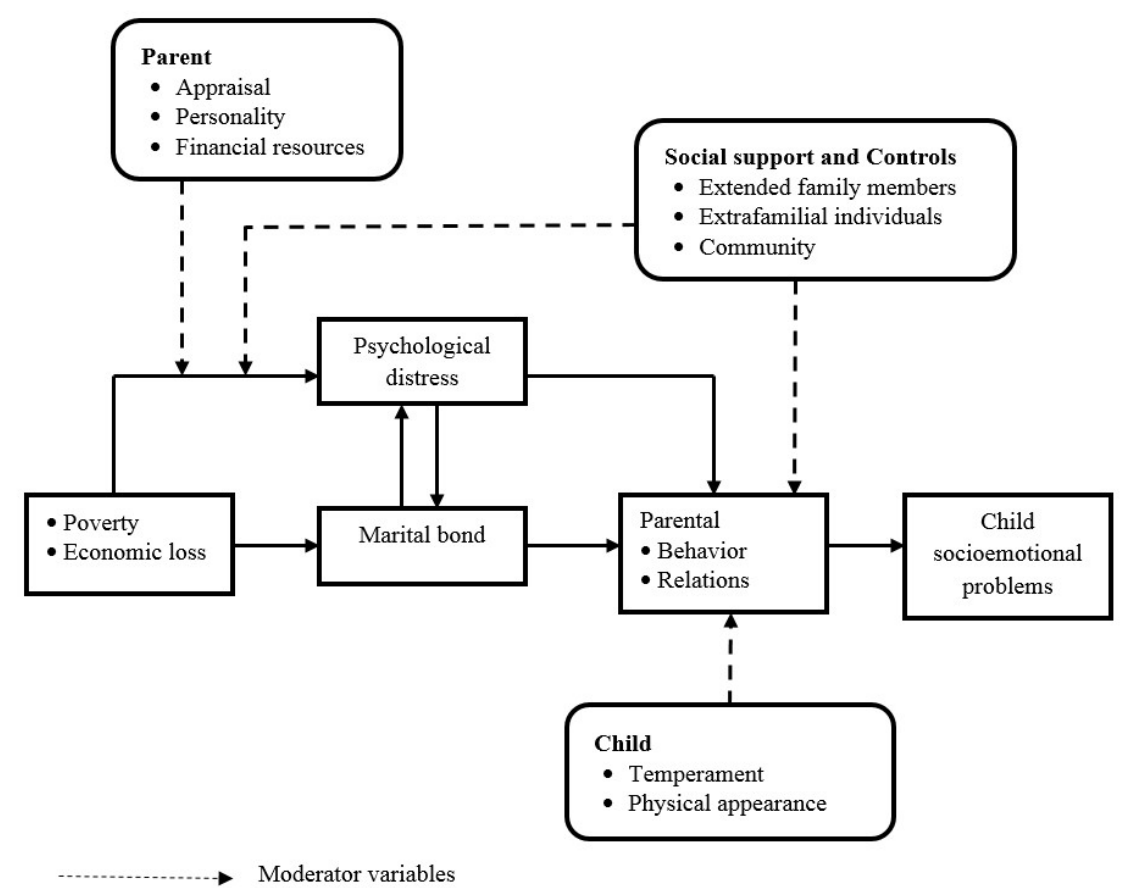

Source: Adapted from McLoyd (1990).

Leventhal and Brooks-Gunn (2002) point to complementary pathways from poverty to child (human) development. According to them, besides stress, such pathways involve low quality of home environment, low quality of childcare and schools, ill-being and inadequate parenting behaviors and practices, existence of dysfunctional neighborhoods, exposure to violence and low-quality health care.

Parents living in poverty are less likely to be part of social networks that can help them find jobs; they are also more likely to live in poor neighborhoods with a scarcity of positive role models (Bird, 2011). There is evidence linking the stress associated with living in dysfunctional neighborhoods with health conditions such as obesity and diabetes 
(Ludwig et al., 2011). However, merely moving the poor to better neighborhoods is insufficient to break the poverty cycle (Mullainathan \& Shaffir, 2013).

Evidence shows that protective factors such as empathy and social competence can act as a buffer to protect children from the environmental risks associated with poverty (Cecconello \& Koller, 2000). Increasing social competence helps to manage interactions with other children, decreasing cortisol and stress levels (Gunnar \& Donzella, 2002). Positive peers, positive communities, caring adults and positive school environments are sources of such protective factors (Child Welfare Information Gateway, 2014) especially when they constitute functional networks that provide affective and social support (Poletto \& Koller 2008).

\subsubsection{HOW SOCIETIES CREATE STRUCTURES THAT PERPETUATE LOW HUMAN DEVELOPMENT}

Why do social structures and systems perpetuate the cycles of low human development? Broadening the focus of figure 7 , we note that one of the hallmarks of human societies across history has been a lax attitude toward the suffering of all human beings - a panorama that started to change only in recent centuries. The configuration of societies typically followed a blueprint based on extractive political and economic institutions, power concentrated in the hands of elites, lack of voice for the majority of people, warfare, persecution and homicide of marginalized groups, slavery, serfdom and strong inequalities (Trevor-Roper, 1969; Stannard, 1993; Turchin, 2007; Pinker, 2012; Turchin, 2016). Pressures for social inclusiveness and the design of social "technologies" (e.g., Nordic states) to foster full human progress are very recent developments in historical terms.

Hence, it is no surprise that social structures and systems still carry several marks of inequity (to varying degrees) in most countries. North (2005) emphasizes how a society's artifactual structure inherited from the past - institutions, beliefs, tools, techniques, external symbol storage systems - constrains its economic performance. In this sense, modern social systems lead to the replication of low human development through extractive institutions and structural-demographic dynamics. Ironically, even evolutionary motives may predispose individuals reared in harsh conditions to prefer 
authoritarian political leaders (Safra, Algan, Tecu, Grèzes, Baumard, \& Chevallier, 2017), contributing to the prevalence of social structures that maintain poverty.

Institutions also have similarities with the concept of dynamic capabilities inasmuch as they serve the function of coordinating the employment of societal capabilities and resources (in particular, the stock of accumulated knowledge) to achieve society's goals. Institutions may foster, mobilize and develop human potential to advance societal wellbeing, or they may serve to subordinate collective resources and potential to the interests of narrow elites, as observed in most of human history.

The combination of formal rules, informal constraints and their enforcement characteristics determine the institutional structure in a society (North, 2005). Institutions in an economy determine the matrix of incentives for entrepreneurship and, broadly, for choices and investments with a long-term focus (North, 2005; Acemoglu \& Robinson, 2013). They are the rules of the game, but the institutional framework also encompasses how the game is played (Williamson, 2000). When, for historical reasons, political and economic institutions in a society are of the extractive kind, one can expect the existence of diverse societal conceptual and practical apparatus in service of maintaining the status quo and directing resources to enrich narrow elites. This has been the case, for instance, in Latin America.

However, the view espoused by institutionalists typically lack a strong proposition regarding the dynamics of power struggles in a society, in particular the roles performed by individuals from the general population and from the elites. For example, Acemoglu \& Robinson (2013) discuss institutional drift and the role of special events ("critical junctures") in reshaping the path of societies over time. However, they do not delve into the inner dynamics driving intraelite competition in countries (a common proximate cause of revolutions), and they also prematurely dismiss the influence of the geographic factors discussed by Diamond (1997).

Turchin's structural-demographic theory $(2007 ; 2016)$ fills that void by describing how long-term social pressures may lead to revolutions and historical cycles in countries. The theory assumes a constant, dynamic interplay among three crucial social actors: the general population, the elites and the state. What is relevant to the discussion presented in this chapter is the role performed by state in that theory. Historically, the state has been a disputed source of jobs to the elite, whose interests it represents; the view of the state 
as a sponsor of elite's interests in many countries is also espoused by North (2015). However, the state cannot go too far in overtly defending specific economic interests, especially in modern democracies, because it depends on its perceived legitimacy. The latter reflects the degree to which the state is perceived as impersonal and capable of sustaining the democratic narrative. Thus, the state has to reconcile the tension of maintaining institutions that benefit the few (especially in underdeveloped countries) while providing public goods and services to the voting population.

We expand Turchin's proposition by describing the role of the state as a manager of paradoxes. In dealing with the paradox of maintaining extractive institutions while catering to the needs of the majority in underdeveloped countries, the state harbors inevitable distributive conflicts, which are often camouflaged with the clever maneuvering of symbolic strategies (through the weaving of discourses and narratives). These strategies are useful inasmuch as they create a sense of modernity that attenuate the tension brought about by archaic power structures. Hence, the state may provide lowquality educational and health services to the poor, while the discourse espoused by public executives emphasizes instances of apparent progress or modernity in those dimensions (e.g., the existence of "meritocracy" in public educational systems). Furthermore, to accomplish the goal of transpiring modernity, it is important (in the case of underdeveloped countries) to import "fads" in the realm of social policies, such as policies aimed at early childhood, even if they are implemented only at face value. Symbolic utility matters.

In the end, extractive institutions and distributive conflicts camouflaged in the state result in low priority being given to the eradication of poverty or the promotion of the conditions of full human development. The result is the maintenance of the repertoire of low-quality public policies in the health, education and social domains, which will influence the process of poverty replication through the various channels reaching the immediate environment of vulnerable children. Very often, public policy promotes only cosmetic change, and poverty relief depends more on economic cycles such as the recent commodities boom in Latin America (The Economist, 2016). 


\subsection{COMMON INTERVENTIONS TO BREAK THE CYCLE}

Naudeau et al. (2011) review the common set of interventions at the disposal of public policy makers: (1) center-based programs that focus on school readiness; (2) home-based programs for behavior change in the domains of health, nutrition and parenting; (3) communication/media campaigns for families with young children; and (4) income transfers for families with young children. Programs emphasizing behavior change or communication are commonplace and provide symbolic utility, but, as the literature review indicates, they are clearly incomplete.

Shonkoff et al. (2012) summarize the types of intervention according to their focus: levers for innovation (e.g., primary health care, child welfare, and family economic stability), caregiver and community's capacities (e.g., skills and knowledge; financial, psychological and institutional resources) and foundations of healthy development (stable, responsive relationships; safe, supportive environments; appropriate nutrition).

A common avenue for intervention are programs targeting pregnant women with the goal of strengthening their health and nutritional status. A home visiting program (HVP) after a child is born is another tool in the repertoire. Trained professionals work with new mothers to improve child-rearing skills and assist with life issues such as depression and unemployment (Haskins, 2016).

There has been great controversy in the United States regarding the effectiveness of the common programs in that country. Many interventions do not target children's socioemotional or self-regulation skills, and many of them address only a subset of the known drivers of poverty replication. Critically, as Farran and Lipsey (2016) argue, there is no established theory of change guiding the interventions, and their proponents do not know what makes some programs successful while others fail - there are no identified proximal outcomes signaling progress toward long-range expected results. There is also insufficient knowledge about which specific program elements promote strong and lasting gains for children (Weiland, 2016).

In addition, the focus has been traditionally on poor children aged three years and older, with the goal of preparing them for the first years of academic life. There is the implicit assumption that one year of pre-kindergarten can have effects that endure into adulthood. Interventions aimed at younger ages are few and incomplete; some, which seem vital considering the evidence - in particular, parental leave - are absent from the repertoire. 
Evaluations show fading results of the best known US program targeted at developing academic competences of young children (i.e., Head Start), mixed results when it comes to state programs (Farran \& Lipsey, 2016) and modest or null results for HVP targeting the initial periods of life (Osborne, 2016). Startlingly, large disparities in cognitive skills between children of families with low or medium SES and children of families with higher SES are already present at the beginning of kindergarten (Chaudry \& Waldfogel, 2016).

Worse yet, and more relevant to the discussion in this chapter, day care centers in the United States are usually of poor quality (Haskins, 2016) and have less public support than in Europe (Chaudry \& Waldfogel, 2016). Werner and Smith (2001) point to policies that are common in most developed countries but absent from the United States, such as paid parental leave, universal high-quality childcare and early education programs, and universal health care.

One interesting aspect mentioned by Corcoran and Adams (1997) is the possible existence of thresholds in the effects of assistance programs. Families living on welfare or in poor communities may become trapped in poverty due to isolation from mainstream values or societal channels for upward mobility. In the presence of isolated programs and in the absence of what Osborne (2016) calls a continuum of care that supports parents and children, the poverty trap may be insurmountable.

\subsubsection{CHILDCARE AND EARLY EDUCATION}

Considering the evidence that higher levels of basal cortisol in infancy and toddlerhood predict less effective executive functioning at three years of age, and, especially, that children from low-income contexts live in disorganized and chaotic environments, Berry et al. (2014) found that a promising solution to preventing the curse of poverty is childcare. It could work by providing resources not found at home. The provision of childcare is thus a common intervention in the repertoire of governments (Bird, 2011). As discussed above (section 4.4.3.1), a healthy childhood requires regularity, consistency, predictability and controllability (Evans et al., 2005). It also requires sensitivity, responsiveness and attention from caregivers (Gunnar \& Donzella, 2002). When such conditions are absent from the immediate environment, public policy may be effective through the provision of high-quality childcare. 
Childcare centers epitomize Bronfenbrenner's (1994) concept of microsystem, as they embody a pattern of activities, social roles, and interpersonal relations inviting engagement in progressively more complex interactions between the developing person and the immediate environment. Childcare in such contexts, especially at earlier ages, is a promising point of leverage at which to break the poverty cycle: Berry et al. (2014) found that, for children living in contexts of high environmental risk, higher numbers of hours in childcare per week were predictive of lower cortisol levels at 48 months old. However, as reported by Gunnar and Donzella (2002), only high-quality childcare seems to prevent dysregulated cortisol levels in small children.

According to Blair (2010), neurological evidence from animal models suggests that early education and care interventions for children living in poverty contexts may work in part by enhancing self-regulation development in ways that overcome early risk, as well as by developing essential cognitive and social competences. The evidence suggests that public subsidies to childcare lead to cost-effective returns on maternal employment and a better balance for parents in fulfilling family's needs (The NICHD Early Child Care Research Network, 1997).

Research also suggests that children from the poorest families are the most likely to benefit from high-quality center-based care, which includes adequately paid and motivated staff and curricula focused on a broad range of capabilities and self-regulation. The sooner children receive adequate care, the better for their future development (Naudeau et al., 2011). However, an effective, high-quality childcare policy sufficient to buffer the effects of poverty on children may require the enactment of adequate parental leave policies, since very early entry may also be a potential source of stress for children (Zachrisson, Dearing, Lekhal, \& Toppelberg, 2013; Zachrisson, \& Dearing, 2015).

The fact is that the absence of high-quality childcare enacts its price eventually. Without adequate support, by the age of 6 , children from the poorest backgrounds have considerable differences in cognitive and other capabilities, which only tend to be magnified further as they progress through school. Corroborating this view, Noble, McCandliss, and Farah (2007) found that the school environment is a significant mediator between the socioeconomic status of young children and their performance in language, memory and working memory tests. 
There has been a strong worldwide interest in designing programs aimed at the first years of life, even in developing countries such as Brazil (BRAZIL, 2016). At the same time, notwithstanding their overall positive (albeit tepid) effects, pioneer programs such as the US Head Start have attracted criticism based on misunderstandings about aspects of public policy, such as dose-dependence (Strauss, 2013a).

Naudeau et al. (2011) reviewed several experimental studies in developing countries showing that poor children who receive preschool provision outperform their peers in control groups in several educational outcomes. The effects of those interventions are usually expressive. For instance, the IQ of children (up to three years old) from families with low socioeconomic status who have participated in intensive educational programs may reach one full standard deviation higher than the IQ of children from control groups (Ramey \& Ramey, 1998). Evidence suggests a potential high return rate (7-16\% annually) from high-quality programs targeting vulnerable young children (Heckman, Moon, Pinto, Savalyev, \& Yavitz, 2010; Rolnick \& Grunewald, 2007).

The development of resilience in children is a common recommendation for breaking the cycle of low human development. Bandura (1997) stresses the role, in conditions of poverty and risk, of stable social bonds to competent and supportive adults as a means to overcome risk and develop resilience. When those adults are not the parents, other adults from the broader family or even from outside the family can fulfill the role. From a public policy perspective, teachers and other caregivers can help to fulfill that role, in particular with the development of relationships based on trust and mastery-inducing experiences. In any case, capabilities beget capabilities, and mastery of later competences depends on the establishment of proper foundations earlier in life.

Two of the best known projects providing careful interventions aimed at early childhood were the Perry Preschool Study and the Abecedarian Project (Campbell, Ramey, Pungello, Sparling, \& Miller-Johnson, 2002; Schweinhart, 2003). The former enrolled children aged three to four years from low-income families, while the latter enrolled children from the same social stratum at younger ages. The Abecedarian Project not only intervened at critical ages; it also provided full-day childcare between 1972 and 1977 in North Carolina (US). The Perry Preschool Study provided only half-day care to a random sample of children from 1962 to 1967 in Ypsilanti, Michigan. Nonetheless, both interventions had long-term benefits for the participants. 
In the Perry Preschool Study, a tentative causal model suggested that it improved children's intellectual performance at school entry, which in turn improved school motivation, improving children's literacy and making them less likely to require special education for mental impairment. This allowed the children to reach higher levels of schooling, which led to higher monthly earnings in adulthood and less chance of being arrested for criminal activities. Importantly, a cost-benefit analysis showed a return of US\$7.16 for each dollar invested in the program. The available evidence, however, may underestimate the true effects, as it ignores the consequences for physical and mental health (Heckman, 2013).

In the Abecedarian Project, whose design allowed for comparison of three different randomly assigned groups (differing in the time scale of the interventions - three years, five years or eight years), reading and mathematics scores increased as a linear function of the number of treatment years, and the effect sizes were larger for preschool treatment. Compared to the control group, those enrolled in preschool treatment had higher attainment levels in academic measures, accomplished more years of total education, were more likely to attend college and showed a reduction in teenage pregnancy.

These pioneer projects paved the ground for the expansion of the well-known Head Start program in the United States, a nationwide program aimed at low-income children in that country, whose success is still a matter of great controversy (Strauss, 2013b). According to Peters (1998), the theoretical foundations of Head Start considered the role of the environment in producing social disadvantage, leading the government to assume the role of agent of socialization whenever parents could not fulfill their prototypical responsibilities. The ecological perspective inspiring Head Start also aimed to include parents in the effort to support children's development.

In the United States, there has been criticism regarding the Abecedarian and the Perry Preschool Program in terms of their methodological shortcomings, costs and scale-up potential. (See Heckman, 2013, for a sample of the main criticism about the two programs). Nonetheless, providing high-quality childcare as a means to break the poverty cycle seems to be an almost universal consensus among researchers, independently of their school of thought.

However, as discussed in the previous section, Head Start and other preschool programs probably arrive late in children's developmental history, especially if the broader social 
ecosystem and the repertoire of later opportunities in life reinforce the vicious cycle. In this sense, breaking the curse of low human development probably requires an extended effort involving a multicomponent strategy targeted at the early childhood.

Mullainathan \& Shaffir (2013) argue that programs, such as cash transfers, that are intended to ameliorate the situation of the poor often ignore the fact that money is not the only scarce resource. By making such transfers conditional on certain behaviors (for instance, attending classes), such programs can tax people's mental resources, leading to hidden costs, such as reducing the time and energy the parents have to spend with their children. Citing the effects of poverty on mental bandwidth, they strongly advocate the offer of subsidized daycare for children as an effective solution to increase parents' selfregulation and cognitive capacity, while also reducing distress, ultimately creating highly valuable social outcomes that are typically absent in the evaluation of such programs.

\subsubsection{MINIMUM INCOME TRANSFERS}

A multicomponent strategy may involve more than childcare or increasing parents' capabilities. Income transfers seem to be a promising tool in the repertoire of public policies to alleviate poverty. The usual rationale for their implementation is a reduction in the vulnerability of the poor, the provision of a predictable income "floor" and the opportunity for investment in human capital.

Duncan, Ziol-Guest and Kalil (2010) argue that poverty in early childhood (compared to later periods) is more detrimental to adult outcomes; timing matters. Using panel data, they found that low family income from the prenatal period to the first five years of life was strongly associated with lower working hours when the children became adults. Furthermore, their analysis suggests a highly favorable cost-effectiveness for income transfers to parents of younger children. Bird (2011) cites evidence showing that both conditional transfers (such as those used in Brazil and Mexico) and unconditional transfers (such as those used in South Africa) improve the nutritional, health and educational status of children, accruing long-term developmental benefits. Studying families in Norway, Zachrisson and Dearing (2015) found that the lower the income, the higher the internalizing problems for children. Dearing, McCartney, and Taylor (2001) found in a sample of US families that increases in income-to-need ratio were associated with better outcomes in diverse developmental domains. In fact, the most promising 
results came from poor families that had an increase in that ratio of at least one standard deviation above the mean. In that case, the developmental outcomes of children in the first three years of life were similar to those of children from non-poor families.

Noble (2017) speculates that increased family income may trigger a cascade of positive effects for the entire family, creating the right conditions for the development of the critical physiological and cognitive assets in early childhood. In this connection, Heckman (2013) discusses the large body of evidence that suggests that a major determinant of child disadvantage is not the availability of financial resources per se or the mere presence of parents; instead, it is quality of the nurturing environment. In other words, income transfers may remove a great share of stress from the households, fostering the conditions for a supportive environment. In the same vein, Cunha and Heckman (2010) argue that, for adults with low capabilities, subsidizing work and welfare may be a better policy for alleviating poverty than investment in their skills.

In the words of Duncan and Brooks-Gunn (1997, p. 608), income transfers are "but one weapon in an arsenal of possible programs that might improve the life chances of children." They provide means for families to meet their basic needs, while also freeing scarce psychological resources, which can then be employed toward more valued goals, such as better parenting (Mullainathan \& Shaffir, 2013). Studying the effects of a pioneer program of income transfer in a Canadian city in the 1970s, Forget (2011) found it reduced hospitalization rates by $8.5 \%$, especially for injuries, accidents and mental health, while also increasing high school completion rates.

It is still unclear at the time of writing whether providing income transfers to poor families is sufficient - or even necessary - to break the cycle of poverty (e.g., Handa, Peterman, Seidenfeld, \& Tembo, 2016). Nonetheless, while the evidence base is still thin, it is promising, suggesting that such programs have the potential to promote some developmental outcomes in children (Naudeau et al., 2011). On the other hand, as we have emphasized throughout this chapter, a complex problem such as the intergenerational transmission of low human development requires a multidimensional approach. In this sense, it is improbable that income transfers alone are sufficient (Blanden \& Gibbons, 2006).

In sum, cash transfers are a means of providing slack to poor families, creating a margin of safety to deal with financial shocks, among other benefits. Cash provides the means to 
get better nutrition, meet basic needs and access learning materials. In addition, it may free parents' time to spend with their children. The experience with the Mexican program PROGRESA also suggests that the additional income significantly decreases the level of cortisol among poor children, increasing their learning potential and other important abilities (Banerjee \& Duflo, 2011).

Slack, in Mullainathan and Shaffir's (2013) conceptualization, is the opposite of scarcity. Providing slack has the potential to reduce chaos and instability in the lives of the poor. Espousing a similar view when reviewing evidence on the effectiveness of income transfers, Banerjee and Duflo (2011) make the point that those programs may have given the poor the mental space to take a longer view of life. In other words, they add a precious sense of predictability to the poor.

It is remarkable that programs that experimentally tested the effects of conditional income transfers (i.e., linking the transfers to behaviors such as sending children to school) compared to unconditional transfers produced essentially the same results (Baird, McIntosh, \& Ozler, 2009; Banerjee \& Duflo, 2011; Benhassine, Devoto, Duflo, Dupas, \& Pouliquen, 2015). The results show that transfers lead to better educational outcomes for children almost irrespective of binding conditions and are in accord with the rationale discussed in sections 4.4.2 (the evolutionary perspective) and 4.5.2 (the scarcity mindset).

\subsubsection{INCREASING PARENTS' CAPABILITIES}

Parental quality manifests itself through care, nurturing, intellectual stimulation and affection (Bird, 2011). Therefore, one possible avenue for intervention is strengthening parents' capabilities in terms of caregiving competences. This is often accomplished through the addition of a parenting component to center-based interventions (Naudeau et al., 2011).

Indeed, most interventions so far have focused on increasing the parenting capabilities of mothers with the goal of strengthening the quality of home experiences. This includes encouraging mothers to read more to their children and teaching them about stimulating learning activities that they can perform at home (Smith, Brooks-Gunn, \& Klebanov, 1997; Morris, Robinson, Hays-Grudo, Claussen, Hartwig, \& Treat, 2017). 
A particular avenue for increasing parents' capabilities are communication or social marketing campaigns. Although there are several examples throughout the world, there is limited evidence of their impact (Naudeau et al., 2011). The typical core of those campaigns or programs is behavior change, including, in the health domain, practices such as breastfeeding, deworming and handwashing, and, in the capabilities domain, involvement of fathers in the care of children and practices to foster the development of capabilities in children (e.g., reading to children).

Another kind of intervention involves the creation of programs that increase professional capabilities. Professional training programs are moderately effective, but in isolation they typically do not break the cycle of poverty (Mullainathan \& Shaffir, 2013).

Interventions that combine increases in parents' capabilities and income transfers are another promising tool to be considered in the repertoire of public policy makers (Smith, Brooks-Gunn, \& Klebanov, 1997). However, evidence of their effectiveness is limited so far, as the number of programs combining both approaches is low.

\subsection{SYSTEM DYNAMICS: BUILDING A CAUSAL LOOP DIAGRAM}

The processes involved in human development are complex and multifaceted. However, most research in poverty and human development tackles only pieces of the puzzle. In addition to narrow disciplinary boundaries (Meadows \& Wright, 2008), methodological differences and varying levels of analysis, traditional approaches may fail to take account of the feedback loops, delays and nonlinearities characteristic of phenomena in social ecosystems. Hence, there is theoretical and practical value in employing methods that can account for such complexity; science evolves in discovery mode (Bronfenbrenner \& Morris, 2007). From a public policy perspective, it seems desirable to have a proper systemic map of the problem in order to test and advance policies. Therefore, we employ the systems dynamics approach, in particular its main qualitative tool (causal loop diagram), which seems particularly suited to integrating different parts of complex systems into a coherent picture.

Causal loop diagrams (CLDs) represent reinforcing or balancing feedback loops, portraying the causal relationship among the variables in a model. Although they can be quite detailed, CLDs are especially useful as a communication tool. Figure 6 (section 4.4) 
presents a very simple CLD in which arrows convey the meaning of a causal relationship between two variables. Small crossing lines represent delayed effects. In turn, the positive or negative signs associated with each arrow indicate the direction of change between two variables. A positive sign $(+)$ indicates that, ceteris paribus, an increase or decrease in a variable $x$ results in a change in the same direction in the consequent variable $y$. Conversely, a negative sign (-) shows that an increase in the variable $x$ leads to a decrease in model variable $y$. Combinations of such relationships give rise to feedback loops.

Feedback loops represent two types of relationships among variables: reinforcing loops and balancing loops. The former, usually represented by an $\mathrm{R}$ symbol, comprise relationships among variables that propagate increments originating in one of the variables, giving rise to vicious or virtuous circles. Balancing loops, commonly represented by a B symbol, comprise relationships in which a change in a given variable leads to a variation in the opposite direction through the loop. Goal-seeking behaviors, such as the satiation of hunger, are examples of balancing feedback loops.

A point worth stressing is that the system dynamics approach adopts a particular stance toward causality. Instead of considering isolated relationships between manipulated (independent) variables and dependent variables, its assumptions require the consideration of webs of mutual causality between variables, which can lead to the design of quantitative models amenable to different sorts of experiments and simulations. However, in this chapter we opted for proposing a broad conceptual map of the phenomenon with the goal of integrating the different streams of research discussed so far.

\subsubsection{CAUSAL LOOP DIAGRAM}

In order to avoid delving into extensive minutiae, we first propose a broader CLD (figure 10), representing a consolidated, higher altitude view of the phenomenon. This simplified CLD presents the major loops that are detailed in the extensive CLD depicted in figure 11. 
FIGURE 10. BROADER CAUSAL LOOP DIAGRAM

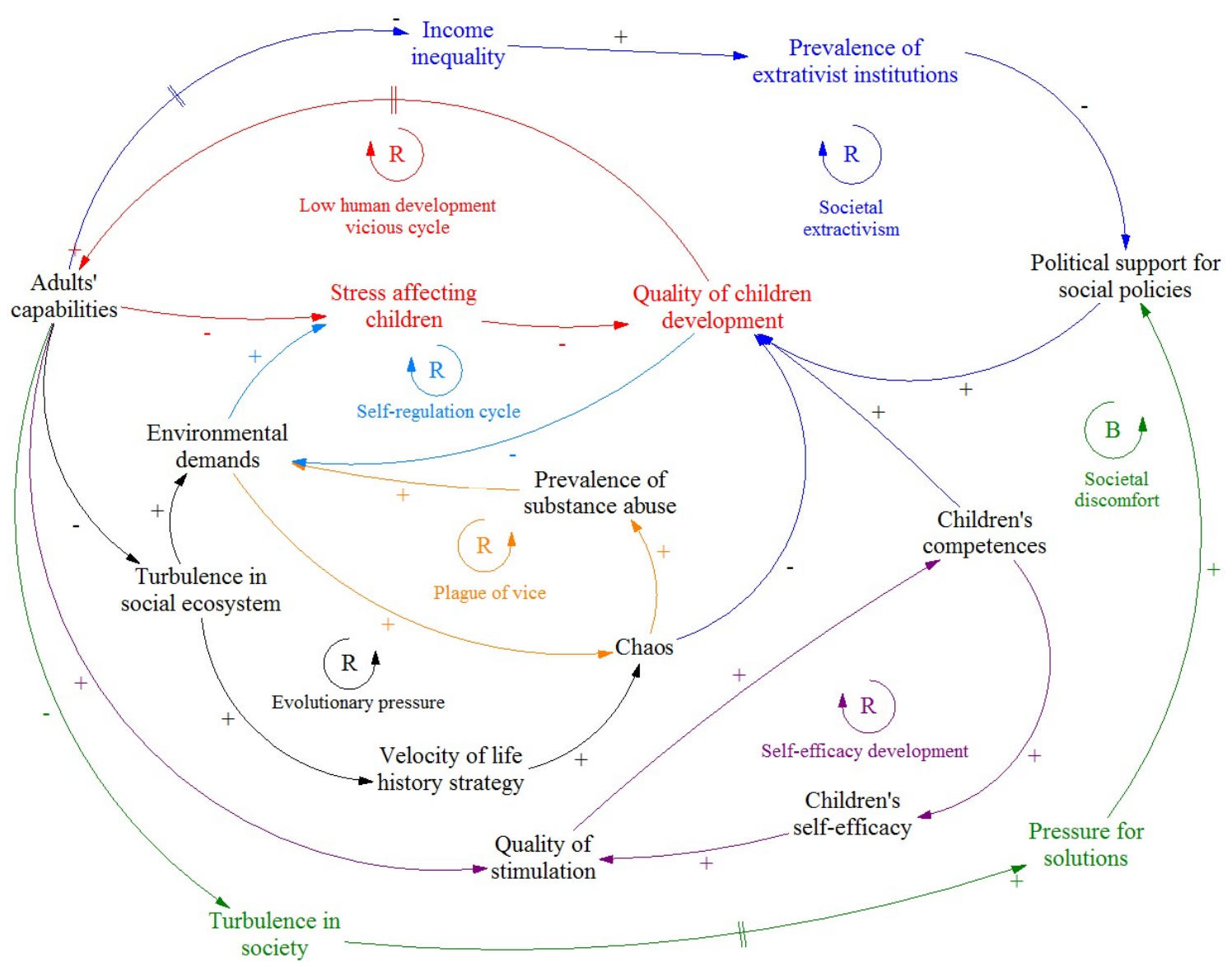

Source: Elaborated by the author.

We now discuss the loops portrayed in figure 10 and emphasize some of elements that integrate the detailed CLD (figure 11).

\subsubsection{LOOP: THE SELF-REGULATION CYCLE}

Adults' capabilities are intrinsically linked to their socioeconomic status, since they ultimately define one's occupation and income. We consider capabilities as a bundle of diverse competences and assets, spanning from the educational and economic domains to non-cognitive competences such as self-regulation (e.g., persistence) and self-efficacy. In turn, socioeconomic status defines the degree to which one suffers from "turbulence" in the social ecosystem. The lower the social class, the more difficult everyday life is. 
Transportation, housing, health and educational services, violence, income uncertainty and other aspects of life accumulate into a bundle of immediate environmental demands that drain parents' psychological resources, creating chaos and stress in family life. When excessive, this stress reaches toxic levels, which are not buffered by family (in particular, maternal) buffers, leading to inadequate development of self-regulation in children. The consequent low quality of children's development, manifested, for instance, in problems such as poor self-control, feeds back to increase environmental demands, reinforcing the cycle.

\subsubsection{LOOP: THE VICIOUS CYCLE OF LOW HUMAN DEVELOPMENT}

The loop represents the major societal and family influences on the development of the first years of life. Maternal buffering (sensitive caregiving behavior in figure 11) results from the combination of parental psychological resources and parents' willingness to provide support. The buffer is important in a context of strong environmental demands. In this sense, availability of additional resources is very helpful, especially for single mothers.

Werner and Smith (2001) found in their study that families with four or fewer children had better conditions for dispensing attention to children's needs. Thus, we consider that the number of offspring may affect the limited pool of parental resources, in particular the amount of energy and attention they may provide to each child. Other factors that can drain the stock of parental energy are job-related stress, which tends to be more acute in occupations of lower social status (Marmot, 2004), and the scarcity mindset brought about by financial stress.

Under conditions of strong environmental demands, the immediate environment can become toxic for the development of children, impairing their self-regulation and bodily systems in the critical first years of life. In a hostile social ecosystem, this impairment will result in adults with low levels of capabilities who are condemned to replicate the same vicious cycle. 


\subsubsection{LOOP: EVOLUTIONARY PRESSURE}

This loop is a subset of the drivers behind the vicious cycle of low human development. Socioeconomic environmental instability cues fast life history strategies that lead individuals to avoid stable families and strong investment in their offspring, contributing to low availability of psychological resources to buffer environmental demands.

\subsubsection{LOOP: DEVELOPMENT OF SELF-EFFICACY}

This loop describes the potential virtuous cycle involving the degree or quality of overall stimulation, the development of a full repertoire of competences in children and the consequent increase in the level of self-efficacy, which encourages still more stimulation.

\subsubsection{LOOP: THE PLAGUE OF VICE}

Notwithstanding some methodological controversy and the risk of stigmatizing a vulnerable population, the prevalence of alcoholism, smoking and drug use tends to be greater among the poor, at least in some contexts (Brandt, 2007; INPAD, 2014; Mossakowski, 2008). Of course, there are significant variations and qualifications in the evidence - in particular, consumption of alcohol and marijuana seems stronger in the upper social classes in the United States (Patrick, Wightman, Schoeni, \& Schulenberg, 2012). Thus, this loop may not be universally present, but it may in some contexts aggravate the environmental demands already in place, contributing to chaos in the family environment.

\subsubsection{LOOP: SOCIETAL EXTRACTIVISM}

In a sense, income equality reflects the actual degree of societal harmony. Of course, low to moderate levels of inequity are a fact in modern societies. The problem arises in contexts of inequity that is elevated above certain thresholds. In fact, we can understand the problem of low human development in a society as the degree to which social (dis)harmony flows from the social ecosystem through parents and then reaches the children. The loop captures the linkages among income inequality, the prevalence of 
extractive institutions and the social policies that contribute to the replication of low human development.

\subsubsection{LOOP: SOCIETAL DISCOMFORT}

In a similar vein, societal discomfort with the consequences of low human development, such as violence and low work productivity, may result in pressure to change the system. However, in underdeveloped countries where extractive institutions predominate (such as Brazil), elites may not suffer fully the consequences of a disharmonious society to the same intensity as the lower social classes do. Thus, the pressure may be too diffuse to produce relevant change. 


\section{FIGURE 11. EXTENDED CAUSAL LOOP DIAGRAM}

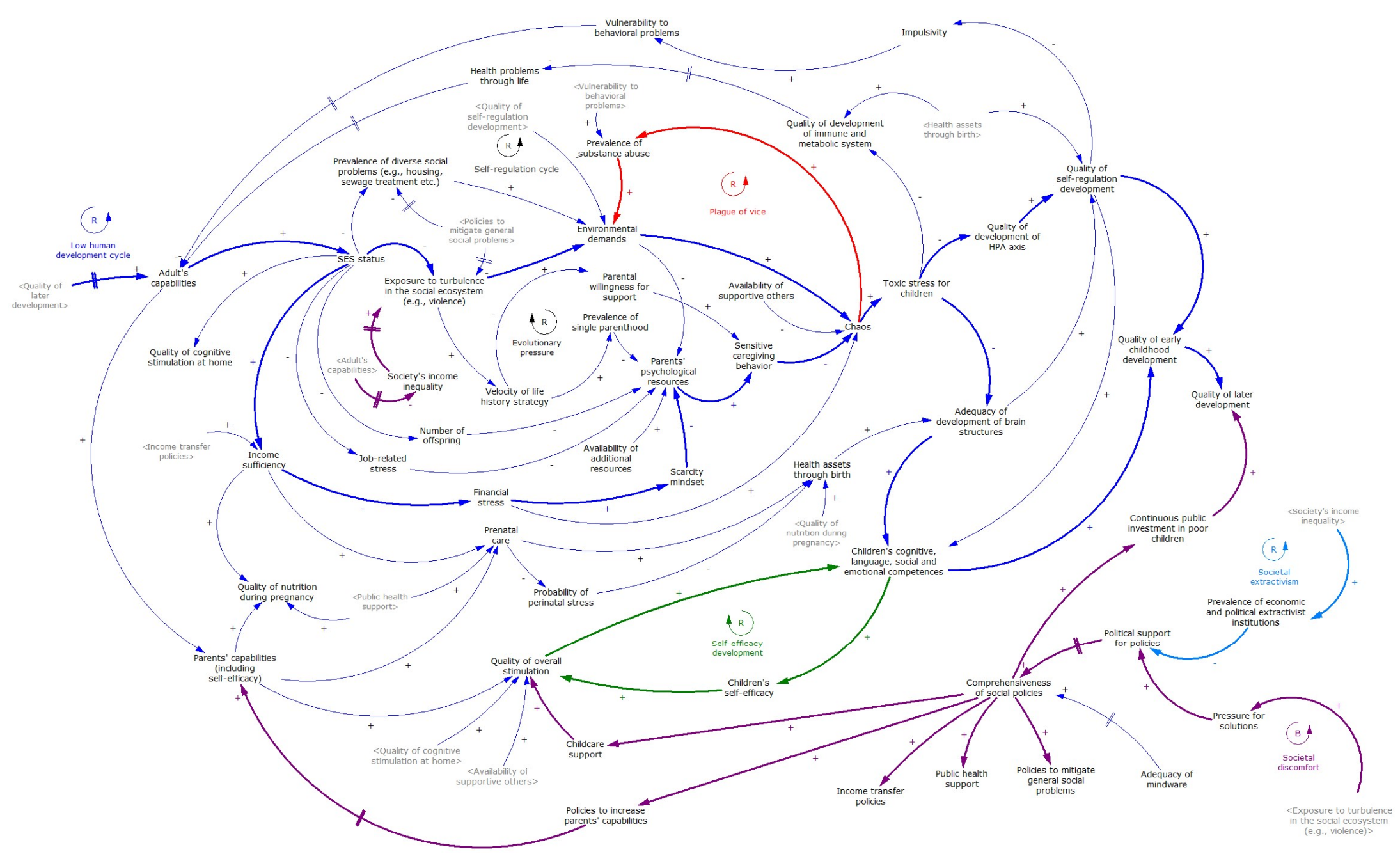




\subsection{DISCUSSION}

Feedback systems thinking, consubstantiated in the system dynamics method, represents a shift of mind that broadens the traditional linear, narrow perspectives employed to study and deal with social problems (Senge, 1990). As Morecroft (2015) emphasizes, we live and work in systems of circular causality, with feedback loops that are often hidden and consequences that are not obvious. Moreover, our societies lack adequate mental models to address the problems that arise in such complex systems. One has only to see the periodic recurrence of phenomena such as boom and bust in real estate, the bullwhip effect in supply chains, road building and subsequent congestion, and cycles of political instability and economic stagnation. The consequence of not being prepared to deal with complex social problems is the adoption of public policies that are either inefficient (albeit costly) or only exacerbate the problems. As Banerjee and Duflo (2011) assert, the triad of ideology-ignorance-inertia is the major cause of failure in governmental programs, in particular those aimed at decreasing poverty.

The qualitative model presented in this chapter contributes to the literature on human development by portraying a web of interrelated causal influences that ultimately define the permanence of the phenomenon over time. It also contributes by integrating different layers of causal processes, ranging from evolutionary and biological to the sociopolitical context. The quality of early childhood development depends on the interplay of those multifaceted processes and on the loops they engender. However, the sheer complexity of the phenomenon - not captured entirely in the map displayed in figure 11 - still challenges public policy makers trying to address the problem. Adequate mental models are necessary to change the course of human development in our world, as we discuss next.

\subsubsection{WHY INVESTMENT IN EARLY CHILDHOOD WILL (VERY PROBABLY) BE INSUFFICIENT IN THE COMING DECADES}

As Heckman (2013) emphasizes, the large body of non-experimental research on early childhood development supports the notion that the absence of a supportive family environment harms childhood and adult outcomes. Early interventions promoting the development of cognitive and socioemotional capabilities have beneficial downstream effects, including reduced crime and teenage pregnancy, increased workforce 
productivity and reduced socioeconomic inequality. In addition, the available evidence suggests they have a higher cost-effectiveness when compared to interventions that arrive later in the lives of poor children. Gaps manifested at the beginning of life only grow wider over time, creating a chasm harder to bridge as time goes by. However, public policy in countries such as the United States and Brazil still lag behind countries that have put sensible policies in place. Why?

First, it seems that the distributive conflict that is present in very unequal societies (such as Brazil) tends to be masked in public discourse; one of the typical characteristics of poverty is the lack of voice of the disadvantaged. The interests of lower social classes tend to receive low priority in the allocation of public funds, and the prevailing mindware may mask or normalize the unequal pattern of governmental spending. In addition, the segments that benefit from a skewed public budget have societal structures that buffer the consequences of living in a society with low average levels of human development. They have access to high-quality education, health and private security, for instance, which decreases their perception of the need to change the system.

The dominant mindware or repertoire of mental models in a society may also validate narratives that put the blame for poverty on individuals, as seems to be the case in the United States. Complex problems must be analyzed using the appropriate complexity lenses, which are typically absent in cultural and political contexts that celebrate linear models and solutions to symptoms. Feedback from public policy making is not only opaque and delayed; it is also easily made to fit the prevailing mental models. Social reality is constructed and almost infinitely malleable. As Strach (2016) recognizes, the framing of an issue determines the aspects emphasized in policy making as well as the institutions and politics created around that issue. Therefore, if the prevailing mental model frames the problem as a series of individual problems, ignoring the role played by the social ecosystem, individual-focused solutions will dominate the repertoire of policies created to address the problem.

On the other hand, as policies aiming at early childhood spread and scientific evidence accumulates, there will be growing pressure in many countries to reshape social spending. One (false) solution to accommodate that pressure is the enactment of policies that provide symbolic utility. Typically, such policies have the purported goal of addressing the problem, but they have insufficient funding and inadequate scope (i.e., they have face value only). 


\subsection{CONCLUSION AND LIMITATIONS}

No single discipline has all the answers to complex social problems (Meadows, 2002b). System dynamics, on the other hand, provides conceptual and methodological tools to integrate findings from diverse disciplines into a coherent (and potentially testable) theoretical framework.

From a system dynamics point of view, capabilities, assets and resources are stocks that accumulate over time. They may include also intangible assets, such as the quality of home environment, life aspirations and the repertoire of beliefs and values that is sometimes (controversially) associated with a culture of poverty (Bird, 2011). Hence, we can also conceive of a repertoire of capabilities developing through life that enables the individual to adjust to his or her social environment and which include the two essential, higher-order individual capabilities of self-efficacy and self-regulation. When properly developed, this set of capabilities builds on itself in an upward spiral that decisively influences an individual's potential in life.

The chapter reviewed the necessary conditions for breaking the vicious cycle of low human development, in particular the well-being of parents, the quality of the immediate environment, the quality of stimulation and the quality of development of key competences, in particular self-regulation. It is clear from the literature review that the timing of interventions and their combined efficacy are both critical for breaking the cycle. At the same time, the chapter makes the point that, rather than targeting individual aspects of the problem, governments should be managing the entire social ecosystem that contributes to the problem's permanence.

The interaction between genetics and the early environment shapes the development of the brain even before a child is born. The quality of early childhood development is crucial in determining one's potential in life, requiring an immediate environment characterized by structure, warmth and stimulation. There is enough evidence to assert that changes in a child's ecology affect his or her developmental trajectory, with longterm consequences in terms of educational achievement, economic productivity, health status and longevity (Shonkoff et al., 2012).

The sheer complexity of the required infrastructure inevitably challenges governmental capabilities. Interventions aimed at early childhood should (ideally) be ample, targeting the living conditions of poor families and children's cognitive and non-cognitive skills - 
a strategy close to what Heckman (2013) calls predistribution. Increasing the well-being of parents, for instance, can involve income transfer to neutralize financial stress, as well as diverse measures in many domains - consider job stress, transportation, housing, violence and other issues that contribute to high levels of environmental demands borne by the poor. At a minimum, governments should be focusing on developing adequate prenatal care and full-time, high-quality childcare.

The development of an efficacious structure to provide adequate ECD policies may be costly. It may also require the full exposure of distributive conflicts in countries where children are not a priority in public budgets. Moreover, in the context of a rapidly aging population, misaligned democratic structures may keep social spending skewed toward the elderly and the special interest groups that dominate the state in countries marked by extractive institutions.

Nonetheless, reality is inescapable. The future of any society depends on the stocks of the next generation, and in particular on the quality of the development of their critical capabilities. Societies unconsciously choose between social structures that lead to productivity and well-being or social structures that lead to suffering, low productivity, low social cohesion and diverse social problems. There is no reason to tolerate the constant waste of human potential engendered by ill-designed social structures. On the contrary, the wealth of evidence reviewed in this chapter suggests that the suffering that accompanies the lives of children in contexts of deprivation is preventable and its roots largely manageable. Startlingly, as hinted by Bronfenbrenner and Morris (2007), many of the conditions leading to chaos and toxic stress in early childhood are often unforeseen consequences of policy decisions made both in the public and in the private sector, such as the sacrifice of maternal leave (in the United States) in favor of immediate economic production. Importantly, investing in early childhood is cheaper than trying to compensate the deficits later (an alternative with limited potential for success) or, in particular, tackling the problems that will haunt societies later. In addition, there is no trade-off between efficiency and equity in early childhood investment (Cunha \& Heckman, 2010), making the related policies very appealing from a socioeconomic perspective.

Thus, a critical barrier to the redirection of societal investments is mindware, or the prevailing repertoire of mental models in a society. Public discourse and the mental models of influencers seem to lack an understanding of the importance of investment in 
early childhood. Shonkoff et al. (2012) correctly identified the gap (in the United States) between the evidence on the importance of children's development in the first years of life and the public discourse centered on policies for school readiness targeted at older children. This mismatch between science and public policy is an opportunity for complex social causes marketing, as we will discuss in chapter 7.

The model presented in this chapter fits what Bronfenbrenner and Morris (2007) call science in discovery mode, in contrast to traditional endeavors that follow the mode of verification paradigm. Its contribution may be especially suited to what the authors classify as the earlier stages of evolution of the science of human development. A model built in discovery mode does not aim to test empirical validity but to indicate the plausibility of relationships - inspired by theory - for inclusion in posterior research designs.

Regarding limitations, the CLD presented in this chapter does not of course capture all possible influences on the phenomenon. In addition, by adopting a higher altitude view, it ignores (or implicitly averages out) the effects of variables that represent individual dispositions, such as children's temperament. As examples of influencing factors or policies not included in the model, we did not explore the possible role of microfinance in alleviating circumstances of poverty (Yunus, Moingeon, \& Lehmann-Ortega, 2010). The impact of this and other policies remain as suggestions for future studies.

Several theoretical and practical questions also await the development of a more extensive body of research to provide better answers. For instance, is there a "natural" level of social maladies that persists independently of top-notch social policies? Why even in Nordic countries - the paradigm for good ECD policies - are there sizable population segments with children living in relative poverty? What is the minimum amount of investment, in terms of percentage of GDP, required to revamp a social ecosystem in a developing country such as Brazil?

Finally, a relevant limitation concerns the lack of development of a stock and flow model, which could provide the basis for simulations and scenario testing. The lack of a valid quantitative model precludes the identification of the main leverage points for change. We address this limitation in the next chapter. 


\title{
5. THE CAPED MODEL: INTERGENERATIONAL PERSISTENCE OF LOW HUMAN DEVELOPMENT
}

There can be no keener revelation of a society's soul than the way in which it treats its children. (Nelson Mandela)

\begin{abstract}
Low human development replicates across generations, even in developed countries. Capabilities and harshness of environmental demands interact to produce low levels of early childhood development, creating a "curse" very early in the lives of individuals living in poverty. After presenting the elements of a model created to portray the feedback loops behind these dynamics, we present the results of simulations testing individual and comprehensive policies, such as income transfer and prenatal care. The results suggest that many intuitive solutions may be insufficient to break the poverty cycle.
\end{abstract}

Keywords: poverty, human development, early childhood development, system dynamics.

\subsection{POVERTY IS A CURSE}

Poverty is more than a temporary strain on the social tissue of a country. Its hallmark is the existence of a broad repertoire of insufficient capabilities or resources in communities and families. Worse, such a repertoire tends to be transmitted from one generation to the next, perpetuating the cycle (Blanden \& Gibbons, 2006; Bird, 2011). In the United States, there is a high probability that a child born to a poor family will remain poor throughout her life (Mitnik \& Grusky, 2015). The same is true in underdeveloped, socially stratified countries such as Brazil (IBGE, 2017).

The effects of harsh rearing environments are determinant for creating path dependence in a child's life. As time goes by, a child born in poverty has fewer and fewer opportunities to break the cycle. The father of social psychology, Kurt Lewin, proposed that the difference between the rich and the poor is fundamentally determined by a range of possibilities in their "life spaces" (Lewin, 2015), which only gets narrower over time. 
A child born into poverty tends to face an environment marked by high levels of stress and low levels of parental buffering (Blair \& Ursache, 2011). The prevalence of toxic stress in the first years of life of poor children is a recipe for permanent damage in bodily systems and brain development, leading to a myriad of health problems and deficiencies in critical capabilities throughout life (Blair \& Ursache, 2011; National Scientific Council on the Developing Child, 2007). In this sense, it is no exaggeration to say that poverty acts as a curse that starts narrowing the Lewinian range of possibilities even before a child is born.

Intergenerational transmission of low human development presents strong challenges for societies throughout the world. Some societies care about creating relatively egalitarian social ecosystems in which people have higher probabilities of reaching their potential. However, incomplete mental models may hinder the attainment of this goal. In other countries, governments pay lip service to the need to invest in human capital, and the challenge in such cases becomes one of managing the consequences of low human development - low productivity, higher crime rates and low levels of societal harmony (Enamorado, López-Calva, Rodríguez-Castelán, \& Winkler, 2016). In any case, there is need for a better understanding of how public policy may address the complex problem of the replication of low human development, given that it sometimes accentuates the problem, even when led by good intentions (Raphael, 2011).

There are three major problems generally associated with public policies throughout the world: (1) they are often based on linear models that ignore the effects produced beyond their original context; (2) they are not evidence based; and (3) the politically incentivized short-term time horizon predominates, as there are few mechanisms in our democracies to ensure a focus on adequate long-term policies.

In this chapter, we present the Caped model, a small simulation model that combines family capabilities and harshness of environmental demands to explain the intergenerational transmission of low human development. Avoiding the traditional focus of system dynamics on hard variables and considering the explanatory role of higherorder theoretical concepts, we adopt a combination of soft variables to model the problem. Employing a quantifiable structure, we test the model through a proof-of-concept approach, simulating scenarios that suggest points for intervention into the system. 
The chapter proceeds as follows. First, we present the system dynamics method that guides the development of the model. Then, we briefly review previous work that has used the method to address some aspects of low human development replication, before presenting the Caped model, its assumptions, validation process and the simulated scenarios. We conclude by discussing the findings and their limitations and by offering suggestions for future studies.

\subsection{THE SYSTEM DYNAMICS METHOD}

System dynamics is a method pioneered by Forrester (1961) and explained in texts by Ford (2010) and Sterman (2000). It focuses on understanding the structures in a system that produces dynamically certain patterns of behavior. The method is especially suited for modeling complex social systems. It propitiates a " 10,000 meter view" of the system, portraying its structures and policies in an aggregate manner. System dynamics provides a deeper understanding of how complex systems behave over time, giving a dynamic view of such systems. By nature, this is an interdisciplinary approach (Sterman, 2000). One of the distinctive characteristics of the method is the presence of a dynamic hypothesis as the basis for explaining how feedback loops in a system produce the behaviors of interest.

Building a system dynamics model implies, first, knowledge about the detailed elements of the system. However - and this is where the method can be of greater value - there are often gaps in understanding of how important elements or variables, when considered in terms of their mutual interaction over time, combine to produce the behaviors of interest. By constructing a model and observing the interplay of elements within it, it is possible to achieve a better understanding of the real system. As Forrester (1961, p. 56) remarks, "a useful model of a real system should be able to represent the nature of the system; it should show how changes in policies or structure will produce better or worse behavior. It should show the kinds of external disturbance to which the system is vulnerable."

Hence, by carving out the relevant variables and their interrelationships, a modeler aims to mimic the structure of the real system and to replicate the patterns of behavior in the variables of interest - what is known in system dynamics modeling as reproducing the reference mode. A proper model will be able to reproduce changes in the system in response to new circumstances and policies (Sterman, 2000). Moreover, building a model 
forces the elimination of vagueness and enforces precision, in particular regarding the relative importance of the various elements of the system. There lies a powerful contribution of the method: often our assumptions about the effects of individual elements in the system cannot lead to the observed behaviors, which may be counterintuitive.

The quantification of endogenous relationships in the system dynamics method depends on the specification of stocks, flows and auxiliary variables. A diagram depicting stocks and flows is the representation, in essence, of a system of differential equations. Stocks represent tangible or intangible elements (or resources) that accumulate over time. Flows change the level of the stocks, increasing or depleting them. Auxiliary variables (or converters) represent constants and policy elements embedded in the systems. Clouds represent everything that is outside the system (figure 12).

\section{FIGURE 12. STOCK AND FLOW REPRESENTATION}

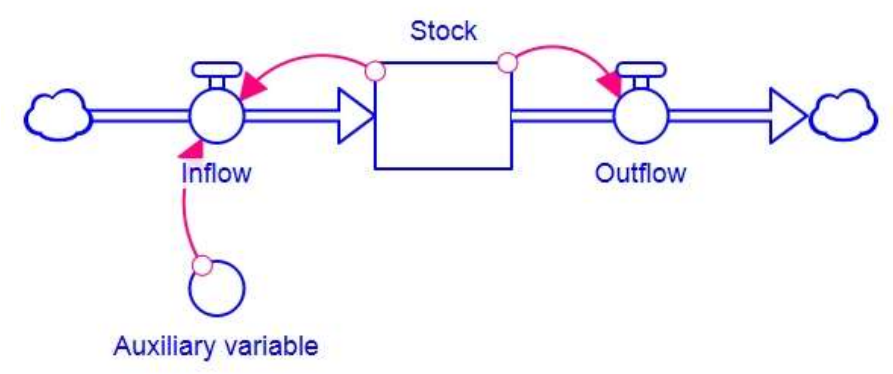

Source: Elaborated by the author.

The first step in the creation of a model, according to Forrester (1961), is the specification of its structure, or the general nature of the interrelationships within the model. A reasonable structure is the one that fits the descriptive knowledge of the system. Forrester (1968) sees a model's structure as consisting of four hierarchical levels, starting with the closed boundary and then progressively encompassing feedback loops, levels, rates and converters. After specifying the structure of the model, the modeler can proceed to assign plausible numerical valuables to the variables before starting the process of model validation.

In essence, a system dynamics model has as its primary goal the portrayal of the essential relationships that are hypothesized to generate endogenously the expected dynamic 
behavior (Randers, 1973). This guideline also reduces the pressure (or temptation) to include all theoretical assumptions about the phenomenon under study.

Feedback loops determine the evolution of dynamic phenomena in complex systems (Richardson, 1999). A good example comes from the work of Wittenborn, Rahmandad, Rick, and Hosseinichimeh (2015) on depression, which illustrates the role of a factor (the stress-capability gap) in driving both a reinforcing loop (resource erosion) and a balancing loop (resilience building) (figure 13).

FIGURE 13. EXAMPLE OF FEEDBACK LOOPS DRIVING THE EVOLUTION OF A STOCK

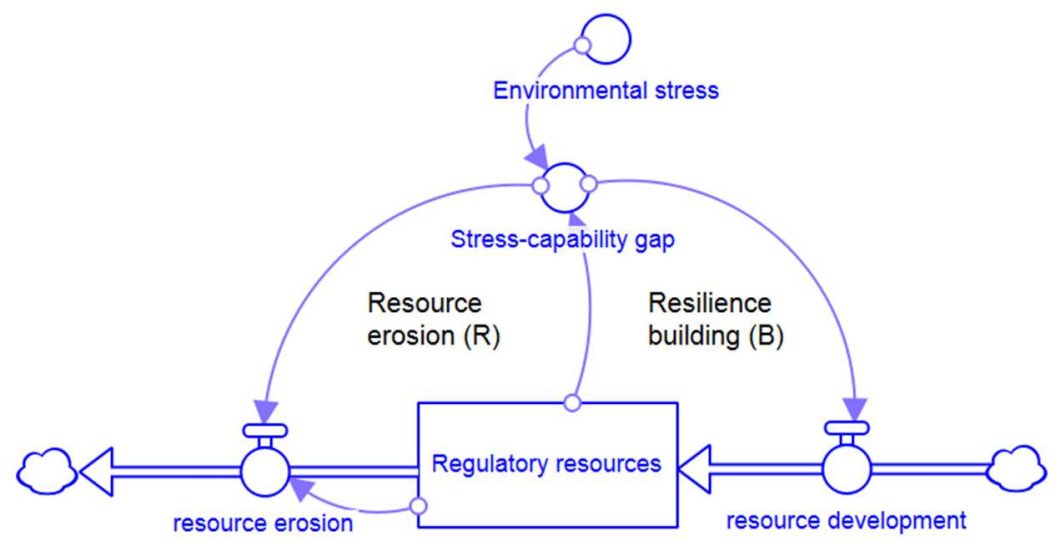

Source: Adapted from Wittenborn, Rahmandad, Rick, \& Hosseinichimeh (2015).

\subsection{PREVIOUS WORK ON SYSTEM DYNAMICS}

Broadly speaking, human development does not seem to be a popular topic among system dynamicists, who tend to focus their inquiries on other socioeconomic or physical systems. Focus on psychological aspects of problems is also rare (Levine, 2000). In fact, most previous work in the system dynamics field dealing with poverty or human development has adopted an economic lens, focusing on income, investment, debt and related variables (e.g., Radianti, 2004; Ansah, 2010). One exception is the model of sustainable human development developed by Di Giulio, Vaglio, Canova, Grasso, Lelli, Migliavacca, and Pareglio (2004) and Pareglio, Vaglio, Grasso, Migliavacca, and Di Giulio (2005), which operationalized the capabilities framework proposed by Sen (1999). 
We briefly refer to other studies that have tapped into aspects of human development. Unsurprisingly, they usually find that real systems have policy resistance, prevalence of linear mental models and a focus on points of low leverage for change.

Qureshi and Davidsen (2012) present an integrative model, linking sectors such as government, economic actors, population, education and health. Their study suggests that investments in human capital (education and health) should be prioritized over investments in economic services and infrastructure, especially considering the interdependence between human capital and economic growth. Bacaksizlar and Barlas (2015) investigate the problem of unequal access to education in Turkey, identifying this as a major cause in the replication of poverty in that country inasmuch as poor educational levels preclude access to higher paying jobs. Critically, they found that the current situation is strongly resistant to single policies aimed at breaking the poverty cycle, even over a couple of generations. Thus, they conclude, breaking the cycle requires multidimensional policies that include access to high-quality education.

Zagonel, Rohrbaugh, Richardson, and Andersen (2004) developed a model to explain why common policies to aid families living in conditions of social vulnerability often backfire - typically by not acting on the conditions that prevent recidivism into the same programs of social support designed to help them. The causes of this recidivism seem to be familiarity with traditional social work (familiarity that upholds the prevailing mental models) and a lack of awareness of the broader system, or what Banerjee and Duflo (2011) call the ideology-ignorance-inertia triad.

In the same vein, Saeed (2016b) discusses the usual consequences of social policies inspired by linear models or paradigms. In the case of poverty, common policies such as economic growth, capital formation and technology transfer lead to subsequent problems that include national indebtedness and environmental degradation. Worse, they often backfire, leading to continued or increased poverty. Moreover, regarding the particular problem of hunger, use of birth control, organization of poor farmers into cooperatives and provision of financial assistance, among other policies, are often ineffective in the long term because they target symptoms instead of root causes (Saeed, 1987; 2016a). Latent structures, which embody the goals of the systems and ultimately determine its resistance to linear policies, are usually ignored in such approaches. 
Finally, although there are calls in the child development literature for methods that consider dynamic interrelationships among variables (e.g., Yoshikawa \& Hsueh, 2001), we found no study or paper that employed system dynamics to create simulation models to illuminate the dynamics of interest.

\subsection{MODELING STRATEGY}

We opted to develop a small model to conduct simulations. Small models, conceived as models with few significant stocks and at most eight major feedback loops, are useful for generating and communicating crucial insights, especially regarding counterintuitive behaviors that are not obvious without the adoption of an endogenous perspective (Ghaffarzadegan, Lyneis, \& Richardson, 2011).

By focusing on soft variables, the model may raise the issue of measurement. One common misunderstanding about the system dynamics method regards the definition of parameters for the model. Often, the numerical values assigned to parameters depend on "arbitrary" estimation, which means that the confidence, in practice, relates more to the range in which the "true" value must fall (Forrester, 1961). In addition, models will in most cases be relatively insensitive to changes of values within that range. In other words, in practice, models are sensitive to changes in point values only for a handful of variables. When the model shows that some variables are essential for explaining the dynamics of the behaviors of interest but that there is lack of adequate measurement instruments for them, it is a mistake to exclude those variables. This would be equivalent to assuming (erroneously) that their impact is zero. What such a situation indicates is the need to develop better measurements for those variables. As Baron (2008) states, a normative model of hypothesis testing can be specified in terms of calculating in advance the value of relevant information.

On the other hand, there is no shortage of individual measurement instruments for many variables included in the model presented in this chapter. For instance, the Home Observation for Measurement of the Environment (HOME) assesses the quality of the home environment and parent-child interactions. In the same vein, most of the competences aggregated in the model as children's general competences can be measured before the age of three. Tests that tap into self-regulation or executive functions vary in the age at which they can be applied. The Stroop test (adapted as the day/night test), for 
instance, requires a child to be at least three years old (Naudeau et al., 2011). However, there are valid instruments or measures that tap into self-regulation or self-regulation antecedents at earlier ages (e.g., Sethi, Mischel, Aber, Shoda, \& Rodriguez, 2000), as well as comprehensive questionnaires that tap into several aspects associated with early childhood development - for instance, the instrument for underdeveloped countries proposed by Bornstein, Brito, Nonoyama-Tarumi, Ota, Petrovic, and Putnik (2012).

We opted to employ a proof-of-concept approach, in which the modeler sets the parameters and runs different simulations intended to replicate the effects of common policies or exogenous shocks, without necessarily matching the specificities of a given program or context. For an example of model tested under the same approach, see the work of Ghaffarzadegan, Xue, and Larson (2017).

\subsubsection{REFERENCE MODE}

Figure 14 presents the reference mode for the stocks in the model as well for the focal variable of interest (quality of children's development). We opted to analyze the Brazilian case, since it epitomizes a situation similar to that of many Latin American countries: there has been slow progress in early childhood development in the last decades, even if we consider the current level of social policies aimed at children to be qualitatively better than that of a few decades ago (Campos, 1992). The variables presented in the figure will be discussed below. 
FIGURE 14. REFERENCE MODE FOR THE CAPED MODEL

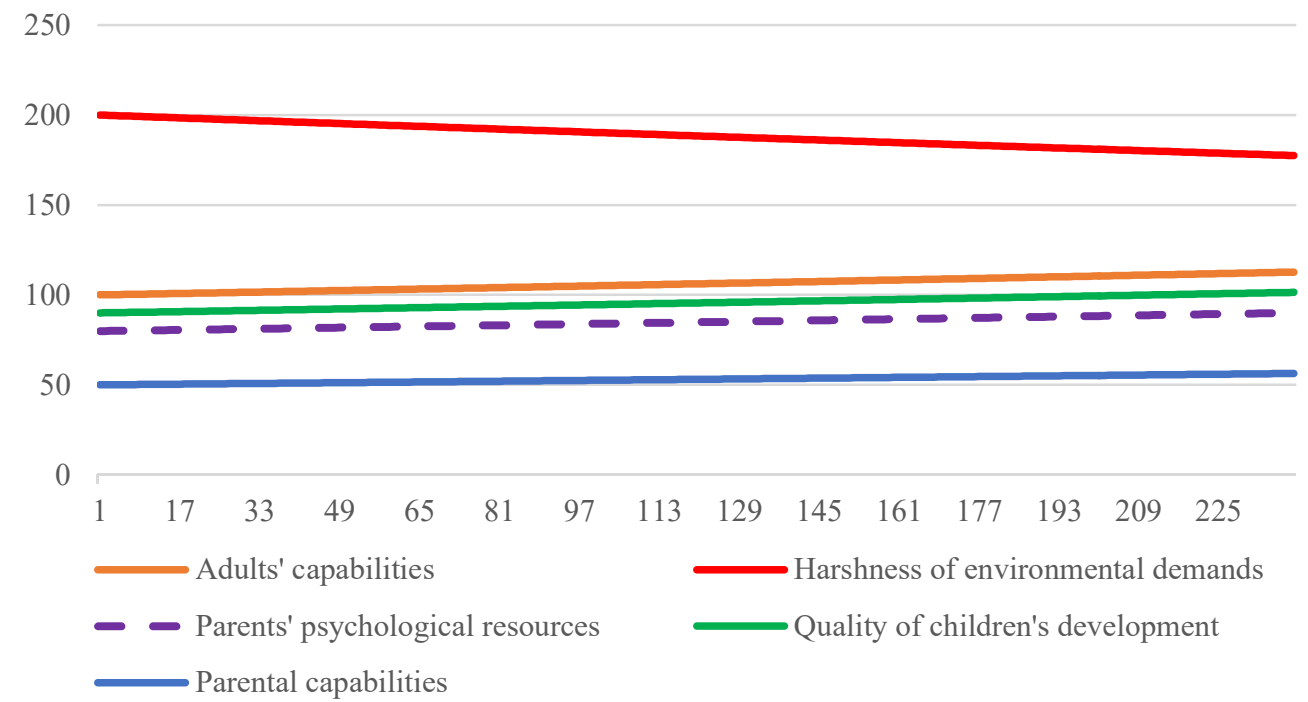

Source: Elaborated by the author.

The reference mode illustrates a situation of very slow social progress, which is a hallmark of the evolution of Brazilian social indicators over the last decades. In Brazil, economic development from the last half of the last century was accompanied by rapid industrialization, which fueled growth in cities, creating several social problems in the process. Brazil became a country with median income status, and economic growth fueled demand for qualified workers, sparking investment in educational systems, albeit of overall low quality. Over time, educational levels increased and some social policies were put in place, but never with the intensity and quality necessary to break the extractive profile of the country's economic institutions (Acemoglu \& Robinson, 2013). The increases in social budgets were accommodated not through redistributive policies (which would require discussion of the subterraneous tensions among social groups) but through continuous increases in the tax burden, until the latter started to curtail the economy's potential for growth (Mendes, 2014). However, the increase in the tax burden due to greater social spending often replicated the extractive profile of the country's institutions, favoring the upper social strata at the expense of the poor, which also explains why social progress has been so slow. A typical case is the profile of educational spending, which has led to spending on university students (most of them from privileged families and private schools) equivalent to OECD levels (in terms of PPP dollars), whereas spending 
on the initial years of education (which cater to poor families) is less than half of OECD levels (OECD, 2017b). At the same time, in the absence of powerful internal drivers for economic growth, the country remains dependent on external economic stimuli to ignite economic boom cycles (favoring more social spending), as the recent commodities cycle demonstrates (The Economist, 2015).

Camargo (2018) summarized the long-term profile of the Brazilian state: Brazil is one the most unequal countries in the world and a relatively poor country. A quarter of its population are below the official poverty line, and poverty impacts children disproportionally (four in every ten live in poor families). Critically, the Brazilian state spends six times more per capita on pensions than on the education of children.

The result of that dynamic is a social ecosystem in which the evolution of human capabilities is very slow. Consider the case of education. The average years of schooling in the Brazilian adult population (25 years of age and older) increased between 2004 and 2015 from 6.4 to 7.9 years (IBGE, 2016), a figure that is less than the minimum number of years required to complete the fundamental educational cycle. While there is apparent progress in the number of years of schooling, the country ranks among the lowest in the PISA international assessment of children's educational competences, with a shameful status among its peers. This is not an exaggeration: Brazil ranks among the five worst performers (out of 70 countries) in mathematics, and $70.3 \%$ of its students score below level two, the minimum level at which an individual is expected to be able to fulfill his or her role as a citizen (PISA, 2016). Similar results are observed in the reading and science versions of the assessment. In addition, functional illiteracy still reaches $27 \%$ of the Brazilian adult population. Only $8 \%$ are considered fully literate in the sense of having the competence to read and interpret texts in typical situations, as well as the ability to perform basic mathematical operations and read data displays such as trends and projections (IPM, 2016). In sum, we believe that the reference mode reflects the slow progress in the evolution of Brazilian social indicators over recent decades.

Figure 15 presents a diagram of subsystems that summarizes the characteristics of the main sectors in the system. Throughout the text, we refer to the critical period of early childhood (from prenatal to the first three years of life) as ECD. 
FIGURE 15. DIAGRAM OF SUBSYSTEMS

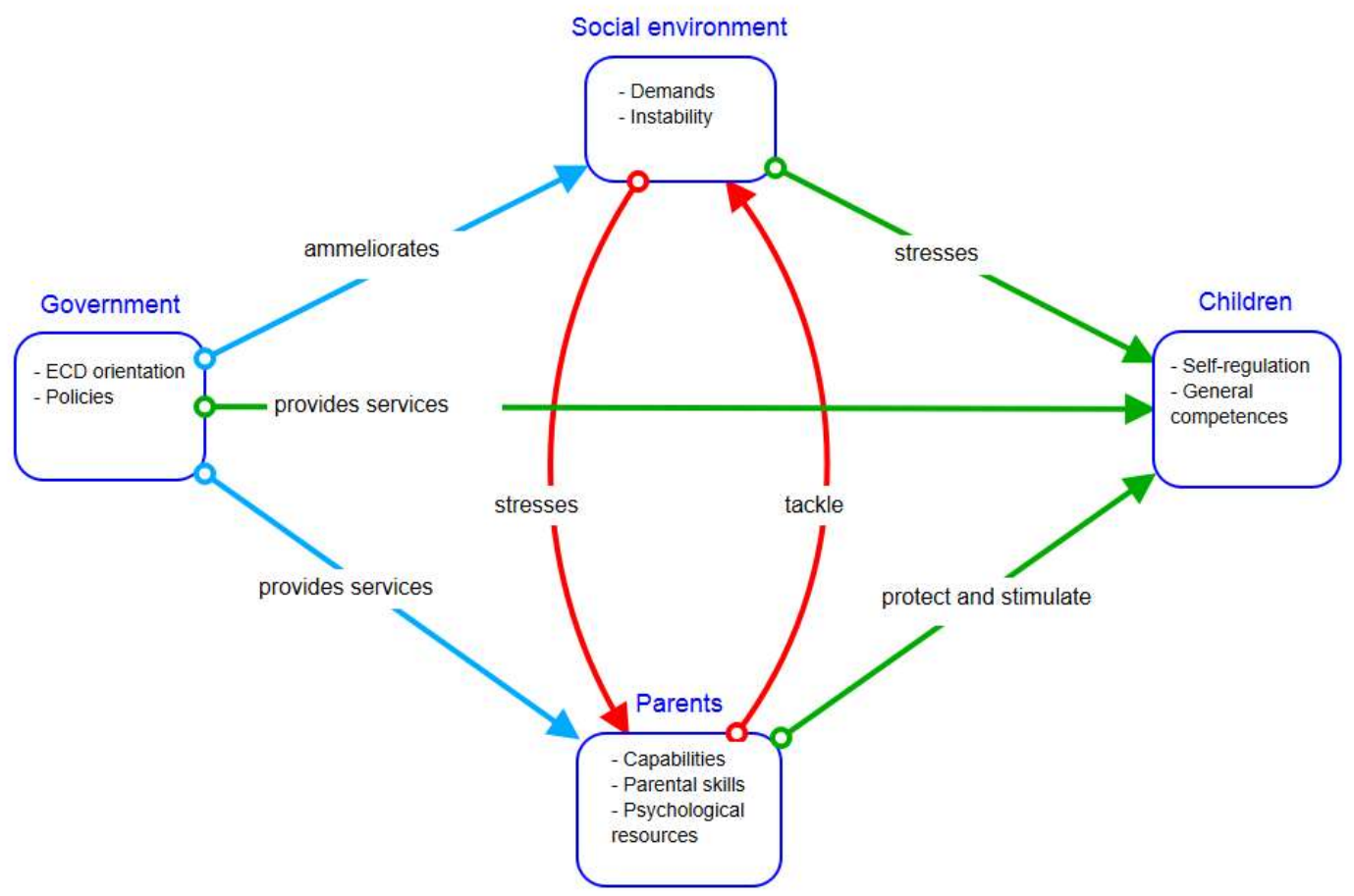

Source: Elaborated by the author.

Table 8 presents the model boundary chart with three types of variables: endogenous, exogenous and excluded, as suggested by Sterman (2000). 
Table 8. Model boundary chart

\begin{tabular}{lll}
\hline Endogenous & Exogenous & Excluded \\
\hline Adults' capabilities & Policies & $\begin{array}{l}\text { Evolutionary pressures (in } \\
\text { particular, Life History } \\
\text { Theory) }\end{array}$ \\
Parental capabilities & $\begin{array}{l}\text { Instability of social } \\
\text { ecosystems } \\
\text { Income variability }\end{array}$ & $\begin{array}{l}\text { Social consequences (e.g., } \\
\text { crime) }\end{array}$ \\
Children's capabilities & & Political process and agenda- \\
Harshness of environmental & & setting \\
demands & & Resources from other adults \\
Adults' psychological resources & & Economic institutions \\
Stress/resources gap & Social inequality index \\
Income sufficiency & \\
Financial stress & \\
Quality of ECD development & \\
\hline Source: Elaborated by the author. &
\end{tabular}

Source: Elaborated by the author.

\subsubsection{DYNAMIC HYPOTHESIS}

The dynamics hypothesis is depicted in figure 16. In essence, it shows four reinforcing loops that are behind the cycles of human development considered from the viewpoint of the family. We note that these loops tend to be weakly activated in the cases of underdeveloped countries and poor population segments in developed nations. 
FIGURE 16. DYNAMIC HYPOTHESIS

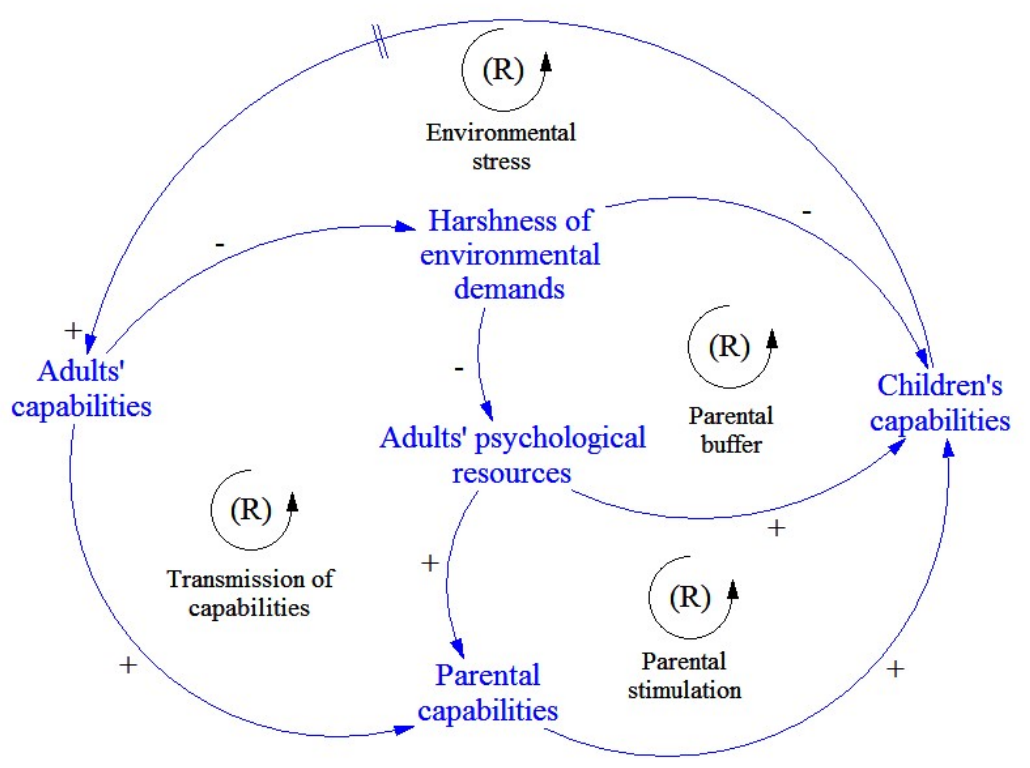

Source: Elaborated by the author.

The model assumes that low adult capabilities (and consequently lower socio-economic status) is associated with diverse sources of environmental instability, which drains mental resources from parents. Sources of additional instability may be the intense urbanization and all its associated problems that occurred in Brazil during the second half of the last century (IBGE, 2006). In any case, excessive harshness of environmental demands is a drain on psychological resources. It prevents adequate functioning of parental buffers and channels toxic stress to children, which precludes the proper development of their capabilities. Over a long timespan, a capability-deprived child will become an adult with low capabilities, reinforcing the cycle. Two additional feedback loops represent the influence of adult (parental) capabilities and their psychological resources on the development of children's capabilities.

The model concentrates on key relationships that have been uncovered repeatedly in the literature of ECD. Figure 17 presents an example of a conceptual model drawn from the neuroscience literature (Hackman, Farah, \& Meaney, 2010). The goal of the Caped model, however, is to present a dynamic portrayal of the phenomenon, identifying key feedback links. 


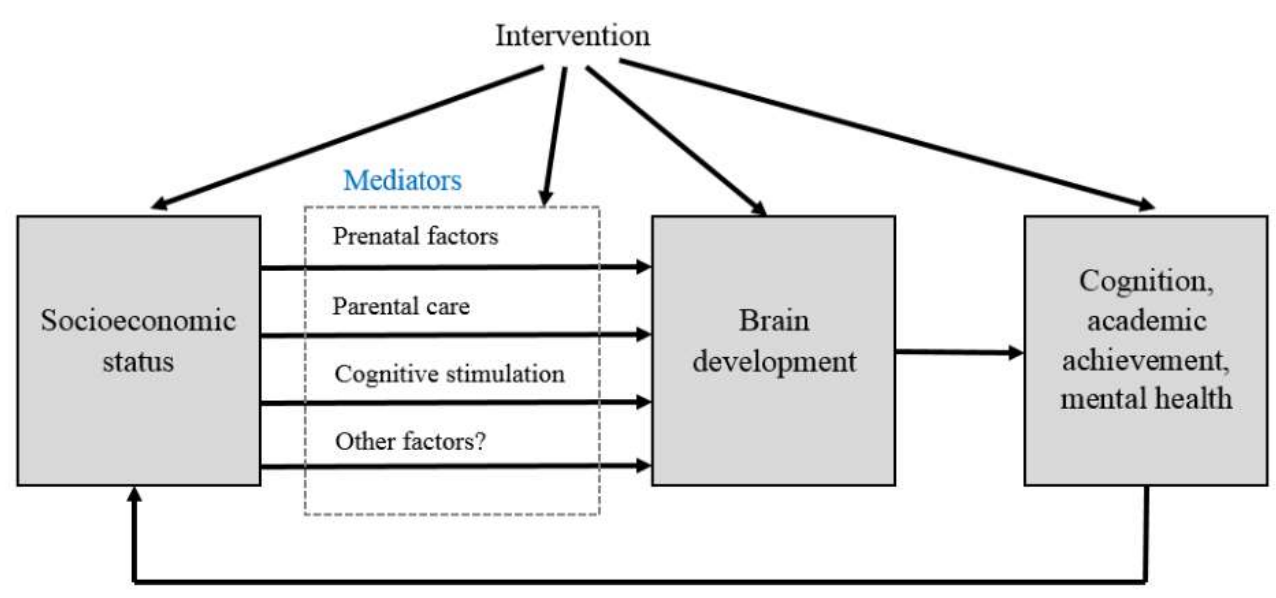

Source: Adapted from Hackman, Farah, \& Meaney (2010).

\subsection{MAIN ELEMENTS IN THE CAPED MODEL}

The Caped model brings a different perspective to previous modeling efforts by concentrating on feedback loops that operate at the family level, while also reflecting the influence of public policies and other macro factors. The term Caped refers to the combination of capabilities and (the harshness of) environmental demands. We normalized all variables by employing a range from 0 to 1 . Appendix D presents the equations.

We note that our approach has connections to the work of the economist Amartya Sen, who defines capabilities as the substantive "freedoms" that an individual enjoys to lead the kind of life she or he values (Sen, 1999). However, while the concept of capabilities proposed by Sen may come across as loosely defined, we prefer to delineate it along the lines of first-order and second-order capabilities, both conceived as stocks. The former encompasses cognitive, social, emotional and cultural competences, including professional skills. The latter encompasses what we call generative competences: selfregulation (an umbrella concept for executive functions and elements of self-control, such as persistence) and self-efficacy. 
Unlike Sen's framework, the concept of capabilities employed here excludes aspects related to political participation, since these are not relevant within the scope of this work. Next, we discuss each element of the model separately.

\subsubsection{QUALITY OF CHILDREN'S DEVELOPMENT}

We conceptualize quality of ECD development as the average of two stocks, selfregulation and children's general capabilities. The model aggregates cognitive, language, social, emotional and self-efficacy competences under the latter stock. Research shows that these depend on the proper functioning of self-regulation, such as the ability to concentrate and pay attention (National Scientific Council on the Developing Child, 2007; Naudeau et al., 2011).

Self-regulation, or the capacity to alter dominant responses and to control behavior, thoughts and emotions, is a decisive causal factor in producing desirable outcomes in the most important contexts of modern life, such as school, diet, work, prosocial behavior and well-being. Beyond regulating responses to specific opportunities, it may operate more by forming and breaking habits or stable patterns of behavior (de Ridder, LensveltMulders, Finkenauer, Stok, \& Baumeister, 2012). Importantly, its foundation is established in the first years of life, depending on adequate levels of stress, maternal buffering and stimulation. Due to strong instability in their early environments, children from low-income families typically manifest over time multiple self-regulatory deficits: low self-control, attentional-control problems, weaker inhibitory control and diminished capacity for working memory (Evans \& Kim, 2013; Kidd, Palmeri, \& Aslin, 2013).

On the basis of the available neurological evidence, Blair (2010) summarizes the positive effects of self-regulation development as a means to overcome early risk. In addition, her view supports the conceptualization of capabilities taken in this chapter by stating that (p. 185) "in what is termed human capability formation, early inputs (parenting quality, effective preschool, and early elementary education) appear to influence cognitive and personality factors that promote the capacity of the individual to benefit from latter opportunities."

Recent evidence corroborates this proposition. Hackman, Gallop, Evans, and Farah (2015) found that socioeconomic status (measured as income-to-needs ratio and level of maternal education) in early childhood is strongly associated with the level of 
development of executive functions (the basis for self-regulation), which then remains stable throughout later years. However, they also found that executive functions respond to later changes in a family's socioeconomic status, suggesting some degree of plasticity for those capabilities.

In sum, under poverty conditions, the model assumes a "biological embedding" of social ranking (McEwen, 2012); the foundations of children's development will be weak in proportion to the presence of detrimental conditions in their immediate social environment.

\subsubsection{ADULTS' CAPABILITIES}

Adults' capabilities are a bundle of professional, cognitive, emotional, cultural and social competences, as well as what we consider the higher-order, individual generative capabilities of self-regulation and self-efficacy. Self-efficacy, which is similar to the concept of agency and internal locus of control, encompasses the belief that one is capable of producing efficacious action in one's social environment (Bandura, 1997). Hence, generative capabilities refer to the development of a meta-capability to use existent resources and generate further resources and capabilities in order to manage one's wellbeing in the social environment. That bundle of capabilities ultimately defines the socioeconomic status (SES) of an individual. SES, which is traditionally conceived as a combination of education, occupational prestige and income levels, and is usually measured as a discrete variable (e.g., Kamakura \& Mazzon, 2013), may be seen as a proxy for an individual's underlying capabilities.

In any case, adults' capabilities are the major outcome of the process of human development. While we do not treat them here in detail, we recognize that some of them, particularly social and cultural capital, may be special markers of social status, creating differential access to occupations and social networks. In very unequal societies, it is as if people from different social standings live in different worlds - their daily lives occur in different physical and sociocultural settings. In this sense, one of the more intriguing lines of research on poverty concerns the persistence of low economic status through group-level influences on individuals (Durlauf, 2006).

The representation linking the quality of ECD to adults' capabilities assumes a deterministic fashion, inasmuch as the social investment in human capital (education and 
health) is also a consequence of social inequality. Typically, a society that neglects children living in poverty will not prioritize their later education. Even in societies where social hierarchy is less rigid (e.g., the United Kingdom), one can gauge the replication of low human development through an examination of the distinctive repertoire of capabilities associated with each social class. Research on the social determinants of health typically finds strong differences in several markers of health across social classes (Marmot, 2004; see also Braveman \& Gottlieb, 2014, for a review). The poor have shorter lives, suffer from more health problems and experience greater incidence of negative emotions. Not only does poverty tend to get under a child's skin very early, but it is also associated with many kinds of environmental stressors (e.g., housing, job security) that manifest in the lives of those occupying the lower rungs of society. Such stressors impair the full development of human capital through life via several interrelated mechanisms, from insufficient levels of education to living hand to mouth.

Measurement of adults' capabilities should be ample and multifaceted. Although there are individual questionnaires measuring capabilities such as self-regulation and selfefficacy, as well as proxies for education such as years of formal schooling, a comprehensive set of instruments still appears to be lacking.

\subsubsection{PARENTAL CAPABILITIES}

Basically, parental capabilities consist of nurturing and stimulating skills. Nurturing is particularly important in the first years of life, as it provides structure and buffering against environmental stresses. Similarly, stimulating skills are important for building cognitive, language and related competences in children, as well as their self-efficacy. In the context of poverty, however, these capabilities may be severely diminished. Poverty or low socioeconomic status has been associated with authoritarian patterns of parenting, more punishment and scolding of children, and lower levels of responsiveness to the socioemotional needs expressed by children (Hackman, Farah, \& Meaney, 2010; McLoyd, 1990). The model assumes that this is caused by low educational levels (adults' capabilities) and by the effects of harshness of environmental demands, as suggested in the literature (e.g., Berry et al., 2014; Leventhal \& Brooks-Gunn, 2002; McLoyd, 1990). If there is a broad conclusion that could be drawn from the literature on children development, it is the one summarized by Velasquez-Manoff (2013): 
With humans, the mark of early-life hardship persists in nervous systems wired slightly differently. A nurturing bond with a caregiver in a stimulating environment appears essential for proper brain development and healthy maturation of the stress response. That sounds easy enough, except that such bonds, and the broader social networks that support them, are precisely what poverty disrupts. If you're an underpaid, overworked parent - worried, behind on rent, living in a crime-ridden neighborhood-your parental skills are more likely to be compromised.

\subsubsection{HARSHNESS OF ENVIRONMENTAL DEMANDS}

The stock of harshness of environmental demands is directly associated with adults' capabilities. We opted to conceptualize the harshness associated with everyday demands in different contexts of life as a stock that potentially drains individuals' time, attention, decision-making ability and energy. Individuals navigate different social ecosystems, which provide the basis for the satisfaction of the diverse needs present in human experience. In the social ecosystems associated with poverty, virtually all goals are difficult to achieve - from simple, everyday goals, such as buying high-quality meals, to more complex ones, such as having access to adequate health care.

In the evolutionary literature, harshness (along with unpredictability) is a feature of social and natural ecosystems associated with the activation of life history strategies (slow versus fast). The harsher the environment, the faster the life history strategy and the lower the parental investment on offspring (Ellis, Figueredo, Brumbach, \& Schlomer, 2009).

Lower social classes have been associated with lower sense of personal control (Kraus, Piff, \& Keltner, 2009). The groundbreaking work of the epidemiologist Michael Marmot shows a strong relationship among perceptions of personal agency, social class and the effects of stress: the lower in the socioeconomic ladder, the less the perception of agency and the more detrimental the effects of stress on health and longevity (Marmot, 2004). The non-poor, on the other hand, have access to more resources to cope with everyday demands, which increases their perception of agency and controllability.

The model assumes that having low levels of capabilities is synonymous with being in a lower social class. In such cases, individuals are exposed to harsher levels of environmental demands, such as violence, poor housing, difficult transportation, inadequate levels of public service and uncertain income. Consider, for instance, the case of the city of São Paulo. The collective organization Rede Nossa São Paulo compiled a comprehensive set of socioeconomic data for its different neighborhoods (Rede Nossa 
São Paulo, 2016). The data showed distinct profiles for the neighborhoods on a continuum of disadvantages that inversely replicated their socioeconomic profile. In other words, the poorer the area, the greater the harshness of the environmental demands faced by its inhabitants. The poor neighborhoods typically have low access to cultural products and services, higher predominance of favelas (shantytowns), higher incidence of teenage pregnancy, inadequate prenatal care, lack of jobs and higher levels of violence and homicide, among other social indicators. The rate of homicides for young men (aged 15 to 29) ranges from 6 per 100,000 inhabitants in the best neighborhood to an appalling 104 per 100,000 in the worst. Startlingly, the average age at death ranges from 53.8 years in the worst district to 79.6 in the best, on a continuum that roughly reproduces the socioeconomic profile of the neighborhoods (figure 18).

FIGURE 18. AVERAGE AGE AT DEATH ACROSS THE 96 NEIGHBORHOODS IN THE CITY OF SÃO PAULO (BRAZIL)

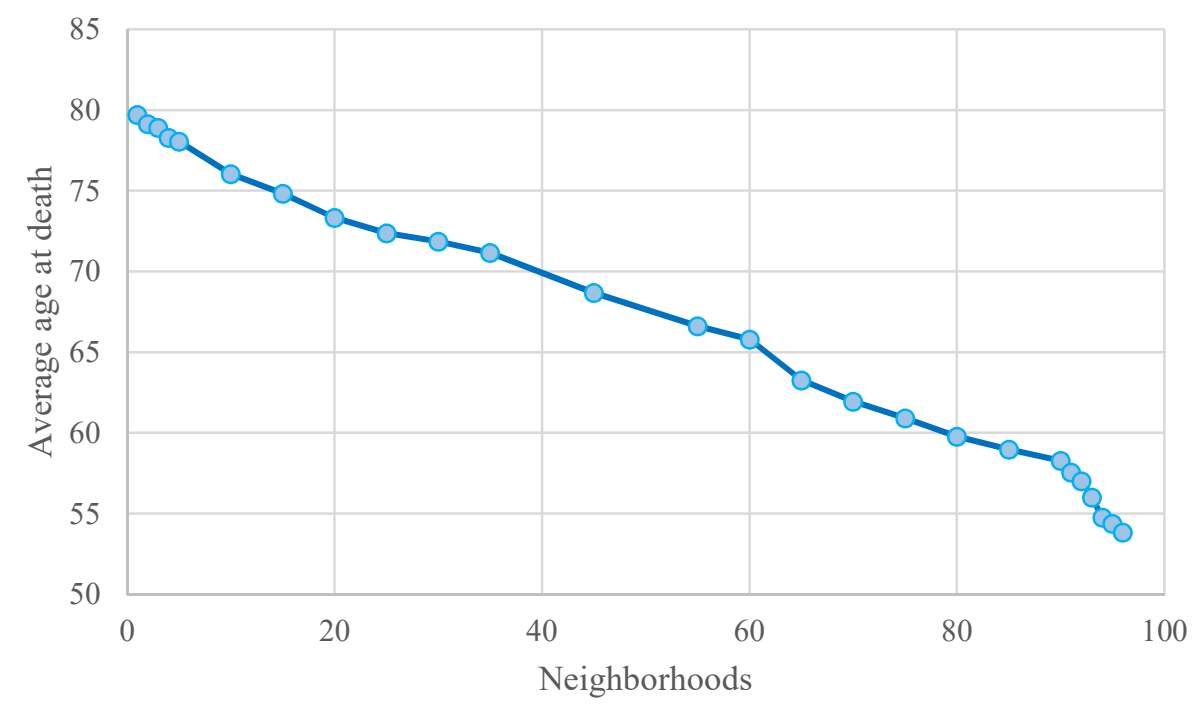

Source: Rede Nossa São Paulo (2016).

The profile of those environments or social ecosystems clearly varies according to social class. In their study, Kamakura \& Mazzon (2013) identified seven social classes in Brazil. Importantly, there are strong inequalities and differences in the profiles of those classes. For instance, in the upper social class, $64.1 \%$ of household heads had 15 or more years of formal education, while the figure was only $0.2 \%$ for the most disadvantaged class. Similar differences were found in terms of income, leisure, access to public services 
(including cultural products, treated water, paved streets and adequate sewage systems) and possession of household appliances. The differences extended to values and perceptions: in a sample of respondents from the city of São Paulo, the authors found that the poorest segment perceived themselves as having little control over their own lives.

The point is that in very unequal societies (such as Brazil), there is a steep gradient in terms of the harshness of environmental demands faced by the citizens. Even in societies where inequality is mild, one can expect that a strong burden is carried by the poor, who have to juggle the requirements to satisfice basic needs in a context of scarcity of financial and cognitive resources (Mullainathan \& Shaffir, 2013). For instance, in a sample of children aged between 8 and 10 years living in the rural United States, Evans and English (2002) found several physical and psychosocial stressors in their social ecosystem, ranging from noise, substandard housing, safety hazards and crowding to family turmoil, child-family separation and community violence. Similarly, in a sample of AfricanAmerican mothers and their seventh and eighth-grade children, Ceballo and McLoyd (2002) found that poorer and high-crime social environments led to worse emotional support and harsher punishment from mothers. As McLoyd (1990) remarks, in lowerclass life there is an overrepresentation of a broad range of life events producing frustration and chronic conditions that lie outside an individual's personal control.

Hence, the model assumes a distribution of the harshness of environmental demands in association with the level of adults' capabilities as depicted in figure 19. The level of harshness is highest at low levels of capabilities, but it decreases steeply as the capabilities increase until it saturates at a comfortable level. 
FIGURE 19. HARSHNESS OF ENVIRONMENTAL DEMANDS AND ADULTS' CAPABILITIES

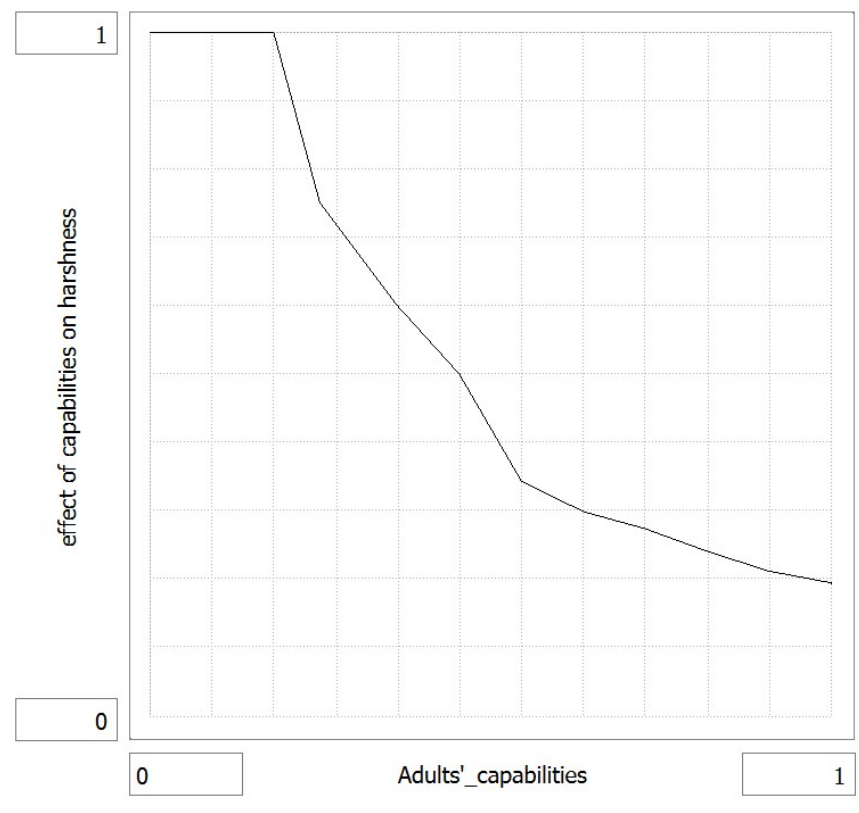

Source: Elaborated by the author.

The model also deals with income sufficiency and the associated financial stress as a different pathway between adults' capabilities and the overall stress influencing parental resources. Separating financial demands from other demands that comprise the bundle of everyday demands has the advantage of allowing a closer investigation of policies such as minimum income transfers. Of course, environmental and financial demands are closely related, as they both depend on an individual's capabilities and financial resources to buffer several of the everyday demands. Thus, we average the dual sources of stress in the stress/resources gap variable (see the model in figure 20).

Once again, we feel that better ways are required to measure the plethora of social ecosystem demands. Proxies such as life evaluation, which seems to vary directly as a function of income (Kahneman \& Deaton, 2010), and stress or metabolic syndrome markers, which vary according to socioeconomic status or social hierarchy (Cohen, Doyle, \& Baum, 2006; Marmot, 2004), may be sufficient to indicate the combined effect of the demands. Nonetheless, more nuance is needed in order to understand the differential contribution of each source of stress. 
One promising alternative is to evaluate the utility of each living condition across different dimensions (e.g., housing, income stability, violence and access to leisure). Utility may be a viable criterion, inasmuch as it is defined as the extent of accomplishment of our goals (Baron, 2008). Societal context constrains the boundaries for the measurement of utility. A middle-class European citizen would balk at the prospect of living in the typical upper-class house in Brazil, which employs several prison-like security devices. Thus, the measurement for housing, for instance, would take into account what are the best and worst conditions within a given society.

Finally, a dimension that probably requires integration into that set of measures is consumption, the degree to which one participates in the marketplace, since the feeling of not being able to afford the pleasures of modern life may also be a source of stress (Hamilton \& Catterall, 2005).

\subsubsection{PARENTS' PSYCHOLOGICAL RESOURCES}

In the social environments associated with poverty, there is little time to recover from one frustration before the next one arises. The impacts are often strong. In a study investigating the association of income with life satisfaction and incidence of emotions, Kahneman \& Deaton (2010) found that the poor reported greater prevalence of stress and negative emotions (sadness, worry), as well as headache and asthma. Divorce and living alone were also more common among the poor. Spears (2011) found that poverty impairs economic decision-making by depleting cognitive control.

Under the umbrella of psychological resources, we consider the levels of energy, attention and regular self-regulation resources (e.g., self-control and persistence toward goals). As in the model developed by Wittenborn, Rahmandad, Rick, and Hosseinichimeh (2015), the relationship between ecosystem demands and parents' psychological resources may be one of resilience (when resources develop in response to demands) or of stress building (when the demands are too much to cope with). In the model, the stress/resources gap variable is function of stress from environmental demands, financial stress and parental psychological resources. The nonlinear curve embedded in the stress from environmental demands variable has a tipping point when the ecosystem demands reach 0.7 - above that level, stress increases steeply (figure 20). 
There are theoretical reasons to expect a tipping point above which self-regulation yields to the effects of stress and individuals become more likely to adopt ill-adapted behaviors, such as procrastination, search for immediate gratification and aggression (Baumeister, 2002). Besides leading to lifelong health consequences, in particular for the poor (Chemin, de Laat, \& Haushofer, 2013; Adam, Quinn, Tavernier, McQuillan, Dahlke, \& Gilbert, 2017), stress also affects the quality of decision-making (Baron, 2008). Making numerous difficult decisions under strong pressure from the environment impairs the regulation of thoughts, emotions and behaviors. Excessive severity and chronicity of stressors over long periods may leave little time for recuperation of psychological resources after each occurrence, depleting emotional reserves (McLoyd, 1990). Thus, coping with stress may easily drain the stock of psychological resources (encompassing energy and self-regulation) at a rate faster than the rate of replenishment. Ironically, many programs targeted at the poor implicitly assume unbounded cognitive capacity, attention and self-control (Datta \& Mullainathan, 2014).

FIGURE 20. STRESS FROM ENVIRONMENTAL DEMANDS

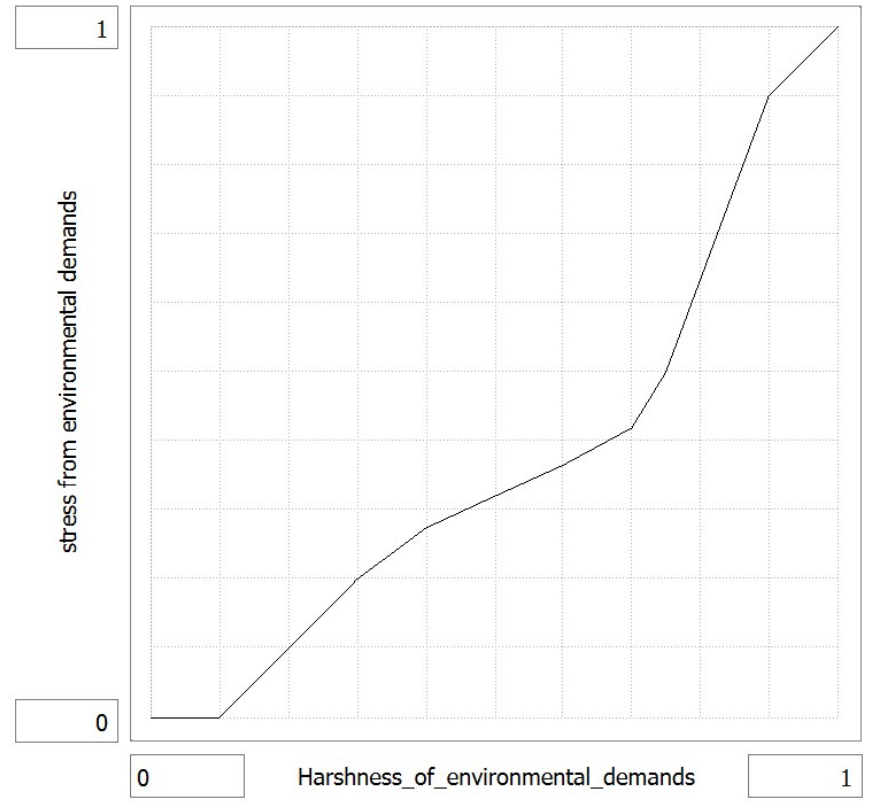

Source: Elaborated by the author. 


\subsubsection{COMPREHENSIVENESS OF ECD SOCIAL POLICIES}

The model was designed with social policies embedded, for two reasons. First, the policies are already in place in Brazil, and they have been determining the dynamics of the stocks over time. Second, we were interested in testing the intuitions of researchers and practitioners about the efficacy of the policies (see section 5.6 for the validation process).

The level of social policies seems to matter. Bradley, Elkins, Herrin, and Elbel (2011) found that the higher the ratio of social expenditures to health expenditures across 30 OECD countries in the period of 1995 to 2005, the better the results concerning infant mortality, life expectancy and potential life years lost, after controlling for the level of health expenditures and GDP. Social expenditures consisted of spending on housing, income transfers, unemployment coverage and similar policies.

The model assumes that the comprehensiveness of social policies - their quality and coverage - is essential for breaking the poverty curse. Indeed, designing policies that shape the broader environment to which families are exposed is a common suggestion among researchers who study early childhood development (e.g., Hackman, Farah, \& Meaney, 2010). The model further assumes different levels of comprehensiveness for the policies. Variables range from a minimum of 1 to a maximum of 5 . At the initial levels, public-sponsored interventions provide poor services in terms of prenatal care, childcare, income transfer, home visits and general policies to soften environmental demands.

As the literature is not decisive regarding the effectiveness of many policies, we assume a high degree of uncertainty in terms of their effects. We note that the literature is more positive on the effects of high-quality childcare and prenatal care (e.g., Naudeau et al., 2011; The NICHD Early Child Care Research Network, 1997).

Nations differ in how institutions redistribute wealth among the population and the extent to which governments allocate resources to strengthen the social infrastructure (Raphael, 2011). The comprehensiveness of ECD policies reflects the degree to which a society opts to address the root causes of poor human development (e.g., violence) through policies that weaken the positive feedback loops responsible for social inequality. As Meadows (1999) points out, these loops often involve processes that ensure lower taxes for the rich and good education for their children. In light of the strength of such loops in unequal societies, policies that enact balancing feedback loops, such as anti-poverty programs, are 
usually ineffective. Thus, it would make more sense to design policies to decrease the force of the prevailing loops that reinforce inequality, such as universal high-quality education and progressive income tax.

\subsubsection{STOCK AND FLOW MODEL}

Figure 21 presents the stock and flow model. Quality of children's development is the focal variable of interest, averaging levels of self-regulation and children's general capabilities. The quality of societal investment in human capital through life variable represents the degree to which social structures maintain, improve or deteriorate the initial levels of children's development. This applies particularly to the educational system, which is expected to build diverse capabilities through a young person's life.

We designed the model keeping in mind homogeneous groups of people living in poverty. The reader should consider the poorer neighborhoods in a city, the poorer cities in a state or the lower socioeconomic strata of an entire population. For those groups of people, we assume the possibility of measuring the intangibles portrayed in the model at regular time intervals. 
FIGURE 21. THE CAPED MODEL

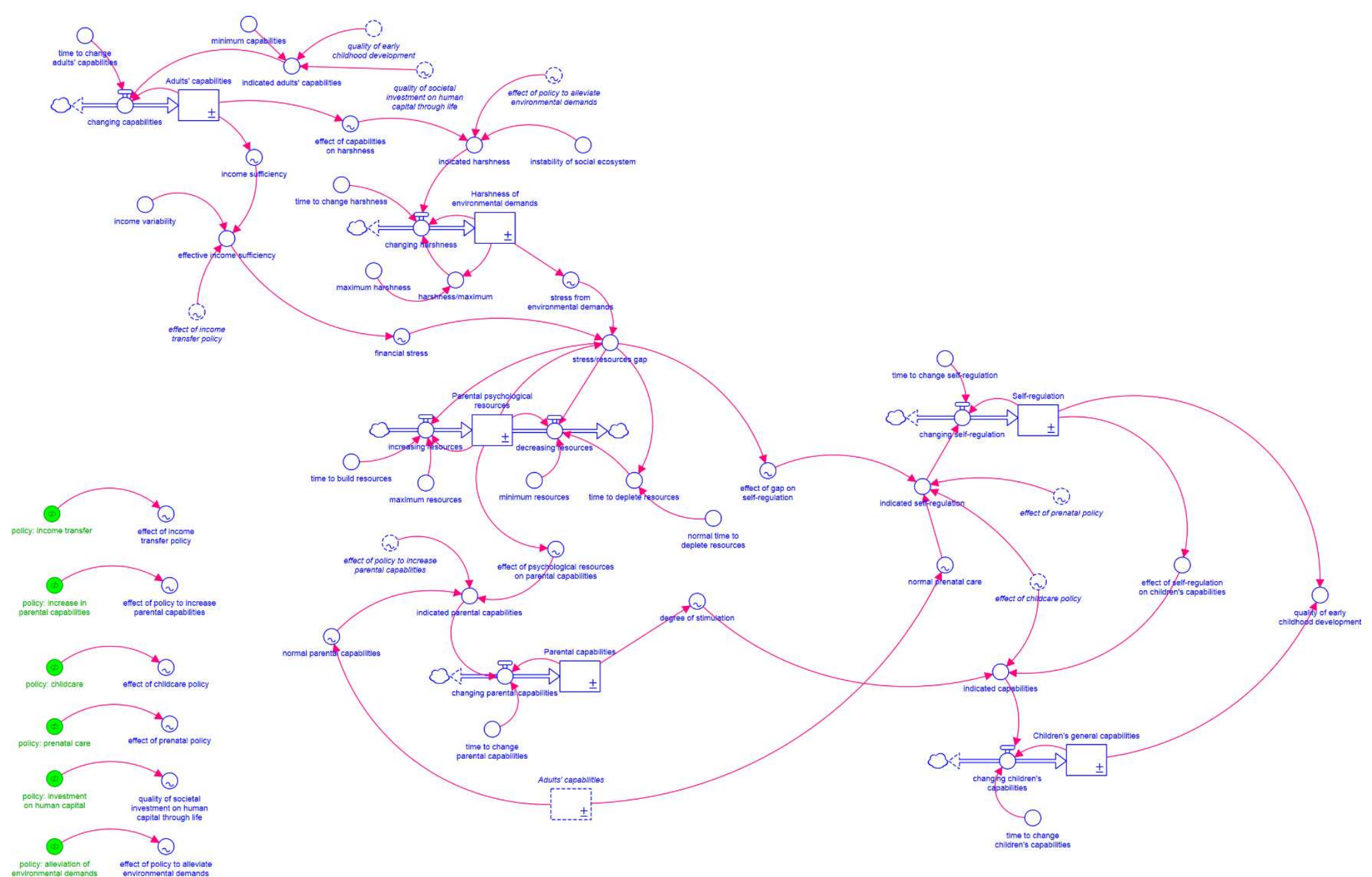

Source: Elaborated by the author. 


\subsection{VALIDATION PROCESS}

We adopted a multilevel approach to validation of the model. Following the system dynamics tradition, our initial approach to validation required verifying whether the model is an acceptable representation of the different sectors in a system and whether its behavior corresponds to the behaviors of the actual system. As Barlas (1996, p. 184) asserts, the validity of a model is an expression of its "usefulness with respect to some purpose." Validation rests on a gradual "confidence building” process, which does not preclude the employment of formal tests. In sum, model testing is not the same as "proving" that the model is "right" (Sterman, 2002).

According to Forrester (1961), the validity of a model as a description of a system should be examined by taking into account system boundaries, interacting variables and values of parameters. With regard to behaviors, the model should generate time patterns of behavior that matches - or does not differ in a significant way - the behavior of the real system. Of course, exact correspondence is an impossibility, since the goal of modeling is not to reproduce the entire system but to understand the dynamics underlying a problem. In addition, close correspondence between the behaviors generated by the model and the behaviors in the real system does not in itself validate the model; it is a necessary but not a sufficient condition of validity. A model, as Forrester (1961) stresses, is a statement of a "law of behavior." However, a model of a social system cannot predict actual states of the system in the future, since "noise" or unexplained factors may alter the course of the real system in significant ways. On the other hand, it is possible to study the kinds of behavior exhibited by the system, including its sensitivity to noise disturbances.

In the process of validation, we followed most of the guidelines outlined by Senge and Forrester (1980) and Barlas (1996), performing direct structure and structure-oriented behavior tests. Special attention was given to extreme condition tests, walkthroughs, behavioral sensitivity and modified-behavior tests.

Forrester (1961) warns against the common attitude of expecting only quantitative validation of a model. Models often depend on knowledge extracted from qualitative sources or on weakly established quantitative relationships. The modeler should always express the relationships in a quantitative fashion - numerical expressions arise from beliefs about relative magnitudes, limiting conditions and probable consequences. 
However, such numbers often do not spring from exactly measured relationships, especially given the complex web of causation in social systems. Therefore, although quantitative validation is always desirable, in a case where most elements of a model come from non-numerical sources, the defense of the model's validity should also rest on the type of knowledge that provided the basis for the model. In addition, the individual parameters in a model should always have conceptual meaning in the context of the real system - they should be validated against past incidents and experiences. Hence, an additional level of validation requires comparison of the conceptual basis of the model with the theories and frameworks employed to study the phenomenon. The model, of course, represents a theory in itself, by portraying a set of causal propositions in an integrated manner.

Finally, although early childhood policies in Brazil are in their early stages and tend to be incomplete, we strove to reach social workers involved with their implementation. We also contacted researchers and individuals involved in the design of social policies in general. Using Stella Architect (Isee Systems, 2016), we created a version of the model to be simulated on the web. It presented the model and its dynamic hypothesis, as well as basic explanations of the conceptual elements. The participant could simulate the effects of social policies, with the goal of breaking the cycle of low human development in Brazil. At the end, there was a link to a brief survey hosted on the Qualtrics platform (www.qualtrics.com). Specifically, we asked for feedback regarding the general validity of the model, the plausibility of the feedback loops and other suggestions or criticisms. One major organization involved in the design of ECD programs refused to participate in the validation effort, claiming statutory reasons.

Appendix D presents a snapshot of the web version of the model (in Portuguese) in addition to the survey.

\subsection{BASE RUN}

The model is initialized in equilibrium. Appendix D presents the initial parameters for the model, which is simulated for a period of 50 years (equivalent to two generations of adults). We assume that societal pressures mount over time, leading to the enactment of some social policies, as happened in Brazil during the transition that started with the collapse of the "Brazilian economic miracle" in the 1970s and ended with the 
promulgation of the 1988 Constitution. Hence, in year 10 of the simulation, some social policies start to produce effects. We change the level of the policy for childcare to 1.5 , the policy for prenatal care to 2.0, the policy for investment in human capital to 1.5 and the policy for alleviation of environmental demands to 2.0. Figure 22 presents the base run.

For simplicity, we assume in the base run that income variability is negligible. As the variable may be important in the generation of stress, we investigate its influence in the scenario that tests the income transfers policy (see section 5.8.1).

\section{FIGURE 22. BASE RUN}

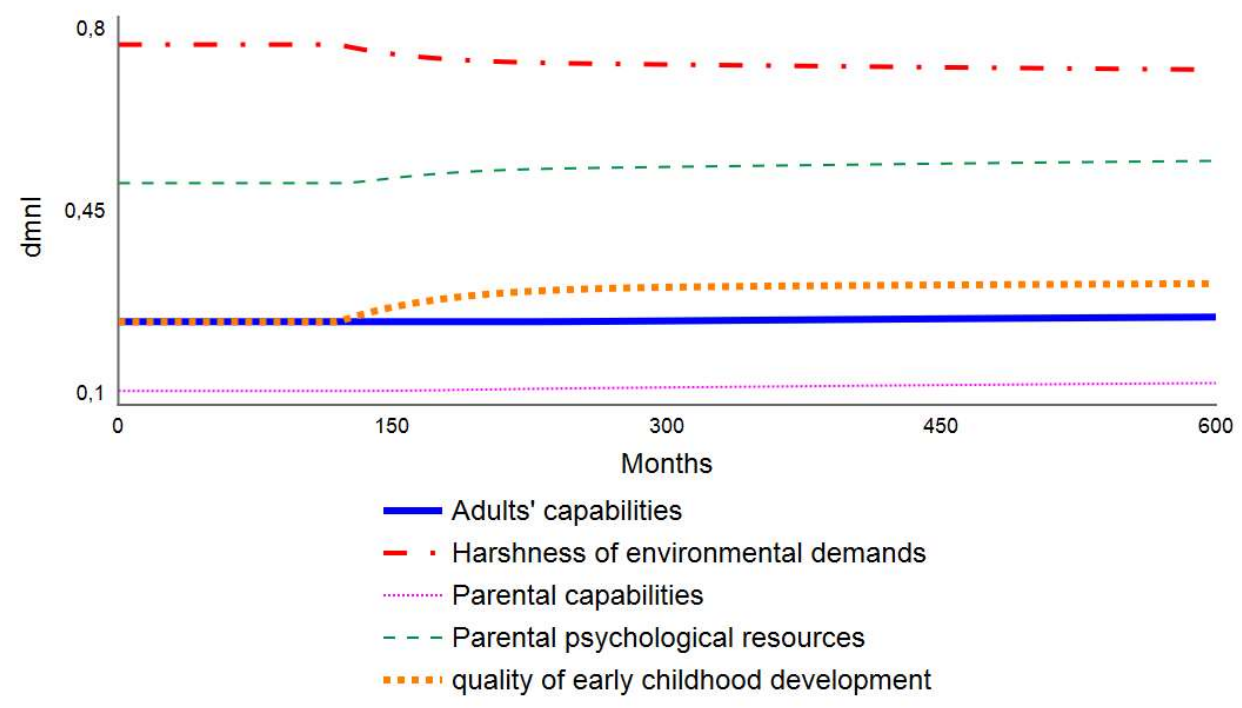

Source: Elaborated by the author. Note: dmnl stands for dimensionless indicators.

\subsubsection{SENSITIVITY ANALYSIS}

Sensitivity analysis is a core component of the system dynamics method (Tank-Nielsen, 1980). We adopted the pragmatic approach commonly employed by system dynamicists, which involves halving and doubling the values for parameters to gauge their effects on the behaviors displayed by the model. For each policy tested, we ran 1,000 simulations in Stella, using incremental distribution. This allowed us to account for the uncertainty associated with the parameters (specifically those associated with the efficacy of 
policies). If the model's behavior is insensitive to the range of the tested values, then we can increase our confidence that changing that parameter probably will not change the system (and vice versa).

\subsection{SCENARIOS}

Scenarios are useful to identify leverage points at which to intervene in a system, in particular when there is controversy about proper solutions or when programs based on "common sense" fail to achieve their expected results.

One of the major concerns regarding early childhood policies is that they may fail to achieve the threshold of sufficiency to break the cycle of low human development. ECD policies in Brazil, for instance, have focused only on a subset of potential levers, such as increasing parental capabilities or prenatal care. In the United States, on the other hand, there seems to be a major focus on preschool programs.

We first tested scenarios with individual policies in action (table 9). Each scenario represents an experiment testing a mental model. The last scenario tests the effect of combined policies.

We note that in actual contexts the policies interact with different levels of prevailing social conditions. Richer areas in a country or state may have better governmental structures, with better educational and health services, for instance. Any complementary ECD policy in such cases will thus benefit from interaction with the existing level of social services. Hence, a policy that aims to increase parental capabilities in a city with relatively good schools has a better chance of reaching a given threshold of stronger effects for the average family enrolled. It may also spark the development of ECD capabilities within local branches of government, creating conditions for further highquality interventions. In other words, it may create new reinforcing positive loops, replicating a common archetype found in systems: the "Matthew effect" or the "success to the successful" archetype (Braun, 2002). This often-overlooked aspect of ECD policies may (ironically) ameliorate life for poor families living in richer areas while failing to achieve significant improvements for those already living in poorer areas (who are probably more in need). 
In all cases, the levels of the policies range from 1 (a level at which society cares very little about the policy) to 5 (where the policy has maximum priority). The simulations assume different timings for the implementation of the policies. In some cases, the realism of this assumption depends on the additional assumption that pilot programs are in place beforehand and that governments can easily scale them up.

We also report the results of sensitivity analysis for the efficacy of each policy. Considering the existence of a high degree of uncertainty about the long-term efficacy of each policy, the analysis tests the response of the focal variable (quality of ECD development) to a wide range of parameters. The ranges are broader than the ranges adopted in the model. We halved the lower limit and doubled the upper limit for the efficacy of each policy and considered the effects of the policy from the beginning of the simulation. The main goal of the sensitivity tests was to identify which policies would have the greatest impact on the focal variable depending on their actual efficacy. 
Table 9. Scenarios tested

$\begin{array}{ll}\text { Scenario } & \text { Rationale/description } \\ \text { 1. Income transfer policy } & \begin{array}{l}\text { Income transfers have the potential to remove the major } \\ \text { sources of stress in situations of poverty: (lack of) income } \\ \text { sufficiency and income variability. They seem especially } \\ \text { suited for poor families with small children. }\end{array} \\ & \text { The development of the brain and other important } \\ \text { biological mechanisms start in the womb. Poverty has } \\ \text { been associated with influences that affect such } \\ \text { mechanisms, such as nutritional deficits, consumption of } \\ \text { alcohol by mothers and different sources of stress. } \\ \text { In contexts of stress and environmental unpredictability, } \\ \text { high-quality childcare may provide the necessary buffer } \\ \text { for small children, as well as adequate levels of } \\ \text { stimulation for developing the basis of essential } \\ \text { capabilities. }\end{array}$

4. Increase in parental capabilities

Policies have been implemented to increase capabilities regarding cognitive stimulation and caring. They strive to develop new habits in parents, such as reading to their children.

5. Investment in human capital This scenario accounts for the quality of educational and health policies for later periods in life. There are policies in Brazil, for instance, that focus on developing the necessary educational skills in vulnerable segments of the population, avoiding the replication of functional illiteracy in the country.

6. Attenuation of environmental This scenario encompasses the comprehensiveness and demands efficacy of social policies aimed at the plethora of factors affecting the lives of the poor: housing, basic sanitation, transportation, job-related stress, crime, etc.

7. Comprehensive interventions

Different combinations of the former policies may lead to threshold effects, with the potential to break the replication of low human development across generations.

\subsubsection{SCENARIO 1: INCOME TRANSFER POLICIES}

Starting in year 10 of the simulation, we steadily increased the level of income transfers so that, by the end of year 50 , the maximum level is achieved. The model shows a marked 
increase in the level of parental psychological resources and moderately better figures for the remaining variables (figure 23).

FIGURE 23. SIMULATION FOR INCOME TRANSFER POLICIES

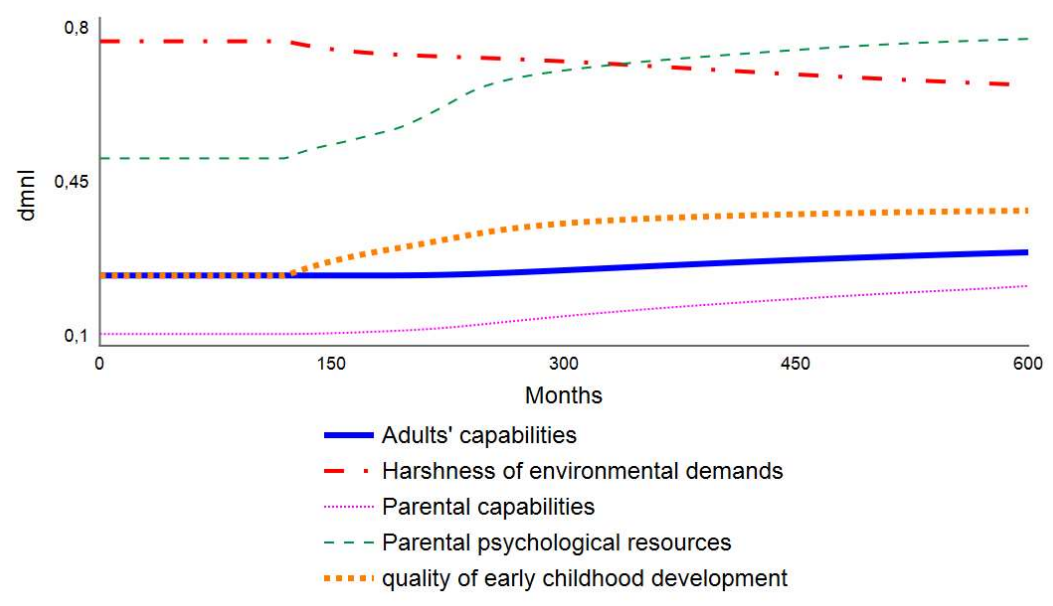

Source: Elaborated by the author.

Figure 24 presents the result of the sensitivity analysis for the efficacy of income transfer policies, showing a confidence interval of $100 \%$ for the focal variable (quality of ECD development). In the original model, the efficacy responds (nonlinearly) to the level of the policy, ranging from an effect of 1 (no effect) to an effect of 2 (doubling the level of income sufficiency). In the sensitivity test, we tested the effects in the range of 0.5 to 4 . We also enabled the income variability variable, corresponding to consequences of economic cycles of ten years. We assumed uniform cycles leading to increases or decreases of $5 \%$ in income in each period.

The results are consistent with evidence from real-world programs (e.g., Forget, 2011), which typically show increases in some aspects of the lives of the poor, such as freeing mental resources previously affected by stress. However, according to the model, income transfers, which have been touted by a variety of influential thinkers (e.g., Milton Friedman and Friedrich Hayek) as a tool for the alleviation of poverty, seem to be no panacea when it comes to breaking the intergenerational transmission of low human development. On the other hand, they seem to attenuate the negative effects of recessions. 
FIGURE 24. SENSITIVITY ANALYSIS FOR THE EFFICACY OF INCOME TRANSFER POLICIES

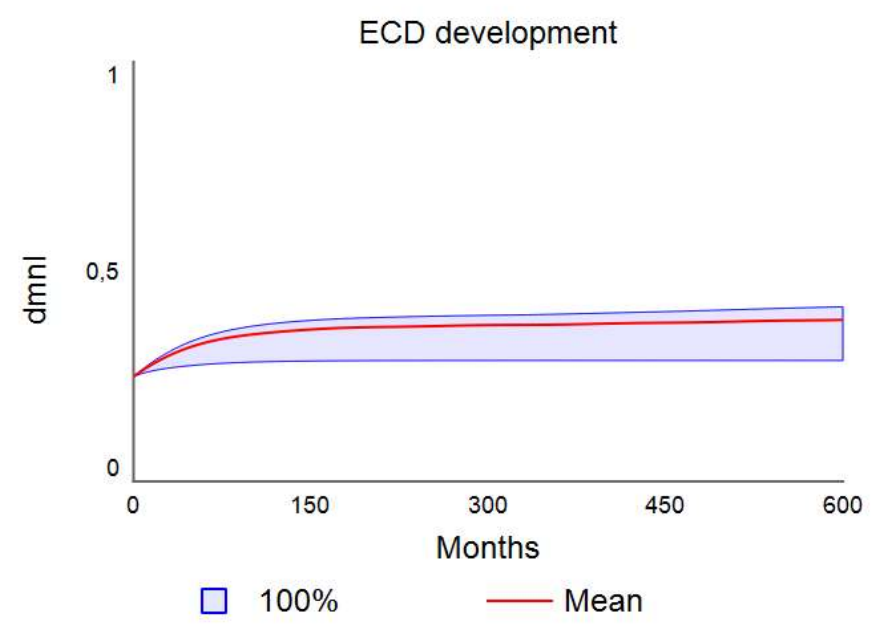

Source: Elaborated by the author.

\subsubsection{SCENARIO 2: PRENATAL POLICIES}

We increased the level of social investment in high-quality prenatal care, assuming that virtually all vulnerable segments of the population have access to this service between years 10 and 25 of the simulation. In the model, prenatal care directly influences the formation of the self-regulation stock. A high level of service implies full attention to fetal development, including adequate maternal nutrition and efforts to educate mothers to avoid the consumption of alcohol and other drugs. The simulation (figure 25) shows an accentuated increase in the quality of ECD development, confirming the intuition that prenatal care provides a fundamental basis for the ensuing development of psychobiological mechanisms. 
FIGURE 25. SIMULATION FOR HIGH-QUALITY PRENATAL CARE

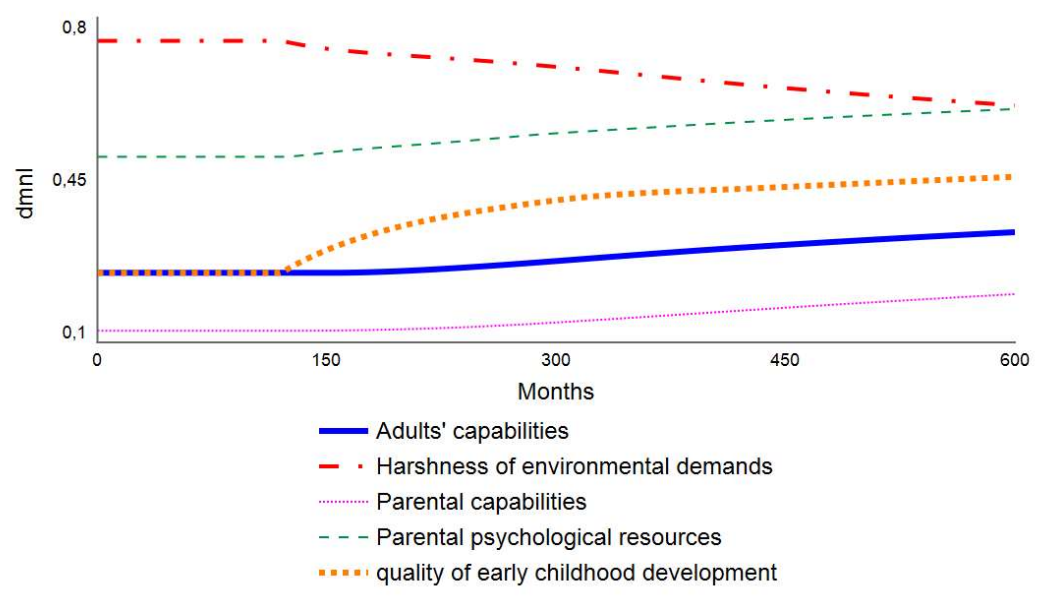

Source: Elaborated by the author.

Extending the simulation over periods longer than 50 years shows that the trends eventually stabilize. The model thus suggests (unsurprisingly) that the policy is a necessary but not a sufficient condition for breaking the poverty cycle.

We note that the Caped model averages the level of prenatal policy in conjunction with other influences to determine the indicated level of self-regulation (see figure 21). Nonetheless, the sensitivity analysis suggests that the model is strongly susceptible to the actual effects of this policy (figure 26).

FIGURE 26. SENSITIVITY ANALYSIS FOR EFFECTS OF PRENATAL CARE POLICIES

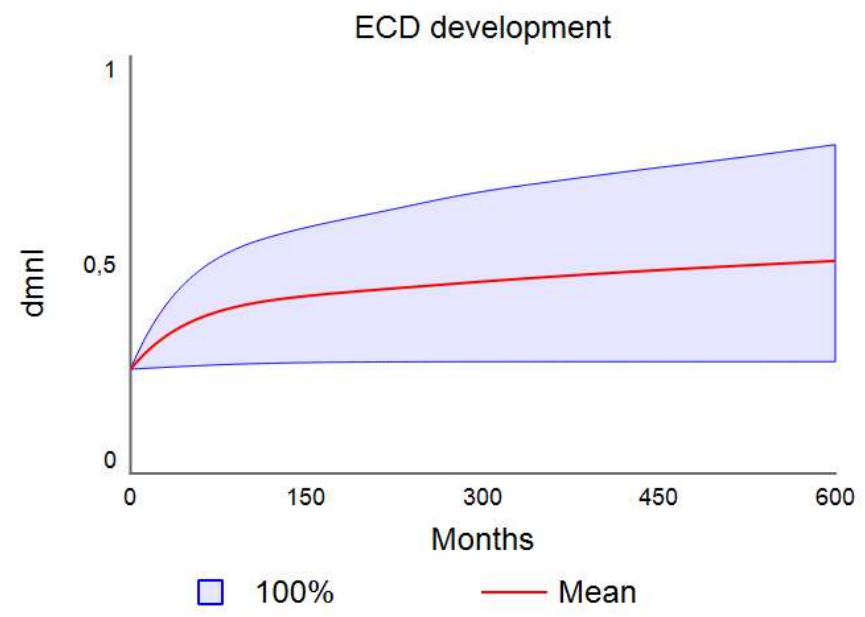

Source: Elaborated by the author. 


\subsubsection{SCENARIO 3: HIGH-QUALITY CHILDCARE}

Scenario 3 involves a highly qualified childcare intervention reaching the poor, based on elements such as coaching of care providers and evidence-based curricula (Weiland, 2016). The base run adopted a slight increase in childcare policy in year 10. We tested the effect of an increase to the median level (3) of the policy in year 15 followed by the adoption of the maximum level in year 20 (figure 27). Such a policy could strongly reorient societal structures toward the needs of young children from the poorer segments of the population.

\section{FIGURE 27. SIMULATION FOR HIGH-QUALITY CHILDCARE POLICIES}

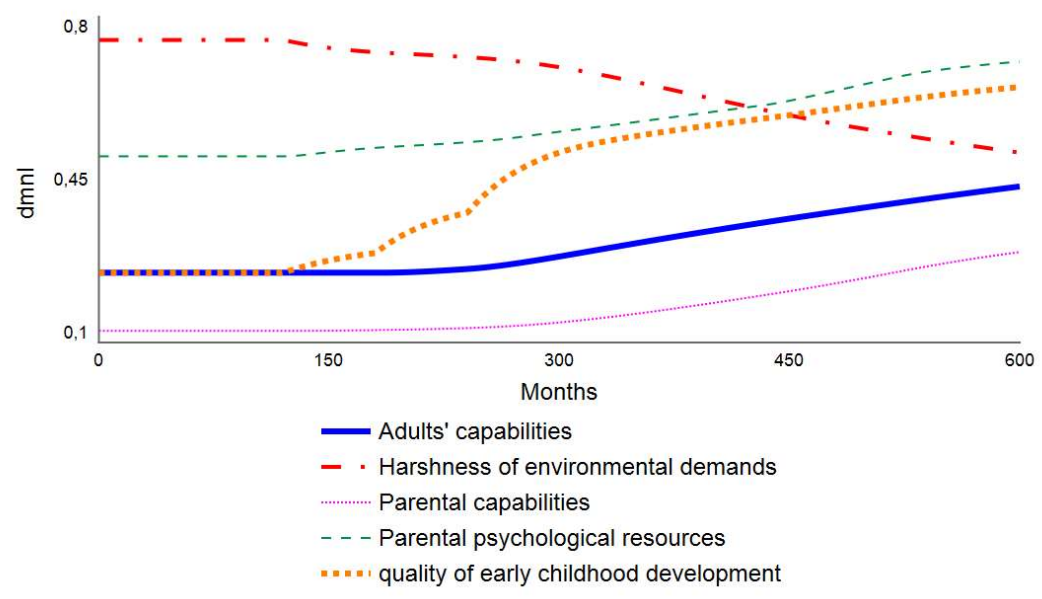

Source: Elaborated by the author.

The sensitivity tests for the effects of childcare policy suggest that this is the variable with the most potential to influence the model's behavior (figure 28). 
FIGURE 28. SENSITIVITY ANALYSIS FOR EFFECTS OF HIGH-QUALITY CHILDCARE POLICIES

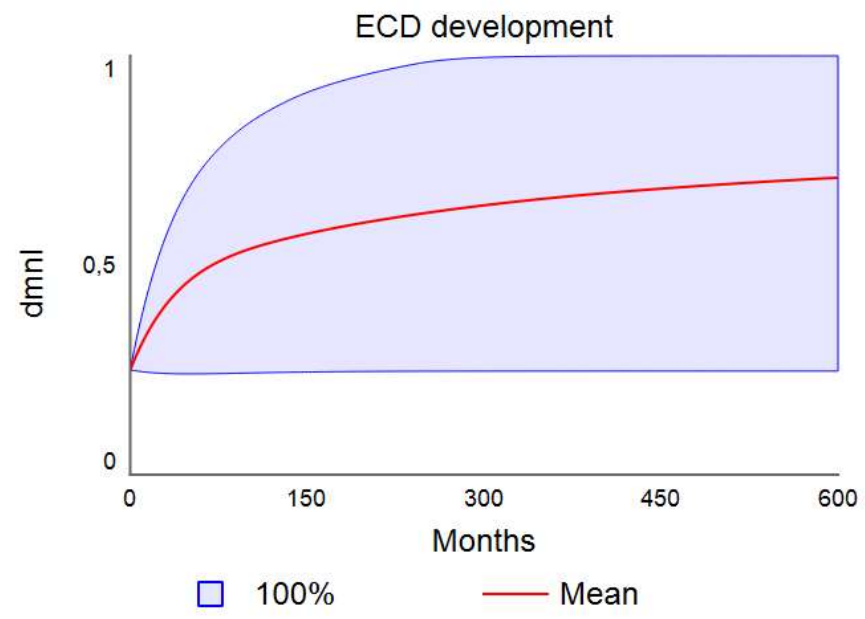

Source: Elaborated by the author.

\subsubsection{SCENARIO 4: PARENTAL CAPABILITIES}

The scenario tests a popular policy. In theory, teaching skills to parents, such as reading to children, playing and providing emotional support, may increase levels of selfregulation (by buffering stress, for instance) and general capabilities (by stimulating the development of language, cognition and related skills). We increased the level of the policy in year 15 of the simulation. However, the model shows only a very modest increase for parental capabilities and no change in the trend of the remaining variables, in comparison with the base run (figure 29). 
FIGURE 29. SIMULATION FOR POLICIES TO INCREASE PARENTAL CAPABILITIES

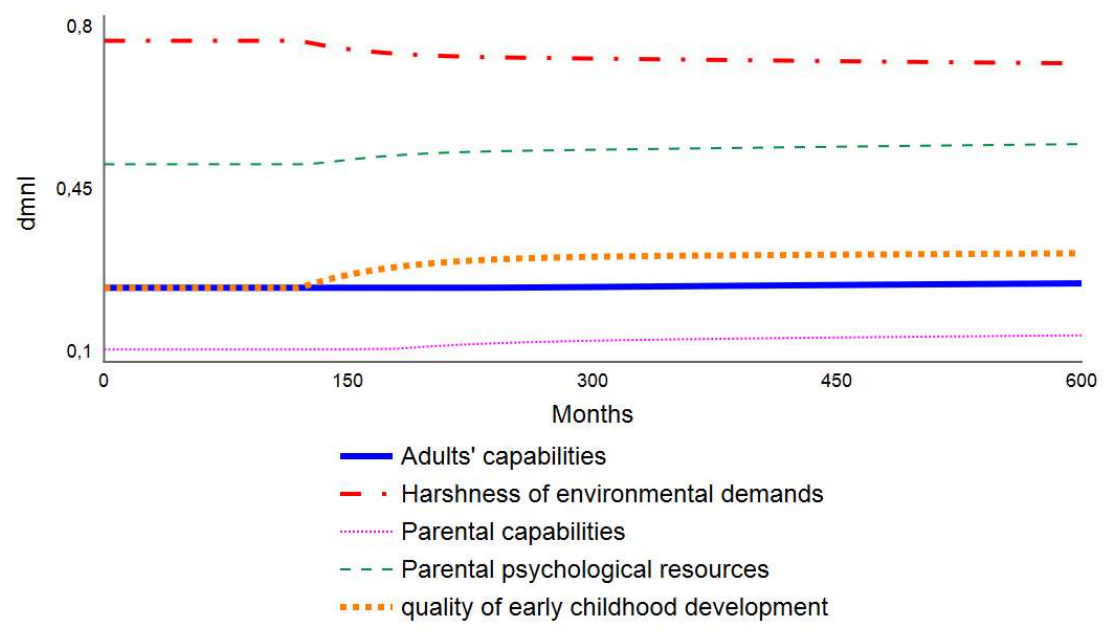

Source: Elaborated by the author.

Hence, the model is strongly insensitive to variations in the level of this policy. It is important to consider that the stock of parental capabilities in the model responds to three key variables: a "normal" or "natural" indication of those capabilities (which is a direct function of adults' capabilities), the effects of psychological resources and the level of the policy. Parents with low educational levels (i.e., low capabilities, broadly speaking) tend to have a poor repertoire of parental practices, such as reading to children and providing adequate stimulation. Moreover, in contexts, such as poverty, that are marked by stress and unpredictability, one can expect low levels of psychological resources (mainly attention and energy) available to be dedicated to those activities. Thus, when the policy is in place, it interacts with all these constraints, and they may limit its efficacy.

Sensitivity analysis confirms this intuition (figure 30). However, we should note the viability of this policy could increase in contexts less extreme than the one represented by the base run of the model, even if it is insufficient to break the poverty cycle. 
FIGURE 30. SENSITIVITY ANALYSIS FOR EFFECTS OF POLICIES TO INCREASE PARENTAL CAPABILITIES

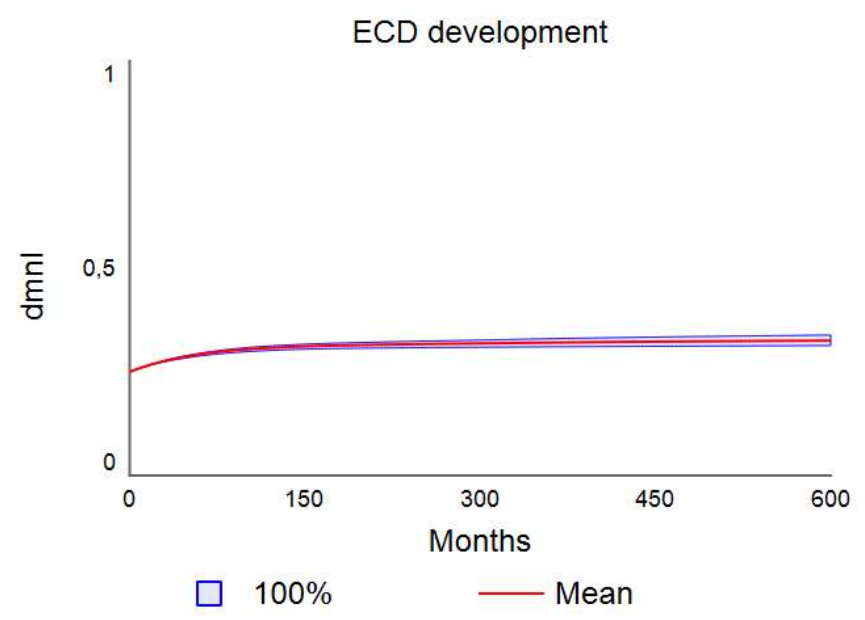

Source: Elaborated by the author.

\subsubsection{SCENARIO 5: INVESTMENT IN HUMAN CAPITAL}

The city of Sobral in the Brazilian state of Ceará became known nationally for the positive results it obtained in its educational system. In one decade, starting in 2005, the city rose from $1,366^{\text {th }}$ position to lead the Brazilian rankings for educational performance in the first years of schooling, without increasing significantly the level of public spending on education (Sobral, n.d.). While we could not locate any research or data regarding the quality of early childhood development in that city and thus cannot make any claim about it, it seems clear that the focus of the intervention was on older children (Barros, 2013). The implicit assumption in the intervention was its sufficiency to break the poverty cycle. Hence, we test this scenario through a progressive increase in the level of policies for human capital starting in year 10 and reaching the maximum level in year 20 of the simulation. All variables in the model show a marked improvement (figure 31). 
FIGURE 31. SIMULATION FOR POLICIES TO INCREASE HUMAN CAPITAL

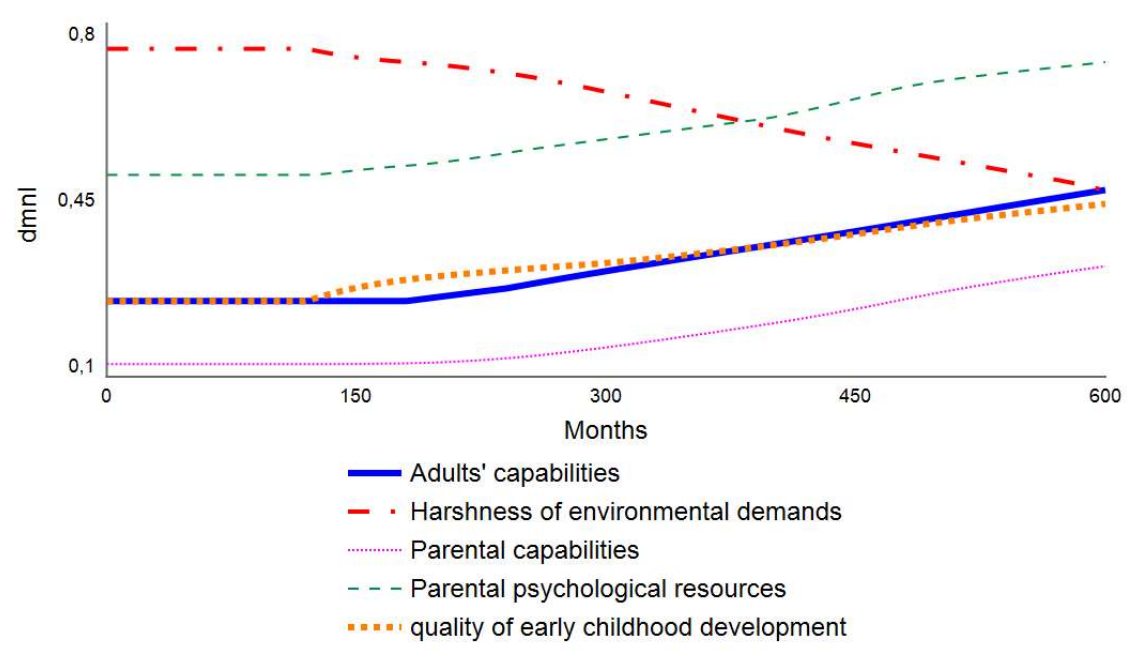

Source: Elaborated by the author.

The policy, which at its maximum level implies total priority given to education (as in the case of Sobral), produces positive results. In the model, it has the disadvantage of acting on low levels for the basic stocks (self-regulation and children's capabilities) in the initial years of life. Thus, it creates conditions for the attainment of children's potential, but that potential would already be compromised in contexts of low human development.

Hence, we should consider the results of the simulation with three important caveats in mind. First, the policies may not be cost effective. Although better management of public educational systems may produce strong results, as was the case in Sobral, the bulk of the evidence suggests that is cheaper for society to intervene sooner than later, and the sooner, the better (Heckman, Moon, Pinto, Savelyev, \& Yavitz, 2010; Heckman, 2013). In the case of Sobral, the program focused on the first years of education, but an extended and more comprehensive intervention (including the health aspects of human capital) would certainly increase the costs. Second, the time horizon of the simulation is very long (50 years), and it is doubtful whether a society can wait such a long to reap the benefits of a single policy. The costs of living in a society with low levels of human development are very high, as we will discuss in the next chapter. Third, and critically, when we extend the simulation over a few more decades, we verify that the quality of ECD development stabilizes around the value of 0.65 . In other words, according to the model, a high-quality intervention to increase human capital will create better conditions for the development 
of children's potential, but the ceiling for that potential is determined beforehand, in the period encompassing gestation and the first years of life.

We tested the sensitivity of the model to the effects of policies designed to increase human capital (figure 32). In the model (see appendix 3), we assumed that such policies could increase the initial level of ECD development by a maximum factor of 1.35. Nevertheless, when the sensitivity test relaxed this assumption, we were able to gauge the response of the model to policies that arrive later in the process of development. The results suggest a ceiling for those interventions.

FIGURE 32. SENSITIVITY ANALYSIS FOR EFFECTS OF POLICIES TO INCREASE HUMAN CAPITAL

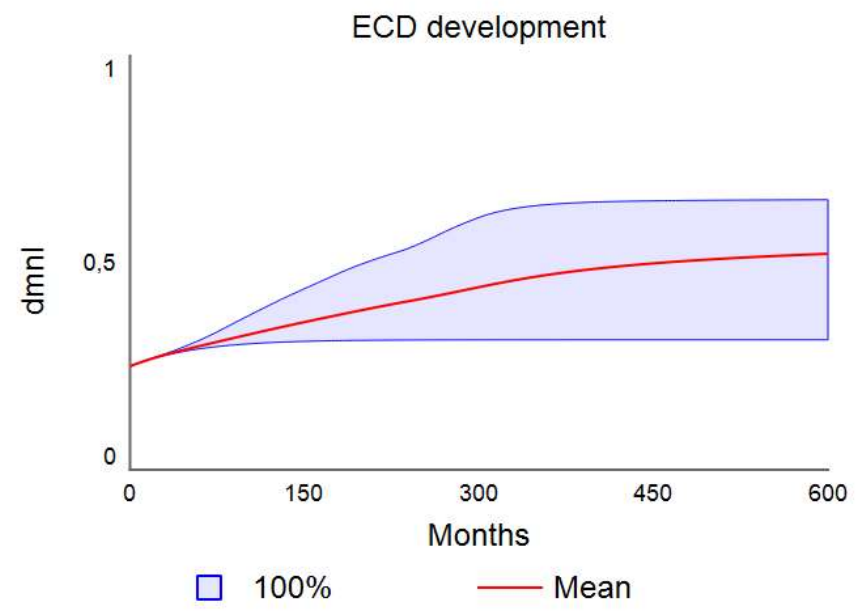

Source: Elaborated by the author.

\subsubsection{SCENARIO 6: ALLEVIATING ENVIRONMENTAL HARSHNESS}

Since the second half of the last century, most countries in the Western world have witnessed material progress. Over time, public budgets increased, and social spending followed the same trend. The situation was no different in Brazil, where, especially following the 1970s, an increasing share of governmental budgets started to be spent on the poor. Housing, urban development, transportation, health care and education (albeit of low quality) started to occupy the attention of public policy makers, in particular after the 1988 Constitution. The poor demanded better public services and, after the democratic 
transition in the country, they could punish (or reward) politicians in elections (Mendes, 2014); voting is mandatory in Brazil.

The model assumes that some policies can attenuate the harshness of environmental demands on the poor, decreasing the levels of stress and uncertainty in their lives. We simulate the effects of high levels of social policies starting in the year 20. Harshness is indeed attenuated (figure 33), and parents' psychological resources increase, but that is not sufficient to influence the main trends of the other variables. Sensitivity analysis (figure 34) suggests this is an intervention with limited effects, according to the model. Nonetheless, we note that these policies may have the merit of reducing the stress in the already difficult lives of the poor. In addition, their effects may spread to other contexts not considered here, such as family conflict and work productivity.

FIGURE 33. SIMULATION FOR POLICIES TO ATTENUATE ENVIRONMENTAL DEMANDS

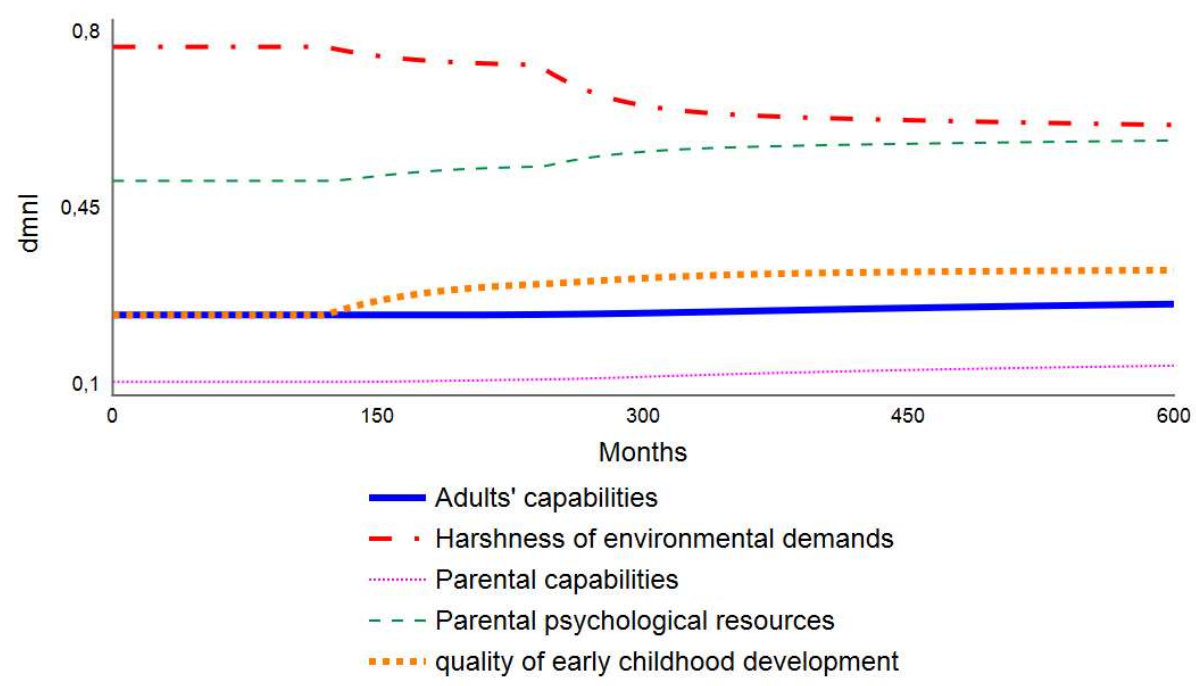

Source: Elaborated by the author. 
FIGURE 34. SENSITIVITY ANALYSIS FOR THE EFFECTS OF POLICIES TO ATTENUATE ENVIRONMENTAL DEMANDS

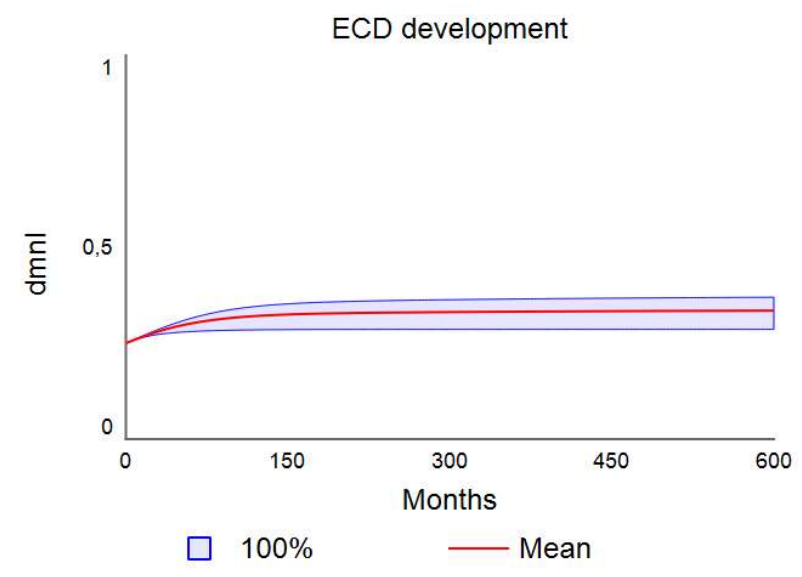

Source: Elaborated by the author.

\subsubsection{SCENARIO 7: COMPREHENSIVE POLICIES}

High-quality social interventions may come in degrees. It is unrealistic to expect governments to implement in a short time the maximum levels of all possible policies that have an influence on ECD development. Modern states suffer from fiscal constraints and competing demands from dominant social actors. Thus, depending on the institutional environment in a society (i.e., the prevalence of extractive versus inclusive institutions see Acemoglu \& Robinson, 2013) and on the perceived importance of ECD policies (something more amenable to change than the former factor), one can expect different combinations of social policies with different levels of quality and comprehensiveness. We tested three levels of comprehensive policies, all starting progressively in year 15 of the simulation and reaching their maximum levels in year 25 (maintaining the base run as a control scenario). To avoid graphical clutter, we report in figure 35 only the results for the focal variable of interest (quality of ECD development).

We first tested the effects of three distinct levels of a combination of policies that individually appeared to be most promising, according to the previous simulations: prenatal care, childcare and investment in human capital. We kept the levels of the remaining policies at their median levels (level 3 in the range of 1 to 5). We named the three comprehensive policies total commitment (reaching maximum levels in year 25), 
societal awakening (reaching level 4 in year 25) and imperfect solution (remaining at the median levels). Even the latter policy, we should note, represents a significant departure from current policies in Brazil and other underdeveloped countries.

We tested two additional policies. The fourth one maintained the same parameters adopted for the societal awakening policy, while setting the parameters for the remaining variables to their lowest levels (1). We named this the intuitive policy, since focusing on prenatal, childcare and human capital may seem sufficient to break the poverty cycle. Finally, we took the same intuitive policy and increased the levels for income transfer policy so that the latter reached the median value (i.e., 3) after year 25 . We called this the intuitive + policy, and it reflects the belief that income transfers are important in addressing the problem.

Figure 35 presents the results. As expected, total commitment is the policy with the greatest potential, but societal awakening is also sufficient to produce high levels of ECD development throughout the simulations. The remaining policies do not break the cycle of low human development within the time horizon of the simulation. Nevertheless, we note that extending the horizon of the simulation shows that they produce quality of ECD development in the high range (close to 0.8 ) after 75 years. This is a remarkable achievement (even though it takes a long time to occur) in comparison with the base run scenario, which leads the focal variable to saturate above the value of 0.32 for the rest of the simulation. 
FIGURE 35. SIMULATION RESULTS FOR FOUR LEVELS OF COMPREHENSIVE POLICIES

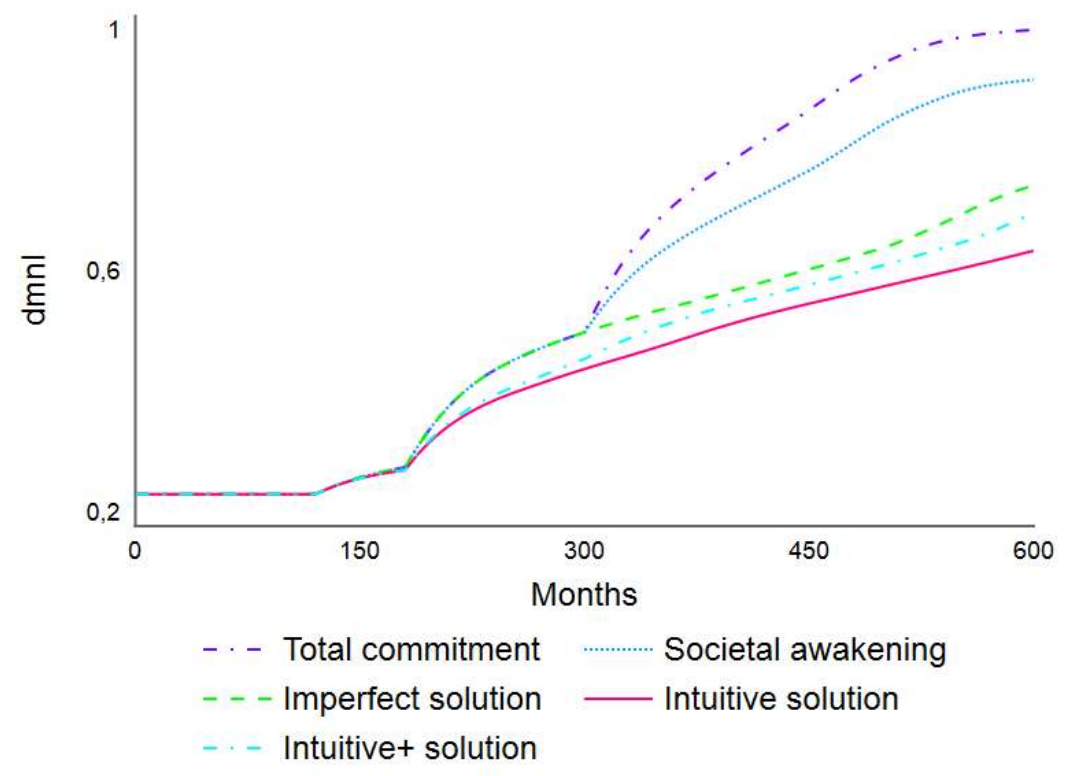

Source: Elaborated by the author.

We also ran the two more effective solutions (total commitment and social awakening) under conditions of greater environmental instability (50\% more than the former runs, in which the variable is set to be neutral). This is an extreme scenario, since it assumes great instability during the entire 50-year period. The impact on the evolution of the curves is significant, but the trend toward breaking the cycle continues unabated and, by the end of the simulation, the focal variable remains close to the scenarios without strong instability. Indeed, a sensitivity analysis confirms this finding, showing that both policies are resilient to environmental instability.

What the simulations in scenario 7 suggest is the need for moderate to high levels of comprehensive social spending on ECD development. Intuitive solutions may require a very long horizon of time to generate a perception of progress, which creates a barrier to their political viability. On the other hand, it seems far-fetched to expect a country with extractive institutions to implement a strong reorientation of social spending in only a few years.

Table 10 presents a summary of the results produced by the model for the seven scenarios. 
Table 10. Comparison of results

\begin{tabular}{|c|c|c|c|}
\hline Scenario & $\begin{array}{l}\text { How does ECD } \\
\text { development } \\
\text { respond to the } \\
\text { policy? }\end{array}$ & $\begin{array}{l}\text { Does the policy } \\
\text { break to curse } \\
\text { of poverty? }\end{array}$ & $\begin{array}{l}\text { Does the model } \\
\text { respond strongly to } \\
\text { the levels of policy } \\
\text { (according to } \\
\text { sensitivity } \\
\text { analysis)? }\end{array}$ \\
\hline 1. Income transfer policy & Increase & No & No \\
\hline 2. High-quality prenatal care & Increase & No & Yes \\
\hline 3. High-quality childcare & Increase & Yes & Yes \\
\hline $\begin{array}{l}\text { 4. Increase in parental } \\
\text { capabilities }\end{array}$ & Slight increase & No & No \\
\hline $\begin{array}{l}\text { 5. Investment in human } \\
\text { capital }\end{array}$ & Increase & No & Yes \\
\hline $\begin{array}{l}\text { 6. Attenuation of } \\
\text { environmental demands }\end{array}$ & Slight increase & No & No \\
\hline $\begin{array}{l}\text { 7. Comprehensive } \\
\text { interventions }\end{array}$ & Strong increase & Yes & - \\
\hline
\end{tabular}

\subsection{DISCUSSION}

Many researchers in the field of early childhood development (e.g., Chaudry \& Waldfogel, 2016) argue in favor of multicomponent strategies to address the problem of low human development. Typically, such strategies include paid parental leave, income transfers, high-quality childcare and home visits. The Caped model and the simulations reported here suggest that these common recommendations are in the right direction.

However, there have been very few interventions based on a comprehensive set of policies. There have been several small-scale programs, combining at best two elements (e.g., income transfer and household visits). It has been impossible so far to assert that a given combination of interventions is sufficient or even necessary to break the transmission of low human development across generations. One can make the case that the set of comprehensive social policies provided by the Nordic states speaks in favor of 
the comprehensive policies supported by the simulations reported here. However, this comparison may be misleading, as the entire Nordic "solution" is the result of historical processes that prevent strong assertions about causality, particularly in the absence of natural experiments. In a similar vein, many interventions testing the effects of specific policies occur in different socioeconomic contexts, making comparisons difficult without comprehensive meta-analysis studies.

Nonetheless, the results from the evaluation of different programs and from diverse streams of research strongly suggest that there are necessary causal drivers of full human development, at least in early childhood. These drivers are adequate prenatal care, attention, love and stimulation from caregivers, stability (structure) in the immediate environment and moderate levels of stress combined with adequate support (buffering), preferably from mothers.

A valid criticism on the Caped model is that it is not operational (there are no hard stocks), since it focuses only on intangibles. However, the intangibles can be measured, and intangibles such as capabilities have always been considered as essential in the discussion about human development. We are confident that the model's dynamics capture the essence of the replication of low human development.

Moreover, some intangibles have been considered in the system dynamics literature as worth modeling even when they are loosely defined. Forrester (1969), for instance, refers to the concept of life space, advanced by the founder of social psychology Kurt Lewin, claiming it is a set of level variables subject to being changed by various rates. Lewin indeed discussed many of its original propositions embedded in what one can easily recognize as system dynamics thinking. In fact, if Lewin's work were portrayed in the language of system dynamics, most (if not all) of it would amount to a set of relationships among intangible constructs. However, the definition of life space in Lewin (1948:2010) is imprecise, encompassing the person and the "psychological environment" as it exists for him or her. The point is that it is possible to model intangibles with a high level of abstraction, even in the case of loosely defined concepts such as life space. (Of course, removing ambiguities must be a goal when defining such constructs). While the implied level of abstraction in the model will still be high, we argue that it is more important to evaluate whether it captures the essence of the phenomenon and whether it is useful for the purpose it was designed for. 
An important caveat in proposing comprehensive ECD policies concerns their costs. According to the World Bank (2011b), although the available evidence from more limited programs suggests that ECD policies have favorable rates of return, there is uncertainty regarding both the costs of full-scale programs (in which staffing tends to represent the lion's share of spending) and their full range of potential benefits. Many of the latter are diffuse and difficult to compute and monetize. As the World Bank suggests, estimating the full benefits requires the development of multi-domain frameworks, which, in turn, requires time-series data for full analysis.

In sum, the model and the reported simulations represent an approximation to the core dynamics involved in the replication of low human development, but better measures are needed to understand which policies have greater potential to break that cycle. The model presents some candidates, in particular the combination of comprehensive policies.

\subsection{CONCLUSION}

We developed a system dynamics model, the Caped model, with the goal of identifying crucial loops for the replication of low human development across generations.

The simulations suggest the need for comprehensive social policies in order to create social ecosystems favorable to human development. The model hence contributes to the literature by replicating insights from different researchers in the field of human development in a quantitative fashion. Schweinhart (2003), for instance, recognizes that high-quality preschool programs are only part of the solution, arguing in favor of broader social interventions, including affordable housing, adequate health care and improved educational opportunities at all levels. Just as Forrester (1969) refers to cities as socioeconomic converters, we can conceive of the repertoire of social policies as socioeconomic converters, whose efficacy depends on levels of spending, organizational capabilities (mostly from the public sector) and appropriate selection of target populations. In Brazil, for instance, most social policies do not target the poorest segments of the population (on the contrary), and this contributes to the replication of the diverse social problems in the country (Mendes, 2014).

Few studies address the replication of low human development with methods that account for feedbacks, delays and nonlinear relationships between variables. The Caped model may also contribute to the literature on human development by identifying constructs that 
have not been measured consistently, in particular the harshness of environmental demands and the bundle of adults' capabilities.

Regarding the limitations of our findings, a small model necessarily simplifies the system under analysis, which leads to loss of nuance and complexity. For instance, the model does not address implementation issues and key political processes involved in setting the agenda. One question that needs to be addressed is this: if the academic literature has been accumulating strong evidence in favor of investing in early childhood, why have governments throughout the world been so slow to change the social structures that replicate poverty? Of course, the reallocation of public spending can elicit political resistance, especially in countries with constrained fiscal budgets and extractive institutions. In addition, the transition from academic knowledge to public policy is usually slow and haphazard. However, considering the extremely relevant consequences of children growing up in hostile social ecosystems, such as higher incidence of crime, lower work productivity and lower levels of economic development, the lack of collective (societal) learning remains a puzzle. In this sense, games and simulations (such as the one used in the process of validation) can serve as tools in the process of translating academic knowledge and changing mental models.

We also circumscribed the model to the vulnerable segments of the population. We did not address interspatial mobility. No intervention in a complex social system is immune to producing effects beyond the context in which it operates. For instance, a significant quality differential in childcare or an educational subsystem in a specific state or area is bound to attract people from other areas, creating pressures on those subsystems - a timetested realization made by Forrester (1971) and Meadows (2002a). The conclusion is that the sea must rise in the country as a whole in order to lift all boats; any significant improvement in local systems will otherwise be short-lived.

A significant limitation is the lack of balancing feedback loops in the model. Clearly, the level of social spending on the poor has not been growing in Brazil, for historical and distributive reasons. The literature on institutions (e.g., Acemoglu \& Robinson, 2013; North, 2005) shows that the prevalence of extractive institutions in a country leads to most of the social spending being directed toward privileged elites.

These limitations serve as suggestions for future developments of the model. Future studies may also expand the model's boundaries to incorporate aging chains of different 
segments of the population. Agent-based models are another way to test the intertemporal effects suggested by the model.

The persistence of low human development levels in underdeveloped and developed countries remain one of the major challenges of modern societies. Typical hallmarks of complex systems underlie the occurrence of the phenomenon, such as path dependence, delays and feedback loops. Such hallmarks also imply a curse of opaque feedback. This hinders collective learning, in the sense that societies suffering the diverse consequences of low human development have nevertheless been incapable of diagnosing the problem properly and thus have been unable to reorient their social structures.

However, there is no escape from this problem. As the Caped model illustrates, change takes a long horizon of time, and it depends on interventions at the proper leverage points in the system. Self-regulation and children's general capabilities are critical stocks that must reach minimum levels if a society hopes to break the intergenerational replication of poverty. 


\title{
6. THE ROOTS OF THE BRAZILIAN SOCIAL HOLOCAUST
}

There are no utopias in our social systems. There appear to be no sustainable modes of behavior that are free of pressures or stresses. But there are many possible modes and some are more desirable than others. (Jay Forester)

\begin{abstract}
The chapter discusses the causes of the replication of low human development in Brazil, paying special attention to extractive institutions. It also discusses the consequences of living in a very unequal society and the reasons the status quo does not change, in particular the narrative (mindware) control exerted by the beneficiaries of historical rent-seeking processes. Brazil has been trapped in an unsustainable dynamics, in which limits to growth have been reached and negative consequences can be expected in the near future. The chapter presents three scenarios representing possible outcomes of the evolution of current dynamics, including a full-blown, Greek-style crisis.
\end{abstract}

Keywords: rent-seeking, institutions, human development, system dynamics.

\subsection{A TALE OF RENT-SEEKING AND DISTRIBUTIONAL CONFLICT}

This chapter builds on the findings of the previous one by looking at the broader, longterm consequences of neglecting early childhood. We discuss the Brazilian case, which epitomizes a situation common in Latin American countries: the existence of institutions that perpetuate cycles of low human development, affecting sizable segments of the population.

The consequences are well known: social inequality, crime, low worker productivity, low economic growth and a life of closed opportunities for children born to poor families. In fact, a hallmark of social inequality is its disproportional burden on children.

We draw on the work of a relevant sample of economists who have investigated the dynamics of the fiscal budget and rent-seeking in Brazil in recent decades (Giambiagi \& Schwartsman, 2014; Lisboa \& Zatif, 2013; Mendes, 2014).

Mendes (2014) identifies three root causes behind the sluggish performance of the Brazilian economy in recent decades. The first cause is the process of democratization in 
the 1980s, which occurred in a social and economic context of strong inequality. The second cause is the deplorable social conditions for the poor during that process, which called for immediate action from the state. The third cause is the existence of deeply entrenched privileges for the higher social classes, manifested in classic rent-seeking processes.

Unequal societies are characterized by a great divide between the great mass of poor people and a small, rich elite. Throughout Brazilian history, the richest groups have utilized their intertwined economic and political power to create, amplify and maintain their privileges (Mendes, 2014). Indeed, there is a rich body of theoretical inquiry into the role of institutions in enabling extractive structures such as the ones observed in Brazil. North (2005), Engerman and Sokoloff (2006) and Acemoglu and Robinson (2013) are among the main authors who have identified the serious inequalities at the beginning of Latin American colonization as the foundation for the development of extractive institutions. Such institutions traditionally protect privileged members of local elites at the expense of social mobility. Economic institutions, indeed, shape opportunities to own land, to obtain schooling, to vote, to obtain capital, to borrow. Institutions have more than an economic flavor; they are also social in nature. We note that in unequal societies the poor also face barriers in gaining access to political channels, social networks and other channels for upward social mobility. The resulting broader institutional framework often leads to what Bowles (2006) calls institutional poverty traps.

Examples of elite privileges in Brazil include subsidized credit to specific groups, commercial protection for national industries, differential access to a permeable judiciary system and a generous pension system for civil servants. Such privileges weaken the very institutions that would be essential in a sustainable process of economic growth. At the same time, they have over time caused increasing, unsustainable levels of public spending (and a growing tax burden), thereby curbing the potential for further growth in the economy (Mendes, 2014).

Mendes (2014) summarizes the main problem as a runaway appropriation process that spiraled out of control. The transition to democracy in the 1980s opened up diverse opportunities for rent-seeking behavior in a context of fragile institutions. In socioeconomic ecosystems prone to rent-seeking, such as Brazil, privileged groups strive to expand their benefits at the expense of the general collectivity. The more influence and power a group has, the more it can increase its privileges. Other groups work 
simultaneously to garner benefits. In addition, as Lisboa and Latif (2013) remark, rentseeking, once established, is difficult to eradicate, as its beneficiaries fight hard to maintain their privileges, while the entire dynamics and the roots of its consequences are absolutely opaque to society.

As expected, in natural and social systems, positive feedback loops eventually reach a limit. In the case of the Brazilian economy, this limit has been the amount of taxes that society is willing to pay to sustain runaway mechanisms of appropriation of the public budget (Mendes, 2014). The limits also appear in the low managerial capabilities of government branches, which lead to unsatisfactory levels of public service and increasing social unrest. Not only does public spending favor the richest segments in unequal societies, but also another scarce resource, policy makers' (effective) attention to the needs of the poor, is typically lacking in such contexts. In countries such as Brazil, the public administration framework has all the hallmarks of inefficient models: weak managerial capabilities, low focus on results and high levels of sterile bureaucracy (see Kettl, 2000, for a comprehensive review of public administration frameworks). Public spending in Brazil is not only socially perverse but also inefficient (Giambiagi \& Schwartsman, 2014). Most public policies ignore opportunity costs and the need for evidence-based evaluation.

Mendes (2014) observes that democratization in Brazil led to greater political interest in the poor, considering their reinstated voting rights. This interest, coupled with severe deficiencies in social policies that had accumulated over decades, led to an expansion in social programs targeting the poor with increased public spending. This new source of spending, however, did not displace the spending that had benefited the richest segments of the population. At the same time, several organized middle-income segments, such as unionized industrial workers, retirees and civil servants, increased the pressure for more benefits. The resultant interplay of all these forces amounted to a distorted redistributive game and led to unsustainable growth in public spending. The consequences included persistent low levels of public and private investment and stagnant productivity.

Another result of the increasing pressure for resources was a progressive decay in the quality of the taxation system. As tax revenues were incessantly chased to keep pace with runaway spending, Brazil rapidly reached levels of tax burden significantly above levels observed in countries with similar incomes. From a complexity point of view, the fact that a taxation system approaches its limits while the underlying pressures continue to 
accumulate may lead to a state of system-wide criticality, in which relatively trivial external events or policy changes can provoke far-reaching reactions, such as collapse of current structures and larger scale "avalanches" (Miller, 2015). One element that speaks in favor of such criticality is the evolution of Brazilian public debt, which is accelerating over the last few years in direction to unsustainable levels.

Nevertheless, the most serious consequence of the Brazilian distributive conflict is lack of resources (including managerial ones) to invest in the right priorities. Over time, the country has been paying the price for insufficient investment in the true drivers of productivity growth, such as public (basic) education. Moreover, as we will see, the predominant mental models in Brazil tend to downplay the importance of the redistribution of public resources.

In such a scenario, governments - and the state as a symbolic social actor - are agents of social injustice. It is a true vicious cycle: the economy cannot grow at high, sustainable rates because governments spend most of the public resources on the wrong priorities, dissipating the available resources through the various channels created by the pressure of privileged segments. The consequences of this distorted ensemble of institutions and political structures are concrete and very substantial for societies. Since this is the case, why does the status quo go unchallenged?

We propose four major reasons for the permanence of the status quo. First, the feedback from public policies is, as a rule, opaque, delayed and biased (Forrester, 1969). Second, individuals internalize cultural and social norms, rationalizing the patterns of unequal social structures (Bourdieu, 1987; Prilleltensky, 2008). Third, economic cycles may lead to improvements in the lives of the poor, masking the effects of deeply entrenched unequal social structures. Finally, those who benefit from the status quo control more than the political structures. They produce and disseminate strong narratives that elude the enactment of policies capable of challenging current structures and increasing social well-being in the long term.

However, no status quo is free from tensions. As we saw in chapter 2, fissures in the status quo arise in response to the confluence of the diverse spheres that comprise human life. Democratization in Brazil, following a long period of dictatorship, gave formal voice to the poor through mandatory voting. The democratization itself reflected a common trend occurring in similar Latin American countries (which had experienced the same authoritarian cycle decades before). Political voice, coupled with unfulfilled social 
demands from the poor (which had accumulated during previous years), contributed to the unsustainable dynamics we have described. Runaway rent-seeking processes, on the other hand, seem to be the major factor expanding the fissure in the status quo. Given the underlying dynamics, we can certainly expect disruptions in the status quo in the coming years.

The chapter proceeds as follows. First, we expose the reversed Robin Hood nature of the Brazilian state. One of its hallmarks is its elusiveness; its nature is difficult to identify if one taps into the collective mental models manifested in the public discourse. Next, we discuss another factor that contributes to obscuring the diagnosis of the Brazilian problem, which is the occasional contribution of economic growth and institutional development to amelioration of the lives of the poor. We show that the lives of Brazilians have been improving in recent years, even if the progress is modest. Next, we discuss one major consequence of a society dominated by extractive institutions, which is a permanent sense of societal discomfort. In this sequence, we explore how political narratives obscure the root causes of that discomfort and how "band-aids" are employed to tackle it. Finally, we present a system dynamics model that portrays the major feedback loops identified in the literature reviewed in this chapter, discussing three possible scenarios for the coming years.

\subsection{A REVERSED ROBIN HOOD STATE}

In a country where social inequality prevails, one can expect the existence of a social ecosystem that closes most doors to upward social mobility. In Brazil, indeed, there are few opportunities for socioeconomic inclusion (Barros, Henriques, \& Mendonça, 2000). An adequate metaphor, we posit, is the assignment of a train ticket to every child born in the country. Poor children receive a ticket to a poorly maintained train that runs on poorly maintained tracks. Their chances of boarding better trains running on better tracks decrease exponentially at each train stop.

Indeed, the hallmark of poverty in countries such as Brazil is the disproportionate burden placed on the shoulders of poor children. Most social spending in Brazil and other Latin American countries favor the old, in particular through pensions systems (Bolle, 2017; Giambiagi \& Schwartsman, 2014). Public policies aimed at early childhood (between birth and five years of age) were rare before the 1980s, and children from the most 
vulnerable social segments received the smallest share of social spending in Brazil (Campos, 1992). There is little data from that time, but it is safe to assume that poor children have never received adequate attention from public budgets in the country. This low priority has manifested itself in the coverage of public childcare. Critically (see chapter 4 ), in 2015 only $25 \%$ of children up to the age of four were attending a childcare center, while those staying at home belonged mostly to lower-income families (IBGE, 2015b).

State policies, unsurprisingly, explain most social inequality in Brazil. Medeiros and Sousa (2013) found that one-third of the inequality is explained by factors such as the levels of salaries and pensions in the public system. In Brazil, the best paid jobs are typically in the public sector, particularly in sectors that tend to have disproportionate influence in extractive societies. Judges, prosecutors and individuals in charge of registry services are the public service elite in the country. The pension system is also disproportionately skewed toward civil servants.

The spending profile of the Brazilian state reveals the canalization of significant shares of public resources to the richest segments of the society (World Bank, 2017). In fact, two-thirds of tax revenue in Brazil is spent on social programs, but $85 \%$ of that revenue goes straight to the richest segments of the population through mechanisms such as the pension system (Giambiagi \& Schwartsman, 2014).

In an extractive society, analyzing the profile of spending is the key to understanding the persistence of strong inequality. However, taxation also tends to penalize the poor. About half of tax revenues in Brazil come from indirect taxes on consumption (shouldered disproportionally by the poor), while direct taxes, such as income tax, are very generous to the rich (Oxfam, 2017).

Figure 36 displays schematically the nature of the Brazilian state. 
FIGURE 36. A REVERSED ROBIN HOOD STATE

Source: Taxation

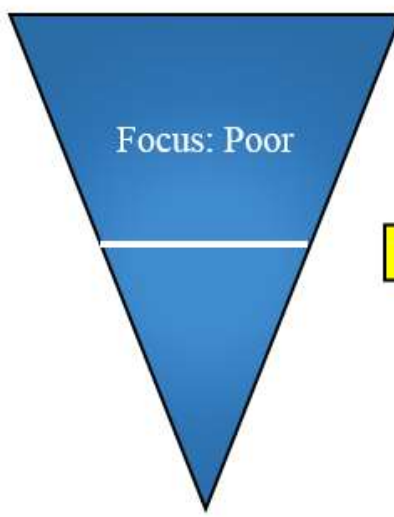

Spending

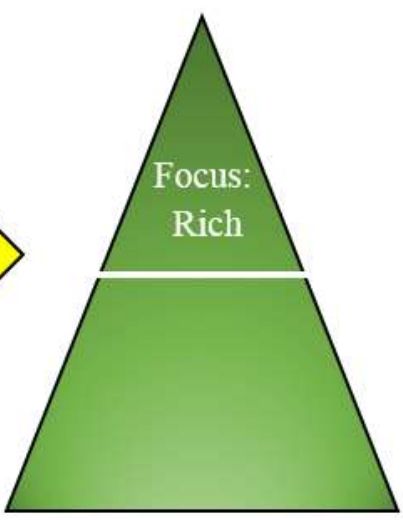

Source: Elaborated by the author.

The evidence reviewed by the World Bank (2017) is very clear: the accumulation of structural imbalances over recent decades has threatened the health of the fiscal budget, affecting the country's potential for growth and, consequently, for redistributive policies. Since the 1980s, public spending has been increasing at rates higher than GDP growth (Mendes, 2014). This imbalance has been accommodated through expansions in the public debt, whose trajectory has led to increasing concerns about unsustainability.

We can expect a strong association between the educational level in poor families and the Gini coefficient (Menezes Filho \& Oliveira, 2014). Education is, in fact, one of the main transmission chains of inequality in a society. In Brazil, although 98\% of children are in elementary school (BRASIL, 2014), they receive a service of poor quality. There is little emphasis, in practice, in creating high-quality educational systems. One consequence is a high drop-out rate - only five out of ten children complete high school in Brazil (IBGE, 2015a).

Indeed, perhaps nothing better epitomizes the inverted priorities in Brazil than the profile of spending on education. In a comparison with OECD countries in terms of PPP dollars, Brazil ranks among the lowest when it comes to spending on basic education. However, its level of investment in university education reaches European levels - the difference in spending per capita between basic education and university education amounts to $207 \%$, compared to $50 \%$ for the average of OECD countries (OECD, 2017b). In other words, Brazil spends too little on the system that serves the poor, whereas it spends like a wealthy 
country on universities that cater mostly to the rich (who do not pay tuition fees). In practice, this is a reversed Robin Hood state.

\subsection{IMPROVEMENTS IN THE LOT OF THE POOR}

Of course, economic growth can occur in extractive societies. In the case of Brazil (but also in other Latin American countries), external demand, such as the recent commodities boom that followed the rapid industrialization of China (The Economist, 2015), can induce strong effects in the country's economy, which supplies many valuable primary goods to international markets.

Ironically, as the founder of the system dynamics field, Jay Forrester, constantly remarked (e.g., Forrester, 1971), individuals often mistake symptoms for causes. Therefore, when economic activity grows following strong international demand, it leads to perceptions of progress and well-being, favoring the political actors in power, even when their contribution to the phenomenon is marginal or negligible. In fact, the recent progress in Brazilian social indicators results from a combination of internal and external factors. Examples of the former are the end of hyperinflation in the 1990s, increased spending on education and health following democratization, enactment of effective social policies (the income transfer program Bolsa-Família, in particular) and the haphazard development of better economic institutions.

We briefly discuss three social indicators that epitomize the recent progress in the lives of the poor: the Gini coefficient, the Human Development Index (HDI), and the incidence of teen pregnancy.

Figure 37 presents the evolution of the Gini coefficient in Brazil since 1976. The closer the coefficient to zero, the more equal the society. It is worth noting that, even after the recent improvements, Brazil still has a coefficient that is higher than the Latin American average (The Economist, 2016). By way of comparison, consider that almost all OECD countries have coefficients below 0.32. Given the combination of internal and external factors mentioned above, there has been progress in recent years, but it is still slight. 
FIGURE 37. EVOLUTION OF GINI COEFFICIENT IN BRAZIL (1976-2014)

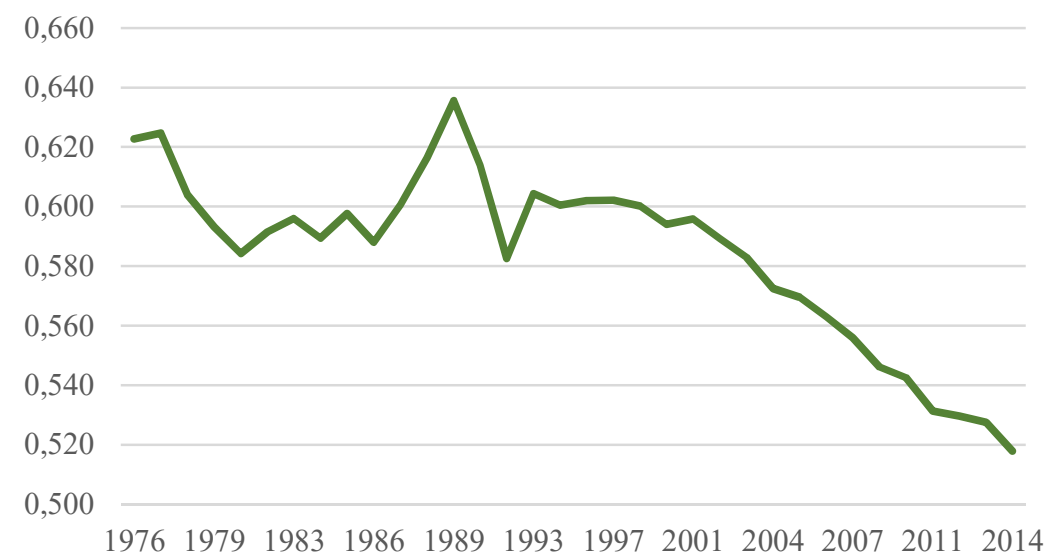

Source: Ipeadata (n.d.).

In terms of HDI (figure 38), Brazil ranks $79^{\text {th }}$ out of 188 countries (right below Azerbaijan), achieving a high level of human development (like most Latin American countries). In the version of the index that accounts for social inequality, IHDI, the country ranks $76^{\text {th }}$ out of 150 countries (United Nations Development Programme, n.d.a).

FIGURE 38. EVOLUTION OF HUMAN DEVELOPMENT INDEX IN BRAZIL

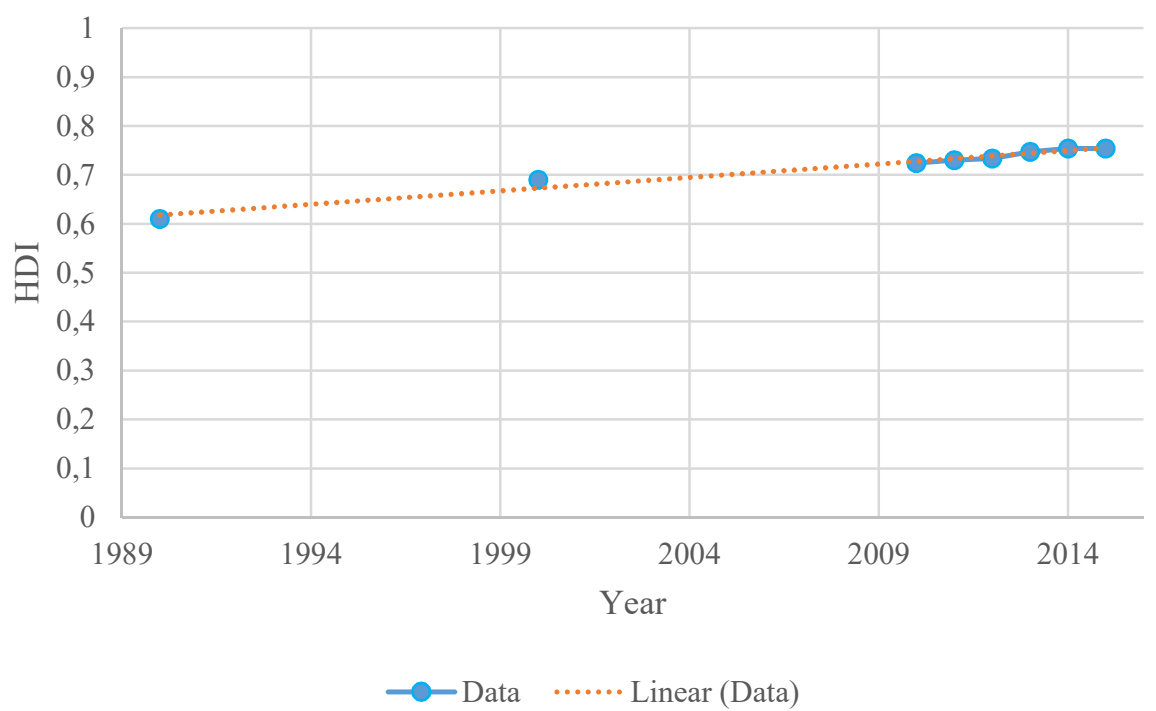

Source: United Nations Development Programme (n.d.a). 
However, we must note that the HDI index is an imperfect proxy for human development. In its educational dimension, for instance, it reflects only number of years at school and does not account for quality of schooling. While duration of schooling has been increasing steadily in Brazil, its quality remains very low, which may explain why worker productivity has not advanced in recent decades. Indeed, Brazil is among the lowest scoring countries in the PISA international assessment, ranking among the five worst performers (out of 70 countries) in mathematics and achieving similar results in the other competences measured by the assessment (PISA, 2016). Moreover, functional illiteracy reaches $27 \%$ of the Brazilian adult population, and only $8 \%$ are considered fully literate (IPM, 2016).

Finally, one of the hallmarks of the replication of the cycle of low human development in a country (see chapter 4) is the existence of high levels of teen pregnancy among the poor population. Compared to other countries, the incidence of teen pregnancy is still high in Brazil (World Bank, 2012), but it has nonetheless responded positively (albeit weakly) to the improvement in the lives of the poor in recent years (figure 39).

\section{FIGURE 39. EVOLUTION OF TEEN PREGNANCY IN BRAZIL}

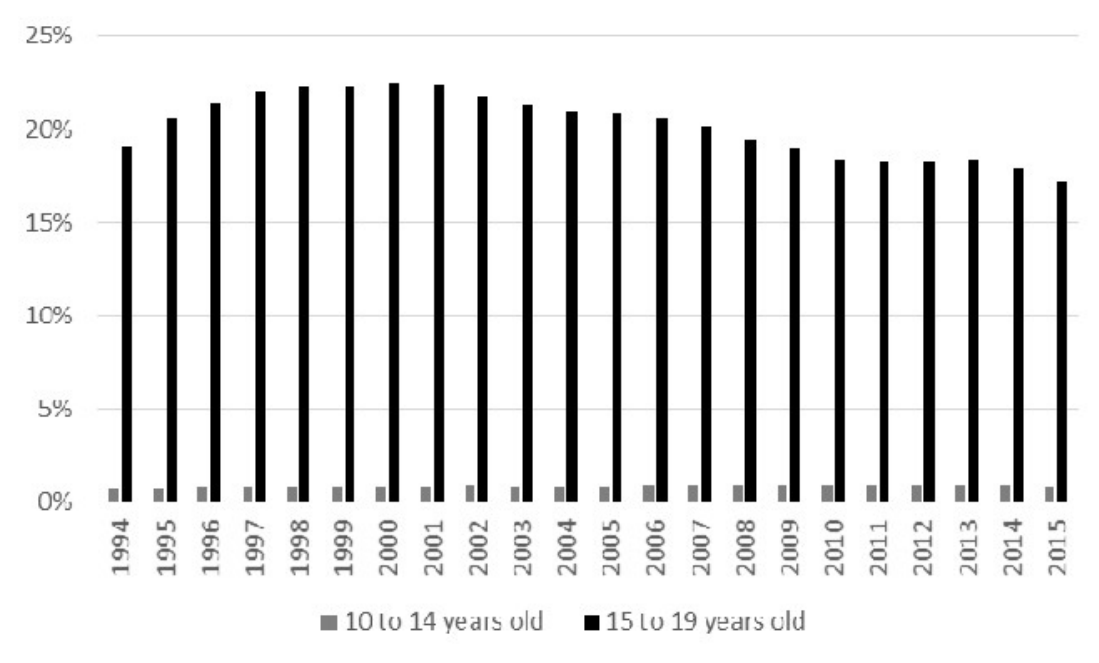

Source: SINASC (n.d.)

\subsection{THERE IS NOWHERE TO HIDE: SOCIETAL DISCOMFORT}

The consequences of an unequal society based on extractive institutions are extrapolated in the economic dimension. Increased levels of crime are one of the major social 
consequences. Startlingly, $10 \%$ of homicide victims in the world each year are Brazilian (Instituto Igarapé, n.d.). Brazil has the highest number of years of life lost to violence of any country affiliated with the World Health Organization, and the country has the fourth largest prison population in the world (Murray, Cerqueira, \& Kahn, 2013). Cerqueira (2010) found that variations in seven factors explain two-thirds of the evolution in homicide rates between 1980 and 2007 in the country: national income, inequality levels, the proportion of young males in the population, the availability of firearms, use of illegal drugs, numbers of police officers and rates of incarceration. Income and income inequality are among the major variables explaining the variance in most periods. Unsurprisingly, the patterns of violence observed in Brazil are also common to other Latin American countries, and the causes - social inequality, low economic growth, a high proportion of susceptible demographic groups and low state capabilities - are very similar (Soares \& Naritomi, 2010).

Unequal societies create social ecosystems detrimental to human development. Basic conditions for adequate social functioning, such as basic sanitation, housing, policing and transportation, are provided at insufficient levels. Fundamental public services such as health and education are usually of poor quality. In such a context, the cycle of low human development repeats itself across generations. For instance, two out of three young criminals in the Brazilian state of São Paulo live in households without a father; one-third of them have relatives with criminal records (Lobel \& Pagnan, 2016).

The problems caused by an unequal society are not always visible; however, they lead to a feeling of permanent societal discomfort. In Brazil, that discomfort is almost palpable, and it often surfaces in major surveys. Worry about crime ranks first or second in surveys of the population's major concerns, and even children report the highest levels of concern with crime compared to children from other countries (UNICEF, 2017).

Figure 40 presents the evolution of homicides in Brazil since the 1980s. We note that even in São Paulo, the state that has been acclaimed for reducing homicide rates in recent decades, robberies and thefts have consistently increased since the 1990s (Justus, Kahn, \& Cerqueira, 2016), creating a constant feeling of distress among the population. 
FIGURE 40. HOMICIDES IN BRAZIL (1980-2009)

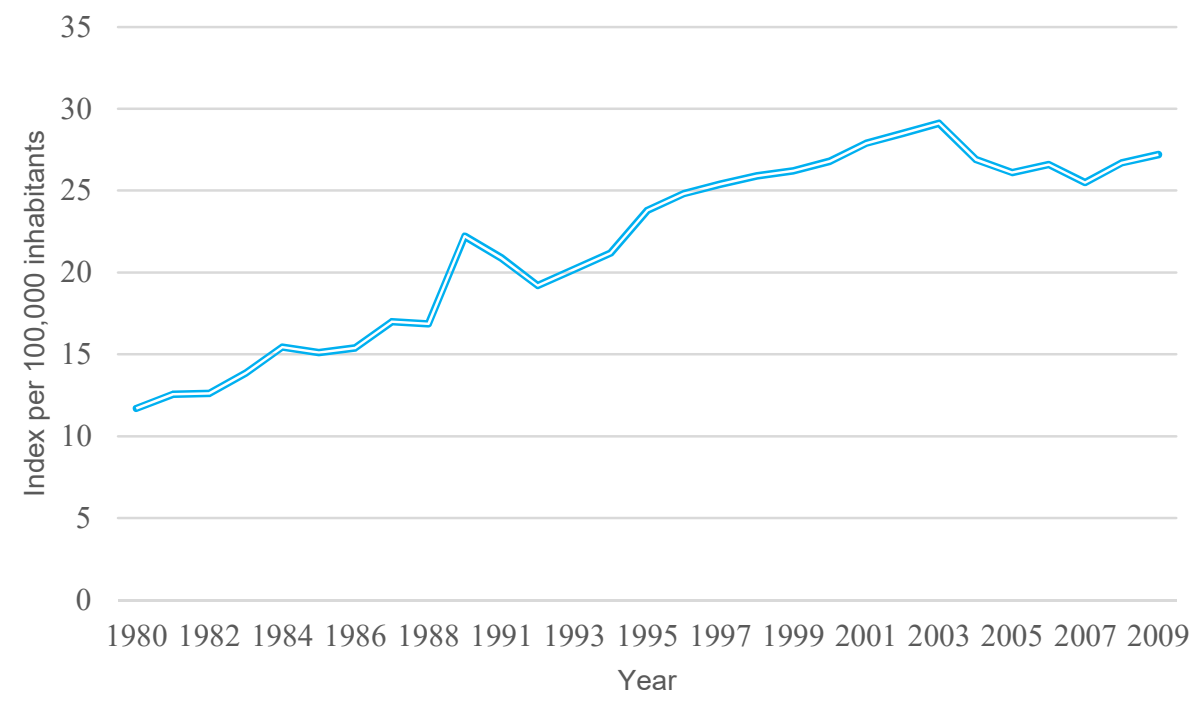

Source: IBGE (n.d.); Souza (1994).

Another consequence of an unequal society is the prevalence of distrust in social relationships. Interpersonal trust is the grease that facilitates exchanges in all spheres of social life, decreasing the costs of monitoring and enforcement (Knack, 2001). However, Brazil is one of the countries in the world where levels of trust are lowest. Within Latin America, Brazil exhibits the lowest scores for interpersonal trust and trust in institutions (Latinobarómetro, 2016).

Finally, another major consequence of inequality is stagnation in worker productivity (figure 41), which decreases the entire country's potential for economic growth. The stagnation in productivity is startling when one considers that the average number of years of schooling has increased steadily over the last three decades (IBGE, 2015a). By way of comparison, the average productivity in OECD countries is 3.5 times higher than in Brazil (The Conference Board, 2015). 
FIGURE 41. EVOLUTION OF WORKER PRODUCTIVITY IN BRAZIL

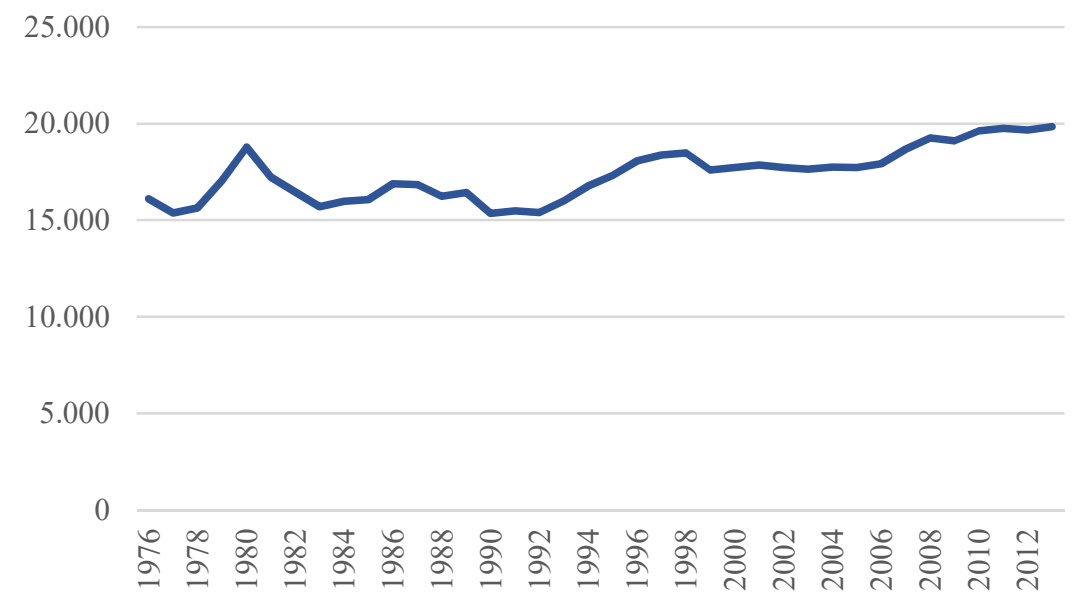

Source: The Conference Board (2015).

\subsection{THE MINDWARE WAR: NARRATIVES AND POLITICAL DISCOURSE}

A widely reproduced quotation from the influential economist John Maynard Keynes emphasizes how new ideas gradually dominate public discourse, eventually ruling the world. ${ }^{4}$ However, one thing that Keynes apparently got wrong in this respect is the role of vested interests in shaping the mental models shared in a society.

Shared mental models define how a society interprets reality. For every issue, there is an underlying stock of interrelated beliefs and schemas that defines its boundaries and, in the case of problems, constrains the set of possible solutions. We employ the term mindware, coined by Harvard educator David Perkins (Perkins, 1995), to refer to that stock of beliefs and schemas.

We adopt the premise that the state is more than an arbiter of distributive conflicts in a society. The state is an agent in change of perpetuating of the system (Turchin, 2016). Networks of economic and political interests occupy niches of power within the state and, once they have acquired power, they strive to maintain it, creating narratives that justify their privileges. Adopting that premise, in turn, leads to the proposition that social and

\footnotetext{
${ }^{4}$ The ideas of economists and political philosophers, both when they are right and when they are wrong, are more powerful than is commonly understood. Indeed the world is ruled by little else. Practical men, who believe themselves to be quite exempt from any intellectual influence, are usually the slaves of some defunct economist. Madmen in authority, who hear voices in the air, are distilling their frenzy from some academic scribbler of a few years back. I am sure that the power of vested interests is vastly exaggerated compared with the gradual encroachment of ideas. (Keynes, 1935, p.383).
} 
economic sectors that benefit from rent-seeking continuously work to shape the mental models, or the mindware, that constrain the terms of public discourse.

Hence, the propagation of convenient (and seductive) mindware may be a powerful strategy to obfuscate the existence of rent-seeking in a society. Political parties on the left, for instance, often resort to Marxist narratives or theories of class dominance (e.g., Bourdieu, 1986), whereas parties on the right tend to embrace narratives that sanctify the private sector. Hence, the beneficiaries of the status quo are able to design and propagate mindware that either hides or normalizes the prevailing extractive institutions. They usually succeed.

It is unsurprising, for instance, that most people in the state of São Paulo are against charging tuition fees in the state's public universities (DATAFOLHA, 2017). The gross cost per student in the same state's public universities is about 10 times higher than in its basic education system (Governo Aberto SP, n.d.). In the same state, coverage for childcare, a public service used mostly by the poor, is less than $50 \%$ (Carbonari, 2014).

Another example is the tax-free zone, known as Zona Franca de Manaus, in the Brazilian Amazon. Conceived as an instrument for developing the north of Brazil and avoiding environmental degradation in the Amazon forest, it became a clear example of a failed public policy. It was never able to achieve its intended results, despite costing the public coffers almost the same (in terms of percentage of GDP) as the Bolsa-Família income transfer program (World Bank, 2017), which benefits 50 million Brazilians (compared to just 2 million inhabitants in the city of Manaus). However, when tax privileges were called into question a few years ago, there was a great (and organized) outcry from the beneficiaries, including the promotion of multi-channel campaigns to defend the status quo (e.g., Suframa News, 2014).

To evaluate the proposition that the prevailing mindware reflects the interests of those groups that benefit from the status quo, we searched the websites of the seven biggest political parties in Brazil to identify documents diagnosing the causes of Brazilian problems. In cases where we found no such document, we searched the political party's program. We then carried out a content analysis of those documents, crosschecking them against the common exemplars of rent-seeking identified by authors such as Giambiagi and Schwartsman (2014), Lisboa and Latif (2013) and Mendes (2014). Table 11 presents the results. Only explicit mentions to rent-seeking factors were considered. We note that, 
in most cases, the references are made in passing, without the presentation of a supporting rationale.

Table 11. Does the mindware of political parties incorporate rent-seeking?

\begin{tabular}{|c|c|c|c|c|c|c|c|}
\hline Subject & PMDB & PT & PSDB & PP & PDT & PTB & DEM \\
\hline $\begin{array}{l}\text { Zona Franca de } \\
\text { Manaus (tax- } \\
\text { free zone) }\end{array}$ & No & No & No & No & No & No & No \\
\hline $\begin{array}{l}\text { Trade } \\
\text { protectionism }\end{array}$ & Yes & No & No & No & No & No & No \\
\hline $\begin{array}{l}\text { Public pensions } \\
\text { system }\end{array}$ & No & No & Yes & No & No & No & No \\
\hline Tax privileges & Yes & No & Yes & No & No & No & No \\
\hline "Sistema S" & No & No & No & No & No & No & No \\
\hline BNDES & No & No & No & No & No & No & No \\
\hline $\begin{array}{l}\text { "Free" tuition at } \\
\text { public } \\
\text { universities }\end{array}$ & No & No & No & No & No & No & No \\
\hline $\begin{array}{l}\text { Intergenerational } \\
\text { myopia (i.e., low } \\
\text { priority to } \\
\text { children) }\end{array}$ & No & No & No & No & No & No & No \\
\hline
\end{tabular}

Notes. In number of affiliates, the largest parties in Brazil are (in this order): PMDB, PT, PSDB, PP, PDT, PTB and DEM (Maia, 2017). Documents reviewed: "Uma ponte para o futuro" (PMDB), "Carta de Princípios" \& "Carta ao Povo Brasileiro" (PT), "O Brasil que queremos" (PSDB), party program (PP), party program (PDT), party program (PTB), "O Brasil que vai dar certo" (DEM).

Interestingly, virtually no document discusses the hidden distributive conflict that is so characteristic of the Brazilian society. At best, there are vague mentions, but they do not identify the social actors behind the privileges. Overall, the documents either ignore the systemic structure of the problems or screen them with a heavy layer of rhetorical smoke. In some cases, the documents even stress the need for more rent-seeking programs (e.g., protectionism). While this exercise is insufficient to test the proposition of cultural dominance by rent-seekers, it suggests that current mindware about the root causes of Brazilian problems, at least in the case of the major political parties, is clearly misleading. 
Finally, it is common in discussions about Brazilian problems for one interest group to pinpoint the privileges of other groups while ignoring its own. Thus, leftist groups with ties to public universities condemn tax privileges conceded to protected economic groups while staying silent about the unjust rent transfer from society as a whole to students from the upper social classes. Similarly, industrial sectors complain about the market concentration in the banking sector, which contributes to higher interest rates, while keeping silent about their tax benefits.

Baumgartner and Jones (2009) call policy monopolies the dominance of interest groups over special topics of public policy, including the venues that operationalize the policies. Contrary to the US context, where policy monopolies are often dismantled through the action of competing groups, in Brazil they are almost a hereditary charter that warrants permanent access to society's scarce resources.

\subsection{THE DESPERATE SEARCH FOR BAND-AIDS}

The consequences of a tangled web of narratives that normalizes the status quo include the absence of a clear diagnosis of the causes of everyday social problems, such as crime. Importantly, in the absence of such a diagnosis, people cope with problems by looking for solutions to relieve the symptoms. For instance, the constant increase in rates of crime in Brazil has led the middle and upper classes to incarcerate themselves in highly secure houses, residential buildings and gated communities. The private security industry mushroomed in the 1990s in response to unabated increases in crime in the country (Zanetic, 2005). Brazil currently spends around 1.6\% of its GDP on private security and related insurance services (Jaitman et al., 2017; Wentzel, 2017). That percentage is three times higher than the public spending on the widely acclaimed Bolsa-Família income transfer program. To bring the same sensation of safety from their houses to the streets, the well-off in the city of São Paulo have resorted to bulletproof cars, making the city one of the world's leaders in this market (The Guardian, 2017).

Figure 42a presents an extreme but true example (collected by the author) of an adaptation to the kind of social ecosystem engendered by an unequal society. It is a warning to residents of a high-income residential building, requiring the use of permanent security staff for simple transactions such as paying for and receiving a pizza delivery. Figure $42 \mathrm{~b}$ shows a common configuration in the access to residential buildings in the city of São 
Paulo. Residents enter and leave the building through a different access from service providers, but both need to go through what is referred to as the "cage."

FIGURE 42. A: WARNING IN A HIGH-INCOME RESIDENTIAL BUILDING IN THE CITY OF SÃO PAULO. B: A “CAGE” IN A RESIDENTIAL BUILDING IN THE SAME CITY
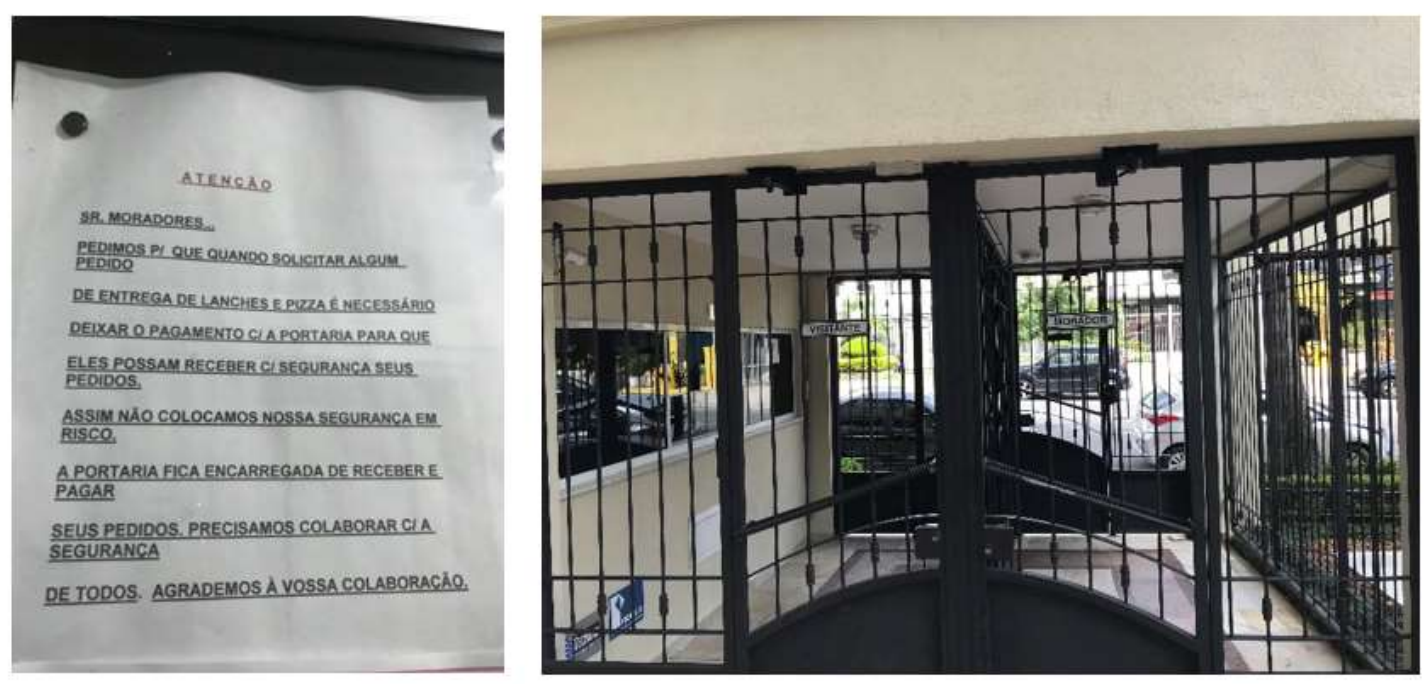

Source: Elaborated by the author.

These examples reflect an almost universal law regarding how groups and societies tackle complex social problems. If there is an easy route to alleviate symptoms, it will be taken. Band-aids are attractors in social systems, since people often mistake the symptoms for the real causes of problems (Forrester, 1971).

\subsection{THE SYSTEM DYNAMICS METHOD}

System dynamics is a method pioneered by Forrester (1961) and further elaborated by Ford (2010) and Sterman (2000). It focuses on understanding the structures in a system that produces dynamically different patterns of behavior. The method is especially suited to modeling complex social systems. It propitiates a " 10,000 meter view" of the system, portraying its structures and policies in an aggregate manner. The method of system dynamics enforces clear statements of assumptions, in particular those concerned with relationships among the variables. 


\subsubsection{REFERENCE MODE}

Following the system dynamics tradition, figure 43 presents the reference mode. It shows the behavior of two critical stocks in the model (see section 6.8): societal discomfort, which is assumed to increase over time (reflecting phenomena such as crime), and human development, which evolves slowly due to inadequate social investment.

\section{FIGURE 43. REFERENCE MODE}

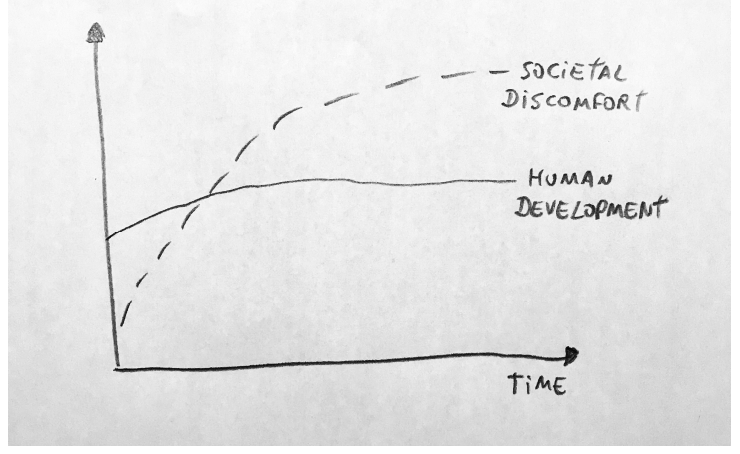

Source: Elaborated by the author.

\subsubsection{DIAGRAM OF SUBSECTORS AND MODEL BOUNDARY CHART}

Figure 44 presents the diagram of subsectors and their critical relationships. 
FIGURE 44. DIAGRAM OF SUBSECTORS

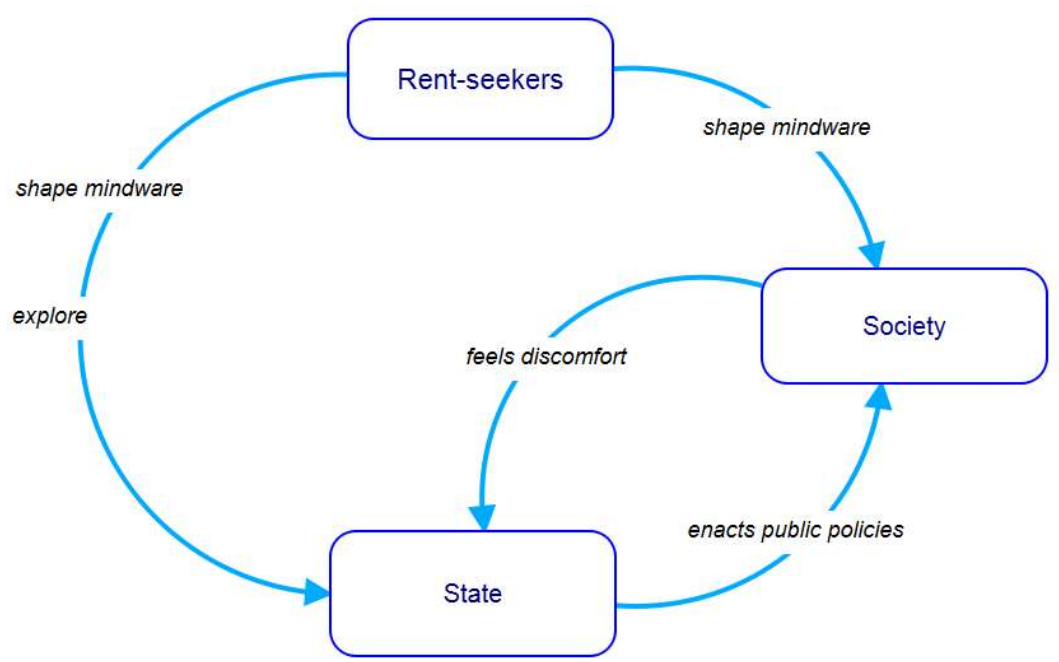

Source: Elaborated by the author.

Table 12 presents the model boundary chart with three types of variables: endogenous; exogenous and excluded, as suggested by Sterman (2000). 
Table 12. Model boundary chart

\begin{tabular}{lll}
\hline Endogenous & Exogenous & Excluded \\
\hline GDP & Commodities boom & Dynamics of public debt \\
Tax burden & $\begin{array}{l}\text { Historical degree of } \\
\text { rent-seeking }\end{array}$ & $\begin{array}{l}\text { Political dynamics } \\
\text { Tax revenue }\end{array}$ \\
Social inequality & $\begin{array}{l}\text { Political voice of the } \\
\text { poor }\end{array}$ & $\begin{array}{l}\text { Structural-demographic } \\
\text { dynamics (Turchin, 2007) }\end{array}$ \\
Societal pressure for resources & & \\
Human development & Potential rate of & \\
Societal problems & economic growth & \\
Societal discomfort & & \\
Power of rent-seekers & Maximum tax burden & \\
Pressure for solutions & \\
Attractiveness of effective & & \\
solutions & & \\
Attractiveness of band-aids & & \\
\end{tabular}

\subsubsection{DYNAMIC HYPOTHESIS}

The dynamic hypothesis is summarized as follows. In a rent-seeking democratic society, a constant pressure from a myriad of groups leads to an increasing level of tax revenues. Over time, as the limit the society tolerates for taxation is approached, economic growth is impaired, decreasing the flow of resources that keeps the system running, and societal problems caused by low priority to human development accumulate. These processes increase perceived discomfort, which in turn leads to pressure for solutions. However, there are, roughly speaking, two categories of solutions: band-aids, which only alleviate symptoms, and effective solutions. The latter, however, are typically not part of the collective mindware, since rent-seekers are able to shape narratives and mental models that normalize the status quo. Narrative control is thus a strategic tool that prevents society 
from uncovering and dealing with its deep-rooted distributive conflicts. Figure 45 presents the causal loop diagram (CLD).

FIGURE 45. CAUSAL LOOP DIAGRAM

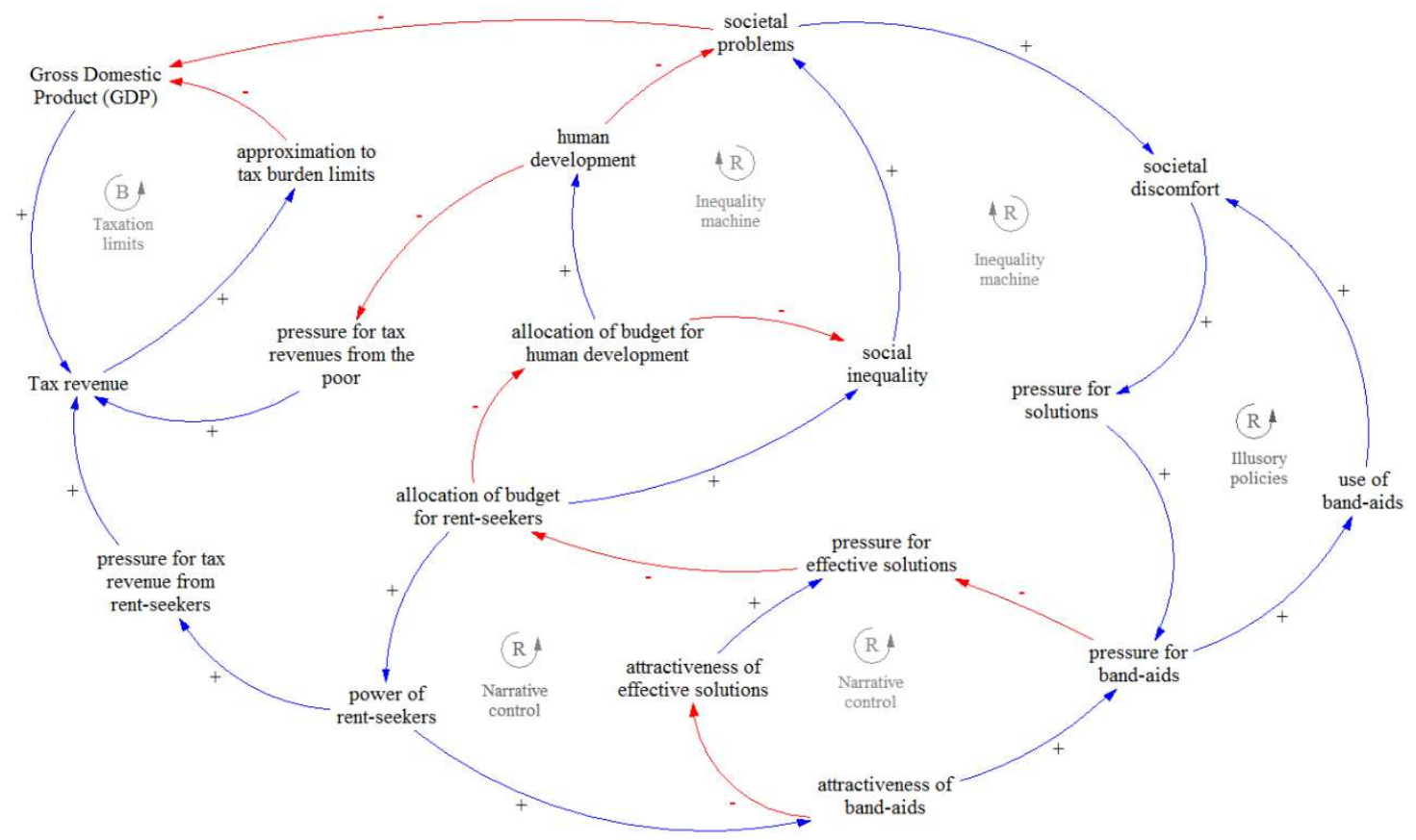

Source: Elaborated by the author.

\subsubsection{VALIDATION}

To validate the model, we followed most of the guidelines outlined by Senge and Forrester (1980) and Barlas (1996), performing direct structure and structure-oriented behavior tests. We also presented the model to experts on human development and related social phenomena. The goal was to verify whether the model is useful for its purpose, in this case understanding the replication of low human development in Brazil.

We also report in section 6.8.3 the sensitivity tests conducted to gauge the influence of the exogenous variables incorporated into the model as well as the influence of major stocks. 


\subsection{THE MODEL}

Figure 46 presents the stock and flow model created with the aid of Stella Architect software (Isee Systems, 2016). Appendix E presents the equations used in the model. 
FIGURE 46. STOCK AND FLOW MODEL

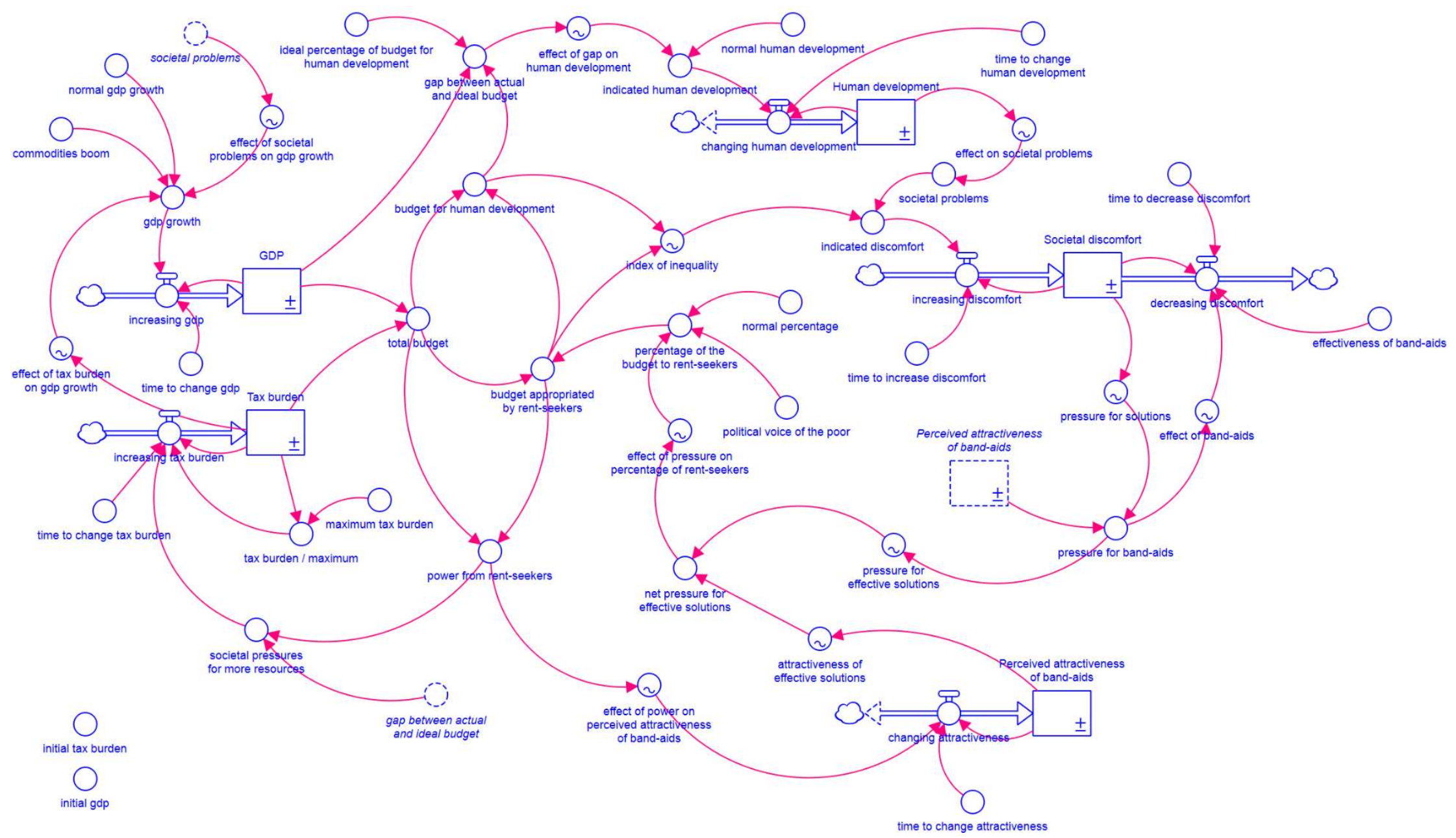

Source: Elaborated by the author. 


\subsubsection{BASE RUN AND POLICY ANALYSIS}

We did not start the model in equilibrium. Appendix E presents the parameters for the base run. The model is initialized according to a scenario that resembles the Brazilian case in the late 1980s. In this scenario, there is strong pressure to enact social policies to address demands accumulated during previous decades. Human development levels were low, because education, health and other public services were neglected during previous decades. Additionally, the democratization process gave the poor a certain amount of political power. At the beginning of the simulation, rent-seeking was already present, but since the Brazilian state was being reorganized, it took some time before the agents could sense new opportunities, giving rise to a runaway spiral of resource extraction from the state. In any case, the lion's share of public budgets was already in the hands of rentseekers. The level of social problems, which directly reflect levels of human development, were already at their highest, but social discomfort was moderate. Actual economic growth is curbed due to the consequences of extractive institutions, such as low worker productivity. We also simulated the effects of the commodities boom that stimulated the country's economy in several years of this century.

The simulations run for 50 years. Figure 47 presents the base run. We note the goal is to replicate not the growth in GDP (whose evolution is shown on the right scale axis) but the evolution of the variables depicted in the reference mode (figure 43). 
FIGURE 47. BASE RUN

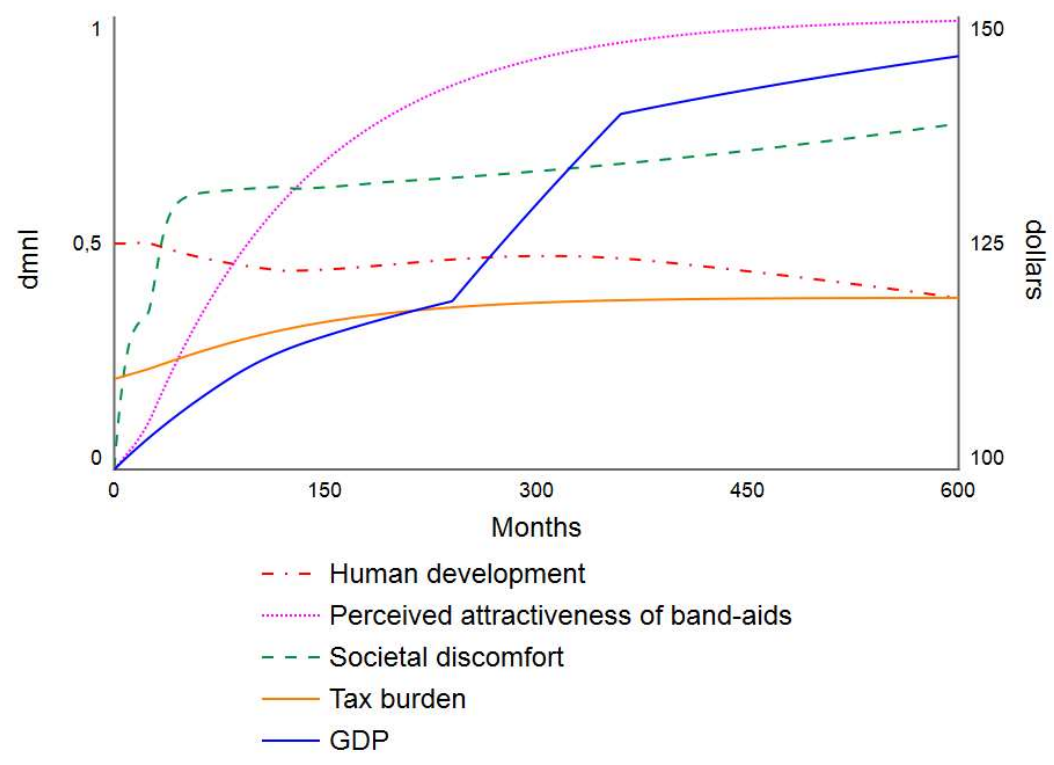

Source: Elaborated by the author.

\subsubsection{SCENARIOS}

We test three scenarios. In the first scenario, successful efforts toward social change (see the model for social change in the next chapter) lead to a progressive decrease in the degree of rent-seeking, creating a virtuous cycle for social development. We call this the ideal scenario. The second scenario (full Greek tragedy) assumes the effects of societal problems accumulate to the point of making the economy dysfunctional (e.g., by debt insolvency), leading to a full-blown, Greek-style crisis and long-term decadence. The third scenario, partial Greek tragedy, assumes that the crisis occurs but that it triggers a forced change in patterns of rent-seeking, putting the country back on course for economic growth at the end of the crisis.

For simplicity, the model assumes that the tax burden will always gravitate toward the maximum accepted by society. Hence, in all scenarios, the tax burden slowly reaches its maximum. In real contexts, the maximum tax burden may be endogenously determined. Figure 48 presents the results of the simulation for the first scenario. It shows, as expected, positive developments for all variables. We note, nevertheless, that it takes some decades to observe those positive consequences, which can be a true challenge in the context of a myopic political system. Rent-seeking structures, we suspect, die hard. 
FIGURE 48. IDEAL SCENARIO

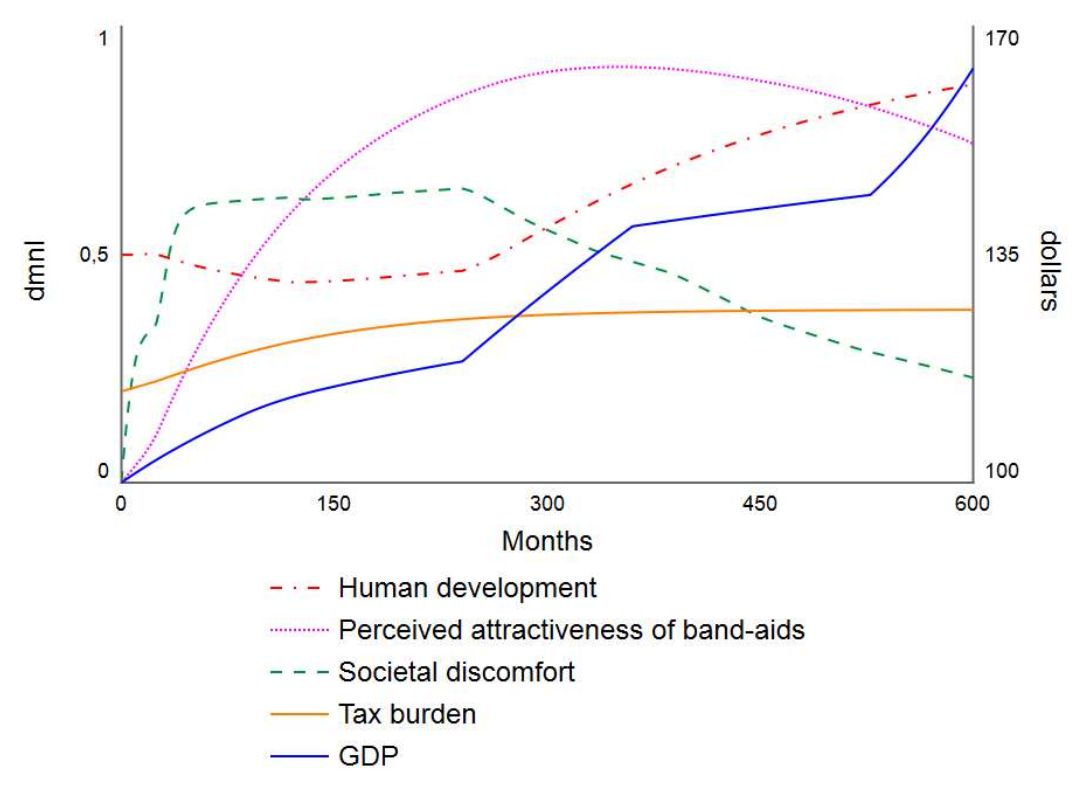

Source: Elaborated by the author.

A Greek-style crisis resulting from the unbalanced fiscal dynamics in Brazil is considered one of two probable scenarios for the coming years, the other being long-term economic stagnation (Lisboa, Pessôa \& Almeida, 2015). Figure 49 depicts the full Greek tragedy. GDP enters a trajectory of steep contraction. The efficacy of band-aids is reduced, leading to an increase in societal discomfort, which reaches a new level after only a couple of years. Human development declines over a long timespan. 
FIGURE 49. FULL GREEK TRAGEDY SCENARIO

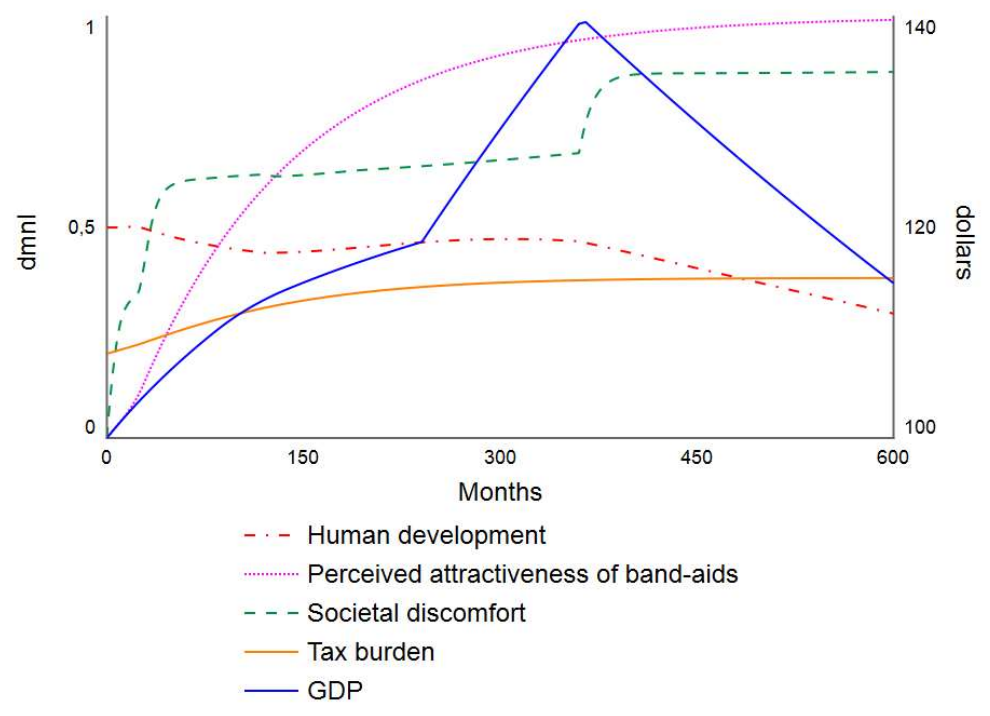

Source: Elaborated by the author.

However, one possible outcome of a full distributive crisis may be societal awakening, leading to a permanent decrease in the historical levels of rent-seeking. The partial Greek tragedy scenario (figure 50) represents such an outcome. However, in this scenario, it takes almost 30 years for societal discomfort to return to its previous levels and about one generation (roughly 20 years) for human development to show undeniable progress. 


\section{FIGURE 50. PARTIAL GREEK TRAGEDY SCENARIO}

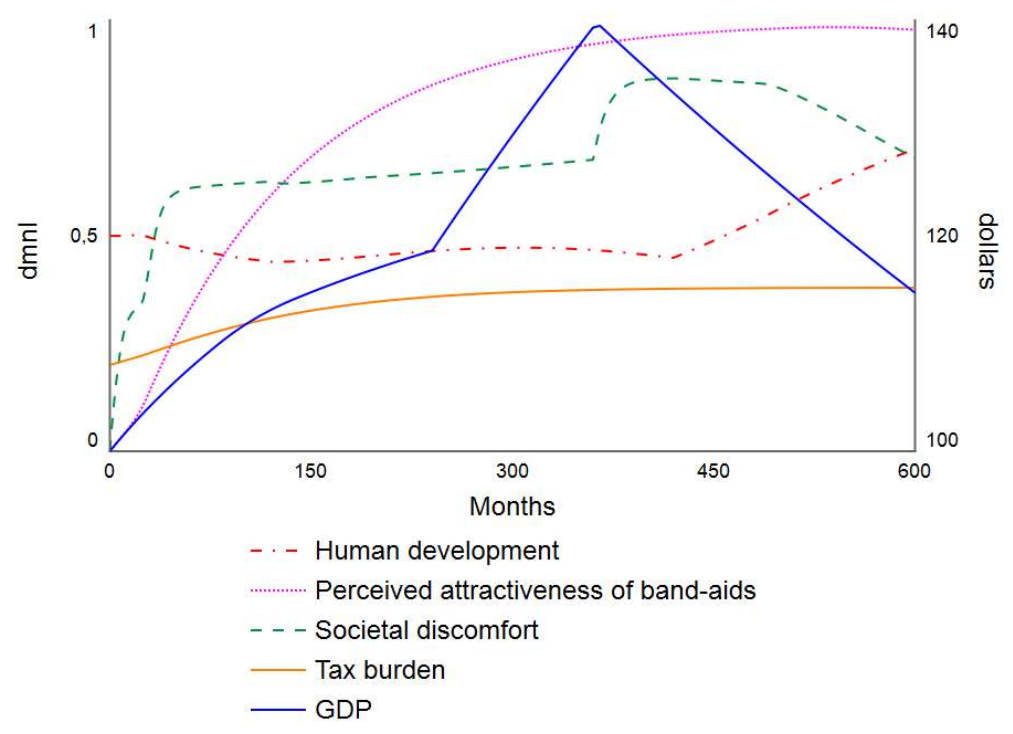

Source: Elaborated by the author.

\subsubsection{SENSITIVITY ANALYSIS}

We ran a sensitivity analysis using the parameters for the base run scenario and taking human development as the variable of focal interest. We utilized the simulation features in Stella Architect software, performing 1,000 runs with incremental distribution for the manipulated variables, using plausible ranges. The results showed that the model is strongly sensitive to the levels of ideal percentage of public budget (as a percentage of GDP) applied to human development, moderately sensitive to the maximum level of tax burden, and insensitive to "normal" (potential) GDP growth. To justify the latter result, we note that the dynamics portrayed in the model are sufficiently strong to curb the potential growth in GDP. Figure 51 presents the results of the sensitivity tests. 
FIGURE 51. SENSITIVITY ANALYSIS

51a. Sensitivity to percentage of public budget

51b. Sensitivity to maximum level of tax burden
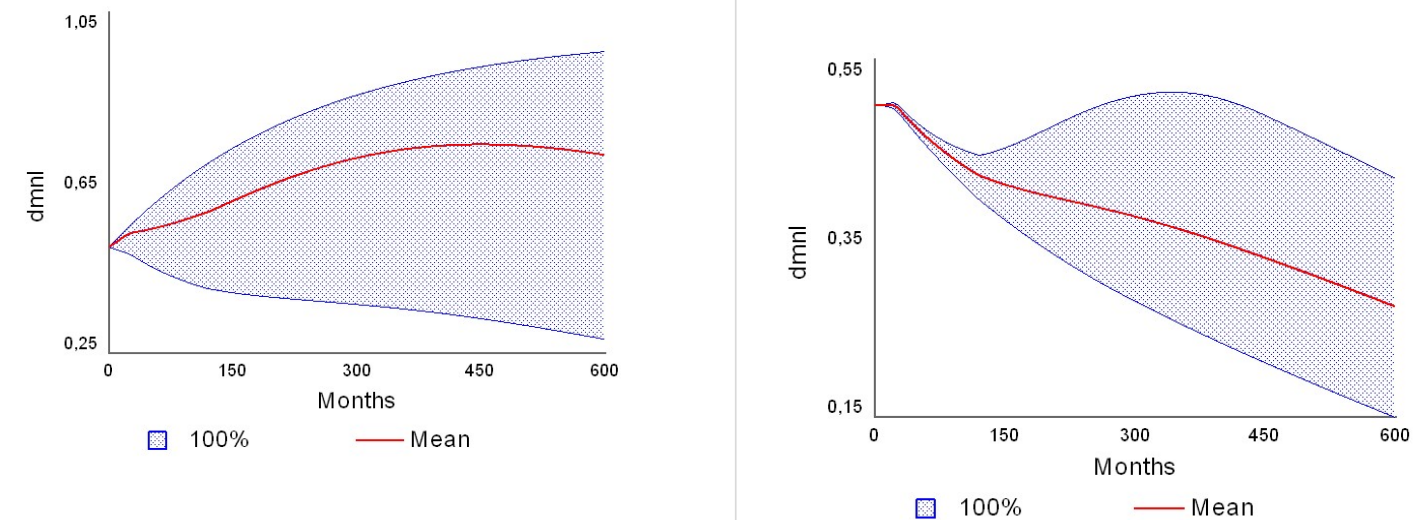

51c. Sensitivity to normal GDP growth

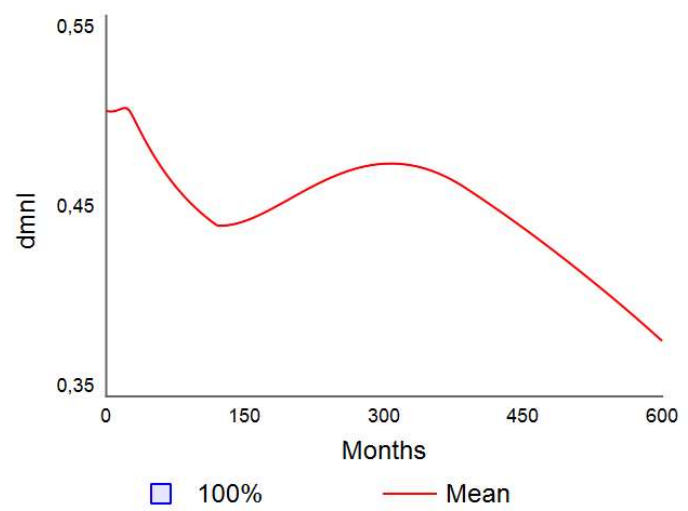

Source: Elaborated by the author.

\subsection{DISCUSSION AND CONCLUSION}

One constantly hears Brazilian politicians claiming that the recipe for tackling poverty is economic growth. Moreover, this is a common theme in the political parties' programs reviewed in table 11. Barros, Henriques, and Mendonça (2000) oppose such a strategy, arguing that it requires high rates of economic expansion and a long time horizon to produce any alleviation in overall poverty. However, as we have seen throughout this chapter, the refutation of this strategy should be made on different terms. First, although 
the problem of poverty in Brazil can be alleviated through economic growth, its root causes are directly linked to the permanence of extractive institutions and rent-seeking structures. Second, these institutions and structures are precisely what prevents the country's economy from growing to its full potential.

For the entire twentieth century, Brazilian per capita income hovered around one-quarter of the level for developed countries (IBGE, 2006). The model and the simulations reported in this chapter suggest the existence of key feedback loops, created by the predominance of rent-seeking, which virtually condemns the country to a perpetual middle-income trap. In a country where extractive institutions are in place, private interests capture the state, causing the governmental apparatus to be responsible for the existence of conditions that prevent full human development. To use a strong metaphor, the consequence is a Brazilian social holocaust, inasmuch as enormous human potential is squandered through social structures whose existence is almost purposeful.

In Brazil, the tax burden has reached its limit, as evidenced by recent episodes when attempts to recreate former taxes were strongly contested. Taxation levels are higher than in countries with similar levels of income. At the same time, tax laws contain several loopholes that either benefit the rich or create inefficacious and ill-designed programs, such as the incentivized taxation program for small businesses. Taxes are levied disproportionally on the poor. When one considers the application of public resources, the landscape is similar. The public budget does not provide sufficient wealth redistribution, acting instead as an instrument of income concentration, as most of the social spending benefits the richest segments of the population. Thus, it is unsurprising that levels of education and worker productivity remain disappointing in Brazil and that diverse negative consequences, such as crime and distrust, continue to take their toll on societal well-being.

Why is Brazilian society blind to these consequences? Mindware, shared mental models, are an important piece in this puzzle. Groups that benefit from the status quo, imposing the diffuse costs of their privileges on the entire society, are able to concoct narratives that normalize the current state of affairs. Overcoming the influence of deeply rooted mindware may be necessary to produce change. It is certainly no easy task. The upper social classes may exhibit a strong sense of entitlement (Piff, 2014), prioritizing their own self-interests (Piff, Stancato, Côté, Mendoza-Denton, \& Keltner, 2012). In addition, what often prevents well-meaning social actors from defeating policy resistance is not lack of 
commitment, knowledge or resources but lack of systems thinking capability (Sterman, 2002).

To that end, we think one of the greatest names in the system dynamics field, Donella Meadows, has a good proposal for how to overcome the counterintuitive forces of resistance in complex systems. Meadows (1999) proposes the creation of informational loops that bring the state of the system to the attention of key social actors. In the Brazilian case, it seems that one possible intervention to change the system would be the creation of feedback loops that make the costs of rent-seeking practices transparent to the entire society. In the words of Lisboa and Latif (2013), Brazil has been experiencing a "democratization of privileges," as public-sponsored privileges spread to diverse social groups, while the perception of their costs and social impact remain diffuse.

Nonetheless, it is clearly insufficient to provide information. The employment of elements of complex social problems (CSP) management outlined in chapter 2, particularly the design and marketing of the right mindware, may help in addressing this issue. Some economists have been diagnosing the problems discussed in this chapter (and proposing adequate solutions) for several years, but so far these attempts to infuse the debate with rationality have failed. As we discussed in chapter 2, and as we will explore in next chapter, the appeal and marketing of mindware depends on much more than its rational basis.

Regarding the limitations of the model, it does not account for the important dynamics of fiscal solvency related to the evolution of the unsustainable pension system in Brazil. It also assumes a crude relationship between human development and evolution of GDP. These limitations indicate possibilities for future research.

Finally, we must recognize that there are no utopias in social systems (Forrester, 1971). No society is free of pressures or stresses. We must choose, instead, what kind of stresses we deem acceptable. Is it desirable to submit the well-being of the majority of individuals in a country, causing much avoidable suffering, in order to sustain the privileges of the few? What kinds of societal designs are possible, considering the historical paths already taken by extractive societies? 


\title{
7. A THEORY OF SOCIAL CHANGE
}

When an ideology gets very old, it comes to live in Brazil.5 (Millôr Fernandes)

That is the real purpose of system dynamics: To create the future we truly desirenot just in the here and now, but globally and for the long term. Not just for us, but for our children. Not just for our children, but for all the children. (John Sterman)

\begin{abstract}
The chapter presents a model for social change proposing concepts such as pushing factors, catalyzers, and enabling factors. The model portrays the dynamics of processes of social change. At the frontiers of societies, natural, technological, cultural or economic forces create fissures in current mental models. This gap is perceived by formal or informal groups, who push for social change, eliciting potential opposition from other groups. Proposed changes battle for the public's attention and support in a marketplace of ideas. Public support facilitates garnering additional support from institutional validators, who are the social actors enacting policies in the system to adjust it to the proposed changes. Examples of causes, such as early childhood development and basic sanitation, are discussed.
\end{abstract}

Keywords: social change, political institutions, social behavior, social marketing, system dynamics.

\subsection{SURPRISING CHANGES}

In his book about the history of the cigarette industry in the United States, Harvard professor and historian of medicine Allan Brandt remarks that we would not now allow a deadly product like cigarettes to be introduced in the market (Brandt, 2007). However, 11 years after Brandt's book, another similar product, marijuana, has been gaining popular acceptance, leading to a change in policymaking, notwithstanding its possible long-term harmful effects on health (CDC, n.d.).

Acceptance of marijuana is far from being the sole example of a surprising change in societal tone regarding a controversial issue. Recent decades witnessed greater

\footnotetext{
5 "Quando uma ideologia fica bem velhinha, vem morar no Brasil."
} 
acceptance of same-sex marriage, a decrease in tobacco consumption, a reduction in the employment of nuclear energy, and several other changes reflecting shifts in public attitudes.

Figure 52 presents a snapshot of the evolution of attitudes in the US population toward controversial subjects. Not only have attitudes been changing, but, as in the case of samesex marriage, they tend to change concomitantly in several demographic segments in the United States, implying a broader phenomenon. Regarding the shift in attitudes toward same-sex marriage, we note that the same trend is occurring in the United Kingdom but not in countries such as Brazil or Japan, which suggests that it is not a universal change caused by socioeconomic development.

\section{FIGURE 52. SAMPLE OF SHIFTING ATTITUDES IN THE UNITED STATES}
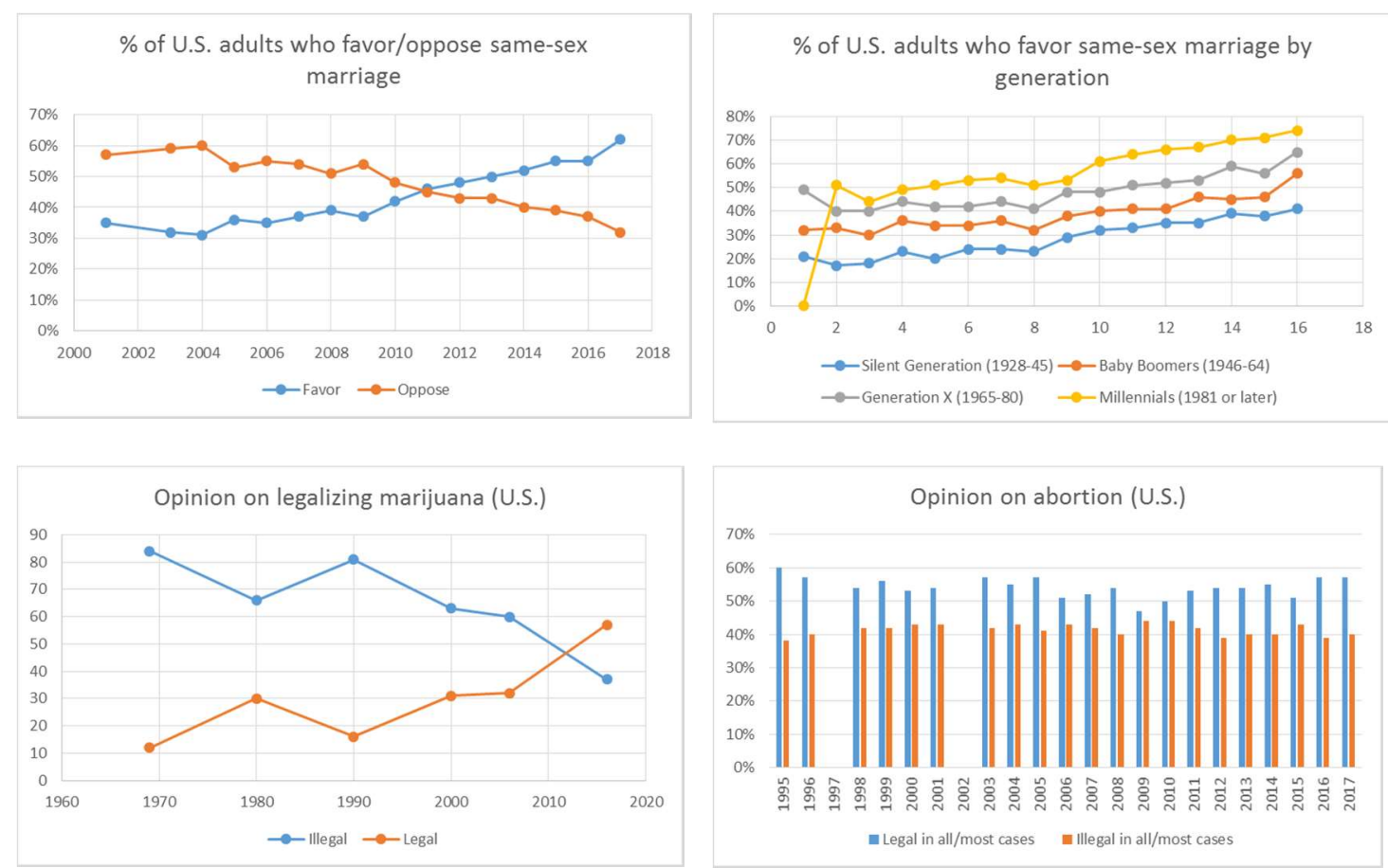

Source: Pew Research Center (n.d.)

Most social change does not occur by happenstance, resulting, instead, from the longterm actions of persistent social actors. In some cases, however, idiosyncratic factors, such as accidents or the viral spread of a cultural product, may trigger or accelerate a cascade of changes in social systems. The existence of several paths leading to social 
change calls for an integrative model capable of representing the important intricacies present in this phenomenon.

This chapter aims to model social change using the system dynamics method. We are interested in purposeful social change, such as the changes intended in social marketing initiatives - consider the adoption of safety behaviors (e.g., wearing seatbelts in cars) or increases in organ donation. However, we are also interested in broader and more organic changes, such as the empowerment of women and the increase in attention to early childhood development.

\subsection{SOCIAL CHANGE}

Innumerable political and social groups strive continuously to change the social ecosystem. We could say that, every day, thousands of causes wake up with the vain hope of conquering one of the scarcest resources in modern world - human attention. However, only a few succeed. Gaining attention is often only the first of several hurdles in the process of social change. The proposal of new ideas or causes often elicits opposition from discordant groups. Groups supporting the cause may disaggregate or lose interest in it over time. The proposal may also lose its place in the policy agenda and never be converted into policies or practical interventions in the system. Worse, even when the cause survives all these obstacles, policies supporting the proposed change may simply be inefficacious, failing to bring about significant change in the social system. This is the case, for instance, with policies that act on the symptoms instead of the root causes of problems such as crime.

Before proceeding, it is important to define what we understand by social change. We define social change as significant, consequential change in attitudes and behaviors in a social system - a whole society, some of its segments (e.g., the medical community), an organization or a social group.

Understanding how social change happens is essential to any individual or group tackling the most pressing complex problems of our societies. Poverty, low human development, climate change, road congestion and many other so-called wicked problems require changes in prevailing mindsets and mental models, in particular those espoused by influencers and institutional actors, such as politicians and business leaders. Changing mental models is a necessary condition for the enactment of policies and interventions in 
the social system. We adopt the term coined by Harvard educator David Perkins, and we refer to mental models as mindware throughout the text (Perkins, 1995).

Replacing mindware is not an easy process. Consider the case of the quest for continuous economic growth, with all its associated consequences, such as climate change. Jay Forrester, in the preface to the second edition of his internationally famous book World Dynamics, argued in favor of the identification of alternative policies and practices to move the world away from the unsustainable quest for growth toward a viable socioeconomic equilibrium (Forrester, 1973). Those changes would involve, according to him, fundamental changes in laws, values, religious attitudes and expectations. However, to the present day, applied behavioral science has little to say about how to induce collective learning at the broader societal level - at least at the velocity required to address the challenges posed by the unsustainable quest for endless growth (Randers, 2012).

With the goal of understanding how social change occurs, this chapter proposes a set of dynamic relationships between key elements in social systems. In the proposed model, we argue that social change can occur at three different speeds. They may be slow, taking a long time to occur, in particular when they involve an activist group advocating for a controversial subject. However, they may also occur rapidly, as when a political actor spends his or her political capital pushing for the approval of unpopular laws. One example is the law requiring drivers to use seatbelts, approved two decades ago in the city of São Paulo, Brazil; although it met with resistance, in a short time it gained approval from the population. Finally, social change may occur in a mixed timeframe: slow at first and then accelerated by a fortuitous event that catalyzes public opinion and tips the general attitude toward the proposed change. Consider the case of the famous Vietnam War photo, the "napalm girl” Kim Phuc running from bombs in her village. Many analysts think this photo catalyzed a change in an already divided public opinion, precipitating the end of the Vietnam War (Time, 2016).

\subsection{PREVIOUS WORK IN THE SYSTEM DYNAMICS LITERATURE}

There are very few theoretical frameworks in social marketing or marketing-related disciplines to explain why social change occurs or how social advocates could adopt a systemic perspective to direct their efforts to produce effective change. In the same vein, 
in the system dynamics literature there is little work on the dynamics of broad social change. A pioneer effort was the $\mathrm{PhD}$ dissertation produced by Jørgen Randers in 1973, under Jay Forrester's supervision.

Randers (1973) developed a model to explain the acceptance of new ideas sponsored by reforming groups. In his model, acceptance of new ideas depends not only on their perceived advantage, but also on the characteristics and the dynamics of the groups pushing for reform. The model assumes the idea's merits could lead to widespread acceptance even without group promotion - and even considering that its "true utility" would appear only after full-scale implementation. The model also accounts for the resistance arising from opposing groups. Figure 53 presents the simplified causal loop diagram that summarizes Randers' model (\#newidea12 model in his dissertation). It covers key feedback loops involved in the adoption of new ideas, and it conforms to other theoretical models of diffusion of new ideas (e.g., Rogers, 1983).

Stroh (2015) also proposes a model for social change using system dynamics. We feel, however, that some relevant aspects of the phenomenon are missing from those studies, as we will discuss below.

\section{FIGURE 53. RANDERS' CAUSAL LOOP DIAGRAM FOR SOCIAL CHANGE}

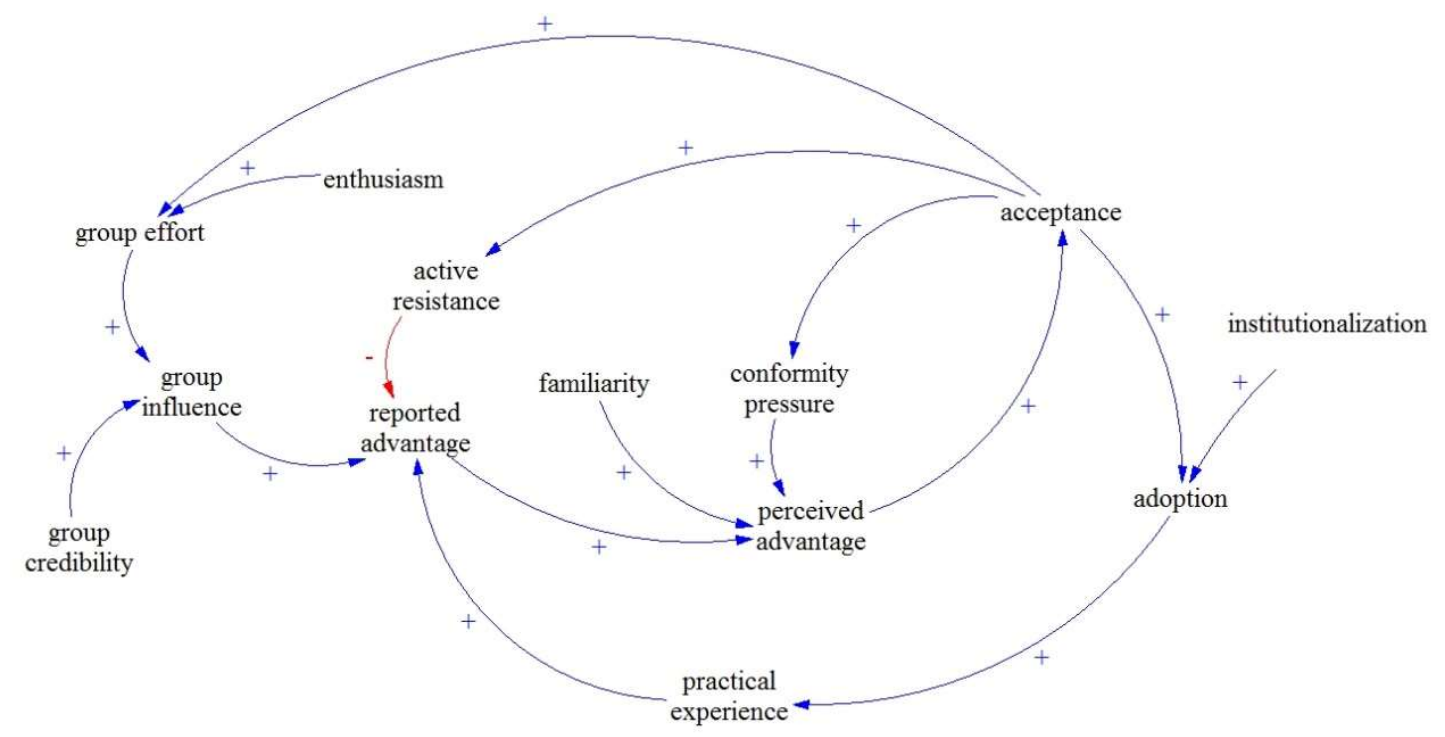

Source: Adapted from Randers (1973). 


\subsection{WHY WE NEED A SYSTEM DYNAMICS MODEL}

A model of social change must explain why important but unappealing issues such as early childhood development, bone marrow donation, climate change and basic sanitation fail to elicit adequate societal responses. Thus, the model must explain success and failures.

Most literature on agenda-setting, social advocacy and social marketing does not present a general framework capable of explaining social change from a dynamic point of view. Even research that presents a proposal of how interest in social issues ebbs and flows over time relies on what seems to be unwarranted generalizations from case studies. We refer, in particular, to the influential work of Baumgartner and Jones (2009). The authors claim that changes in policies dealing with relevant social issues, such as nuclear energy and tobacco control, reflect previous changes in images (i.e., mindware) and the actions of groups exploring the different venues for policies in the US federalist system (e.g., by challenging policies through the judicial system or by looking for change at state level). However, Baumgartner and Jones' framework seems to have little generalizability in explaining similar changes in policies in countries such as Brazil (where states have much less power and where there is little tradition of challenging public policies in courts). In addition, it does not explain the forces behind the appearance of new mindware, nor does it portray the feedback loops linking the entire system of societal change - its portrayal of the policy system as marked by punctuated equilibrium may be only an obscured, partial view of the dynamics at play.

\subsection{ELEMENTS OF THE FRAMEWORK}

The framework presented in this chapter was developed in an inductive fashion, by aggregating common elements found in several societal changes that have occurred since last century.

Two exogenous forces - what we call pushing factors and catalyzers - may create (independently or concurrently) a gap between the perceived current state of affairs and the referent mindware they embody. Usually, those forces run their course at the frontiers of a society (its interfaces with the natural world, with other societies and with the symbolic universe of ideas). 
Once a gap manifests itself, it can mobilize segments of the population. Sometimes, the gap is exposed through a crisis or a strong perturbation in the social system. The model assumes that formalized groups or loosely connected networks of like-minded people promote a cause through different means, accumulating a stock of enabling factors. Causes gain visibility through speeches, rallies, books, op-ed articles and overt manifestations of support. This visibility, in turn, enables the aggregation of opposing groups, who strive to offer a contrasting narrative, often defending the status quo.

The competition between the narratives and, in the end, between the capabilities of supporting and opposing groups, determines how the public and what we call institutional validators perceive the situation. Of course, the public is bombarded every day by an infinitude of causes. Human attention is a scarce resource, and it is becoming ever scarcer. Therefore, only a small fraction of causes will cross this crucial threshold.

With the passage of time, increasing public support toward a cause or mindware may lead to support from institutional validators, leading to actions with the potential to close the original gap. However, other paths are also possible. The proposal of new mindware may flourish in the media agenda and/or policy venues, and validation from these institutional channels may feed back to the public, creating a reinforcing feedback loop with the potential to accelerate the diffusion of the cause. In other words, groups supporting a cause may decide to circumvent the public and act mainly on policy venues.

Next, we present a more detailed discussion of the elements of the framework. Figure 54 presents the diagram of subsectors, and figure 55 presents a stylized representation of the reference mode for a successful generic cause. 
FIGURE 54. DIAGRAM OF SUBSECTORS

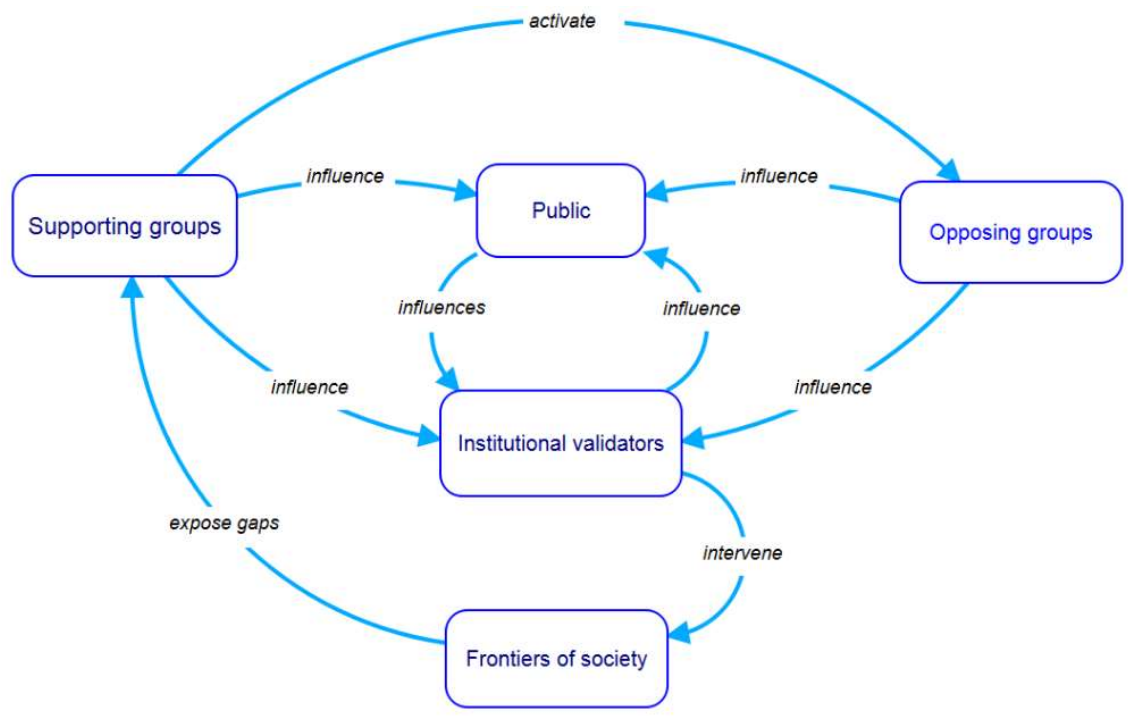

Source: Elaborated by the author.

FIGURE 55. REFERENCE MODE

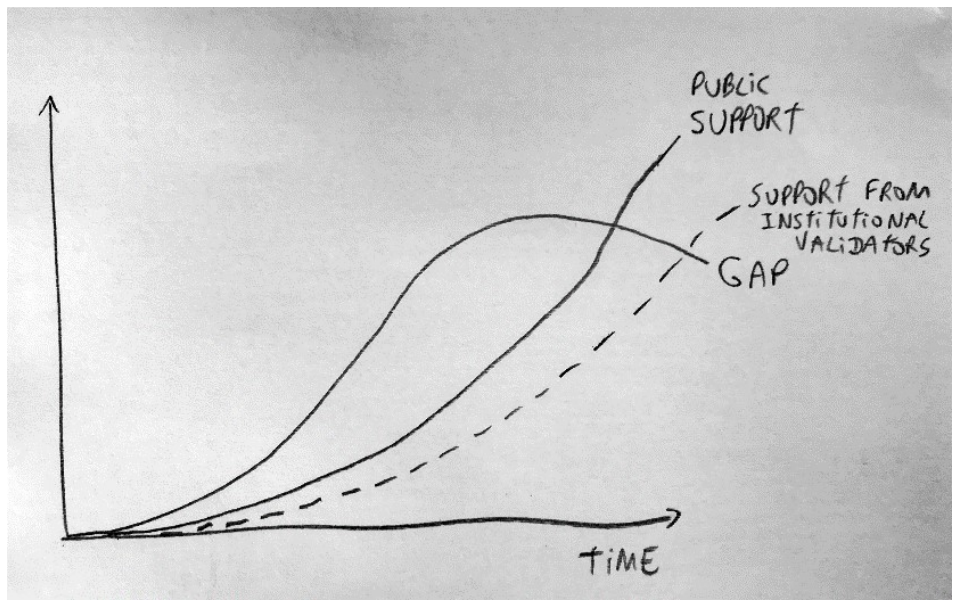

Source: Elaborated by the author.

Table 813 presents the model boundary chart with three types of variables: endogenous; exogenous and excluded, as suggested by Sterman (2000). 
Table 13. Model boundary chart

\begin{tabular}{|c|c|c|}
\hline Endogenous & Exogenous & Excluded \\
\hline $\begin{array}{l}\text { Exposed gap } \\
\text { Capabilities of supporting and } \\
\text { opposing groups }\end{array}$ & $\begin{array}{l}\text { Pushing factors } \\
\text { Catalyzers } \\
\text { Quality of framing }\end{array}$ & $\begin{array}{l}\text { Sources of pushing factors } \\
\text { and catalyzers } \\
\text { Role of technology }\end{array}$ \\
\hline $\begin{array}{l}\text { Enabling and disabling factors } \\
\text { Appeal of mindware } \\
\text { Public support }\end{array}$ & $\begin{array}{l}\text { Effectiveness of policies } \\
\text { Initial degree of } \\
\text { contentiousness }\end{array}$ & $\begin{array}{l}\text { Role of institutions } \\
\text { Progression of causes through } \\
\text { policy venues }\end{array}$ \\
\hline $\begin{array}{l}\text { Support from institutional } \\
\text { validators }\end{array}$ & $\begin{array}{l}\text { Intuitive appeal of idea } \\
\text { Institutional efficiency } \\
\text { General power from } \\
\text { opposing groups }\end{array}$ & $\begin{array}{l}\text { Distributive conflict } \\
\text { Goal erosion (i.e., the barriers } \\
\text { to close the gap are perceived } \\
\text { as insurmountable) }\end{array}$ \\
\hline Policies to close the gap & $\begin{array}{l}\text { Crowdedness of markets } \\
\text { of ideas }\end{array}$ & $\begin{array}{l}\text { Buildup and dissolution of } \\
\text { policy subsystems } \\
\text { Role of social media }\end{array}$ \\
\hline
\end{tabular}

\subsubsection{PUSHING FACTORS}

We define pushing factors as long-term forces that create fissures at the frontiers of a society. They are diverse in nature. They may be natural phenomena, such as long-term climate change. They may result from the interchange of cultural elements from distinct societies, such as the trend in underdeveloped countries to copy fads from developed ones. Pushing factors may include technological expansion, which keeps creating fissures in traditional mindware and redefining ways of life (e.g., invention of the automobile, development of Uber and other services in the "gig economy"), long-term consequences of social innovations or cultural products (e.g., pesticides, cigarettes), processes of economic development in a region or sector and increases in the general levels of education, which prompt demands of transparency from public and private organizations. 
Pushing factors may also be what we call memetic expansions, with reference to the copying potential embedded in diverse mindware or memeplexes (Blackmore, 2000; Stanovich, 2011). Ideas or mindware with strong appeal tend to spread, from Rastafarian beliefs to scientific theories, from Pilates training to political ideology. One particular case of memetic expansion, which probably reflects more than simply the copying of appealing ideas, is the empowerment of excluded groups. Two major manifestations of this trend are the expansion of the empathy circle (Singer, 2011) and the softening of the diverse hierarchies in social life (Kellerman, 2012), which we now discuss briefly.

We emphasize the empowerment of excluded groups as a powerful pushing factor, since it has been changing (not without friction) several mental models in our modern societies. The philosopher Peter Singer proposed the concept of an empathy circle, which widens to encompass different marginalized groups, including non-human groups such as animals (Singer, 2011). In fact, the continuous expansion of the empathy circle may have an evolutionary base. The cultural drive hypothesis posits a broad reinforcing feedback loop consisting of a diverse set of mental competences (such as theory of the mind and greater innovativeness), which led to increased social tolerance and social sensitivity (among other effects) and bigger brains. The latter, in turn, led to increasingly good copying capabilities, fostering the refinement of that initial repertoire of mental competences (Laland, 2017). Social tolerance may thus be an ongoing by-product of a long process of evolution of human intelligence. In the same vein, Pinker (2012) offered an account for the historical decline of violence in the last century, taking into consideration factors such as the increase in literacy, which increasingly made it possible for people to imagine themselves suffering the plight of others. An increasing capacity to adopt the viewpoints of others may thus be a major factor explaining the expansion of the empathy circle.

Similarly, since the middle of the last century, the submissive role of women in society from being confined to home to being expected to obey their husbands - started to change. More broadly, since the end of World War II, the strong traditional hierarchies that were a staple of family and social life in industrialized countries started to be challenged - at home, at work, in the public sphere (Kellerman, 2012). This movement, again, did not occur without friction, and pushing factors typically require some decades to manifest their effects. 
In some cases, there is a combination of pushing factors. Memetic expansion and the tendency to copy fads from developed countries may explain, for instance, the adoption of dictatorship in countries such as Brazil in the first half of the last century. The same can be said of price control in Brazil in the 1980s and the wave of liberalization that swept the global economy in the 1990 s.

The forces behind pushing factors may meet with different degrees of resistance, depending on the cultural milieu of a country. In conservative societies (e.g., Japan), they may take a longer time to manifest their effects. They are also influenced by the institutional structure in a society. Modern societies have higher educational levels, for instance. They also have democratic institutions, and they tolerate the dissent that will inevitably occur when individuals and groups perceive the existence of gaps.

\subsubsection{CATALYZERS}

Factors that we call catalyzers expose societal gaps in an abrupt manner, shaking people's belief in the adequacy of an attitudinal object or exposing a sudden problem or desired change. Examples are the Three Mile Island nuclear accident in the United States in 1979 and the 1964 report of the US General Surgeon that concretely stated the link between cigarette consumption and cancer. They may also come from the cultural sphere, as when the book The Jungle shocked US society at the beginning of the last century, exposing malpractice in the meat packing industry and leading to the creation of the FDA (Foods and Drugs Administration) (Panko, 2017). Another example was the Race to the Moon program, which mobilized the United States toward what seemed to be an impossible goal.

The concept of catalyzers has similarities with the loosely defined idea of critical junctures, which Acemoglu and Robinson (2013) propose as drivers of socioeconomic or institutional change, citing, for instance, the Black Death and its effects in accelerating the end of feudalism in Western Europe.

One interesting case of someone who was a source of a highly contagious body of ideas (thus a source of a pushing factor) and also an enabler who promoted heavily those ideas through several means was the US economist Milton Friedman. (See section 7.5.5 for a discussion of the concept of enabler). In the preface to his famous book Capitalism and 
Freedom, Friedman (1962:1982, p. 7), referred to crisis in the same vein as we define catalyzers, asserting that

only a crisis actual or perceived produces real change. When that crisis occurs, the actions that are taken depend on the ideas that are lying around. That, I believe, is our basic function: to develop alternatives to existing policies, to keep them alive and available until the politically impossible becomes politically inevitable.

\subsubsection{THE EXPOSED GAP}

Pushing factors and catalyzers create over time a preferred state of affairs, which contrasts with the current status quo. The ensuing gap is what we call an exposed gap - an existing gap in the system that will inevitably be perceived by groups or like-minded individuals. Consider the case of a health campaign aiming at increasing awareness of an illness. Sponsors typically call attention to the gap between the perceived prevalence of the problem (which may be not perceived at all) and its actual incidence.

In the context of education, an interesting case is the Brazilian city of Sobral, which in 10 years rose from the bottom of the Brazilian educational rankings to top position (Sobral, n.d.). It is plausible to suppose that the beginning of the impressive revolution in Sobral's educational system began when a major footwear company installed its industrial plant in the city and realized that it could not fill basic job positions, even when the sole requisite was not being illiterate (Barros, 2013). The gap was evident and became strongly salient, leading to a series of policies that culminated with a decrease in the gap over time. Meadows (1999), drawing on the seminal work of Thomas Kuhn, argues that exposing anomalies and failures in prevailing paradigms is essential for steering societies toward new sets of beliefs. However, merely exposing gaps is not sufficient to ignite the process of social change, as Meadows also recognizes, pointing to the need to recruit change agents and enable them to act in places of social visibility and power.

Young adults are often a source of societal change. By sensing gaps between the current state of affairs and the ideals that they develop during their upbringing, they may aggregate with like-minded individuals, creating groups that will advocate change. This seems especially to be the case in Western democratic societies. 


\subsubsection{CAPABILITIES OF SUPPORTING GROUPS}

Warren (2008) conceptualizes capabilities as asset stocks combining a group's skills, on the one hand, and technical and managerial systems and processes, on the other. As he asserts, most capabilities in organizations are concerned with building and retaining resources. So, we add, are capabilities in social groups advocating change.

Groups supporting a new mindware may be collectively organized, as advocacy groups and political parties are. However, it is relatively common that a cause is promoted through a loosely connected network of like-minded people. Popular musicians in Brazil, for instance, wrote songs against the dictatorship in the country in the 1970s. It is very difficult to assert whether such efforts had any discernible impact on public support for the military governments - economic hardship tends to be the major causal factor determining the fate of a dictatorship - but, nonetheless, it is undeniable that there was a collective effort to change the state of affairs in the country. The point is that loosely concerted collective efforts, which depend on a group's skills but usually not on other elements comprising Warren's definition of capabilities, may be sufficient to attract scarce resources and ignite processes of social change. Essential resources include human attention, people, money, reputation and supportive organizations.

In sum, we assume that the promotion of new mindware may occur through loosely connected individuals, who put together their skills to attract scarce resources. This conceptualization of collective effort has the advantage of accounting for the existence of movements for social change that are relatively informal and unorganized.

Capabilities include lobbying, promotion and recruitment of influencers. Some factors seem to facilitate the development of capabilities, such as the intuitive appeal of a new mindware. In addition, success in increasing public support and support from institutional validators may feed back to increase initial capabilities, in particular by attracting more individuals who will increase the collective repertoire of skills.

For simplicity, we refer to supporting groups or individuals as enablers. Opposing parties, by the same logic, are referred to as disablers. 


\subsubsection{ENABLING FACTORS}

Enabling factors are actions to promote the new mindware. They include the myriad of actions undertaken by formal or informal groups to promote a cause or idea. Enabling factors often take place in upstream societal channels (Carvalho \& Mazzon, 2015). Marijuana use, for instance, has been portrayed in Hollywood movies and has also been promoted by influential individuals. Actions to promote a cause also include publications, meetings, rallies, advertising and public relation activities. Downstream channels are also important; for instance, ideas percolate through societal communication channels and become the subject of daily conversations.

By now, the reader may question the difference between an enabling factor and a pushing factor based on memetic expansion. Basically, the difference is that the former is actively promoted while the latter piggybacks on the (passive) copying potential of a given mindware or set of ideas.

One difference between the model advanced in this chapter and Randers' model is the conceptualization of groups as either formal groups (as in Randers' model) or informal networks of like-minded people whose motivation springs mainly from the assertion of their identity and common preferences and worldviews. Thus, enablers may be aware of their formal role, or they may be social agents acting on their particular social networks, inspired by common mindware.

Shonkoff et al. (2012), for instance, point to the role that pediatricians in the United States may have in building support for policies aimed at the first years of life. In their words (2012, p. e240),

pediatricians are strategically situated to mobilize the science of early childhood development and its underlying neurobiology to stimulate fresh thinking about both the scope of primary health care and its relation to other programs serving young children and their families.

One common drawback regarding groups of enablers is their sensitivity to variations in enthusiasm. Hence, groups may quickly disband in the face of slow progress, losing their collective capabilities. This seems to be the case of the Occupy movement in the United States (Tsukayama, 2017). 


\subsubsection{APPEAL OF THE GAP}

Performing enabling actions with the goal of exposing gaps is not sufficient to induce social change. The public has a finite set of worries and a limited attention span, and thus only a small number of causes are able to mobilize the public agenda. One common limitation in models of diffusion of new ideas, including Rander's model presented at the beginning of this chapter, is the lack of treatment of this major bottleneck.

The marketplace of ideas is a tough one, as Laland (2017, p. 257) recognizes, since success depends not just on an idea's merit, but also on "appeal, the learning strategies involved, the nature of competition, the level of exposure, the extent of promotion, the size of the target population, and multiple other factors, including a major dose of chance."

Consider, for instance, the hundreds of causes that have resorted to "awareness months" as a major promotion tool. Competition is tough, the "market" is certainly crowded and the actual results reflect a power law in terms of capacity to grab public attention. Only a few causes succeed. Figure 56 exemplifies this phenomenon by comparing a cause that is a winner in this market (breast cancer) to other, less successful competitors. In fact, the stickiness of symbols associated with breast cancer prevention (e.g., the pink ribbon) has been so successful that its major sponsors have been criticized for overshadowing the actions of groups that promote different approaches to the disease (Strach, 2016). 


\section{FIGURE 56. INTEREST IN AWARENESS MONTHS}

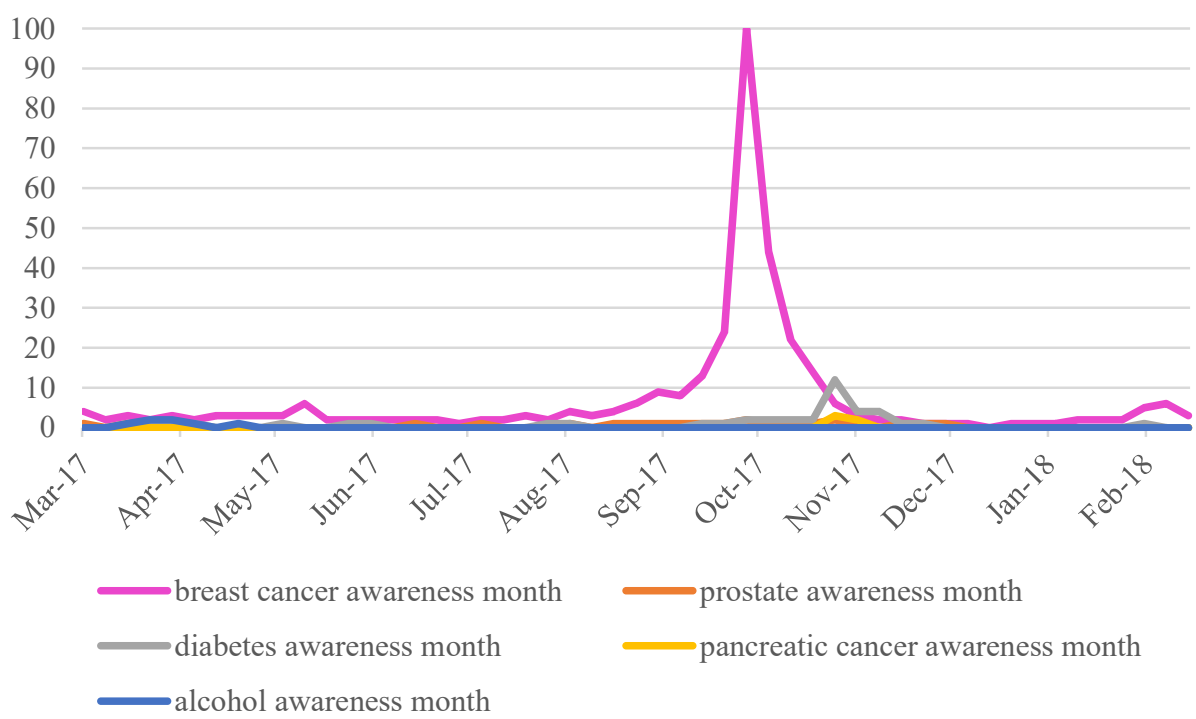

Source: Google Trends.

\subsubsection{INCREASING APPEAL}

As Schwarz, Newman, and Leach (2016) remark, it is often more complicated to sell a message based on truth than the simplifying myths that dominate the mindware shared by the public. In fact, promoting mindware based on systemic approaches to complex social problems is a challenge to anyone trying to promote rational policies.

In the model, the appeal of new mindware is directly linked to the stock of enabling factors. The more new mindware is promoted, the more it increases its appeal. However, the appeal may also increase depending on how the mindware is framed. For the sake of simplicity, we treat framing as an exogenous variable, since (1) we are interested in testing the sensitivity of the model to variations in framing it, and (2) we want to include a random factor to account for the dose of chance acknowledged by Laland (2017). In practice, the quality of framing probably depends on already existent capabilities of supporting groups, such as the competence to listen to the target segments and adapt the appeal. Framing is essential inasmuch as whoever gets his or her problem statement accepted defines the boundaries for the acceptable solutions (Daly, 2011).

The quality of framing is often associated with presentation of stories or narratives. There is a growing field of theory and practice of narratives. One common theme in narrative 
frameworks is the need to identify a tension in the system to engage attention (Daly, 2011; Holladay, 2015; Zak, 2014), an idea germane to the concept of exposing the gap discussed in section 7.5.3. Other elements include the use of emotions associated with characters and the clever use of metaphors, which are useful to translate complex concepts into familiar schemas (Zaltman, 2003). For instance, the "serve and return" metaphor for the dynamic nature of a healthy mother-child relationship (Shonkoff et al., 2012) facilitates the understanding of a critical element in the process of early childhood development.

Mindware tends to have more appeal when it presents compelling benefits to its target audience. It must answer the question "what is in it for me?" (Daly, 2011; Kotler \& Lee, 2009) from the perspective of those audiences. Proponents of marijuana use argue that it is beneficial for some health conditions; proponents of gun liberation in Brazil claim (against the bulk of the evidence) that it will increase safety. The evaluation of benefits includes the applicability of the mindware to practical problems or evolutionary concerns, such as the health of children.

The appeal of the proposed mindware must be crystal clear and gripping, so that it is positioned clearly in the minds of individuals (Kotler \& Lee, 2009). A sense of urgency is also helpful (Daly, 2011). Other important factors are the perceived legitimacy of the supporting groups and the perceptions of congruence between the mindware and the values espoused by the audience (Kidwell, Farmer, \& Hardesty, 2013).

In addition, we posit that ideas that reflect and embody deep cultural values have a bigger chance of winning the framing battle. Suggestive examples can be found in the case of proposed solutions to complex problems in the United States, which tend to be framed as individual solutions, as Strach (2016) found in the case of breast cancer cause marketing. In such cases, the narratives seem to be more easily absorbed by institutional validators (see section 7.5.9).

An aspect often overlooked by proponents of a cause is the need for new mindware to elicit the metacognitive evaluation known as feeling of rightness (FoR); it should make sense, at least superficially (Thompson, Turner, \& Pennycook, 2011) and lead to perceptions of fluency.

So far, we have seen that an appeal increases when it is fluent, relevant to target audiences, coherent with cultural values, sponsored by legitimate groups and presented in engaging ways (e.g., using narratives and metaphors). 
An important aspect of appeals is how the public perceive the truth associated with the underlying claims. Schwarz, Newman, and Leach (2016) identify five key criteria that individuals employ as they evaluate the truth of a statement: general acceptance by others, amount of supporting evidence, compatibility with previous beliefs, general coherence of the statement and credibility of the source of the information. Importantly, there is a common bifurcation (present also in other frameworks) by which people either adopt an effortful analytic strategy or, influenced by the statement's fluency, draw conclusions based on what feels right (see table 14).

\section{Table 14. Five criteria used for judging truth}

\begin{tabular}{|c|c|c|}
\hline Criteria & Analytic evaluation & Intuitive evaluation \\
\hline Social consensus & $\begin{array}{l}\text { Look for supporting data or poll } \\
\text { a group or audience }\end{array}$ & Does it feel familiar? \\
\hline Support & $\begin{array}{l}\text { Look for high-quality } \\
\text { corroborating evidence or use } \\
\text { one's own memory }\end{array}$ & $\begin{array}{l}\text { Is the evidence easy to generate } \\
\text { or recall? }\end{array}$ \\
\hline Consistency & $\begin{array}{l}\text { Recall one's own general } \\
\text { knowledge and assess the match } \\
\text { or mismatch with new } \\
\text { information }\end{array}$ & $\begin{array}{l}\text { Does it feel right? Is it difficult to } \\
\text { process? }\end{array}$ \\
\hline $\begin{array}{l}\text { Coherence (good } \\
\text { story) }\end{array}$ & $\begin{array}{l}\text { Do the elements of the story } \\
\text { logically fit together? }\end{array}$ & Does the story flow smoothly? \\
\hline Credibility & $\begin{array}{l}\text { Is the source an expert? Does the } \\
\text { source have a competing } \\
\text { interest? }\end{array}$ & $\begin{array}{l}\text { Does the source seem familiar } \\
\text { and trustworthy? }\end{array}$ \\
\hline
\end{tabular}

Source: Adapted from Schwarz, Newman, \& Leach (2016).

We should note that fluency is a double-edged property. Wise advocates should make true information as easy to process as possible, as Schwarz, Newman, and Leach (2016) recommend. Simple, memorable claims have a clear advantage in grabbing people's attention. On the other hand, fluency can lead to advancement of ineffective solutions. Weiland (2016) cites the case of the Creative Curriculum, a program for developing competences of young children that has been discredited by rigorously collected evidence. Although ineffective, it is one of the top choices in the repertoire of public education executives. Indeed, wrong (i.e., inefficacious) mindware often has a distinctive 
appeal, based on its familiarity and fluency and the inertia of currently shared mental models.

Finally, there is the common sleeper effect (Hovland, Lumsdaine, \& Sheffield, 1949) through which people forget the specific source of a message - in particular, of messages that are incongruent with one's preferences, favoring its acceptance over time (Kumkale \& Albarracín, 2004). This seems crucial for messages or campaigns that involve opposition and a strong change in the status quo. As time goes by, a message's fluency and familiarity grow, and it starts drawing less and less scrutiny from receivers (Schwarz, Newman, \& Leach, 2016). Repetition, of course, is mandatory in the production of enabling factors.

We simplified the model by assuming that supporting groups influence the public and the different institutional validators equally. However, this often may not be the case, as many groups try to influence politicians and policy venues without paying much attention to the public.

\subsubsection{WHY ADEQUATE SOLUTIONS TO COMPLEX SOCIAL PROBLEMS ARE OFTEN NOT ADOPTED}

There appear to be a number of reasons for the low appeal of what seem to be good, correct solutions to pressing social problems.

First, the appeal of proposals for overcoming societal gaps may be low when they lack the elements discussed in section 7.5.6. Many proposals found in the arena of public discourse are diffuse, and they therefore fail to lead to the production of effective policies. They lack a marketing mindset and do not mobilize hearts and minds.

Second and importantly, the appeal of the mindware may also be low because of prevailing societal solutions that embody the shifting the burden archetype (Braun, 2002). Different groups, in particular the middle classes, may have already found solutions to their pressing problems. For instance, families with higher incomes react to the low quality of public education by enrolling their children in the private system, thereby decreasing the pressure for change in the public system. The same could be said of the private security industry that flourished in Brazil in the 1990s. These band-aid solutions 
create a series of societal traps or low-quality equilibriums that represent, in practice, strong barriers to address society's root problems.

\subsubsection{COUNTERPRESSURE FROM OPPOSING GROUPS, DISABLING FACTORS AND THE APPEAL OF OPPOSING MINDWARE}

Causes are often contentious, leading to opposition from other social groups. Indeed, one of the traps in addressing complex social problems is the fact that new mindware tends to be ascribed to political tribes, which metamorphoses the different approaches to the problems into diluted identity markers. Hence, the defense of policies to address climate change may be labeled as a leftish political proposal, thus eliciting gratuitous opposition and creating an additional barrier for those interested in promoting the right policies.

It is more difficult for proposed mindware to prosper if it affects economic interests, has a strong moral tone (e.g., abortion) or represents policies that require a long time span to produce effects. Social actors who benefit from entrenched interests have potentially high levels of capabilities to promote disabling actions. They are able to sell competing narratives, to elicit doubt from the public and to use their political representatives to erect high walls against change. One example comes from climate change deniers and their supporting organizations sponsored by several industries that benefit from the status quo (The Guardian, 2016). The model assumes that, depending on the degree of contentiousness associated with the proposed mindware (and also on the level of enabling factors), opposing groups will congregate and develop their own capabilities to battle in the marketplace of ideas.

Disablers usually have the force of the status quo at their disposal. This force comes from, among other factors, the strong emotional attachment individuals have to their stock of beliefs - people often trade off the affective value of belief distortions against the costly mistakes they may induce (Bénabou \& Tirole, 2016).

\subsubsection{COMPETITION WITH OTHER MINDWARE}

Proposed mindware may clash with what Baumgartner and Jones (2009) call policy monopolies. These are entrenched groups that dominate the political venues - and the social discourse - surrounding an issue. 
Sometimes groups that do not benefit from the status quo, but who advocate a different course of action in the same context, sell competing narratives. One example is the Netflix movie What the Health (Andersen \& Kuhn, 2017), which presents a case for vegetarianism while at same time downplaying or blatantly dismissing the strong body of evidence linking the consumption of sugar and refined carbohydrates to diseases such as diabetes (Lustig, 2017). This case illustrates a common trap associated with complex social issues. Very often, all complexity and nuance surrounding a complex problem is stripped away in favor of diluted versions, which are then promoted by different kinds of pundits and partisan influencers. Thus, what should be treated as a rational issue becomes raw material for ideological, sterile disputes.

In addition, human beings have a knack for avoiding bad news. Discussing the possibility of collapse in human well-being due to a pollution crisis (versus a reduction in material well-being due to decreased industrialization), Forrester (1973) bets that the most probable course of action in such a scenario is to wait and hope that the pollution threat was exaggerated. In the face of threats to the status quo, one can always count on the existence of individuals or groups promoting comforting mindware to anxious ears.

Thus, social change may be crippled (or, at best, delayed) by opposing interests. For almost every social cause, there are individuals, groups or organizations that benefit from the current state of the system. Consider, for instance, the tobacco, oil and processed food industries, conservative politicians who depend on the votes of climate change deniers and drivers who oppose laws forbidding drinking and driving.

\subsubsection{PUBLIC SUPPORT}

Public support results from the combination of general positive attitudes toward an issue and the perception of social norms. Support, of course, comes in degrees, and building it seems to be a necessary step in promoting most instances of social change.

One common mistake made by organized groups trying to influence public policy or gather support for a specific social cause is the lack of a marketing mindset in their efforts. Segmentation, positioning, branding, testing, co-creation and other tools in the marketing repertoire are essential for reaching influencers and early innovators. In other words, while we treat public support as a broad asset-stock, we should bear in mind that the 
public is comprised of different segments and that some segments may have a disproportionate influence on changing the prevailing mindware.

In the context of early childhood policies, public support is essential for supporting programs, not only through positive attitudes but also through financial support from taxation, since most programs aimed at low-income families depend on public budgets (Haskins, 2016).

In another context, Diamond (2006) discusses how businesses can leverage their purchasing power to induce sustainable practices in the supply chain. However, far from being altruistic, such behavior typically arises in response to changes in public attitudes. The public may exert pressure on visible links in a supply chain - for instance, pressing McDonald's to eradicate malpractice in meat packing - or it may reward businesses that act in accord with what are considered good practices.

In the model, we assume that public support responds to the quality of an appeal or, when there is opposition, to the balance between the contrasting appeals. We also consider that it may be more difficult to gather public support when there is a myriad of causes competing for attention; one example is the aforementioned competition among causes in the health domain. We therefore employ an indicator for crowdedness in the marketplace of ideas.

Public support is often diffuse and may grow slowly, as in the case of the causes of marijuana use and same-sex marriage in the United States. In many cases, it seems that public support depends on threshold effects of social norms. In particular, overcoming a critical tipping point in the percentage of supporters may be necessary to ignite change (Nyborg et al., 2016).

\subsubsection{SUPPORT FROM INSTITUTIONAL VALIDATORS}

Societal change resembles organizational change inasmuch as it also requires the alignment of technical, political and cultural spheres (Schein, 2010). Institutional validators are key social actors that corroborate a proposed change by incorporating it into the cultural repertoire of accepted practices or beliefs or by enacting policies to address the exposed gap. 
There is no scarcity of theoretical accounts to explain the rise and decline of subjects in the policy system, such as the model of three agendas (public, media and policy agendas - see Andreasen, 2006) and Baumgartner and Jones' punctuated equilibria framework. We can conceive the latter system as a processing mechanism that senses tensions in society and produces responses with the aim of resolving those tensions. However, the underlying processes contain many nuances. Groups dispute over the definition of issues (and, consequently, over the boundaries of acceptable solutions); new problems may command attention, obfuscating old ones; policies may be ineffective or may have only symbolic value.

Institutional validators include the media and the political system. We aggregate these while recognizing that the effects of their actions are different. While the media reverberate public support for a cause and influence the acceptance of new mindware, the policy system alone is capable of enacting policies to close or decrease the gap in cases that are amenable only to concrete changes (e.g., policies for mitigation of climate change). We also recognize, without addressing it explicitly in the model, that the scope of validators is ample and that it includes schools, businesses (in particular, big companies) and the judicial system.

The defining characteristic of a validator is its power to reshape the system through the production of policies or the validation of attitudes and social norms. Thus, politicians who command majorities are validators, but minority political parties are not. However, the latter can be enablers by adopting measures that help expose societal gaps. On the other hand, media gatekeepers and journalists, among other key cultural actors, may be both validators and enablers.

Analyzing the cycles of policy making in the United States, Peters and Hogwood (1985) found that changes in the salience of issues in public opinion were followed by increases in organizational activity (i.e., creation of policy bodies and enactment of policies). The media are an important actor in this process. Support from the media is especially important when the new mindware represents a paradigm shift. Validation from powerful media outlets helps to normalize the proposed change. One example is the endorsement of several media actors, including the newspaper The New York Times, of the call for the legalization of marijuana (The New York Times, 2014).

The model assumes the crucial influence of public support on the process of building support from institutional validators, an account that is coherent with Baumgartner and 
Jones's influential framework. The more political actors perceive a consensus (and the pressure that implies) among the public, the more they will update their mindware and the more they will be predisposed to act on the issue. Another possible path to the enactment of policies occurs when political actors sense the gaps themselves and spend their political or electoral capital on sponsoring a change, even when it initially lacks popular support, as we saw in the example of seat belts in the city of São Paulo. In fact, rationalization may be a powerful force making people accept policies that they had previously rejected once they become the status quo (Laurin, 2018).

\subsubsection{EFFECTIVENESS OF POLICIES}

Even when there is political will to change the system, policies may be insufficient or inadequate. Many adopted policies are based on flawed mental models and therefore act only on symptoms. One example is the problem of traffic-related deaths in Brazil, which has led to the adoption of inefficient policies while the problem continues to grow worse year after year (Lajolo, 2017). Besides the fact that policies may be based on flawed mental models, there are the practical difficulties of changing some states of affairs, which often lead to goal erosion. Thus, it is important to realize that the effectiveness of policies will depend on the degree to which they address the root causes of problems as well as on the state's capabilities to implement public programs. Institutional response in many cases must create an institutional framework (e.g., taxation, regulation and design of incentives) conductive to the proposed change.

\subsection{CAUSAL LOOP DIAGRAM}

Based on the discussion in this chapter, we present in figure 57 the causal loop diagram, which shows six feedback loops. There are two reinforcing loops: one associated with an increase in capabilities of supporting groups and one reinforcing loop linking public support and support from institutional validators. Two balancing loops account for the effects of opposing groups on the two paths of support. Finally, the "closing the gap" balancing loop captures the final effect of all successful efforts of change. 


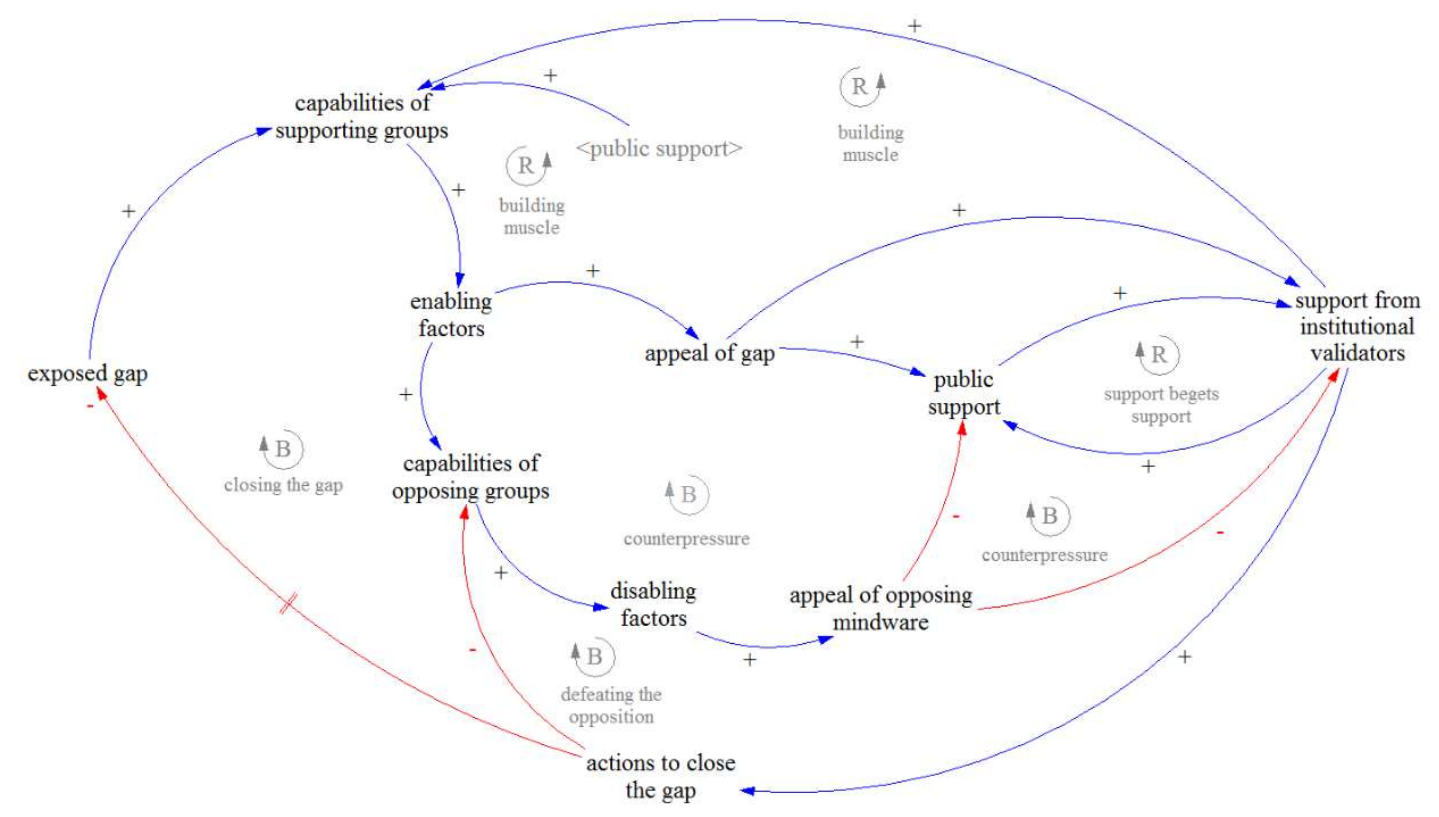

Source: Elaborated by the author.

\subsection{VALIDATION}

We employed a multipronged strategy to validate the model. The main goal was to gauge the usefulness of the model with respect to the purpose of representing the dynamics of interest (Barlas, 1996). In the process of validation, we followed most of the guidelines outlined by Senge and Forrester (1980) and Barlas (1996), performing direct structure and structure-oriented behavior tests. Special attention was given to extreme condition tests, walkthroughs, behavioral sensitivity and modified-behavior tests.

We verified whether the model was capable of replicating different social changes such as the ones exemplified at the beginning of this chapter. As part of the validation process, we also participated in meetings and online groups of an incipient Brazilian political movement composed mostly of young adults. Besides the main goal of validating the conceptual structure of the model, additional goals included gauging the extent to which the group was able to build capabilities, diagnose paths for change and increase the appeal of gaps it identified in Brazilian society. We do not discuss this political movement further in this chapter, noting, however, that it helped in the conceptualization of the model. 
We also report sensitivity tests to account for the influence of exogenous variables. One important aspect in the process of social change seems to be the persistence of groups that promote a new mindware. As enthusiasm may recede or the funding for programs (e.g., health campaigns) may decrease, we felt that the time taken to lose capabilities could be an important variable for explaining the fate of new mindware.

\subsection{STOCK AND FLOW DIAGRAM}

Figure 58 presents the stock and flow diagram. As we employed modules to decrease the visual clutter, we present them in the appropriate sequence. In the first diagram, we specify the need for input of critical parameters, which tend to vary according to the cause or mindware under study.

The model assumes that policies act on changing the current mindware about a subject. As we were interested in building a general model for social change, encompassing changes both in attitudes and in concrete policies (e.g., building nuclear plants), we opted to conceptualize the gap as a divergence between mindware. Hence, we circumvent the issue of gauging the effectiveness of policies to address the root causes of some problems that involve hard policies (e.g., climate change and its effects on the energy matrix of a country). Nonetheless, in such cases, policies that act only on symptoms will lead to the eventual reappearance of the gap. 


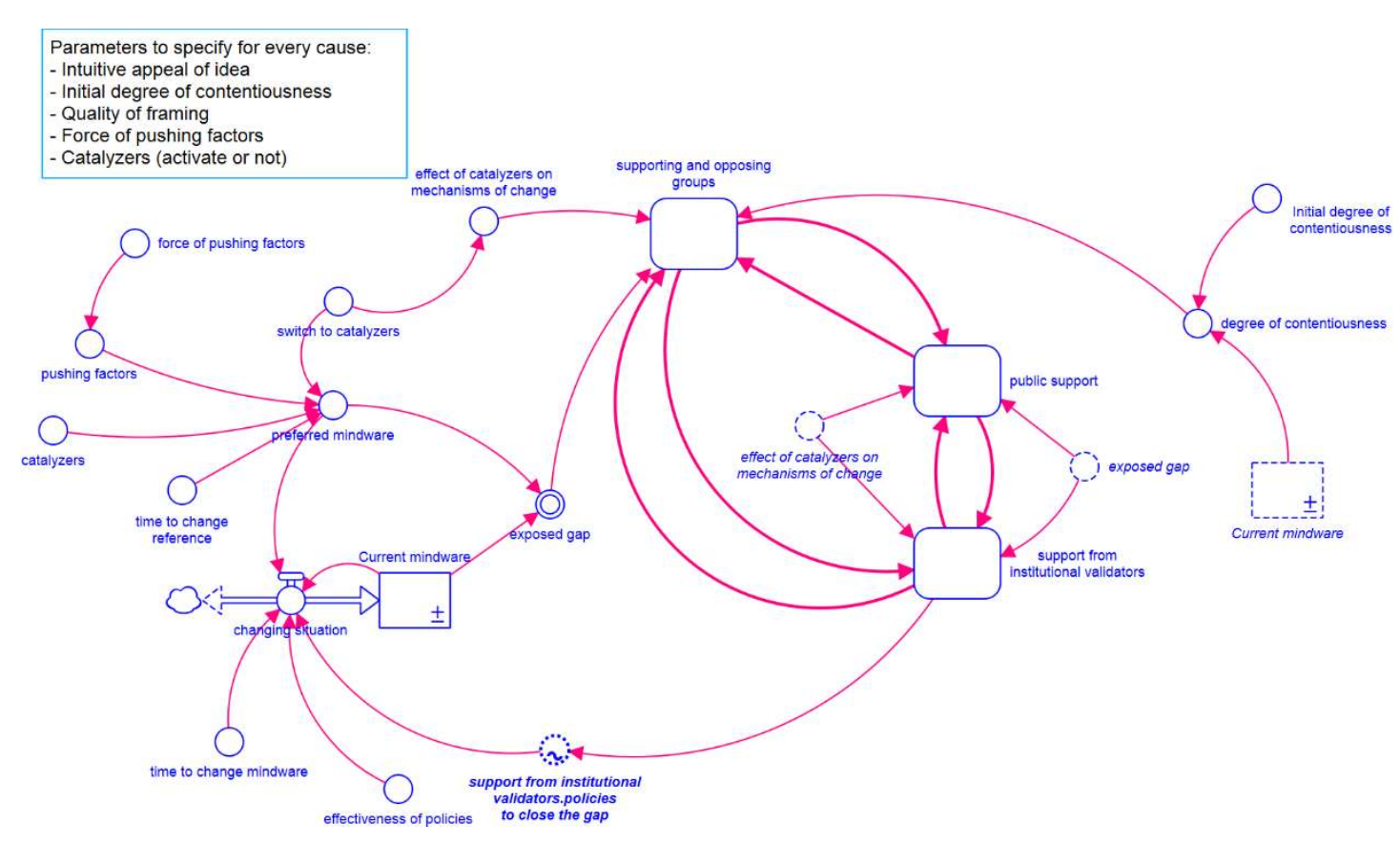

Source: Elaborated by the author.

Figures 59 to 61 present the models inside each module. Contrary to textbook recommendations (e.g., Sterman, 2000), we preferred to model the effects of some variables using weights and summative indexes (see appendix $\mathrm{F}$ for all equations and parameters in the model). We present the rationale for this choice using an example. As a new cause progresses through policy venues, the ensuing success can reverberate and help in the process of building the capabilities of supporting groups, such as lobbying. The more a group practices its capabilities, the more these capabilities improve. Thus, it is reasonable to expect the existence of this feedback loop. At the same time, the development of capabilities also depends on attracting new supporters who are energized by the new mindware's intuitive appeal and by the effect of pushing factors. Which set of effects has more influence on the rate at which capabilities are built? The model assumes that the latter path is stronger. We could represent the overall effects in the traditional multiplicative fashion, but (being fully aware of the controversial ground we are stepping into) we feel that the use of weights leads to better comprehension, in particular from audiences not trained in system dynamics. 
We also note in the module for supporting and opposing groups (figure 59) that the latter require only half as much time as the former to build capabilities. This assumption reflects the realization that the forces of inertia, status quo bias and resistance to change tend to be stronger in most instances of proposed social change.

FIGURE 59. MODULE FOR SUPPORTING AND OPPOSING GROUPS

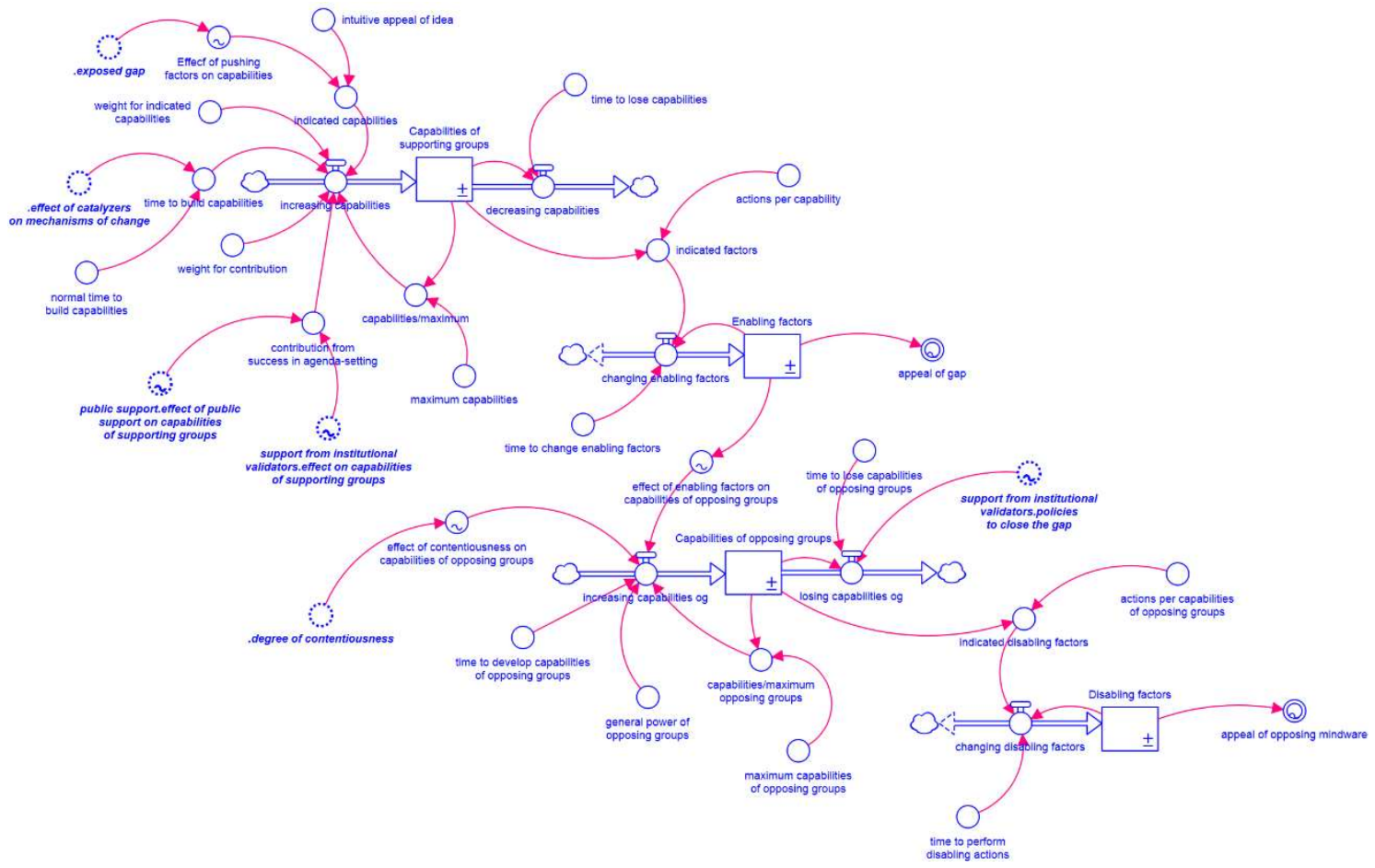

Source: Elaborated by the author. 
FIGURE 60. MODULE FOR PUBLIC SUPPORT

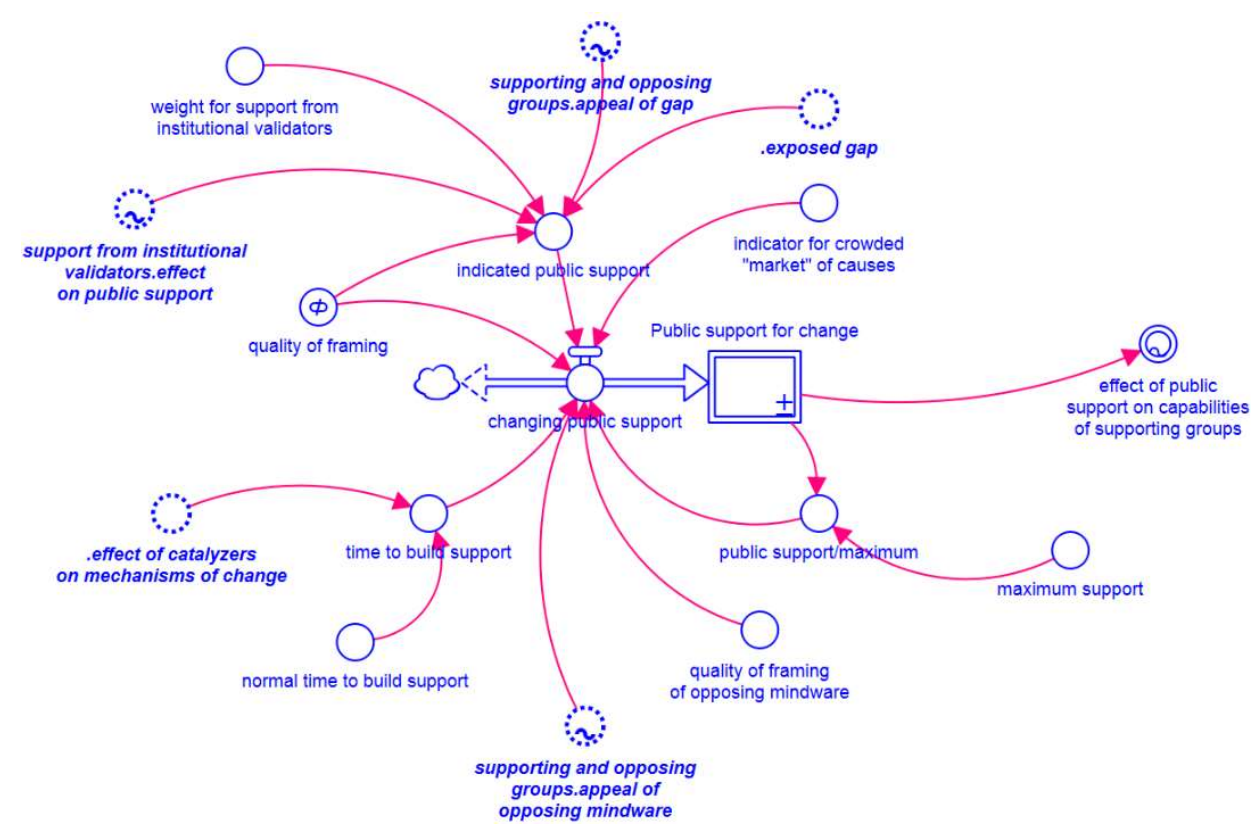

Source: Elaborated by the author.

FIGURE 61. MODULE FOR SUPPORT FROM INSTITUTIONAL VALIDATORS

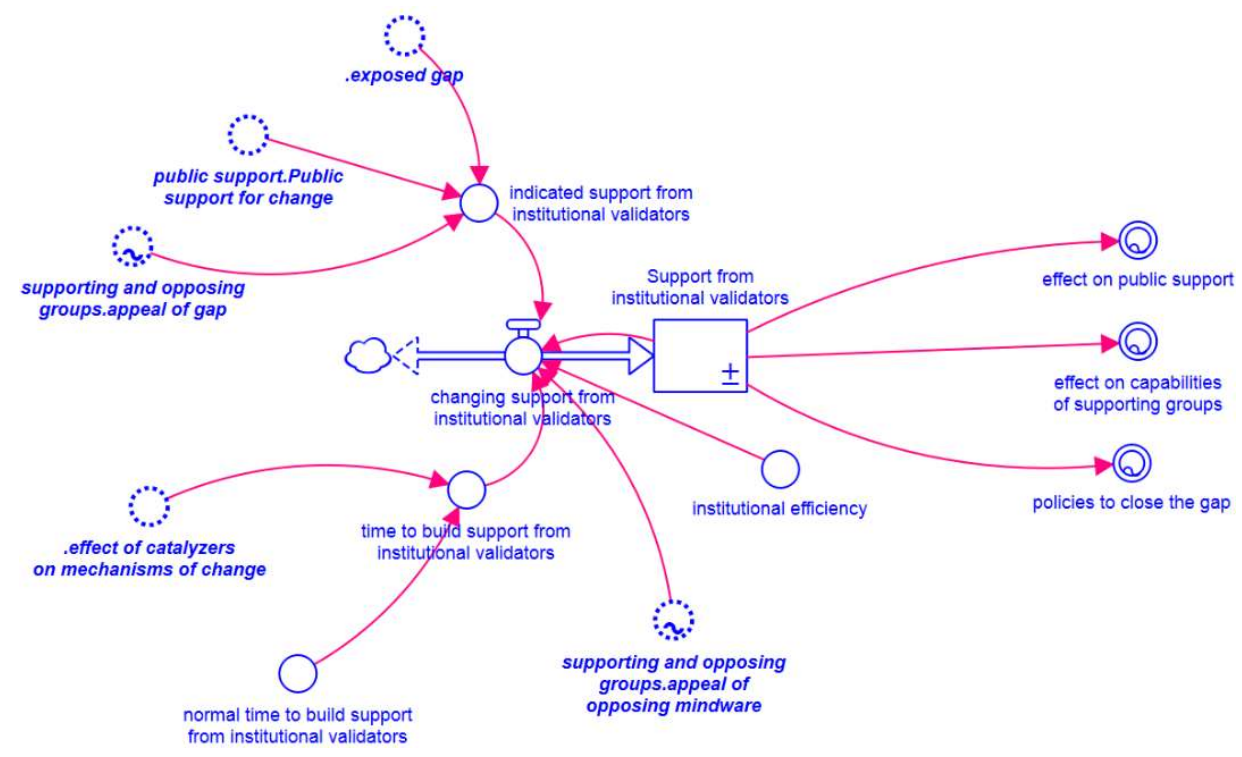

Source: Elaborated by the author.

\subsection{BASE RUN AND PROFILES OF SOCIAL CHANGE}

The base run represents a generic cause, with moderate appeal and little degree of initial contentiousness. Pushing factors increase slowly over the simulated period (50 years). 
Quality of framing is slightly above average, and the marketplace of ideas is not too crowded. Institutional efficiency is set to maximum, meaning that the policy system is able to connect fully to popular sentiment. We could be talking, for instance, of mindware that promotes policies to curb road deaths or a health campaign that aims to reduce skin cancer. The base run (figure 62) reproduces the reference mode.

FIGURE 62. BASE RUN

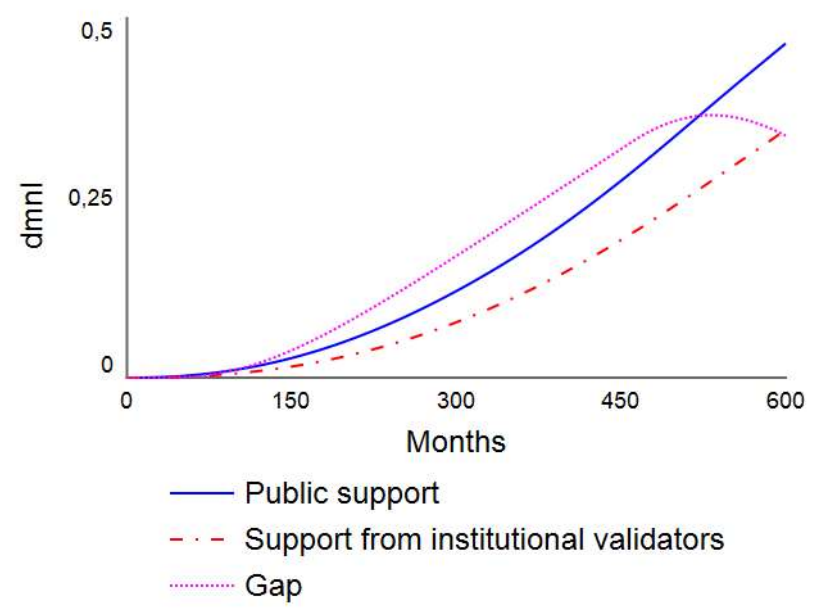

Source: Elaborated by the author.

Maintaining most parameters from the base run, we now test how the model responds to five different causes.

\subsubsection{BASIC SANITATION}

Especially in underdeveloped countries, basic sanitation is not a popular issue, regardless of its several important downstream effects in terms of the population's overall health. In Brazil, for instance, only $50 \%$ of the population are covered by access to basic sanitation (Velasco, 2017). Nonetheless, this figure represents a progress of 10 percentage points over the situation 10 years ago. We posit that the issue has been gaining prominence over a long time horizon, following the increase in the educational level of the population. It is an issue with little initial appeal and virtually no overt opposition. The only possible opposition comes from tension with other issues (and their sponsors) over public budgets. We assume an increase in appeal over time, owing to the recognition of the problem by a 
better-educated population. The simulation also assumes that the quality of framing is bland. Figure 63 shows a result that seems similar to actual developments in the Brazilian context. Interestingly, support from institutional validators increases faster than public support, which lags behind because of unappealing framing.

\section{FIGURE 63. PROFILE OF CHANGE FOR BASIC SANITATION}

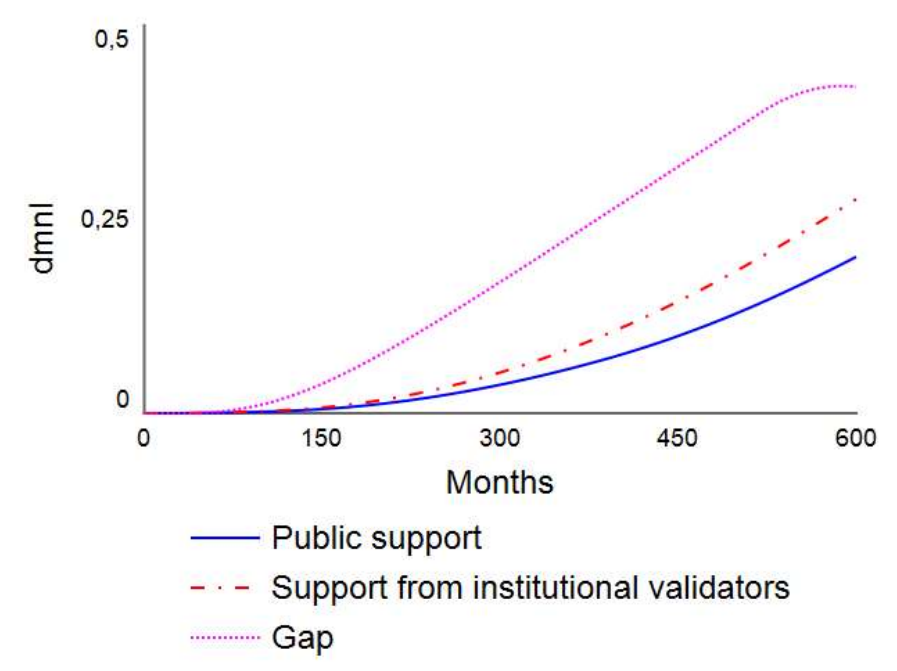

Source: Elaborated by the author.

\subsubsection{MARIJUANA}

The simulation tries to replicate the evolution of acceptance of marijuana use in Western societies. It is an issue with a high level of initial contentiousness but also with strong appeal among some segments of society. Exposure to marijuana and the associated positive tone adopted in Hollywood movies, TV shows and other elements of youth culture over the last two decades (Gilbert, 2013) has led to higher levels of enabling factors in the system. We also assume an increasing quality of framing over time. Pushing factors have a moderate force in the simulation, reflecting their nature of memetic expansion. Figure 64 shows the results. The decrease in the gap reflects the enactment of policies allowing the use of marijuana for medicinal or recreational purposes. 
FIGURE 64. PROFILE FOR CHANGE: ACCEPTANCE OF MARIJUANA

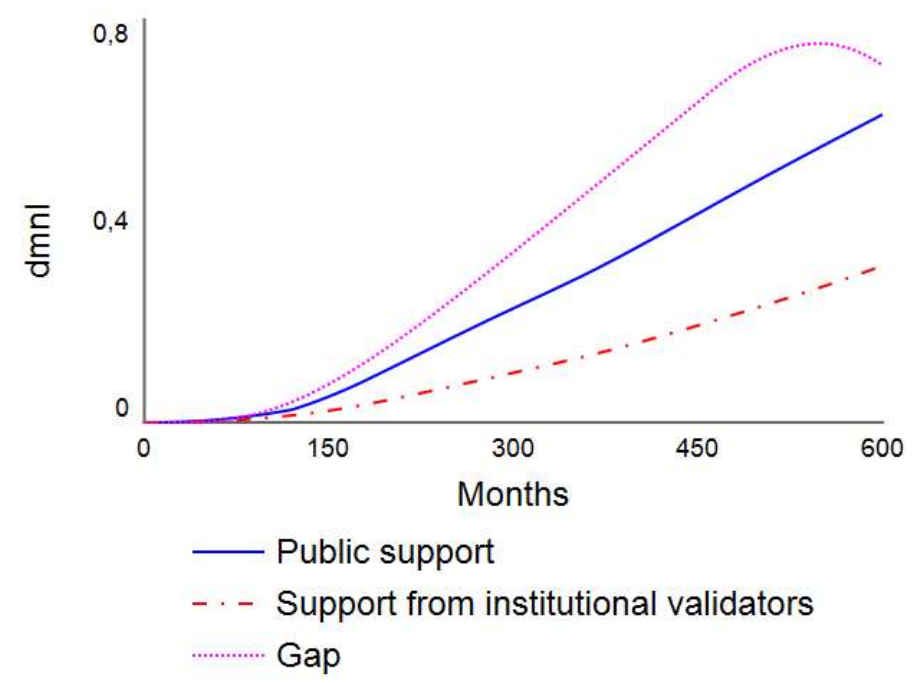

Source: Elaborated by the author.

\subsubsection{CLIMATE CHANGE}

In a popular TED talk, behavioral economist Dan Ariely (2011) claims that, if we had to design a problem to maximize human apathy, that problem would be climate change. It is perceived as an abstract event in the future; there is no perceptible feedback on its evolution; we do not see people suffering from it; it will affect other people first; and, finally, anything that we as individuals could do to prevent it is a minuscule drop in the ocean. Hence, this is a cause with low intuitive appeal. It also has a high degree of contentiousness because of entrenched economic interests that benefit from the status quo. On the other hand, we can expect the force of pushing factors to grow stronger over time, as nature keeps making the effects of climate change clearer. We also assumed that the quality of framing increases after year 20. Figure 65 presents the results of the simulation, which suggest that this has not been a popular issue. 
FIGURE 65. PROFILE FOR CHANGE: CLIMATE CHANGE MINDWARE

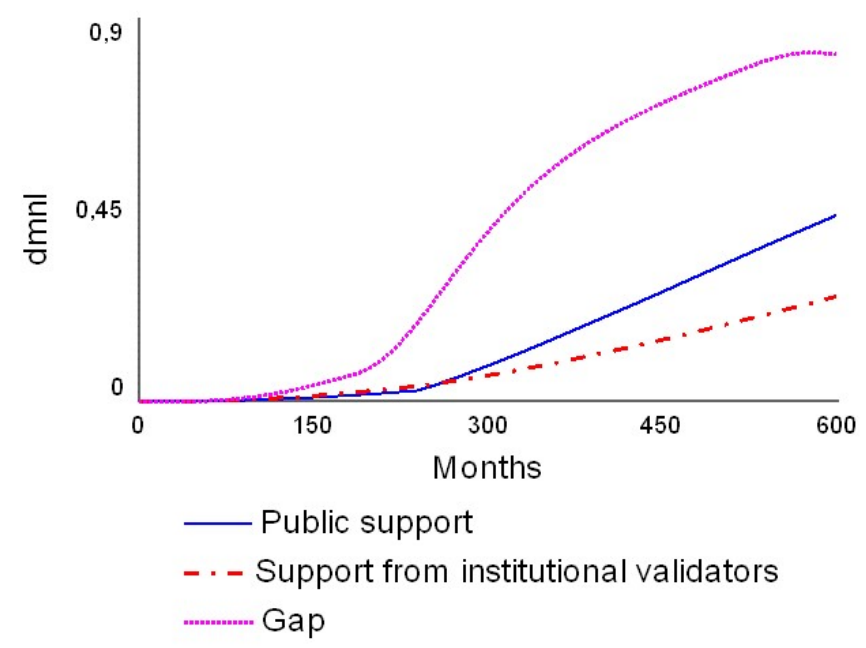

Source: Elaborated by the author.

We also tested a scenario in which a strong catalyzer was present, such as an unprecedented natural disaster capable of exposing the problem in visceral terms to skeptics, influencers and the broader public. The event occurs in year 30 of the simulation, and the model assumes that it commands a radical shortening in society's response. Since there may be a high degree of uncertainty regarding the effectiveness of policies, we assumed a moderate level of effectiveness ( 0.6 on a scale of 0 to 1$)$. Of course, the model oversimplifies the situation by assuming an efficacious response to the occurrence of a natural catastrophe (figure 66). 
FIGURE 66. PROFILE FOR CHANGE: CLIMATE CHANGE MINDWARE WITH THE PRESENCE OF A CATALYZER

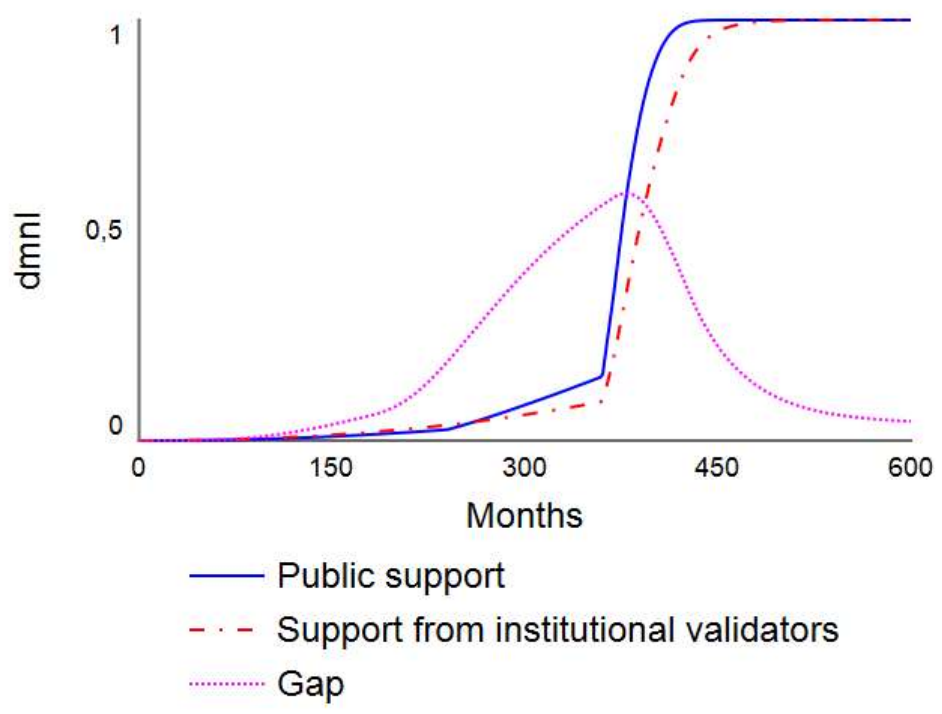

Source: Elaborated by the author.

\subsubsection{NUCLEAR ENERGY}

Nuclear energy is an interesting case. As Baumgartner and Jones (2009) report, there was widespread support in the middle of last century for building nuclear plants in the United States. However, from the 1960s, a growing opposition started to voice its concerns, slowly building support in the public's minds for its position, according to polls conducted in different years. Then, in 1979, an accident at the Three Mile Island plant played the role of a catalyzer (according to our framework), abruptly tipping public opinion against nuclear energy. Figure 67 presents the results of the simulation, which, of course, assumes the viewpoint of opponents of nuclear plants. 


\section{FIGURE 67. PROFILE FOR CHANGE: REPEALING NUCLEAR ENERGY}

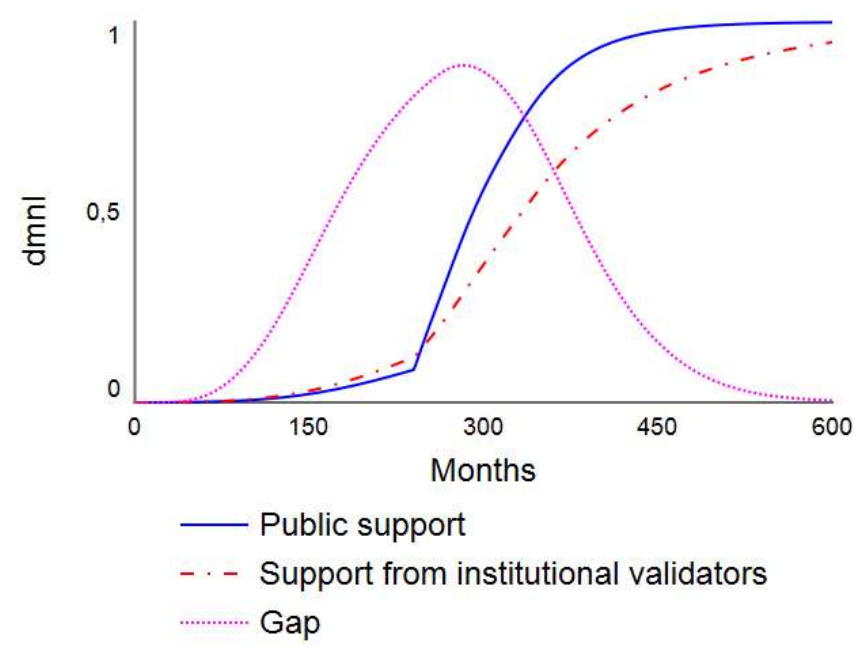

Source: Elaborated by the author.

\subsubsection{ECD DEVELOPMENT}

As seen in previous chapters, early childhood development should be the major focus of social spending in order to break the vicious cycle of low human development in countries such as Brazil, preventing several detrimental consequences such as crime and low economic productivity.

However, even without considering the distributive conflict that prevents countries with extractive institutions from developing their human capital (see chapter 6), the required policies have a long time horizon and lack the appeal of immediate solutions. The simulation (figure 68) suggests the need for unassailable persistence from supporting groups. 
FIGURE 68. PROFILE FOR CHANGE: ECD DEVELOPMENT

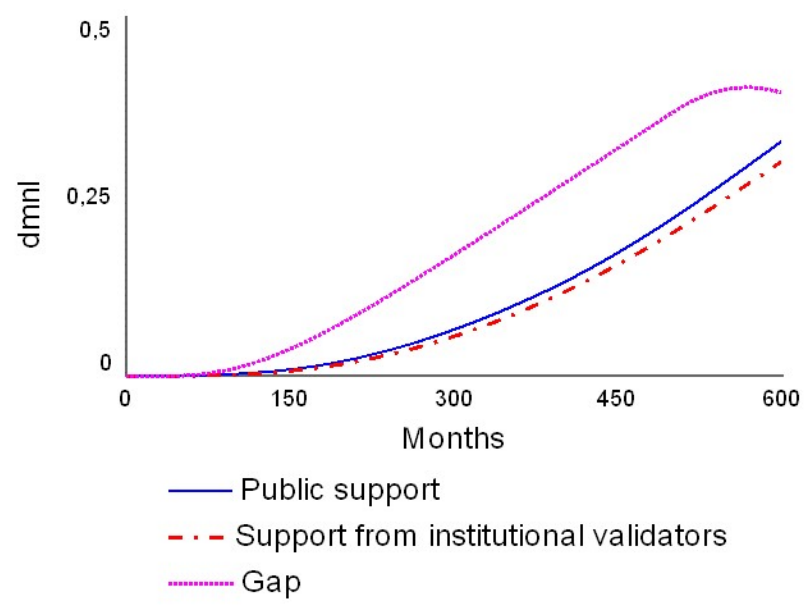

Source: Elaborated by the author.

\subsection{SENSITIVITY ANALYSIS}

We ran a sensitivity analysis using the same parameters as for the base run scenario. The analysis confirmed the general notion in systems dynamics that systems are generally insensitive to changes in most parameter values. The level of capabilities of supporting groups was shown to influence the behavior of the main variable of interest (exposed gap). Contrary to our expectations, the model was relatively insensitive to time taken to lose the capabilities of supporting groups. Counterintuitively, the capabilities of opposing groups did not exert strong influence on that variable. On the other hand, three variables - catalyzers, their effects on the time necessary to build supporting groups' capabilities and the force of pushing factors - had similar and very powerful effects on the variable of interest.

\subsection{DISCUSSION AND CONCLUSION}

"Nothing is stronger than an idea whose time has come" is a famous quote from the French poet Victor Hugo. The structure of the model presented in this chapter resembles this proposition. In the frontiers of society, several forces slowly and inevitably create fissures in current paradigms. They are natural, technological, economic or cultural forces. By creating gaps between the existent mindware and a new reference, they capture 
the interest of groups of supporters, challenging old mental models through processes that generate friction and (potentially) conflict.

The model accounts for different paths for the diffusion and promotion of new mindware. By employing the "grammar" of system dynamics to processes that have so far only been treated discursively, we expect to contribute to the literature associated with social change.

A model for social change is enriched when it integrates concepts from diverse frameworks and theories. One can find recommendations for influencing the adoption of new ideas or behaviors in the fields of marketing, social advocacy, public relations and even organizational change theory. However, those frameworks typically embody linear thinking paradigms and do not specify the dynamics that explain why some ideas thrive and others die.

Ideas compete in a marketplace whose currency is people's attention. The public has a very limited span of attention. Its bandwidth for processing the daily overload of information is narrow, and so is the mental space of institutional validators. However, some ideas, causes and mindware succeed in overcoming this barrier. They conquer hearts and minds, and some of them go on to produce change in social ecosystems.

However, not all changes are beneficial. The permission to make recreational use of marijuana, for instance, often meets considerable resistance from public health specialists, who claim that the drug's long-term effects are detrimental and partly unknown. In other words, the model is agnostic regarding the nature (positive or not) of the proposed change.

Tackling complex social problems is challenging for governments, since solutions often depend on programs that (1) need to be tested and refined before their replication at scale; (2) may elicit harsh and persistent opposition; (3) are imperfect solutions; (4) may be hard to comprehend; (5) compete with other social causes for attention; and (6) demand a long horizon of time to produce relevant results.

The model incorporates social, cultural and political spheres associated with social change. In fact, we can conceive the political system of a country as a broad "technology" that senses tensions or gaps between the problems and societal aspirations, searches for alternatives to close those gaps and, finally, enacts different measures (laws and public 
policies) to influence the structures causing the problems. The efficacy and the velocity of these processes ultimately determine a society's capacity to evolve.

Some mechanisms may sabotage the entire process. First, the systemic causes of problems are difficult to diagnose, often leading to policies that address only symptoms. Second, the results of public policies often take several years to emerge, which presents a challenge to the shortsightedness of the political system. Third, the policies often interact in unexpected ways with other variables in the system, creating new problems. Finally, the feedback from the interventions is opaque and easily distorted, preventing the development of connections between causes and consequences and updates to mental models. We can assess the efficacy of any political system by the degree to which it is able to overcome those traps.

Finally, a model dealing with gaps may also be seen as a model dealing with anomalies, resembling the processes involved in scientific paradigm shifts. Often, new scientific disciplines arise, as was the case of behavioral economics (Thaler, 2015), in response to anomalies in traditional paradigms, meeting strong resistance from status quo defenders until their superiority finally prevails.

From a practical perspective, the model proposed in the chapter can help in the articulation of campaigns and programs to promote ideas that benefit our societies, such as campaigns to promote new mindware regarding the effects of climate change.

In terms of limitations, the model does not account for the possibility of goal erosion, which may occur when a society perceives the barriers to overcome the exposed gap as insurmountable. The model also treats the current mindware as an adequate representation of the actual state of affairs, which could be an oversimplification in many cases. In addition, the reported simulations need to be validated against real cases, in particular those with the potential to falsify the model. The liberalizing trends in customs observed in Western countries are not observed in more traditional societies. Do individuals in those countries perceive the gaps in the same way but find their appeal less compelling? Or does the absence of an adequate institutional edifice prevent enablers from coming together and organizing? These limitations, among others, and the possible incorporation of loops encompassing some variables treated as exogenous in the model, remain as suggestions for further refinement of the work. 


\section{CONCLUSION}

This disposition to admire - and almost to worship - the rich and the powerful, and to despise or at least neglect persons of poor and mean condition, is (on one hand) necessary to establish and maintain the distinction of ranks and the order of society, and (on the other) the great and most universal cause of the corruption of our moral sentiments. (Adam Smith)

In this dissertation, we advocate the need for a new discipline to tackle complex social problems. Based on theoretical discussions on human development, we present integrative frameworks to understand the replication of low human development across generations. We also present a model for social change.

\subsection{SUMMARY}

In chapter 2, we identify the major gaps associated with the social marketing discipline, in particular the lack of complexity and systems thinking and the forsaking of ideas as a legitimate goal of the discipline. We note that this criticism can be levied upon similar disciplines, such as behavioral economics. In fact, this realization corroborates the claim that boundaries among disciplines are often artificial, hindering the proper understanding of complex social problems. We propose a new discipline, CSP management, with the goal of integrating knowledge from disciplines that deal with human behavior and with complexity and systems thinking.

In chapter 3, we discuss the concepts of poverty, well-being and human development. We emphasize the change in interest in modern societies from the alleviation of poverty to the promotion of social ecosystems conducive to human development and well-being. We also propose the concept of individual generative capabilities, a high-order set of capabilities consisting of self-regulation and self-efficacy. We summarize the discussion in a systems map created using the DSRP method.

In chapter 4, we review the literature on childhood development, including its biological and evolutionary basis, and common policies. We present a causal loop diagram (CLD) 
subsuming the major feedback loops that explain the intergenerational transmission of low human development.

In chapter 5, we create a stock and flow model, the Caped model, zooming in on key stocks - harshness of environmental demands and parents' and children's capabilities. We design a system dynamics model with social policies in mind. The simulations confirm the intuition that policies that reduce the prevalence of toxic stress and increase the stimulation of children in their first years of life are essential for breaking the curse of poverty.

In chapter 6, we dip our feet into the murky waters of politics and rent-seeking, constructing a model with the goal of explaining why Brazilian society has been blind to the root causes of problems created by the existence of extractive institutions. We propose a mechanism that is usually absent from the discussion of rent-seeking: narrative control by the beneficiaries of the status quo. We also acknowledge the unsustainability of the ongoing dynamics, assuming in two scenarios the possibility of a Greek-style crisis in the coming years.

Finally, in chapter 7, we propose a model for social change in general, addressing channels and constraints. The chapter introduces the concepts - catalyzers, enabling actions and pushing factors - that appear to be behind the major movements of change in recent decades. This understanding of how social change occurs is especially valuable to social actors who are interested in promoting new mindware related to full human development.

\subsection{THE GIST}

In the effort to break the intergenerational transmission of poverty, it is cheaper for a society to act earlier. In practice, every society offers a different range of opportunities for developing individual capabilities. To use the train metaphor that we employed earlier, every society has tracks to personal development, access to which depends on the conditions one is born in and on the train stops one reaches on the journey. The farther into the journey an individual is, the more expensive it is for him or her to take the right trains. Worse, from the beginning of the journey, many individuals are denied the right to upgrade. Inadequate levels of foundational psychobiological resources, lack of supportive adults, dysfunctional neighborhoods, poor-quality schools, teenage pregnancy 
and other factors lock them into a train that runs only on tracks of low human development.

Countries such as Brazil and even the United States (see Werner \& Smith, 2001) spend considerably more money treating the symptoms of problems (e.g., constructing prisons) than addressing the root causes through policies aimed at early childhood. These policies include paid parental leave (absent in the United States), universal access to high-quality childcare and high-quality health care.

On a recent visit to Brazil, Susan Fuhrman, the president of the prestigious Teachers College, Columbia University, remarked that schools have a limited role in promoting better education if other important factors that affect disadvantaged children are left unaddressed, in particular health services and high-quality education in the first years of life (Takahashi, 2018). This dissertation (in particular, chapters 3 and 4) presents models that are in concordance with Fuhrman's view.

To accomplish the goal of full human development, governments and other social actors should act before a child is born. From pregnancy onward, poverty starts imprinting its mark on human beings. In early childhood, there seems to be a short-term, prime temporal window for preventing the curse of poverty. Child development, as stressed by Campbell et al. (2002), is an ongoing process of interactions among hierarchical systems, ranging from the immediate family environment to schools, neighborhoods and other societal structures. The social consequences of not investing in early childhood, however, only appear in the long term.

As Esping-Andersen (2002) emphasizes, childhood poverty translates into fewer years of education, inferior cognitive skills, more criminality and inferior lives. Over time, the consequence is the formation of a mass of low-productivity workers who are highly vulnerable to economic shocks. These workers also produce less revenue for the tax authorities and make more demands on more social services during their active years. Moreover, this cycle of social exclusion keeps reproducing itself, not only in Brazil and similar countries, but also in developed countries.

In a quote that represents well the gist of this dissertation, Shonkoff et al. (2012, p. e237) summarize the paths taken by children who have gone through the worst environmental conditions during sensitive developmental periods: 
Adolescents and adults who manifest higher rates of risk-taking behaviors are also more likely to have trouble maintaining supportive social networks and are at higher risk of school failure, gang membership, unemployment, poverty, homelessness, violent crime, incarceration and becoming single parents. Furthermore, adults in this high-risk group who become parents themselves are less likely to be able to provide the kind of stable and supportive relationships that are needed to protect their children from the damages of toxic stress. This intergenerational cycle of significant adversity, with its predictable repetition of limited educational achievement and poor health, is mediated, at least in part, by the social inequalities and disrupted social networks that contribute to fragile families and parenting difficulties.

$(\ldots)$

It is also important to address the enormous social and economic costs of toxic stress and its consequences for all of society. The multiple dimensions of these costs extend from differential levels of civic participation and their impacts on the quality of community life to the health and skills of the nation's workforce and its ability to participate successfully in a global economy.

However, as we saw in different chapters, what prevents societies from addressing the root causes of the problem is the combination of inadequate mindware, extractive institutions and unequal sociopolitical structures. The blueprint for the creation of desirable social ecosystems is still lacking. Even the laudable European welfare state model - perhaps the closest model to an ideal of collective well-being ever developed is criticized for hindering growth in employment and competitive knowledge-intensive economies (Esping-Andersen, 2002).

The goal of empowering citizens and communities by developing their capabilities calls for a new welfare architecture. Modern economies will increasingly demand strong cognitive skills and professional competences. New family structures, an aging population, harsher environmental conditions and strained public budgets are further complex associated challenges for which no satisfactory repertoire of solutions has so far been developed. The challenges are even more acute for underdeveloped countries such as Brazil.

\subsection{THE ROLE OF MARKETING}

Philip Kotler, the co-founder of social marketing, advocates in a recent book the use of social marketing's repertoire of tools in the effort to eradicate poverty in the world 
(Kotler, 2015). He also recognizes the need for a new comprehensive framework that combines capitalism, management and marketing to understand marketplace developments and its impacts.

A marketing perspective on poverty identifies three kinds of behaviors (Kotler, Roberto, \& Leisner, 2006; Kotler and Lee, 2009). First, there are behaviors that are associated with the replication of poverty, such as unwanted pregnancies, alcohol abuse and a preference for low-risk, low-return income-generating activities. Second, there are behaviors that are associated with escaping poverty, such as the use of irrigation systems to improve crop productivity or the adoption of microfinance instruments. Third, there are behaviors that should prevent poverty, such as maintaining teenagers in school. A marketing perspective also entails the use of classic tools from the discipline, such as market research and segmentation. However, as we have discussed, this is a very limited perspective. It acts mostly on symptoms instead of root causes, it ignores systemic determinants of poverty and the role of institutions, and it does not account for the role of mindware in the perpetuation of the problem.

In his novel The Jungle, Upton Sinclair equates advertising with "the science of persuading people to buy what they do not want" (Sinclair, 1906/2014). This vision is widespread. The popular writer Nassim Taleb equates marketing with "bad manners" and highly unethical practices (Taleb, 2012). The monolith of meaning of marketing (as defined in chapter 2) is a relevant barrier to its use.

Nevertheless, a marketing perspective is still needed in interventions to tackle poverty and human development. Consider the case of home visits to poor families, a popular policy in the repertoire of social interventions. Research on its effectiveness in the United States has shown weak results (Osborne, 2016). In fact, one of the problems behind the low rates of success of this kind of intervention seems to be the blind replication of the same recipe, without adjustment to particular cultural or social contexts. This kind of problem has been defined as one of the plagues of public programs - what Banerjee and Duflo (2012) refer to as ignorance, which forms a triad with inertia and ideology.

However, we see the problem as the lack of a marketing perspective with appropriate sensitivity to social context and the adoption of a citizen-centric perspective. Of course, public programs that depend on scale for their cost-effectiveness require a set of core elements, but we argue that those elements should not be based on bureaucracy and topdown perspectives. 
Osborne (2016) goes in the right direction in the case of home visit programs (HVPs) by stating that public policy makers should require the identification of the core conceptual elements that produce the expected changes. In addition, she defends a flexible approach to providing families with the resources they actually need (p. 40):

Ideally, every mother during pregnancy and at birth would receive one home visit devoted to parenting education, screening for potential risk factors, and connecting with necessary resources. Mothers with identified risks would receive additional home visits commensurate with their needs.

Thus, marketing provides a valuable perspective on public policy, and it must be retained in the toolset of CSP management.

\subsection{THE FUTURE AND THE BARRIERS}

At this point in history, the complete elimination of poverty in the world seems utopian. Similarly, most countries have not been able to produce social ecosystems that foster ideal conditions for the full development of human potential. There are several challenges on the medium-term and long-term horizon that will limit the actions of governments and societies. However, we could heed Sachs' (2005) advice and strive for collective goals that include fostering political systems that promote human well-being and fostering economic systems that spread the benefits of science, technology and the division of labor to all parts of the world.

The results of this work provide several suggestions for public policy makers, public executives and other social actors involved in fighting poverty and promoting human development. System dynamics simulations have the potential to dramatically change the thinking of stakeholders (Ford, 2010). However, to change that thinking, it is necessary to go beyond system dynamics and the traditional repertoires of social marketing. It is necessary to intervene in the very fabric of cultural discourse, assembling scienceinspired, compelling narratives and promoting the corresponding mindware to strategic social segments and the public at large.

As we were finishing this dissertation (at the beginning of 2018), hundreds of thousands of young people were marching in the streets in the United States and Canada to demand 
stricter laws on gun control. Time will say whether these enabling actions will be translated into effective policies. The model presented in chapter 7 suggests that these actions have the potential to produce social change. Similarly, if societies could sense the gap between their current state and the potential afforded by an orientation toward full human development - and if they could understand why this gap really occurs - then there would be greater chances of progress. However, this development depends on the design and active promotion of adequate mindware. Ideas rule the world.

Barriers are diverse, and many are related to the predominant mindware. The first one is the idea of continuous progress and blind faith in technology. As Laland (2017) claims, our modern era began with agriculture, and this first key innovation led to an exponential growth in technologies and ideas, culminating in what he calls today's "innovation society." Critically, the ideology of our modern societies assumes that innovations solve problems, ignoring their potential to create many other problems. We can easily discern in modern cultures the underlying belief that technologies will resolve our problems, from world hunger to health and educational deficits. Continuous progress is taken for granted, easing the pressure to address today the complex social problems of our times.

Other mental models in play reflect the belief that the poor deserve their fate, the "drop in the ocean" effect and the lack of salience of the hardships endured by the poor. The just world hypothesis, which proposes that human beings want to believe in a fair world, holds that people tend to blame the victim when they (the evaluators) cannot do anything to prevent the inequity (Lerner \& Simmons, 1966). Similarly, the belief that strong actions to ameliorate the hardships in the lives of the poor are just a drop in the ocean may lead to inaction and paralysis. In addition, the miseries of the poor often remain out of sight in our societies (Loewenstein \& Small, 2007) and rarely mobilize one of the scarcest resources in the modern world - human attention.

Beyond mindware and lack of systems thinking, the major barrier seems to be the political structures in a society. As we saw in chapter 6, extractive institutions lead to the prevalence of a society that has a reversed Robin Hood nature. In such a context, rentseekers control the repertoire of available solutions to societal problems, leading to the prevalence of band-aids, which drain the impetus for addressing root causes. However, the pattern of extraction of societal resources in Brazil is clearly unsustainable. The continuous increase in public debt has taken the country to the brink of a crisis. The crisis, if it occurs, may be a catalyzer for change, but its outcomes are unpredictable. The 
possibility of an outcome that leads to the creation of favorable social ecosystems depends on the availability (and appeal) of adequate mindware. Thus far, we would deem this scenario improbable.

Finally, there are some limitations to this research. First, the models are not associated with actual programs, which would help in their validation. In the effort to validate the models, we have made contact with numerous social change agents, governmental agencies and nonprofit organizations, with different degrees of success. More "realworld" validation is still needed.

There is also a limitation associated with the use of the system dynamics method, which has limited ability to account for heterogeneous behaviors. Agent-based modeling is a complementary methodological approach that can help in the design and validation of the integrative models inasmuch as it is best suited to modeling individual agents.

We also note that we did not measure or test mental models or mindware. We assumed in chapter 6 that documents from political parties are a valid sample of current mindware, but this may be a fragile assumption. More research (and theoretical work) is needed regarding how to systematize the sampling of societal mindware.

Finally, we note that the models can be improved through the incorporation of aging chains reflecting population dynamics. We chose, instead, to focus on the dynamics of attributes and intangible stocks, but the phenomena studied in this work certainly depend on the prevalence of those stocks in different segments of the population. This limitation is particularly relevant to the Caped model (chapter 5).

All these limitations remain as suggestions for future improvement in the models. 


\section{APPENDICES}

\subsection{APPENDIX A: ADDITIONAL DISCUSSION OF MENTAL MODELS AND POLICIES TO ADDRESS HUMAN DEVELOPMENT}

\subsubsection{AN EXAMPLE CONTRASTING LINEAR MENTAL MODELS AND SYSTEMS THINKING}

We discuss here the case of hunger, or chronic undernourishment. Hunger means that a person is not able to acquire enough food to meet the daily minimum dietary energy requirements over a period of one year (Food and Agriculture Organization of the United Nations, 2015).

Will human societies ever eradicate hunger in the world? Cabrera and Cabrera (2015) stress that there is enough food to feed the world, but the reason that the problem of world hunger cannot be solved is the lack of a mental model that accounts for the social, economic, political, motivational and cultural issues that shape the problem. Figure 69 presents the evolution of world hunger over recent years, contrasting it with metrics that were proposed at the dawn of the new millennium: the Millennium Development Goal (MDG) and the World Food Summit (WFS).

\section{FIGURE 69. WORLD HUNGER}

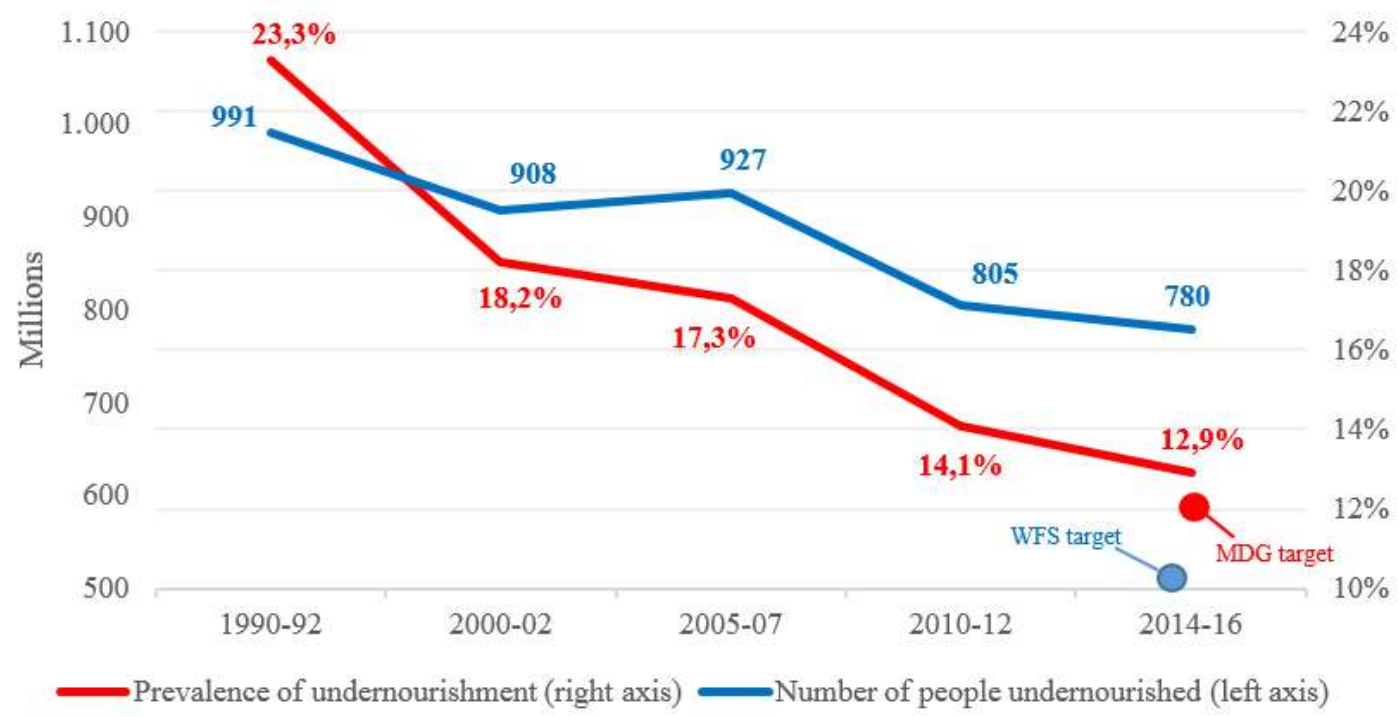

Source: Adapted from Food and Agriculture Organization of the United Nations (2017). 
While the reduction observed in figure 69 is substantial, it is nonetheless uneven across global regions. Figure 70 presents the evolution of undernourishment in the main regions of the world. Great progress was made in Latin America and Southeast Asia. However, sub-Saharan Africa and the Caribbean remain plagued by hunger, notwithstanding the increasing salience of the moral appeals that usually motivate donations to organizations dedicated to this cause. In the latter region, Haiti is a dramatic case, a country where more than $50 \%$ of the population is undernourished $(22 \%$ of children aged under five are stunted) and 59\% live in poverty (United Nations World Food Programme, 2016). Haiti is only 1,000 kilometers away - a mere two-hour flight - from the richest country in the world, the United States.

FIGURE 70. UNDERNOURISHMENT TRENDS IN THE WORLD

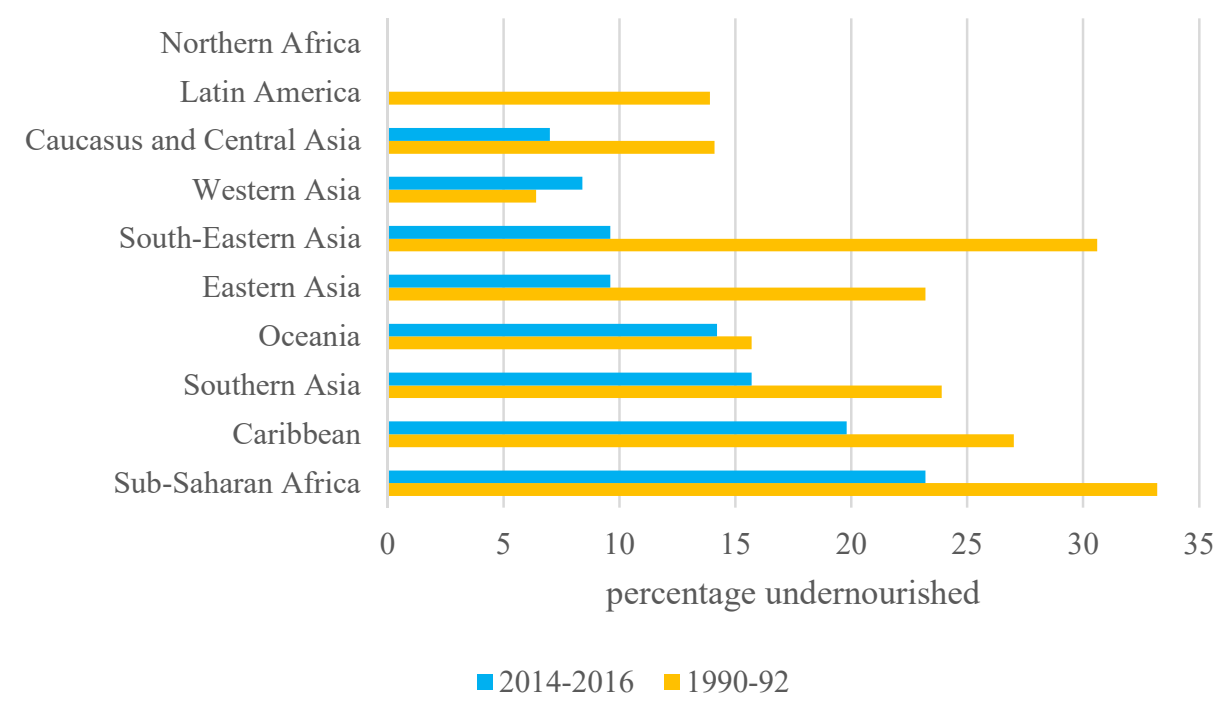

Source: Adapted from Food and Agriculture Organization of the United Nations (2017).

Hunger has all the hallmarks of a complex social problem, but one aspect in particular is worth noting: it has been tackled with interventions based on linear mental models. Such models ignore geographic, demographic and economic aspects of the social ecosystem that produces the phenomenon. Most interventions, while well intentioned and bound to alleviate human suffering to some degree, cannot eliminate the problem because they usually do not act on the system's key pressure points. 
How would a system dynamicist represent the problem of hunger? Saeed (2016a) states that most of the public policies implemented in developing and poor countries can be placed in three broad categories according to their intent: (1) policies aimed at increasing food production, including supplementation by food aid and imports, (2) policies aimed at limiting population growth, and (3) policies that strive to help the poorest population segments.

Saeed's work is a new edition of his 1994 book, so it does not account for a more recent kind of intervention aiming at increasing resilience in social ecosystems. Such interventions encompass investments in the development of economic assets and the creation of economic infrastructure and incentives (e.g., cash transfers conditional on the acquisition of locally produced food) with the goal of providing self-sustaining economic dynamism in the affected regions. Saeed's model, to be fair, accounted for efforts such as the organization of small farms into cooperatives, the introduction of small-scale technologies and the provision of institutionalized financial assistance. It remains an open question whether modern approaches are qualitatively different from traditional ones. Nonetheless, it seems clear that both traditional and modern interventions have been unable to make significant headway in the most acute cases (the sub-Saharan African and Caribbean regions).

Unsurprisingly, the systems producing hunger exhibit resistance to change. In Saeed's model, this resistance springs from the structures of wage determination and capital ownership and the relationships among population growth, food adequacy and living standards. Before delving into a more detailed account, a brief pause is warranted to place in context traditional social marketing programs aimed at fighting hunger or poverty.

Social marketing initiatives are likely to follow some widely accepted recommendations for fighting hunger, namely increasing food production by effective use of agricultural resources and better seeds, fertilizers and farming equipment. Growth in agricultural productivity is a common recommendation (Food and Agriculture Organization, 2015).

Similar initiatives that would call for social marketing programs include improving transportation facilities, fighting waste, identifying and promoting the most economical source of edible calories and family planning campaigns. In fact, all the programs and initiatives discussed in Kotler and Lee (2009) fit squarely with these traditional recipes for fighting poverty and hunger. It is still popular among nonprofit organizations to distribute food to the poor in vulnerable regions as a means of alleviating hunger (e.g., 
Food for the Poor ${ }^{6}$. Even behavioral economics, the most successful competitor of social marketing in the marketplace of ideas, has not been able to offer a comprehensible theoretical framework for the elimination of hunger or poverty. While doing a better job at making salient the influence of situational factors in the perpetuation of the problem, most work in behavioral economics comprises small-scale experiments that deal with the phenomenon at the micro level (e.g., Mullainathan \& Shafir, 2013).

However, the problem with those approaches is the underlying mental model that guides apparently obvious recommendations. As figure 71 shows, the mental models associated with traditional approaches are linear models. They ignore how systemic forces can endogenously produce hunger and undesirable equilibrium states.

\section{FIGURE 71. USUAL MENTAL MODEL ELICITED TO FIGHT HUNGER}

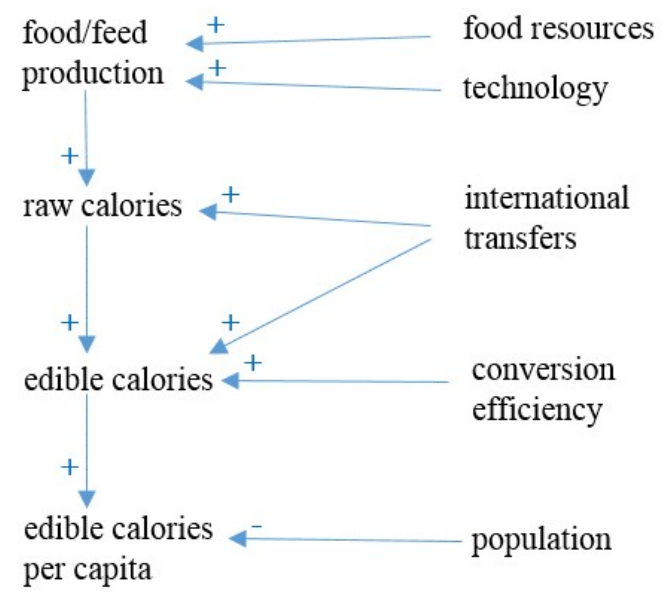

Source: Adapted from Saeed (2016a).

Saeed (2016a) develops a model (in two versions) that captures crucial interrelationships in this complex system (figures 72 and 73). As he emphasizes, the advantage of having such a model, whose behavior must necessarily derive from its structure, is that it can explain policy resistance endogenously instead of resorting to personal or incidental factors.

\footnotetext{
${ }^{6}$ www.foodforthepoor.org
} 
FIGURE 72. REVISED MENTAL MODEL FOR HUNGER POLICIES

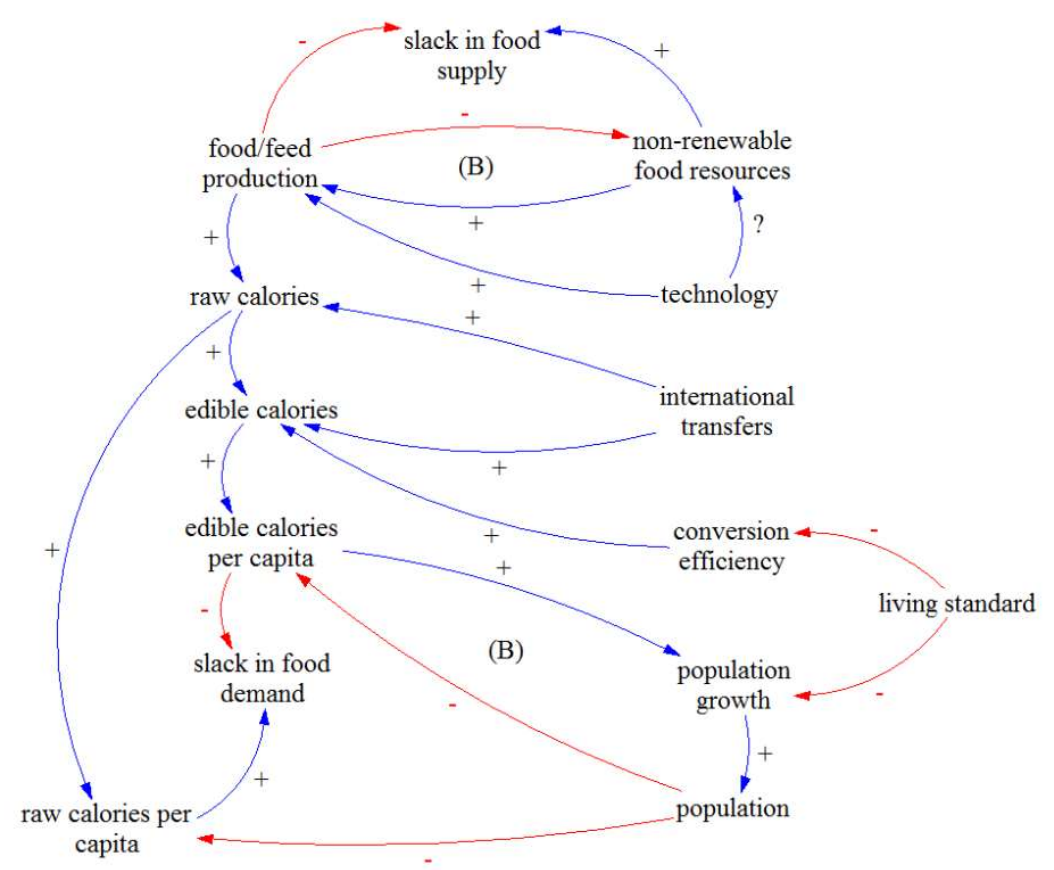

Source: Adapted from Saeed (2016a).

In turn, the correspondence between the policy resilience exhibited by the model and the actual developments in the real world is more than a source of confidence in the model's structure. It is a call to redefine public policy, which should strive to influence the strength of certain feedback loops or to change the structure or the goals of the system. 


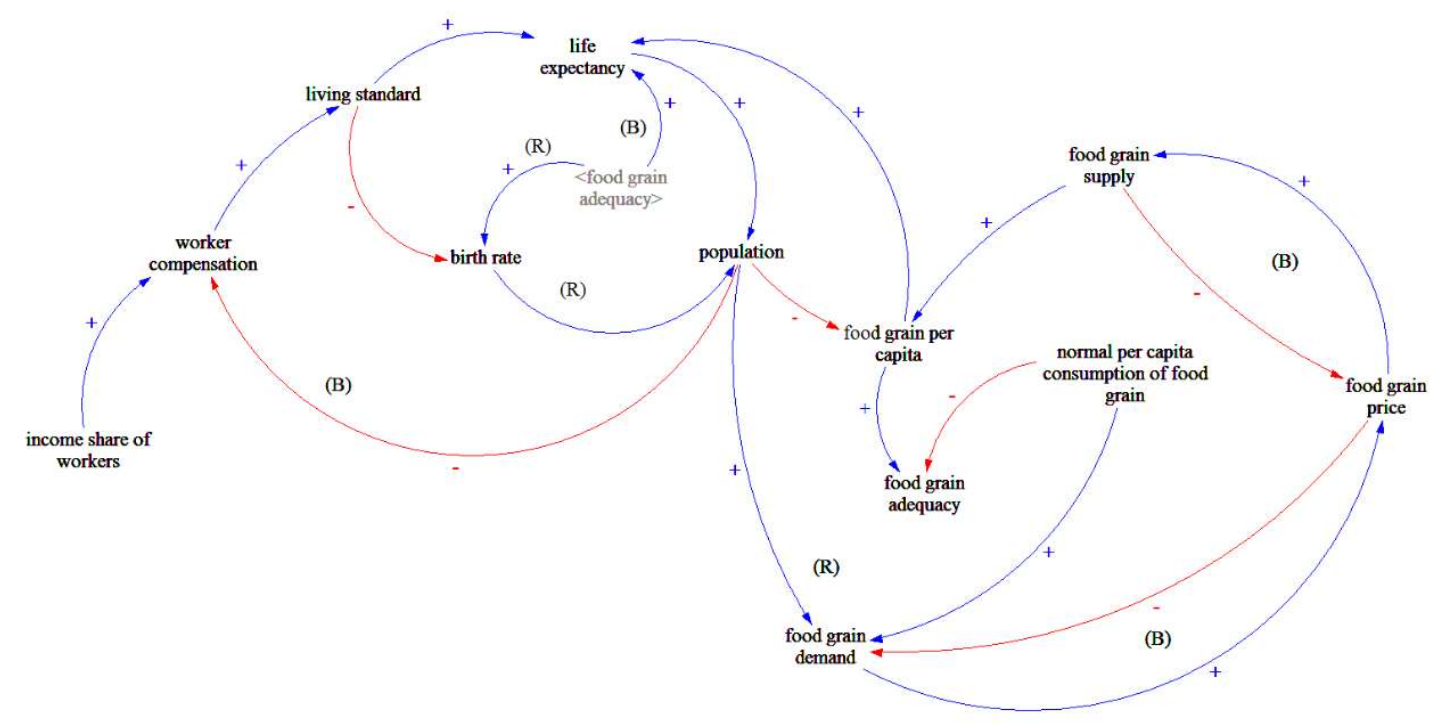

Source: Adapted from Saeed (2016a).

Figure 73 presents Saeed's revised models of the fight against hunger, including four negative feedback loops and a few positive feedback loops that, without any consistent intervention, only speed up the process of adjustment toward an undesirable equilibrium. In this model, only changing the internal goals of the system can prevent the short-lived gains associated with well-intentioned interventions. Two promising entry points for changing the internal goals of the system are increasing the income shares of the workers and the nature of cereal consumption per capita. Both changes would make the system resilient to the normal oscillations that happen in a predictable pattern (for instance, the droughts in the Sahel region of Africa), creating slack in food supply and in food demand. The slack can be absorbed during difficult times.

Changes in income shares of workers, however, are obtained not through radical means but by fiscal measures, such as the imposition of a heavy tax on rent income, which creates a flow of capital resources to self-employed workers. The ensuing rise in their income improves living standards, raising life expectancy and decreasing the birth rate.

In turn, changes in the nature of food consumption can be obtained through an increase in the proportion of animal protein in the diet. While animal protein requires more density 
of cereal production, a diet consisting mostly of raw cereals demands lower levels of production. Hence, when animal protein is part of the national diet, cereal production must rise, since animals (cattle, pigs, etc.) feed on cereals, and there is a loss (in caloric terms) in the conversion from cereals to meat. In other words, to provide the same caloric amount through meat, a society must produce greater levels of cereal. In terms of a national diet, thus, animal protein works as a buffer against bad times, acting like a cereal conversion mechanism that also provides complementary nutrients.

The introduction of those changes sets in motion important feedback loops. The increase in demand for cereals raises prices, increasing production after a typical delay. The increased production, when coupled with increases in workers' capital ownership, leads to more income flowing to households, elevating the opportunity costs of labor, pushing up further compensation demanded for wage-employment and raising living standards again, which diminishes the birth rate and increases life expectancy (a true virtuous cycle). The combination of such policies provides slack in the system that can be exploited in periods of crisis - when the population can resort to more economical patterns of consumption based on cereal grains.

The relevant point here is not the validation of Saeed's model, which presents a different set of solutions to the problem of hunger than traditional approaches. The relevant point is the demonstration of the inability of commonsensical, linear mental models to account for second-order effects of policies. They have been unable to address the problem of hunger, failing to produce significant progress in regions such as sub-Saharan Africa.

\subsubsection{THERE IS LITTLE GUIDANCE ON HOW TO ADDRESS POVERTY FROM A COMPLEXITY PERSPECTIVE}

Só, Franco, Carvalho, Santos, and Armenia (2018) discuss common recipes found in the economic literature for breaking the vicious cycles of poverty. They found strong divergences among the main exponents of that literature (such as Jeffrey Sachs) and identified the lack of a roadmap validated by evidence for breaking out of poverty traps. Nevertheless, most authors emphasize the role of capabilities in the effort to lift countries out of poverty; some authors emphasize state or institutional capabilities, while others focus on human capital and related individual capabilities. 
Adopting an unusual but promising approach, Lade, Haider, Engström, and Schlüter (2017) propose a framework to classify poverty alleviation strategies based on resilience thinking (table 15). The main contribution of this framework comes from the nuances it uncovers. Traditional thinking on the subject tends to concentrate on providing inputs or assets to push people over the barriers between poverty and economic growth. These approaches may be effective in many cases, but in many other instances they can lead to resource depreciation (e.g., by increasing environmental degradation) and cause more poverty in the end. Approaches inspired by resilience thinking, on the other hand, tend to integrate knowledge of how physical, natural and cultural endowments may create poverty traps. Such approaches facilitate the creation of new developmental pathways for overcoming poverty - for instance, through the integration of traditional practices that conserve the environment.

Table 15. Poverty alleviation pathways

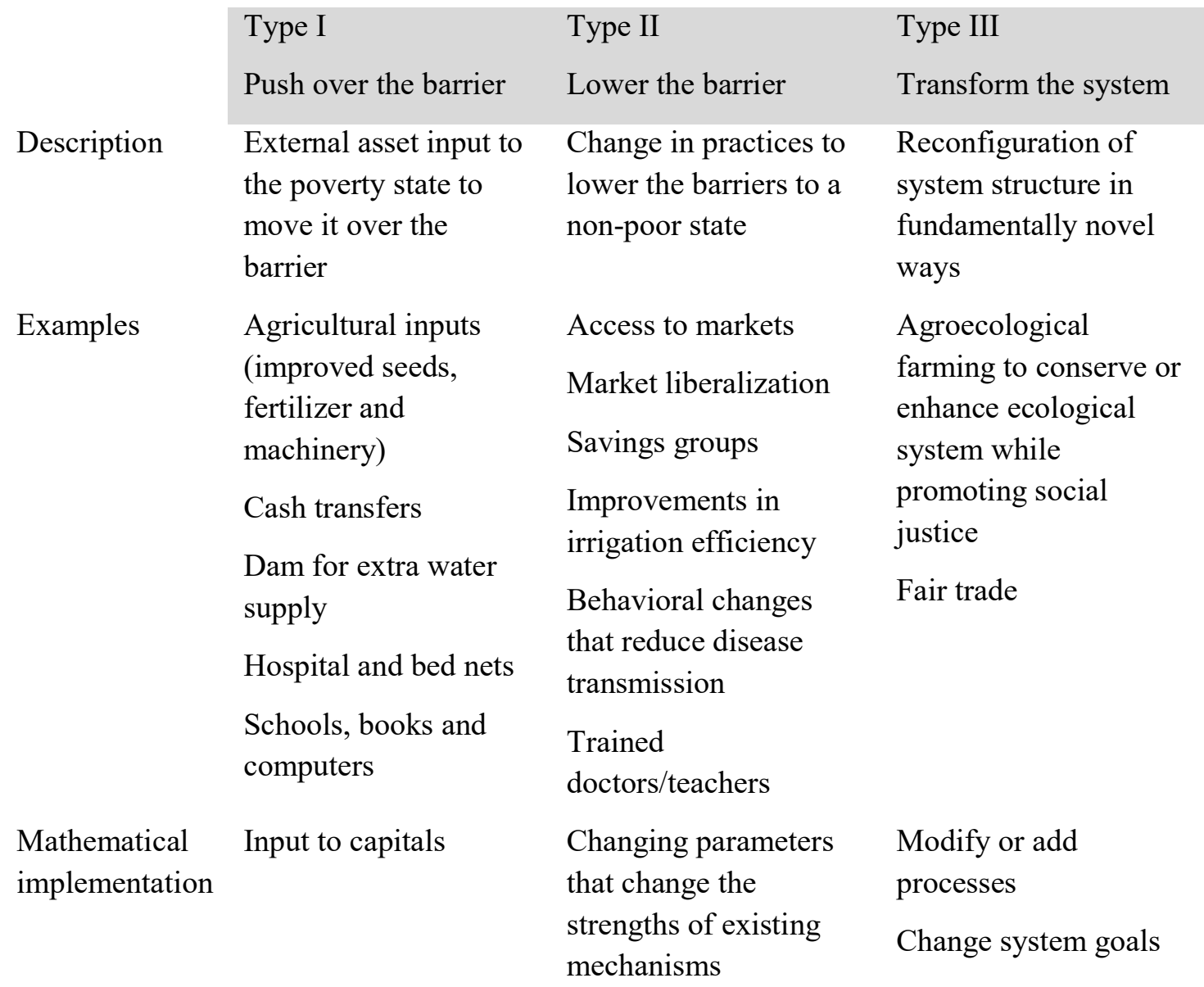

Source: Adapted from Lade, Haider, Engström, \& Schlüter (2017). 
The framework presented in table 15 represents an innovation in traditional thinking about poverty. Nevertheless, as in the case of more traditional thinking, it does not account for the long-term, dynamic effects of policies, which are one of the hallmarks of complex social systems. It also does not account for stocks conducive to human development in social ecosystems, such as human capital and individual generative capabilities (see chapter 3). Finally, it does not address political processes and structures that often explain the persistence of poverty traps (see chapter 6). 


\subsection{APPENDIX B: MORE DETAIL ON SYSTEM DYNAMICS AND ITS NOTATIONS}

System dynamics piggybacks on what Repenning, Kieffer, and Astor (2017) define as the most underrated management skill: the capacity to identify what problem one intends to address. Defining problems is often more important than jumping to possible solutions.

The method of system dynamics has been applied to a myriad of complex social problems that defy common, linear mental models, such as cocaine epidemics (Homer, 1993) and educational reform (Hirsch, Levine, \& Miller, 2007).

This research paradigm puts the researcher very close to the studied phenomenon, in particular if one follows the iterative process proposed by Sterman (2000) and consisting of five interdependent steps: problem articulation (including boundary selection), formulation of a dynamic hypothesis, formulation of the model, testing, and policy formulation and evaluation (figure 74). The process is not a linear sequence but a cycle. The web-like symbol in the middle and the circle of arrows around the edge indicate that iteration is a natural part of the process. The modeling process starts with the system's behavior and initial ideas about feedback structure, and then, gradually, a model takes shape. It is common for modelers to revise, for instance, the problem and the model boundary as they develop a dynamic hypothesis and draw causal loops. This iterative process allows a deep learning process by which one can investigate and clarify ideas as well as uncover the true drivers of a system's behavior. 


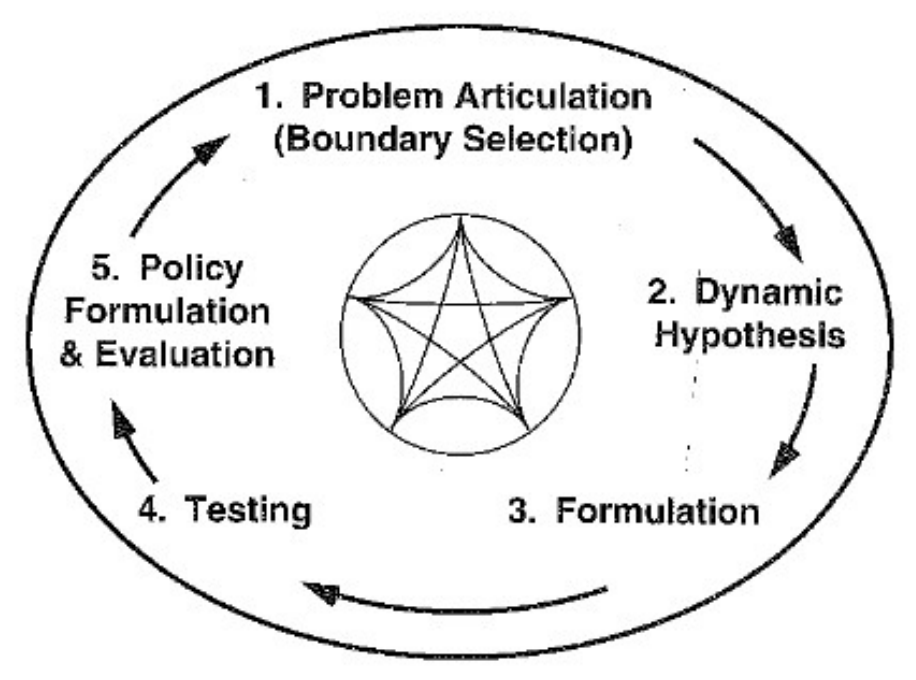

Source: Sterman (2000).

System dynamics models are not predictive models. They are useful for understanding why general patterns of change, such as growth, decay and oscillations, occur. On the other hand, system dynamics models are also evolutionary models inasmuch as they can exhibit multiple equilibria, path dependency, self-organization, chaos, time irreversibility, dormant structures and evolution to increased levels of complexity and entropy (Radzicki \& Sterman, 1994).

However, the discipline of system dynamics still faces its own limitations, and it struggles to be part of the mainstream repertoire of methods for addressing complex social problems. Richardson (1996) points to several factors limiting the growth of the field, including the inexistence of a stock of shared understandings with predictive power. For instance, he argues, it is hard to identify in the system dynamics literature a list of dynamic insights about economic development.

We argue that the limitations of the discipline have two major underlying causes. First, as a collective inquiry organized through a community of practice, it lacks sufficient organizational dynamic capabilities (Warren, 2008) to overcome the shortcomings pinpointed by Richardson (1996). Second, as a discipline competing in the marketplace of ideas, it lacks a marketing orientation to create a better positioning in the minds of relevant social actors. In this sense, its challenges are not very different from those of other mindware competing for human attention. 
Finally, one important limitation is that discussed by Biroscak (2014). The endogenous point of view, which is the hallmark of the system dynamics field, may sometimes blind the modeler - or the stakeholders to whom he or she reports - to the possibility of "black swans," truly unexpected exogenous shocks that can alter the fate of a system.

Table 16 presents the elements and notations of system dynamics models. The notations refer to the Stella Architect software (Isee Systems, 2016). 
Table 16. Elements of system dynamics models

Element Notation Description

Level/stock

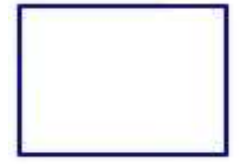

Source/sink

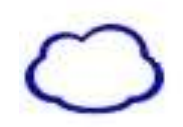

Rate/flow

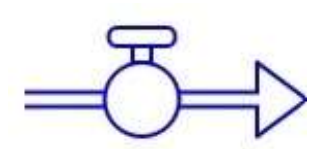

Stocks or asset stocks represent the present state of the system. Only flows change stocks. In other words, stocks accumulate the effects of flows or, simply put, stocks accumulate change. A process of accumulation is not the same as a causal link. Accumulations change according to their inflows and outflows in the same way that water accumulates in a bathtub. If the inflow is greater than the outflow, then the level gradually rises, and vice versa. If the inflow and the outflow are identical, then the level remains constant. Stocks can be physical or intangible. Examples are cars in a dealer's lot, fish in a river, perceived price, organizational managerial capabilities and individual self-control.

Sources and sinks represent elements outside the system, according to the defined boundaries.

Flows represent the movement of material (or intangible matter) in and out of a stock. 


\section{Table 16 (conclusion)}

\section{Element Notation Description}

Auxiliary

variable/converter

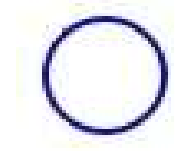

A converter represents a process that converts inputs into an output and is depicted as a circle. Converters receive causal links or information flows and transform them according to whatever rules, physical laws or operating policies apply. A converter's main function is to help explain the flows. An example is a converter that represents the relative price of two competing products or the birth rate in a population.

\section{Causal}

link/Information

link

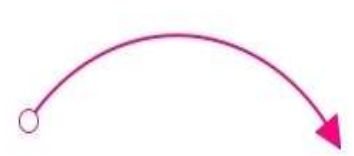

A causal link represents the effect of one variable on another. Solid lines are used to depict a causal link. Dotted lines typically represent information links. 


\subsection{APPENDIX C: WICKED PROBLEMS AND OUR CONTRIBUTION}

Wicked problems have become a staple in the repertoire of concepts adopted by social marketers, as well as by other academics and practitioners involved with complex social systems.In the classic definition proposed by Rittel and Webber (1973), a wicked problem has the following 10 characteristics:

1. There is no definitive formulation of a wicked problem. This means that the information needed to solve the problem depends on the intended solution. In other words (p. 161), "to describe a wicked-problem in sufficient detail, one has to develop an exhaustive inventory of all conceivable solutions ahead of time." Presenting poverty as an example, the authors develop the following discussion (p. 161):

Consider, for example, what would be necessary in identifying the nature of the poverty problem. Does poverty mean low income? Yes, in part. But what are the determinants of low income? Is it deficiency of the national and regional economies, or is it deficiencies of cognitive and occupational skills within the labor force? If the latter, the problem statement and the problem "solution" must encompass the educational processes. But, then, where within the educational system does the real problem lie? What then might it mean to "improve the educational system"? Or does the poverty problem reside in deficient physical and mental health? If so, we must add those etiologies to our information package, and search inside the health services for a plausible cause. Does it include cultural deprivation? spatial dislocation? problems of ego identity? deficient political and social skills? - and so on. If we can formulate the problem by tracing it to some sorts of sources - such that we can say, "Aha! That's the locus of the difficulty," i.e., those are the root causes of the differences between the "is" and the "ought to be" conditions - then we have thereby also formulated a solution. To find the problem is thus the same thing as finding the solution; the problem can't be defined until the solution has been found.

2. Wicked problems have no stopping rule. Executives in charge of tackling a wicked problem can only aspire to finding "good enough" solutions.

3. Solutions to wicked problems are not true-or-false, but good-or-bad. Social actors and groups of interest have different perspectives on the issue, so there is no clear yardstick by which to judge the proposed solutions.

4. There is no immediate and no ultimate test of a solution to a wicked problem. There is no way of knowing beforehand all the consequences, including the unintended ones, that will spring from the adopted course of action. 
5. Every solution to a wicked problem is a "one-shot operation," because there is no opportunity to learn by trial and error; every attempt counts significantly. Every trial counts when actions are irreversible and have consequences that span through time.

6. Wicked problems do not have an enumerable (or an exhaustively describable) set of potential solutions, nor is there a well-described set of permissible operations that may be incorporated into the plan. Ill-defined problems imply ill-defined solutions, and the set of feasible approaches depends on judgment. A host of potential solutions can arise, but there will always be a set of solutions not considered.

7. Every wicked problem is essentially unique. The particularities of the situation can always override common patterns that lie behind wicked problems.

8. Every wicked problem can be considered to be a symptom of another problem. Problems can be defined at several levels of generality. The policy maker should try to settle a problem at as high a level as possible. Marginal improvements usually do not lead to improvement overall.

9. The existence of a discrepancy representing a wicked problem can be explained in numerous ways. The choice of explanation determines the nature of the problem's resolution. There are innumerable ways to refute a hypothesis, and it is hard - or impossible - to pinpoint the exact causes behind changes in the problem.

10. The planner has no right to be wrong. The consequences of the actions planners generate will make them liable.

However, there have been other proposals that are more parsimonious. For instance, Forrester's $(1969 ; 1973)$ characterization of the properties of complex systems captures most of same aspects (see also Forrester, 1961; 1971; 1994; Richardson, 1999):

1. Complex systems are remarkably insensitive to changes in many system parameters. Changes of as much of as $50 \%$ or more in most parameters often have little impact in a model's patterns of behavior. Similarly, the behavior of different companies, cities or economies are very similar notwithstanding the natural differences in their underlying "parameters."

2. Complex systems counteract and compensate for externally applied corrective efforts. Exogenous forces elicit a compensating, counteracting response from the 
internal structures of the system. As Richardson (1999, p. 306) asserts, "a feedback system has the capacity to compensate for imposed changes, pushing itself back toward its original condition"

3. Complex systems resist most policy changes. Systemic compensation and parameter insensitivity often lead to results that are often the opposite of what was expected by policy makers. Intuitive "solutions" to social problems fall into one of several traps found in complex systems:

a. They may create a new mode of system behavior that has unpleasant consequences;

b. The short-term improvement may set the stage for long-term degradation (see item 5);

c. The local goals of parts of the system or the goals of a subsystem may conflict with the system's broader objectives or welfare. For instance, countries strive to grow their economies even at the expense of the global environment;

d. Interventions often act on points of little or no leverage for change. Social systems tend to attract attention to the very points at which an attempt to change will fail. Human experience has accumulated in simple systems. When dealing with complex systems, we tend to focus on the symptoms rather on the causes.

4. Complex systems contain influential pressure points, often in unexpected places, from which forces will radiate to alter system balance. Only a careful examination of system dynamics through models allows the identification of such pressure points. The influence points are not in the locations where most people expect.

5. Complex systems often react in the long run to a policy change in a way opposite to how they react in the short run. In many cases, opposing forces in the system drive the behavior in a direction different than that intended. There is a fundamental conflict between the short-term and long-term consequences of a policy change. This is perhaps the main curse of public policy, which tends to prioritize solutions marked by a "better-before-worse" flavor. On the other hand, "worse-before-better" makes good policies hard to implement, because the short run is more visible and more compelling. 
6. Complex social systems tend toward a condition of poor performance. The preference for solutions that are beneficial only in the short run, the misunderstanding about the causes of improvement and the insistence on efforts that worsen the system lead inevitably to a condition of poor performance. Hence, goals tend to erode. Facing difficult barriers to changing a system's structures, the natural tendency in human beings is to "erode" the goals, adapting them to lower levels of performance.

7. Complex social systems produce behaviors endogenously. In almost all cases, it is illusory to assume that an exogenous "cause" is behind the problems.

Arthur (2014) states a general rule in socioeconomic systems by which, given any system, people will find a way to exploit it. The reasons reflect the lack of "failure mode analysis" in public policy to take stock of four major causes of exploitation: use of asymmetric information by some parties, gaming of performance criteria, takeover of partial control of a system and the use of system elements in unexpected ways.

Other authors reference some unsuspected sources of contribution to wicked problems, such as the government. For instance, Banerjee and Duflo (2011) point to the triad ideology-ignorance-inertia as a major cause of failure in governmental programs. In their definition, ideology is the equivalent of flawed mindware, such as the idealized role of nurses in health programs or misconceptions about how a public program should work. Ignorance refers to a top-down stance that ignores what real people do and know; in other words, a lack of knowledge about the actual social settings in which the programs take place. Inertia, in turn, is the common tendency in the public sector of avoiding paying attention to ongoing programs, which are maintained out of sheer habit.

\subsubsection{OUR CONTRIBUTION}

To the well-known characteristics of wicked problems, we add the following propositions regarding their nature (propositions 1 to 5 ) and the policies to address them (propositions 6 to 9$)$ :

1. Wicked problems emerge in complex ecosystems, where diverse spheres of symbolism and the physical world constrain human thought and action. Natural, 
biological, cultural, social, economic and political contexts interact in the processes that create, maintain and propagate wicked problems.

2. The persistence of wicked problems often depends on the existence of social groups that benefit from the status quo and who control or influence public discourse and policy through policy monopolies and/or existent institutions.

3. As symptoms command the public's attention, societies tend to fall prey to "H. L. Mencken's curse": tackling complex problems with solutions that are clear, simple and wrong. Hence, low-quality solutions are attractors in social ecosystems. In addition, ineffective solutions, when adopted, often create social traps that prevent the development of effective solutions, replicating the shifting the burden archetype (Braun, 2002). Private security, armored cars and barbedwire (or electric) fences may satisfy the immediate safety needs of the middle class, but they also relieve the pressure in the system to search for efficacious policies to control rampant crime. Tax wars may provide resources to broken states, but they worsen the overall quality of the taxation system, leading to an endless race to the bottom.

4. Similar to what Arthur (2002) calls places of "high stress" in systems - points that offer strong incentives for agents to do something different from their prescribed behavior - we propose the concept of "bulges of temptation." They are selffulfilling prophecies inducing normatively dissonant behavior. In most relevant socioeconomic systems, concentrations of power, economic or scarce resources will inevitably create such bulges. Temptation leads eventually to undesirable behaviors.

5. While a few complex social problems draw little attention from the public (e.g., water supply in normal times), most of them spark too much controversy (e.g., climate change, gun control, crime, abortion, policies on drugs, poverty relief). The controversy is usually characterized by opposing points of view based on arguments that vary in their quality. Fallacies and biases tend to dominate the debate. Belief overkill (Baron, 2008) and the belief that there are perfect solutions - the utopian fallacy (Bazerman, Baron, \& Shonk, 2001) - predominate. The resulting noise makes it difficult for the public to evaluate critically the arguments from both sides. Attitudes then depend more on identity markers (political "tribal affiliations") than on balanced evaluations of complex issues. Paralyzed by controversy, the public often opts for inaction and maintenance of the status quo. 
6. Typically, governments do not have managerial capabilities to tackle complex social problems. Not only do they lack adequate capabilities and adequate mindware, but they also they lack systems thinking, which makes them adopt firstorder policies that only worsen the problems over the long term. One common solution for relieving the tension is to take the lip service road: weave shining policies into the public discourse, execute them (even partially) and rationalize failure.

7. In the same vein, public policies put in place to address complex social problems often (1) are not evidence based and, critically, (2) ignore the interplay of the different spheres mentioned in point 1 above. In particular, the short-term incentives in the political arena, where agents try to maximize electoral capital with their eye on the next elections, lead to a sequence of ill-designed but marketable policies that rarely alleviate societal illnesses. There are no mechanisms in our democracies to ensure the focus on long-term adequate policies.

8. Tackling wicked problems requires management of the intangible. The latter includes stocks such as trust, reputation, health and human capital, capabilities such as innovation and strategic management, and the repertoire of mental models (mindware) that determine the contours of the social technologies employed to address the problems. Often intangibles anticipate problems in physical stocks, as illustrated by the famous People Express case (Holland \& Beer, 1990). Marketing mindware is a necessary ingredient in the social change toolkit.

9. Management science does not have adequate mindware to deal with complexity. In public or social organizations, there is need to employ a diverse repertoire of managerial lenses in order to produce policies with better odds of making a difference in addressing complex problems. Besides consideration of the elements discussed above in points 6 and 7, those lenses also need to account for the following:

a. Paradoxes or tensions between contrasting forces. Classic examples of paradoxes in organizations include balancing the focus on the short versus the long term, managing innovation versus optimizing current modes of operation and enacting control while maintaining flexibility (Smith \& Lewis, 2011). Balancing cooperation versus competition - a hallmark in the evolution of complex human societies (Henrich \& Henrich, 2007) - requires designing organizational 
ecosystems in ways that shun the traditional hierarchical mold. Management of paradoxes also includes developing an "ambidextrous mindset" that allows exploration of the current course of action and a constant sensing and exploitation of possible opportunities. Exploration and exploitation are a classic modus operandi in complex systems found in nature.

b. Dissent. Complex social problems involve divergent points of view, and there must be structures and processes to account for the inevitable conflict among different stakeholders.

c. Continuous reflection on goals, results, capabilities and policies. Reflection must necessarily be tied to learning. In turn, learning depends on adequate degrees of "porosity," or the capacity to absorb and process information from the environment and from stakeholders. It is critical that any social system (e.g., public organizations) have in place capabilities to incorporate "fresh eyes" from the outside. This allows the system to revise the predominant mental models in a continuous fashion. Implied in such capabilities, a bias for action is necessary to avoid sterile ruminations in lieu of active reflection.

d. Understanding the dominant logic in subsystems (e.g., the political subsystem). e. Preparing the systems for complexity. This implies taking stock of unintended consequences, bulges of temptation, dynamic interplay of policies and nonlinearities. Consequences of policies and interventions should never be presumed. It is critical to manage in a continuous manner the design of incentives and norms, mechanisms of transparency and accountability, and points of potential exploitation of the system.

f. Preparing the system for resilience, employing adequate degrees of slack and redundancy as part of a humble epistemological stance toward the future.

g. Addressing what matters, avoiding unnecessary suffering and unsustainable pressures on the environment. This includes the consideration of vulnerability of social segments and the ecological footprints of human activity. It also includes a focus on citizen experience, using frameworks for co-creation and models for capturing the unique viewpoints from usually neglected stakeholders, such as future generations. 


\subsection{APPENDIX D: THE CAPED MODEL}

\section{APPENDIX D.1:. VALIDATION OF THE CAPED MODEL}

We present the screens from the website used in the process of validation. The screens were printed from https://exchange.iseesystems.com/public/hamilton/desenvolvimento humano/index.html

Page 1:

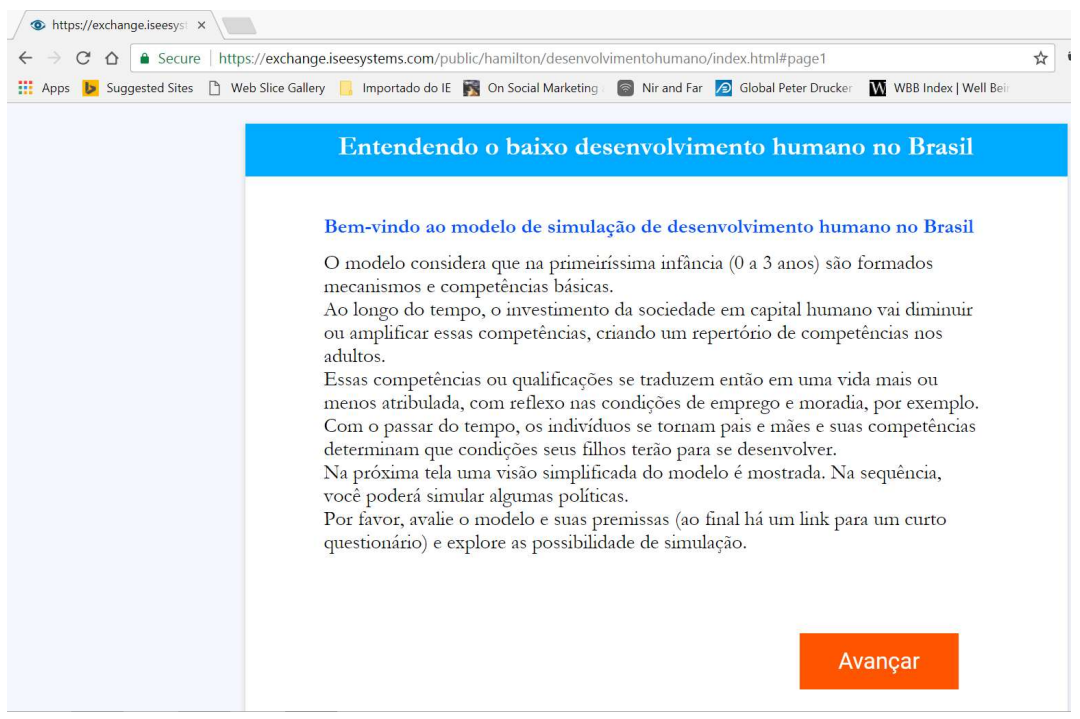

Page 2:

\section{Entendendo o baixo desenvolvimento humano no Brasil}
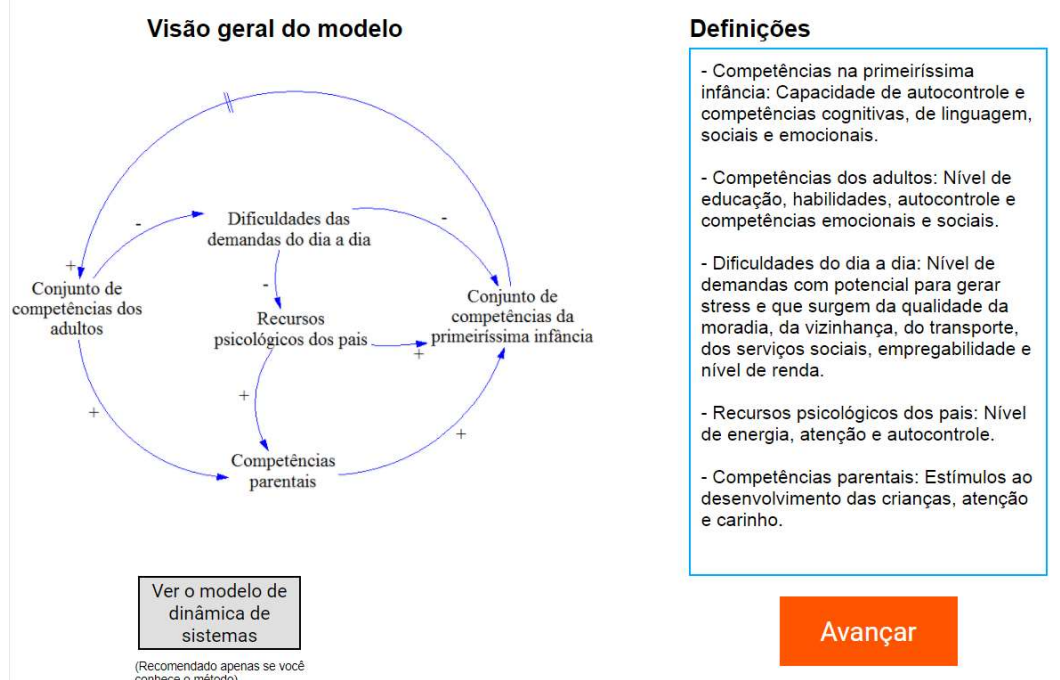


\section{Page 3:}

Entendendo o baixo desenvolvimento humano no Brasil

A simulação considera um horizonte de 50 anos e o segmento mais pobre da população brasileira. No cenário-base, o investimento social nos primeiros anos de vida dos mais pobres é deficiente. Você pode simular o efeito de políticas sociais, variando a intensidade de cada uma no botão que vai de 1 a 5 . Isto é, cada tipo de investimento social pode ir de um nível baixo (correspondendo a 1) até o nível mais alto possível (nível 5). Nas regras da simulação, as políticas só são ativadas a partir do ano 10.

Cada variável de interesse indicada no gráfico tem uma escala que vai de 0 a 1 , em que 0 representa o menor nível possível e 1 representa o estado ideal. Por exemplo, a qualidade do desenvolvimento na primeiríssima infância tem um nível de 0,25 no cenário-base e idealmente todos gostaríamos que se aproximasse de 1. Ao simular, você pode tentar aumentar esse nível, mas considere que as políticas têm custo e que seria bastante improvável implementar todas as políticas no nível máximo (nível 5) ao mesmo tempo.

\section{Page 4:}

\section{Entendendo o baixo desenvolvimento humano no Brasil}
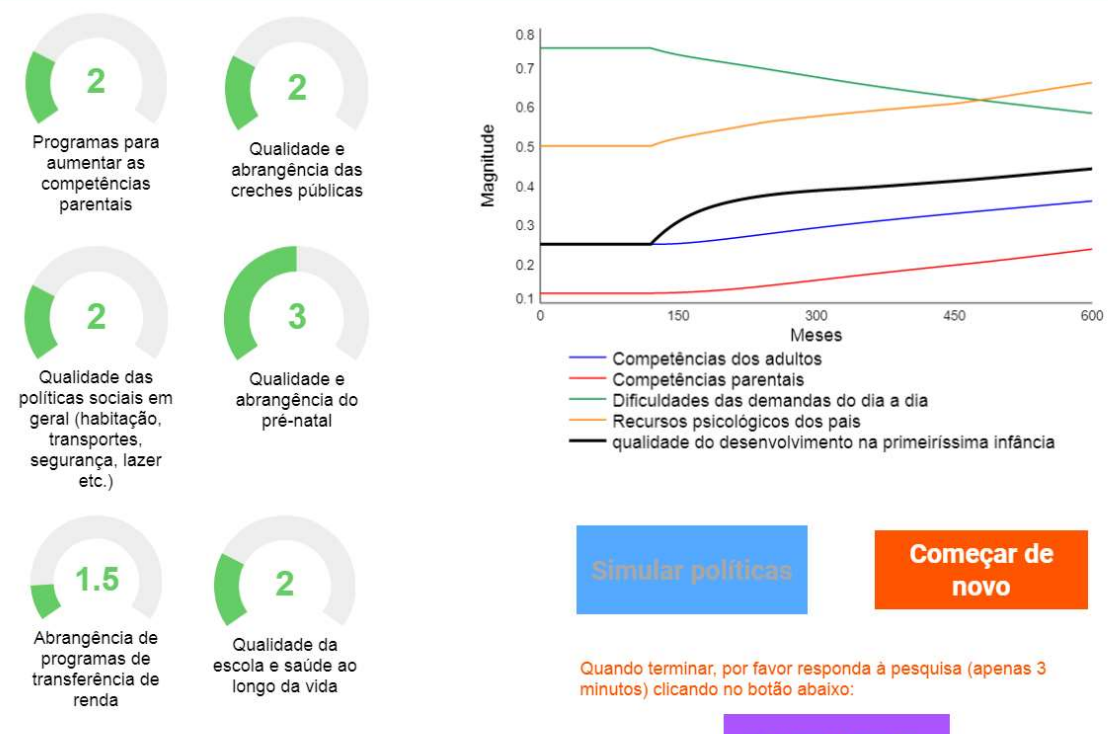

Começar de novo

Quando terminar, por favor responda à pesquisa (apenas 3 minutos) clicando no botẫo abaixo: 
Page 5 (model):

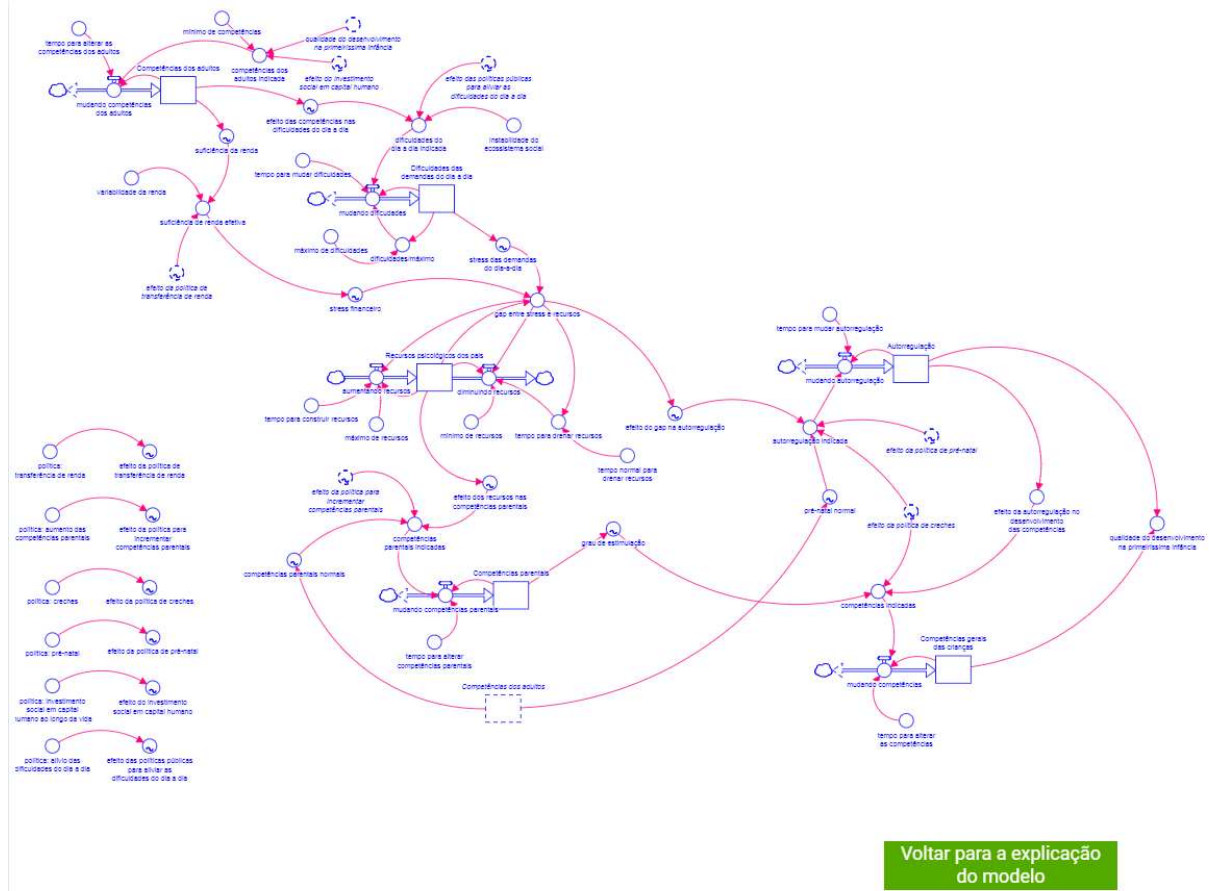




\title{
APPENDIX D.2: SURVEY (IN PORTUGUESE)
}

Obrigado por responder a essa breve pesquisa sobre o modelo de simulação que você acabou de conhecer, que trata da replicação do baixo desenvolvimento humano no Brasil. A pesquisa não leva mais do que 3 minutos.

1. Por favor avalie os seguintes aspectos do modelo de simulação:

$\begin{array}{ccccc}\text { Totalmente } & \text { Pouco } & \text { Muito } & \text { Totalmente } & \text { Não sei } \\ \text { inadequado } & \text { adequado } & \text { adequado } & \text { adequado } & \text { responder }\end{array}$

\author{
Identificação \\ das causas do \\ problema \\ Clareza do \\ modelo \\ Completude \\ do modelo \\ Capacidade de \\ explicar a \\ dinâmica do \\ problema
}

2. De 0 a 10 , que nota você dá para o modelo como um todo?

3. Sobre as políticas que você testou na simulação, você diria que:

$\begin{array}{ccccc}\text { Discordo } & \text { Mais discordo } & \text { Mais concordo } & \text { Concordo } & \text { Não sei } \\ \text { totalmente } & \text { do que } & \text { do que } & \text { totalmente } & \text { responder } \\ & \text { concordo } & \text { discordo } & & \end{array}$

São adequadas

Cobriram

todas as

possibilidades

São desejáveis 
4. O que eventualmente pode ter faltado no modelo?

5. O que eventualmente não ficou claro?

6. Esse espaço final é para comentários e sugestões.

7. Você é:

a) Pesquisador/acadêmico na área da primeiríssima infância

b) Pesquisador/acadêmico em outra área de estudo

c) Profissional (por exemplo: assistente social, enfermeiro(a), educador(a) etc.) que atua especificamente na área da primeiríssima infância

d) Profissional de outra área relacionada com temas sociais

e) Outro 


\section{APPENDIX D.3: EQUATIONS FOR THE CAPED MODEL}

Top-Level Model:

Adults'_capabilities $(\mathrm{t})=$ Adults'_capabilities $(\mathrm{t}-\mathrm{dt})+($ changing_capabilities $) * d t$

INIT Adults'_capabilities $=0,25$

INFLOWS:

changing_capabilities $=($ indicated_adults'_capabilities-

Adults'_capabilities)/time_to_change_adults'_capabilities

Children's_general_capabilities $(\mathrm{t})=$ Children's_general_capabilities $(\mathrm{t}-\mathrm{dt})+$

(changing_children's_capabilities) $* \mathrm{dt}$

INIT Children's_general_capabilities $=0,25$

INFLOWS:

changing_children's_capabilities $=$ (indicated_capabilities-

Children's_general_capabilities)/time_to_change_children's_capabilities

Harshness_of_environmental_demands $(\mathrm{t})=$ Harshness_of_environmental_demands $(\mathrm{t}$ -

dt) + (changing_harshness $) * d t$

INIT Harshness_of_environmental_demands $=0,75$

INFLOWS:

changing_harshness $=(($ indicated_harshness-

Harshness_of_environmental_demands)*(1-

"harshness/maximum"))/time_to_change_harshness

Parental_capabilities $(\mathrm{t})=$ Parental_capabilities $(\mathrm{t}-\mathrm{dt})+($ changing_parental_capabilities $)$

$* \mathrm{dt}$

INIT Parental_capabilities $=0,125$

INFLOWS:

changing_parental_capabilities $=$ (indicated_parental_capabilities-

Parental_capabilities)/time_to_change_parental_capabilities

Parental_psychological_resources $(\mathrm{t})=$ Parental_psychological_resources $(\mathrm{t}-\mathrm{dt})+$ (increasing_resources - decreasing_resources) $* \mathrm{dt}$

INIT Parental_psychological_resources $=0,5$

INFLOWS:

increasing_resources $=(($ maximum_resources-

Parental_psychological_resources)*"stress/resources_gap")/time_to_build_resources OUTFLOWS:

decreasing_resources $=(($ Parental_psychological_resources-

minimum_resources)*"stress/resources_gap")/time_to_deplete_resources

"Self-regulation" $(\mathrm{t})=$ "Self-regulation" $(\mathrm{t}-\mathrm{dt})+($ "changing_self-regulation") $* \mathrm{dt}$

INIT "Self-regulation" $=0,25$

INFLOWS:

"changing_self-regulation" = ("indicated_self-regulation"-"Self-

regulation")/"time_to_change_self-regulation"

degree_of_stimulation $=$ GRAPH(Parental_capabilities)

$(0,000,0,216),(0,100,0,216),(0,125,0,250),(0,300,0,300),(0,400,0,400),(0,500$,

$0,500),(0,600,0,835),(0,700,1,000),(0,800,1,000),(0,900,1,000),(1,000,1,000)$ 
effect_of_capabilities_on_harshness=GRAPH(Adults'_capabilities)

$(0,000,1,000),(0,0909090909091,1,000),(0,181818181818,1,000),(0,250,0,750)$, $(0,363636363636,0,600),(0,454545454545,0,500),(0,545454545455,0,344)$, $(0,636363636364,0,299),(0,727272727273,0,274),(0,818181818182,0,241)$, $(0,909090909091,0,212),(1,000,0,195)$

effect_of_childcare_policy $=$ GRAPH(IF TIME $>120$ THEN policy:_childcare ELSE $0,25)$

$(1,000,0,250),(2,000,0,400),(3,000,0,600),(4,000,0,850),(5,000,1,000)$

"effect_of_gap_on_self-regulation" = GRAPH("stress/resources_gap")

$(0,00,1,000),(1,00,0,250),(1,50,0,250),(3,00,0,200),(4,00,0,150),(5,00,0,150)$,

$(6,00,0,150),(7,00,0,150),(8,00,0,150),(9,00,0,150),(10,00,0,100)$

effect_of_income_transfer_policy $=\mathrm{GRAPH}$ (policy:_income_transfer)

$(1,000,1,000),(2,000,1,100),(3,000,1,500),(4,000,1,800),(5,000,2,000)$

effect_of_policy_to_alleviate_environmental_demands $=$ GRAPH(IF TIME $>120$

THEN policy:_alleviation_of_environmental_demands ELSE 1)

$(1,000,1,000),(2,000,1,050),(3,000,1,100),(4,000,1,150),(5,000,1,200)$

effect_of_policy_to_increase_parental_capabilities = GRAPH(IF TIME $>120$ THEN

policy:_increase_in_parental_capabilities ELSE 1)

$(1,000,1,000),(2,000,1,005),(3,000,1,050),(4,000,1,080),(5,000,1,100)$

effect_of_prenatal_policy $=$ GRAPH(IF TIME $>120$ THEN policy:_prenatal_care

ELSE 0,25)

$(1,000,0,250),(2,000,0,400),(3,000,0,600),(4,000,0,850),(5,000,1,000)$

effect_of_psychological_resources_on_parental_capabilities $=$

GRAPH(Parental_psychological_resources)

$(0,000,0,026),(0,100,0,077),(0,200,0,100),(0,300,0,200),(0,400,0,350),(0,500$,

$0,500),(0,600,0,600),(0,750,0,750),(0,800,1,000),(0,900,1,000),(1,000,1,000)$

"effect_of_self-regulation_on_children's_capabilities" = "Self-regulation"

effective_income_sufficiency $=$

income_sufficiency*income_variability*effect_of_income_transfer_policy

financial_stress $=$ GRAPH(effective_income_sufficiency)

$(0,00,1,000),(0,50,1,000),(0,75,0,500),(0,90,0,400),(1,00,0,200),(1,50,0,100)$,

$(2,00,0,050),(5,00,0,000),(5,71428571429,0,000),(6,42857142857,0,000)$,

$(7,14285714286,0,000),(7,85714285714,0,000),(8,57142857143,0,000)$,

$(9,28571428571,0,000),(10,00,0,000)$

"harshness/maximum" = Harshness_of_environmental_demands/maximum_harshness income_sufficiency $=$ GRAPH(Adults'_capabilities)

$(0,000,0,505),(0,100,0,531),(0,200,0,692),(0,250,0,750),(0,400,0,960),(0,500$ $1,000),(0,600,1,000),(0,700,1,000),(0,800,1,000),(0,900,1,000),(1,000,1,000)$ income_variability $=\operatorname{SINWAVE}(0,05 ; 120) * 0+1$

indicated_adults'_capabilities $=$ MAX(minimum_capabilities; $\operatorname{MIN}(1$;

quality_of_early_childhood_development*quality_of_societal_investment_on_human_ capital_through_life)) 
indicated_capabilities $=\operatorname{MIN}(1 ; \operatorname{MEAN}($ "effect_of_self-

regulation_on_children's_capabilities"; effect_of_childcare_policy;

degree_of_stimulation))

indicated_harshness =

effect_of_capabilities_on_harshness*instability_of_social_ecosystem/effect_of_policy_ to_alleviate_environmental_demands

indicated_parental_capabilities =

effect_of_psychological_resources_on_parental_capabilities*normal_parental_capabilit ies*effect_of_policy_to_increase_parental_capabilities

"indicated_self-regulation" = MIN(1; MEAN(effect_of_prenatal_policy;

effect_of_childcare_policy; "effect_of_gap_on_self-regulation"; normal_prenatal_care))

instability_of_social_ecosystem $=1$

maximum_harshness $=1$

maximum_resources $=1$

minimum_capabilities $=0,25$

minimum_resources $=0$

normal_parental_capabilities = GRAPH(Adults'_capabilities)

$(0,000,0,100),(0,100,0,150),(0,200,0,200),(0,250,0,250),(0,400,0,432),(0,500$,

$0,500),(0,600,0,648),(0,700,0,736),(0,800,0,949),(0,900,1,000),(1,000,1,000)$

normal_prenatal_care $=$ GRAPH(Adults'_capabilities $)$

$(0,000,0,250),(0,100,0,250),(0,200,0,250),(0,300,0,250),(0,400,0,500),(0,500$,

$0,722),(0,600,0,956),(0,700,1,000),(0,800,1,000),(0,900,1,000),(1,000,1,000)$

normal_time_to_deplete_resources $=12$

policy:_alleviation_of_environmental_demands = IF TIME $>120$ THEN 2 ELSE 1

policy:_childcare $=$ IF TIME $>120$ THEN 1,5 ELSE 1

policy:_income_transfer $=1$

policy:_increase_in_parental_capabilities = IF TIME $>120$ THEN (IF TIME $>180$ THEN 1 ELSE 1) ELSE 1

policy:_investment_on_human_capital = IF TIME $>120$ THEN 1,5 ELSE 1

policy:_prenatal_care $=$ IF TIME $>120$ THEN 2 ELSE 1

quality_of_early_childhood_development $=($ Children's_general_capabilities+"Self-

regulation")/2

quality_of_societal_investment_on_human_capital_through_life $=$ GRAPH(IF TIME $>$

120 THEN policy:_investment_on_human_capital ELSE 0,75)

$(1,000,0,750),(2,000,0,927),(3,000,1,201),(4,000,1,288),(5,000,1,351)$

stress_from_environmental_demands $=$

GRAPH(Harshness_of_environmental_demands)

$(0,000,0,000),(0,100,0,000),(0,200,0,100),(0,300,0,200),(0,400,0,274),(0,500$,

$0,320),(0,600,0,365),(0,700,0,419),(0,750,0,500),(0,900,0,900),(1,000,1,000)$

"stress/resources_gap" = MEAN(stress_from_environmental_demands;

financial_stress)/Parental_psychological_resources

time_to_build_resources $=12$

time_to_change_adults'_capabilities $=240$

time_to_change_children's_capabilities $=36$ 
time_to_change_harshness $=12$

time_to_change_parental_capabilities $=60$

"time_to_change_self-regulation" $=36$

time_to_deplete_resources $=$ normal_time_to_deplete_resources/"stress/resources_gap"

In root model and 0 additional modules with 0 sectors. Stocks: 6 (6) Flows: 7 (7)

Converters: 45 (45) Constants: 14 (14) Equations: 38 (38) Graphicals: 15 (15)

\} 


\subsection{APPENDIX E: EQUATIONS FOR THE MODEL IN CHAPTER 6}

Equations for the model in chapter 6 (Brazilian Social Holocaust).

Top-Level Model:

$\operatorname{GDP}(\mathrm{t})=\mathrm{GDP}(\mathrm{t}-\mathrm{dt})+($ increasing_gdp $) * \mathrm{dt}$

INIT GDP = initial_gdp

INFLOWS:

increasing_gdp $=\left(\mathrm{GDP}^{*}\right.$ gdp_growth $) /$ time_to_change_gdp

Human_development $(\mathrm{t})=$ Human_development $(\mathrm{t}-\mathrm{dt})+$

(changing_human_development) $* \mathrm{dt}$

INIT Human_development $=0,5$

INFLOWS:

changing_human_development $=$ (indicated_human_development-

Human_development)/time_to_change_human_development

"Perceived_attractiveness_of_band-aids" $(\mathrm{t})=$ "Perceived_attractiveness_of_band-

aids" $(\mathrm{t}-\mathrm{dt})+($ changing_attractiveness $) * \mathrm{dt}$

INIT "Perceived_attractiveness_of_band-aids" $=0$

INFLOWS:

changing_attractiveness = ("effect_of_power_on_perceived_attractiveness_of_bandaids"-"Perceived_attractiveness_of_band-aids")/time_to_change_attractiveness

Societal_discomfort $(\mathrm{t})=$ Societal_discomfort $(\mathrm{t}-\mathrm{dt})+($ increasing_discomfort -

decreasing_discomfort) $* \mathrm{dt}$

INIT Societal_discomfort $=0$

INFLOWS:

increasing_discomfort $=$ (indicated_discomfort-

Societal_discomfort)/time_to_increase_discomfort

OUTFLOWS:

decreasing_discomfort $=(\operatorname{MAX}(0$; Societal_discomfort $) *$ "effect_of_band-

aids"*"effectiveness_of_band-aids")/time_to_decrease_discomfort

Tax_burden $(\mathrm{t})=$ Tax_burden $(\mathrm{t}-\mathrm{dt})+($ increasing_tax_burden $) * \mathrm{dt}$

INIT Tax_burden = initial_tax_burden

INFLOWS:

increasing_tax_burden $=$

$(($ Tax_burden*(1+societal_pressures_for_more_resources $)) *(1-$

"tax_burden_/_maximum"))/time_to_change_tax_burden

attractiveness_of_effective_solutions = GRAPH(1-"Perceived_attractiveness_of_bandaids")

$(0,000,0,000),(0,100,0,000),(0,200,0,000),(0,300,0,000),(0,400,0,008),(0,500$,

$0,057),(0,600,0,162),(0,700,0,287),(0,800,0,749),(0,900,0,870),(1,000,1,000)$

"budget_appropriated_by_rent-seekers" =

total_budget*"percentage_of_the_budget_to_rent-seekers"

budget_for_human_development = total_budget-"budget_appropriated_by_rentseekers" 
commodities_boom $=$ IF TIME $<360$ THEN IF TIME $>240$ THEN 5 ELSE 1 ELSE 1 "effect_of_band-aids" = GRAPH("pressure_for_band-aids")

$(0,000,0,000),(0,100,0,043),(0,200,0,123),(0,300,0,340),(0,400,0,528),(0,500$, $0,596),(0,600,0,626),(0,700,0,647),(0,800,0,660),(0,900,0,698),(1,000,0,732)$

effect_of_gap_on_human_development $=$

GRAPH(gap_between_actual_and_ideal_budget)

$(0,000,0,004),(0,100,0,030),(0,200,0,043),(0,300,0,060),(0,400,0,157),(0,500$, $0,221),(0,600,0,306),(0,700,0,383),(0,800,0,596),(0,900,0,945),(1,000,1,000)$

"effect_of_power_on_perceived_attractiveness_of_band-aids" =

GRAPH("power_from_rent-seekers")

$(0,000,0,000),(0,100,0,617),(0,200,0,787),(0,300,0,898),(0,400,0,996),(0,500$, $1,000),(0,600,1,000),(0,700,1,000),(0,800,1,000),(0,900,1,000),(1,000,1,000)$

"effect_of_pressure_on_percentage_of_rent-seekers" =

GRAPH(net_pressure_for_effective_solutions)

$(0,000,1,000),(0,100,1,000),(0,200,1,000),(0,300,1,000),(0,400,1,000),(0,500$, $0,902),(0,600,0,757),(0,700,0,383),(0,800,0,247),(0,900,0,204),(1,000,0,187)$ effect_of_societal_problems_on_gdp_growth $=$ GRAPH(societal_problems) $(0,000,1,000),(0,100,1,000),(0,200,1,000),(0,300,1,000),(0,400,1,017),(0,500$, $1,162),(0,600,1,481),(0,700,2,191),(0,800,2,634),(0,900,2,957),(1,000,3,000)$ effect_of_tax_burden_on_gdp_growth $=\mathrm{GRAPH}\left(\mathrm{Tax} \_\right.$burden $)$ $(0,0000,1,000),(0,0400,1,000),(0,0800,1,000),(0,1200,1,000),(0,1600,1,000)$, $(0,2000,1,000),(0,2400,1,000),(0,2800,1,000),(0,3200,0,634),(0,3600,0,617)$, $(0,4000,0,587)$

effect_on_societal_problems $=$ GRAPH(Human_development $)$ $(0,000,1,000),(0,100,1,000),(0,200,1,000),(0,300,1,000),(0,400,0,991),(0,500$, $0,979),(0,600,0,804),(0,700,0,689),(0,800,0,553),(0,900,0,243),(1,000,0,000)$ "effectiveness_of_band-aids" $=\operatorname{MAX}(0 ; 1$-RAMP $(0,001))$

gap_between_actual_and_ideal_budget $=$

budget_for_human_development/(GDP*ideal_percentage_of_budget_for_human_devel opment)

gdp_growth $=$

(normal_gdp_growth*effect_of_tax_burden_on_gdp_growth*commodities_boom)/(IF effect_of_societal_problems_on_gdp_growth $>2$ THEN

effect_of_societal_problems_on_gdp_growth+RAMP(0,025) ELSE

effect_of societal_problems_on_gdp_growth)

ideal_percentage_of_budget_for_human_development $=0,25$

index_of_inequality = GRAPH("budget_appropriated_by_rent-

seekers"/budget for human development)

$(0,000,0,000),(0,100,0,004),(0,200,0,065),(0,300,0,170),(0,400,0,389),(0,500$, $0,506),(0,600,0,717),(0,700,0,968),(0,800,1,000),(0,900,1,000),(1,000,1,000)$

indicated_discomfort $=$ MEAN(index_of_inequality; societal_problems)

indicated_human_development = normal_human_development*MIN $(1$;

effect of gap on human development)

initial_gdp $=100$ 
initial_tax_burden $=0,2$

maximum_tax_burden $=0,38$

net_pressure_for_effective_solutions $=$ MEAN(pressure_for_effective_solutions;

attractiveness_of_effective_solutions)

normal_gdp_growth $=0,055$

normal_human_development $=1$

normal_percentage $=0,4+\operatorname{RAMP}(0,0005)$

"percentage_of_the_budget_to_rent-seekers" =

normal_percentage*"effect_of_pressure_on_percentage_of_rent-

seekers"**political_voice_of_the_poor

political_voice_of_the_poor $=$ IF TIME $<120$ THEN 1 ELSE 0,9

"power_from_rent-seekers" = "budget_appropriated_by_rent-seekers"/total_budget

"pressure_for_band-aids" = MEAN(pressure_for_solutions;

"Perceived_attractiveness_of_band-aids")

pressure_for_effective_solutions $=$ GRAPH(1-"pressure_for_band-aids")

$(0,000,0,000),(0,100,0,000),(0,200,0,000),(0,300,0,000),(0,400,0,000),(0,500$,

$0,036),(0,600,0,247),(0,700,0,891),(0,800,0,968),(0,900,1,000),(1,000,1,000)$

pressure_for_solutions $=$ GRAPH(Societal_discomfort $)$

$(0,000,0,004),(0,100,0,094),(0,200,0,247),(0,300,0,557),(0,400,0,736),(0,500$,

$0,881),(0,600,0,957),(0,700,0,996),(0,800,1,000),(0,900,1,000),(1,000,1,000)$

societal_pressures_for_more_resources $=\operatorname{MEAN}(1$ -

gap_between_actual_and_ideal_budget; "power_from_rent-seekers")

societal_problems $=$ SMTH3(effect_on_societal_problems; 120)

"tax_burden_/_maximum" = Tax_burden/maximum_tax_burden

time_to_change_attractiveness $=120$

time_to_change_gdp $=12$

time_to_change_human_development $=240$

time_to_change_tax_burden $=120$

time_to_decrease_discomfort $=12$

time_to_increase_discomfort $=12$

total_budget $=$ GDP*Tax_burden

$\{$ The model has 52 (52) variables (array expansion in parens).

In root model and 0 additional modules with 0 sectors.

Stocks: 5 (5) Flows: 6 (6) Converters: 41 (41)

Constants: 12 (12) Equations: 35 (35) Graphicals: 11 (11)

There are also 10 expanded macro variables. 


\subsection{APPENDIX F: EQUATIONS FOR THE MODEL OF SOCIAL CHANGE}

Top-Level Model:

Current_mindware $(\mathrm{t})=$ Current_mindware $(\mathrm{t}-\mathrm{dt})+($ changing_situation $) * \mathrm{dt}$

INIT Current_mindware $=0$

INFLOWS:

changing_situation $=$

(support_from_institutional_validators.policies_to_close_the_gap*effectiveness_of_pol icies*(preferred_mindware-Current_mindware))/time_to_change_mindware catalyzers $=0 * \operatorname{PULSE}(0,25 ; 12 ; 36)+1$

degree_of_contentiousness=Initial_degree_of_contentiousness*(1-Current_mindware) effect_of_catalyzers_on_mechanisms_of_change $=$ IF switch_to_catalyzers $=0$ THEN 1 ELSE 20

effectiveness_of_policies $=1$

exposed_gap $=$ ABS(preferred_mindware-Current_mindware)

force_of_pushing_factors $=\operatorname{RAMP}(0,001 ; 12)$

Initial_degree_of_contentiousness $=0,2$

preferred_mindware $=$ MAX $(\mathrm{MIN}(1$; SMTH3 (pushing_factors;

time_to_change_reference) $)$; $\mathrm{MIN}(1$;

SMTH3(pushing_factors*switch_to_catalyzers*catalyzers;

time to_change_reference)))

pushing_factors $=\mathrm{MIN}(1$; force_of_pushing_factors $)$

switch_to_catalyzers $=0$

time_to_change_mindware $=24$

time_to_change_reference $=120$

public_support:

Public_support_for_change $(\mathrm{t})=$ Public_support_for_change $(\mathrm{t}-\mathrm{dt})+$

(changing_public_support) $* \mathrm{dt}$

INIT Public_support_for_change $=0$

INFLOWS:

changing_public_support $=$

(quality_of_framing/quality_of_framing_of_opposing_mindware)*(indicated_public_su pport*(1-supporting_and_opposing_groups.appeal_of_opposing_mindware) $)^{*}(1-$

"public_support/maximum")*"indicator_for_crowded_|"market|"_of_causes"/time_to_b uild_support

effect_of_public_support_on_capabilities_of_supporting_groups $=$

GRAPH(Public_support_for_change)

$(0,000,0,000),(0,100,0,034),(0,200,0,055),(0,300,0,098),(0,400,0,179),(0,500$,

$0,328),(0,600,0,736),(0,700,0,872),(0,800,0,936),(0,900,0,996),(1,000,1,000)$

indicated_public_support $=$

((support_from_institutional_validators.effect_on_public_support*weight_for_support_ from_institutional_validators)+(MEAN(supporting_and_opposing_groups.appeal_of_ga 
$\mathrm{p}$

.exposed_gap)*quality_of_framing))/(quality_of_framing+weight_for_support_from_in stitutional_validators)

"indicator_for_crowded_|"market $\mid$ _of_causes" = 1

maximum_support $=1$

normal_time_to_build_support $=240$

"public_support/maximum" = Public_support_for_change/maximum_support

quality_of_framing $=2$

quality_of_framing_of_opposing_mindware $=1$

time_to_build_support=

normal_time_to_build_support/.effect_of_catalyzers_on_mechanisms_of_change

weight_for_support_from_institutional_validators $=1$

support_from_institutional_validators:

Support_from_institutional_validators $(\mathrm{t})=$ Support_from_institutional_validators $(\mathrm{t}-\mathrm{dt})$

+ (changing_support_from_institutional_validators) $* \mathrm{dt}$

INIT Support_from_institutional_validators $=0$

INFLOWS:

changing_support_from_institutional_validators $=$

indicated_support_from_institutional_validators*(1-

supporting_and_opposing_groups.appeal_of_opposing_mindware)*institutional_efficie ncy*(1-

Support_from_institutional_validators)/time_to_build_support_from_institutional_valid ators

effect_on_capabilities_of_supporting_groups =

GRAPH(Support_from_institutional_validators)

$(0,000,0,000),(0,100,0,115),(0,200,0,243),(0,300,0,345),(0,400,0,426),(0,500$,

0,468), (0,600, 0,562), (0,700, 0,928), (0,800, 1,000), (0,900, 1,000), (1,000, 1,000)

effect_on_public_support $=$ GRAPH(Support_from_institutional_validators)

$(0,000,0,000),(0,100,0,000),(0,200,0,051),(0,300,0,115),(0,400,0,166),(0,500$,

$0,426),(0,600,0,604),(0,700,0,817),(0,800,0,949),(0,900,1,000),(1,000,1,000)$

indicated_support_from_institutional_validators $=$ MEAN(.exposed_gap;

public_support.Public_support_for_change;

supporting_and_opposing_groups.appeal_of_gap)

institutional_efficiency $=1$

normal_time_to_build_support_from_institutional_validators $=240$

policies_to_close_the_gap $=$ GRAPH(Support_from_institutional_validators)

$(0,000,0,000),(0,100,0,000),(0,200,0,000),(0,300,0,089),(0,400,0,174),(0,500$,

$0,279),(0,600,0,429),(0,700,0,575),(0,800,0,741),(0,900,0,980),(1,000,1,000)$

time_to_build_support_from_institutional_validators $=$

normal_time_to_build_support_from_institutional_validators/.effect_of_catalyzers_on_ mechanisms_of_change

supporting_and_opposing_groups: 
Capabilities_of_opposing_groups $(\mathrm{t})=$ Capabilities_of_opposing_groups $(\mathrm{t}-\mathrm{dt})+$ (increasing_capabilities_og - losing_capabilities_og) $* \mathrm{dt}$

INIT Capabilities_of_opposing_groups $=0$

INFLOWS:

increasing_capabilities_og $=$

MEAN(effect_of_enabling_factors_on_capabilities_of_opposing_groups;

effect_of_contentiousness_on_capabilities_of_opposing_groups;

general_power_of_opposing_groups)*(1-

"capabilities/maximum_opposing_groups")/time_to_develop_capabilities_of_opposing groups

OUTFLOWS:

losing_capabilities_og $=\operatorname{MAX}(0$;

Capabilities_of_opposing_groups*support_from_institutional_validators.policies_to_cl ose_the_gap)/time_to_lose_capabilities_of_opposing_groups

Capabilities_of_supporting_groups $(\mathrm{t})=$ Capabilities_of_supporting_groups $(\mathrm{t}-\mathrm{dt})+$ (increasing_capabilities - decreasing_capabilities) $* \mathrm{dt}$

INIT Capabilities_of_supporting_groups $=0$

INFLOWS:

increasing_capabilities $=$

((indicated_capabilities*weight_for_indicated_capabilities+"contribution_from_success in_agenda-setting"*weight_for_contribution $) / 3 *(1-$

"capabilities/maximum"))/time_to_build_capabilities

OUTFLOWS:

decreasing_capabilities =Capabilities_of_supporting_groups/time_to_lose_capabilities

Disabling_factors $(\mathrm{t})=$ Disabling_factors $(\mathrm{t}-\mathrm{dt})+($ changing_disabling_factors $) * d t$

INIT Disabling factors $=0$

INFLOWS:

changing_disabling_factors $=$ (indicated_disabling_factors-

Disabling_factors)/time_to_perform_disabling_actions

Enabling_factors $(\mathrm{t})=$ Enabling_factors $(\mathrm{t}-\mathrm{dt})+($ changing_enabling_factors $) * d t$

INIT Enabling_factors $=0$

INFLOWS:

changing_enabling_factors $=$ (indicated_factors-

Enabling_factors)/time_to_change_enabling_factors

actions_per_capabilities_of_opposing_groups $=0,5$

actions_per_capability $=0,8$

appeal_of_gap $=\mathrm{GRAPH}($ Enabling_factors $)$

$(0,000,0,000),(0,100,0,102),(0,200,0,200),(0,300,0,306),(0,400,0,706),(0,500$,

$0,817),(0,600,0,906),(0,700,0,983),(0,800,1,000),(0,900,1,000),(1,000,1,000)$

appeal_of_opposing_mindware $=\mathrm{GRAPH}$ (Disabling_factors)

$(0,000,0,000),(0,100,0,013),(0,200,0,068),(0,300,0,102),(0,400,0,498),(0,500$,

0,711), (0,600, 0,843), (0,700, 0,962), (0,800, 0,974), (0,900, 1,000), (1,000, 1,000)

"capabilities/maximum" $=$ Capabilities_of_supporting_groups/maximum_capabilities 
"capabilities/maximum_opposing_groups" =

Capabilities_of_opposing_groups/maximum_capabilities_of_opposing_groups

"contribution_from_success_in_agenda-setting" =

MEAN(public_support.effect_of_public_support_on_capabilities_of_supporting_group s; support_from_institutional_validators.effect_on_capabilities_of_supporting_groups)

Effecf_of_pushing_factors_on_capabilities $=\mathrm{GRAPH}($.exposed_gap)

$(0,000,0,000),(0,100,0,000),(0,200,0,089),(0,300,0,306),(0,400,0,596),(0,500$,

$0,770),(0,600,0,838),(0,700,0,919),(0,800,0,970),(0,900,1,000),(1,000,1,000)$

effect_of_contentiousness_on_capabilities_of_opposing_groups $=$

GRAPH(.degree_of_contentiousness)

$(0,000,0,000),(0,100,0,000),(0,200,0,000),(0,300,0,157),(0,400,0,302),(0,500$,

$0,587),(0,600,0,779),(0,700,0,957),(0,800,1,000),(0,900,1,000),(1,000,1,000)$

effect_of_enabling_factors_on_capabilities_of_opposing_groups $=$

GRAPH(Enabling_factors)

$(0,000,0,000),(0,100,0,000),(0,200,0,000),(0,300,0,000),(0,400,0,043),(0,500$,

$0,106),(0,600,0,311),(0,700,0,834),(0,800,0,894),(0,900,0,983),(1,000,1,000)$

general_power_of_opposing_groups $=0$

indicated_capabilities = MEAN(Effecf_of_pushing_factors_on_capabilities;

intuitive_appeal_of_idea)

indicated_disabling_factors $=$

Capabilities_of_opposing_groups*actions_per_capabilities_of_opposing_groups

indicated_factors $=$ Capabilities_of_supporting_groups*actions_per_capability

intuitive_appeal_of_idea $=0,2$

maximum_capabilities $=1$

maximum_capabilities_of_opposing_groups $=1$

normal_time_to_build_capabilities $=120$

time_to_build_capabilities $=$

normal_time_to_build_capabilities/.effect_of_catalyzers_on_mechanisms_of_change

time_to_change_enabling_factors $=12$

time_to_develop_capabilities_of_opposing_groups $=60$

time_to_lose_capabilities $=240$

time_to_lose_capabilities_of_opposing_groups $=36$

time_to_perform_disabling_actions $=12$

weight_for_contribution $=1$

weight_for_indicated_capabilities $=2$

\{ The model has 88 (88) variables (array expansion in parens).

In root model and 3 additional modules with 0 sectors.

Stocks: 7 (7) Flows: 9 (9) Converters: 72 (72)

Constants: 28 (28) Equations: 53 (53) Graphicals: 18 (18)

There are also 20 expanded macro variables. 


\section{REFERENCES}

Abramson, L. Y., Seligman, M. E. P., \& Teasdale, J. D. (1978). Learned helplessness in humans: Critique and reformulation. Journal of Abnormal Psychology, 87(1), 49-74.

Acemoglu, D., \& Robinson, J. A. (2013). Why nations fail: The origins of power, prosperity, and poverty. New York, NY: Crown Business.

Adam, E. K., Quinn, M. E., Tavernier, R., McQuillan, M. T., Dahlke, K. A., \& Gilbert, K. E. (2017). Diurnal cortisol slopes and mental and physical health outcomes: a systematic review and meta-analysis. Psychoneuroendocrinology, 83, 25-41.

Andersen, K. (producer \& director); \& Kuhn, K. (producer \& director). (2017). What the health [Motion picture]. United States: A.U.M. Films and Media.

Andreasen, A. R. (2006). Social marketing in the 21st century. Thousand Oaks, CA: Sage Publications.

Ansah, J. P. (2010). Modeling the dynamics of poverty trap and debt accumulation. Proceedings of the 28th International Conference of the System Dynamics Society. Seoul, South Korea: System Dynamics Society.

Ariely, D. (2011). Self-control: Dan Ariely at TEDxDuke [Video File]. Retrieved from https://www.youtube.com/watch?v=PPQhj6ktYSo

Arthur, W. B. (2013). Complexity economics: A different framework for economic thought. SFI Working Paper 2013-04-012. Santa Fe Institute. Retrieved from http://tuvalu.santafe.edu/ wbarthur/Papers/Comp.Econ.SFI.pdf

Arthur, W. B. (2014). All systems will be gamed: Exploitive behavior in economic and social systems. SFI Working Paper 2014-06-016. Santa Fe Institute. Retrieved from http://tuvalu.santafe.edu/ wbarthur/Papers/All\%20Systems\%20Gamed.pdf

Bacaksizlar, N. G.; \& Barlas, Y. (2015). The Feedback dynamics between poverty and education opportunity: Vicious circle of poverty. Proceedings of the 33rd International Conference of the System Dynamics Society. Cambridge, MA: System Dynamics Society.

Baird, S., McIntosh, C., \& Ozler, B. (2009). Designing cost-effective cash transfer programs to boost schooling among young women in Sub-Saharan Africa. World Bank Policy Research Working Paper No. 5090. Retrieved from http://siteresources.worldbank.org/EXTSAFETYNETSANDTRANSFERS/Resources/ WPS5090.pdf

Baldwin, M.; \& Lammers, J. (2016). Past-focused environmental comparisons promote proenvironmental outcomes for conservatives. Proceedings of the National Academy of Sciences of the United States of America, 113 (52), 14953-14957.

Bales, S. N. (2015). The culture of inequality. Nonprofit Quarterly. Retrieved from https://nonprofitquarterly.org/2017/09/07/the-culture-of-inequality/

Bammer, G. (2017). Should we discipline interdisciplinarity? Palgrave Communications, 3(1), 30. 
Bandura, A. (1997). Self-efficacy: The exercise of control. New York, NY: W.H. Freeman and Company.

Banerjee, A.V., \& Duflo, E. (2011). Poor economics: A radical rethinking of the way to fight global poverty. New York, NY: PublicAffairs.

Barlas, Y. (1996). Formal aspects of model validity and validation in system dynamics. System Dynamics Review, 12(3), 183-210.

Baron, J. (2008). Thinking and deciding (4th ed.). New York: Cambridge University Press.

Barney, J. B., \& Clark, D. N. (2007). Resource-based theory: Creating and sustaining competitive advantage. New York, NY: Oxford University Press.

Barrett, C. B., \& Swallow, B. M. (2006). Fractal poverty traps. World Development, 34(1), 1-15.

Barros, R. P., Henriques, R., \& Mendonça, R. (2000). Desigualdade e pobreza no Brasil: Retrato de uma estabilidade inaceitável. Revista Brasileira de Ciências Sociais, 15(42), 123-142.

Barros, D. (2013). Economia no Brasil só decola com melhor educação básica. Revista Exame. Retrieved from https://exame.abril.com.br/revista-exame/a-diferenca-comecana-escola/

Baumeister, R. F., \& Leary, M. R. (1995). The need to belong: Desire for interpersonal attachments as a fundamental human motivation. Psychological Bulletin, 117(3), 497529. http://doi.org/10.1037/0033-2909.117.3.497

Baumeister, R. F. (2002). Yielding to temptation: Self-control failure, impulsive purchasing, and consumer behavior. Journal of Consumer Research, 28(4), 670-676.

Baumeister, R. F., \& Tierney, J. (2011). Willpower: Rediscovering the greatest human strength. New York, NY: The Penguin Press.

Baumgartner, F. R.; \& Jones, B. D. (2009). Agendas and instability in American politics. Chicago, IL: University of Chicago Press.

Bazerman, M., Baron, J., \& Shonk, K. (2001). You can't enlarge the pie: Six barriers to effective government. New York, NY: Basic Books.

Bénabou, R.; \& Tirole, J. (2016). Mindful economics: The production, consumption, and value of beliefs. Journal of Economic Perspectives, 30(3), 141-164.

Benhassine, N., Devoto, F., Duflo, E., Dupas, P., \& Pouliquen, V. (2015). Turning a shove into a nudge? A "Labeled Cash Transfer" for education. American Economic Journal, $7(3), 86-125$.

Berkowitz, L. (2003). Affect, aggression, and antisocial behavior. In R. J., Davidson, K. R., Scherer, \& H. H., Goldsmith, (Eds.), Handbook of affective sciences. (pp. 804-823). New York, NY: Oxford University Press. 
Berry, D., Blair, C., Ursache, A., Willoughby, M., Garrett-Peters, P., Vernon-Feagans, L., ...\& Granger, D.A. (2014). Child care and cortisol across early childhood: context matters. Developmental Psychology, 50(2), 514-25. http://doi.org/10.1037/a0033379

Bertrand, M., Mullainathan, S., \& Shafir, E. (2004). A behavioral economics view of poverty. American Economic Review, 94(2), 419-423.

Bird, K. (2011). How is poverty transmitted intergenerationally and what might be done to stop it in its tracks? Research highlights and policy recommendations. CPRC Working Paper No. 214. Chronic Poverty Research Centre. Retrieved from http://www.chronicpoverty.org/uploads/publication_files/bird_IGT_synthesis.pdf

Biroscak, B. J. (2014). Use of system dynamics modeling to explicate the theory-ofchange of a social marketing innovation (Doctoral dissertation). University of South Florida. Retrieved from http://scholarcommons.usf.edu/etd/5184/

Biswar-Diener, R. (n.d.). A brief history of eudemonia in positive psychology. Retrieved from https://positiveacorn.com/uploads/segment/file/10/ Brief_History_Eudemonia.pdf

Blackmore, S. (2000). The meme machine. Oxford, UK: Oxford University Press.

Blair, C. (2010). Stress and the development of self-regulation in context. Child Development Perspectives, 4(3), 181-188. http://doi.org/10.1111/j.17508606.2010.00145.x

Blair, C., \& Ursache, A. (2011). A bidirectional model of executive functions and selfregulation. In K. D. Vohs \& R. F. Baumeister (Eds.), Handbook of self-regulation: research, theory and applications (pp. 300-320). New York, NY: The Guilford Press.

Blanden, J.; Gibbons, S. (2006). The persistence of poverty across generations: A view from two British cohorts. Retrieved from https://www.jrf.org.uk/sites/default/ files/jrf/migrated/files/9781861348531.pdf

Bolle, M. (2017). How Latin American governments favor the old. Americas Quarterly. Retrieved from http://www.americasquarterly.org/content/young-and-old-publicspending-out-balance

Bornstein, M. H., Britto, P. R., Nonoyama-Tarumi, Y., Ota, Y., Petrovic, O., \& Putnick, D. L. (2012). Child development in developing countries: Introduction and methods. Child Development, 83(1), 16-31. doi:10.1111/j.1467-8624.2011.01671.x

Bourdieu, P. (1986). The forms of capital. Cultural theory: An anthology, 1, 81-93.

Bourdieu, P. (1987). What makes a social class? On the theoretical and practical existence of groups. Berkeley Journal of Sociology, 32, 1-17.

Bowlby, J. (1969). Attachment and loss: Vol. 1. Attachment. New York, NY: Basic Books.

Bowles, S., Durlauf, S. N., \& Hoff, K. (2006). Poverty traps. Princeton, NJ: Princeton University Press.

Bowles, S. (2006). Institutional poverty traps. In S., Bowles, S. N., Durlauf, \& K. Hoff, (Eds.), Poverty traps, (pp. 116-138). Princeton, NJ: Princeton University Press. 
Bradley, R. H., Caldwell, B. M., \& Elardo, R. (1979). Home environment and cognitive development in the first 2 years: A cross-lagged panel analysis. Developmental Psychology, 15(3), 246-250.

Bradley, R. H., Caldwell, B. M., Rock, S. L., Ramey, C. T., Barnard, K. E., Gray, C., ... \& Johnson, D. L. (1989). Home environment and cognitive development in the first 3 years of life: A collaborative study involving six sites and three ethnic groups in North America. Developmental Psychology, 25(2), 217-235.

Bradley, E. H., Elkins, B. R., Herrin, J., \& Elbel, B. (2011). Health and social services expenditures: Associations with health outcomes. BMJ Quality \& Safety, bmjqs-2010.

Brandt, A. M. (2007). The cigarette century: The rise, fall, and deadly persistence of the product that defined America. New York, NY: Basic Books.

BRASIL - Ministério da Educação e Cultura (2014). Relatório educação para todos 2000-2015. Retrieved from http://portal.mec.gov.br/index.php?option= com_docman\&view=download $\&$ alias $=15774$-ept-relatorio-06062014\&Itemid $=30192$

BRASIL - Ministério do Desenvolvimento Social (n.d.). Programa Criança Feliz. Retrieved from http://mds.gov.br/assuntos/crianca-feliz

Braun, W. (2002). The system archetypes. Retrieved from https://www.albany.edu/faculty/gpr/PAD724/724WebArticles/sys_archetypes.pdf

Braveman, P., \& Gottlieb, L. (2014). The social determinants of health: It's time to consider the causes of the causes. Public Health Reports, 129(1_supp12), 19-31.

BRAZIL, Federal Government (2016). Law $\mathrm{n}^{\circ}$ 13.457. Retrieved from http://www.planalto.gov.br/ccivil_03/_ato2015-2018/2016/lei/113257.htm

Bronfenbrenner, U. (1989). Ecological systems theory. Annals of Child Development, 6, 187-249.

Bronfenbrenner, U. (1994). Ecological models of human development. In T. Husen \& T. N. Postlethwaite (Eds.), International encyclopedia of education (2nd ed. Vol. 3), (pp. 1643-1647), Oxford, UK: Pergamon Press/Elsevier Science.

Bronfenbrenner, U., \& Morris, P. A. (2007). The bioecological model of human development. Handbook of child psychology. I:14.

Brooks-Gunn, J., Duncan, G. J., \& Maritato, N. (1997). Poor families, poor outcomes: The well-being of children and youth. In G. J. Duncan, \& J. Brooks-Gunn (Eds.), Consequences of growing up poor (pp. 1-17). New York, NY: Russel Sage Foundation.

Cabrera, D., \& Cabrera, L. (2015). Systems thinking made simple: New hope for solving wicked problems. n/a: Odyssean.

Cabrera, D., Cabrera, L., \& Powers, E. (2015). A unifying theory of systems thinking with psychosocial applications. Systems Research and Behavioral Science, 32(5), 534545.

Cain, E. (2009). Social protection and vulnerability, risk and exclusion across the lifecycle. Retrieved from: http://www.oecd.org/dataoecd/63/10/43514563.pdf 
Camargo, J. M. (2018). Previdência, desigualdade e pobreza. O Estado de São Paulo. Retrieved from http://economia.estadao.com.br/noticias/geral,previdencia-desigualdadee-pobreza,70002192749

Campbell, F. A., Ramey, C. T., Pungello, E., Sparling, J., \& Miller-Johnson, S. (2002). Early childhood education: Young adult outcomes from the Abecedarian Project. Applied Developmental Science, 6(1), 42-57.

Campos, M. M. M. (1992). Atendimento à infância na década de 80: As políticas federais de financiamento. Cadernos de Pesquisa, 82, 5-20.

Carbonari, F. (2014). O atendimento da demanda por creches previsto no PNE em São Paulo. Retrieved from: http://www.observatoriodopne.org.br/metas-pne/1-educacaoinfantil/analises/o-atendimento-da-demanda-por-creches-previsto-no-pne-em-sao-paulo

Carvalho, H. C., \& Mazzon, J. A. (2013). Homo economicus and social marketing: Questioning traditional models of behavior. Journal of Social Marketing, 3(2), 162-175.

Carvalho, H. C., \& Mazzon, J. A. (2015). A better life is possible: the ultimate purpose of social marketing. Journal of Social Marketing, 5(2), 169-186. http://doi.org/10.1108/JSOCM-05-2014-0029

CDC - Centers for Disease Control and Prevention (n.d.). Marijuana and public health. Retrieved from: https://www.cdc.gov/marijuana/health-effects.htm

Ceballo, R., \& McLoyd, V. C. (2002). Social support and parenting in poor, dangerous neighborhoods. Child Development, 73(4), 1310-1321. doi:10.1111/1467-8624.00473

Cecconello, A. M., \& Koller, S. H. (2000). Competência social e empatia: um estudo sobre resiliência com crianças em situação de pobreza. Estudos de Psicologia, 5(1), 7193. http://doi.org/10.1590/S1413-294X2000000100005

Cerqueira, D. R. C. (2010). Causas e conseqüencias do crime no Brasil [Causes and consequences of crime in Brazil] (Doctoral dissertation). Retrieved from http://www2.dbd.puc-rio.br/pergamum/tesesabertas/0610522_10_pretextual.pdf

Chandola, T., Rouxel, P., Marmot, M. G., \& Kumari, M. (2017). Retirement and socioeconomic differences in diurnal cortisol: Longitudinal evidence from a cohort of British civil servants. The Journals of Gerontology: Series B, 73(3), 447-456. https://doi.org/10.1093/geronb/gbx058.

Chaudry, A., \& Waldfogel, J. (2016). A 10-year strategy of increased coordination \& comprehensive investments in early child development. Behavioral Science \& Policy, 2(1), 47-55.

Chemin, M., de Laat, J., \& Haushofer, J. (2013). Negative rainfall shocks increase levels of the stress hormone cortisol among poor farmers in Kenya. Retrieved from https://papers.ssrn.com/sol3/papers.cfm?abstract_id=2294171

Child Welfare Information Gateway. (2014). Protective factors: Approaches in child welfare. Retrieved from https://www.childwelfare.gov/pubPDFs/protective_factors.pdf

Chisholm, J. S. (1993). Death, hope, and sex. Current Anthropology, 34(1), 1-24. 
Chisholm, J. S. (1996). The evolutionary ecology of attachment organization. Human Nature, 7(1), 1-37. http://doi.org/10.1007/BF02733488

Claro, S., Paunesku, D., \& Dweck, C. S. (2016). Growth mindset tempers the effects of poverty on academic achievement. Proceedings of the National Academy of Sciences, 113(31), 8664-8668.

Cohen, S., Doyle, W. J., \& Baum, A. (2006). Socioeconomic status is associated with stress hormones. Psychosomatic Medicine, 68(3), 414-420.

Comim, F., \& Bagolin, I. P. (2002). Aspectos qualitativos da pobreza no Rio Grande do Sul. Ensaios FEE, 23, 467-490.

Comin, F., Bagolin, I. P., Avila, R., Júnior, S. S. P., \& Picolotto, V. C. (2006). Pobreza multidimensional em Porto Alegre. Retrieved from http://lproweb.procempa.com.br/pmpa/prefpoa/observatorio/usu_doc/indicador_multidi mensional.pdf

Conway, L., \& Schaller, M. (2007). How communication shapes culture. Social Communication, 107-127. http://doi.org/10.4324/9780203837702

Conger, R. D.; Conger, K. J.; \& Elder Jr., G. H. (1997). Family economic hardship and adolescent adjustment: Mediating and moderating processes. In G. J. Duncan, \& J. Brooks-Gunn (Eds.), Consequences of growing up poor (pp. 288-310). New York, NY: Russel Sage Foundation.

Corcoran, M.; \& Adams, T. (1997). Race, sex, and the intergenerational transmission of poverty. In G. J. Duncan, \& J. Brooks-Gunn (Eds.), Consequences of growing up poor (pp. 461-517). New York, NY: Russel Sage Foundation.

Corner, A., \& Randall, A. (2011). Selling climate change? The limitations of social marketing as a strategy for climate change public engagement. Global Environmental Change, 21(3), 1005-1014.

Costanza, R., d'Arge, R., De Groot, R., Farber, S., Grasso, M., Hannon, B., Limburg, K., Naeem, S., O’Neill, R. V., Paruelo, J., Raskin, R. G., Sutton, P., \& van den Belt, M. (1997). The value of the world's ecosystem services and natural capital. Nature, 387(6630), 253-260.

Council for Early Child Development (2010). The science of early child development. Retrieved from https://mccahouse.org/wp-content/uploads/2014/12/Brochure_Science _of_ECD_June2010.pdf

Csikszentmihalyi, M. (1990). Flow: the psychology of optimal experience. New York, NY: Harper Perennial.

Cunha, F., \& Heckman, J. J. (2010). Investing in our young people. Retrieved from: https://papers.ssrn.com/sol3/papers.cfm?abstract_id=1638506

Daly, J. A. (2011). Advocacy: Championing ideas and influencing others. New Haven, CT: Yale University Press.

Darling, N., \& Steinberg, L. (1993). Parenting style as context: An integrative model. Psychological Bulletin, 113(3), 487-496. http://doi.org/10.1037/0033-2909.113.3.487 
DATAFOLHA (2017). Maioria em SP é contra mensalidade em universidades públicas. Retrieved from http://datafolha.folha.uol.com.br/opiniaopublica/2017/12/1945095maioria-em-sp-e-contra-mensalidade-em-universidades-publicas.shtml

Datta, S., \& Mullainathan, S. (2014). Behavioral design: A new approach to development policy. Review of Income and Wealth, 60(1), 7-35.

Davis, M. (1971). That's interesting! Philosophy of the Social Sciences, 1(4), 309-344.

Dearing, E., McCartney, K., \& Taylor, B. A. (2001). Change in family income-to-needs matters more for children with less. Child Development, 72 (6), 1779-1793. doi: $10.1111 / 1467-8624.00378$

Dennett, D. C. (2013). Intuition pumps and other tools for thinking. New York, NY: WW Norton \& Company.

de Ridder, D. T., Lensvelt-Mulders, G., Finkenauer, C., Stok, F. M., \& Baumeister, R. F. (2012). Taking stock of self-control: A meta-analysis of how trait self-control relates to a wide range of behaviors. Personality and Social Psychology Review, 16(1), 76-99.

Di Giulio, E.; Vaglio, A.; Canova, L.; Grasso, M.; Lelli, S.; Migliavacca, S., \& Pareglio, S. (2004). MISS: A model of sustainable human development. Proceedings of the 22nd International Conference of the System Dynamics Society. Oxford, UK: System Dynamics Society.

Diamond, J. (1997). Guns, germs and steel: The fates of human societies. New York, NY: W. W. Norton \& Company.

Diamond, J. (2006). Collapse: How societies choose to fail or succeed. New York, NY: Penguin Books.

Diamond, J. (2013). The world until yesterday: What can we learn from traditional societies? New York, NY: Penguin Books.

Dickerson, S. S., \& Kemeny, M. E. (2004). Acute stressors and cortisol responses: A theoretical integration and synthesis of laboratory research. Psychological Bulletin, 130(3), 355-391. http://doi.org/10.1037/0033-2909.130.3.355

Dinh, T., Pinsof, D., Gangestad, S. W., \& Haselton, M. G. (2017). Cycling on the fast track: Ovulatory shifts in sexual motivation as a proximate mechanism for regulating life history strategies. Evolution and Human Behavior, 38(6), 685-694.

Dorsch, M. J.; Törnblow, K. Y.; Kazemi, A. (2017). A review of resource theories and their implications for understanding consumer behavior. Journal of the Association for Consumer Research, 2(1), 5-25.

Downer, J. T.; \& Pianta, R. C. (2006). Academic and cognitive functioning in first grade: Associations with earlier home and child care predictors and with concurrent home and classrooms experiences. Social Psychology Review, 35(1), 11-30.

Duncan, G. J.; \& Brooks-Gunn, J. (1997). Income effects across the life span: Integration and interpretation. In G. J. Duncan, \& J. Brooks-Gunn (Eds.), Consequences of growing up poor (pp. 596-610). New York, NY: Russel Sage Foundation. 
Duncan, G. J; Ziol-Guest, K.; Kalil, A. (2010). Early-childhood poverty and adult attainment, behavior, and health. Child Development, 81(1), 306-325.

Durlauf, S.N. (2006). Groups, social influences, and inequality. In S. Bowles, S. N. Durlauf, \& K. Hoff (Eds.), Poverty traps, (pp. 141-176). Princeton, NJ: Princeton University Press.

Ellis, B. J., Figueredo, A. J., Brumbach, B. H., \& Schlomer, G. L., (2009). Fundamental dimensions of environmental risk: The impact of harsh versus unpredictable environments on the evolution and development of life history strategies. Human Nature, 20, 204-268. http://doi.org/10.1007/s12110-009-9063-7

Ellis, B. J., Giudice, M. Del, Dishion, T. J., Figueredo, A. J., Gray, P., Griskevicius, V., ... \& Wilson, D. S. (2012). The evolutionary basis of risky adolescent behavior: Implications for science, policy, and practice. Developmental Psychology, 48(3), 598623. http://doi.org/10.1037/a0026220

Enamorado, T., López-Calva, L. F., Rodríguez-Castelán, C., \& Winkler, H. (2016). Income inequality and violent crime: Evidence from Mexico's drug war. Journal of Development Economics, 120, 128-143.

Engerman, S. L., \& Sokoloff, K. L. (2006). The persistence of poverty in the Americas: The role of institutions", In S. Bowles, S. N. Durlauf, \& Hoff, K. (Eds.), Poverty traps, (pp. 43-78). Princeton, NJ: Princeton University Press.

Esping-Andersen, G. (2002). Why we need a new welfare state. New York, NY: Oxford University Press.

Evans, G. W., Gonnella, C., Marcynyszyn, L. A., Gentile, L., \& Salpekar, N. (2005). The role of chaos in poverty and children's socioemotional adjustment. Psychological Science, 16(7), 560-565. http://doi.org/10.1111/j.0956-7976.2005.01575.x

Evans, G. W. and English, K. (2002). The environment of poverty: Multiple stressor exposure, psychophysiological stress, and socioemotional adjustment. Child Development, 73(4), 1238-1248. doi:10.1111/1467-8624.00469

Evans, G. W., \& Kim, P. (2013). Childhood poverty, chronic stress, self-regulation, and coping. Child Development Perspectives, 7(1), 43-48. http://doi.org/10.1111/cdep.12013

Farran, D. C., \& Lipsey, M. W. (2016). Evidence for the benefits of state prekindergarten programs: Myth \& misrepresentation. Behavioral Science \& Policy, 2(1), 9-18.

Figueredo, A. J., Vásquez, G., Brumbach, B. H., \& Schneider, S. M. R. (2004). The heritability of life history strategy: the K-factor, covitality, and personality. Biodemography and Social Biology, 51(3-4), 121-43.

Figueredo, A. J., Vásquez, G., Brumbach, B. H., \& Schneider, S. M. R. (2007). The Kfactor, covitality, and personality: a psychometric test of life history theory. Human Nature, 18(1), 47-73.

Finkenauer, C., Buyukcan-Tetik, A., Baumeister, R. F., Schoemaker, K., Bartels, M., \& Vohs, K. D. (2015). Out of control: Identifying the role of self-control strength in family violence. Current Directions in Psychological Science, 24(4), 261-266. 
Fisk, G. (1967). Marketing systems: An introductory analysis. New York, NY: Harper \& Row.

Fiske, S. T., \& Taylor, S. E. (1991). Social cognition. New York, NY: McGraw-Hill.

Food and Agriculture Organization. (2015). Millennium development goal 1 and world food summit hunger targets: FAO hunger map. Retrieved from http://www.fao.org/3/ai4674e.pdf

Food and Agriculture Organization of the United Nations. (2017). The state of food insecurity and nutrition in the world 2017. Retrieved from http://www.fao.org/3/aI7695e.pdf

Ford, A. (2010). Modeling the environment. Washington, DC: Island Press.

Forgeard, M. J. C., Jayawickreme, E., Kern, M. L., \& Seligman, M. E. P. (2011). Doing the right thing: Measuring well-being for public policy. International Journal of Wellbeing, 1(1), 79-106. http://doi.org/10.5502/ijw.v1i1.15

Forget, E. (2011). The town with no poverty: The health effects of a Canadian guaranteed annual income field experiment. Canadian Public Policy, 37(3), 283-305.

Forrester, J. W. (1961). Industrial dynamics. Cambridge, MA: Productivity Press.

Forrester, J. W. (1968). Industrial dynamics - after the first decade. Management Science, 14(7), 398-415.

Forrester, J. W. (1969). Urban dynamics. Cambridge, MA: MIT Press.

Forrester, J. W. (1971). Counterintuitive behavior of social systems. Theory and Decision, 2(2), 109-140.

Forrester, J. W. (1973). World Dynamics (2nd ed.). Cambridge, MA: Wright-Allen Press.

Forrester, J. W. (1994). Learning through system dynamics as preparation for the 21st century. Retrieved from: http://web.mit.edu/sysdyn/sd-intro/D-4434-1.pdf

French, J., \& Gordon, R. (2015). Strategic social marketing. London, UK: Sage.

Friedman, M. (1962:1982). Capitalism and freedom. Chicago, IL: University of Chicago Press.

Furtado, B.A.; \& Sakowski, P.A.M. (2014). Complexity: A review of the classics. Policy and Complex Systems, 1(2), 3-18.

Gary, M. S.; Wood, R. E. (2016). Unpacking mental models through laboratory experiments. System Dynamics Review, 32(2), 101-129.

Ghaffarzadegan, N.; Lyneis, J.; \& Richardson, G. P. (2011). How small system dynamics models can help the public policy process. System Dynamics Review, 27(1), 22-44.

Ghaffarzadegan, N.; Xue, Y.; Larson, R. C. (2017). Work-education mismatch: An endogenous theory of professionalization. European Journal of Operational Research, 261(3), 1085-1097. 
Giambiagi, F., \& Schwartsman, A. (2014). Complacência: Entenda por que o Brasil cresce menos do que pode. São Paulo, Brazil: Elsevier.

Gilbert, M. (2013). Casual marijuana use becomes common on TV. Boston Globe. Retrieved from https://www.bostonglobe.com/lifestyle/style/2013/06/17/many-showsmarijuana-puffs-are-part-performance/9mET79NyBCHbpIlpiCzjxM/story.html

Gluckman, P. D.; Hanson, M. A.; \& Beedle, A. S. (2007). Early life events and their consequences for later disease: A Life history and evolutionary perspective. American Journal of Human Biology, 19(1), 1-19.

Gordon, R., Carrigan, M., \& Hastings, G. (2011). A framework for sustainable marketing. Marketing Theory, 11(2), 143-163. http://doi.org/10.1177/1470593111403218

Governo Aberto SP. Orçamento do Estado de São Paulo. Retrieved from http://catalogo.governoaberto.sp.gov.br/dataset/656-orcamento-do-estado-de-sao-paulo

Greenfield, E.A.; \& Marks, N.F. (2009). Violence from parents in childhood and obesity in adulthood: Using food in response to stress as a mediator of risk. Social Science \& Medicine, 68(5), 791-798.

Griskevicius, V.; Delton, A. W.; Robertson, T. E.; \& Tybur, J. M. (2011). Environmental contingency in life story strategies: The influence of mortality and socioeconomic status on reproductive timing. Journal of Personality and Social Psychology, 100(2), 241-254.

Griskevicius, V.; Ackerman, J. M.; Cantú, S. M.; Delton, A. W.; Robertson, T. E.; Simpson, J. A.; Thompson, M. E.; \& Tybur, J. M. (2012). When the economy falters, do people spend or save? Responses to resource scarcity depend on childhood environment. Psychological Science, 24(2), 1-9.

Groëßler, A. (2008). System dynamics modelling as an inductive and deductive endeavor: Comment on the paper by Schwaninger and Grosser. Behavioral Science, 25(4), 467-470.

Gunnar, M. R., \& Donzella, B. (2002). Social regulation of the cortisol levels in early human development. Psychoneuroendocrinology, 27(1-2), 199-220.

Hackman, D. A., Farah, M. J., \& Meaney, M. J. (2010). Socioeconomic status and the brain: Mechanistic insights from human and animal research. Nature Reviews Neuroscience, 11(9), 651-659.

Hackman, D. A., Gallop, R., Evans, G. W., \& Farah, M. J. (2015). Socioeconomic status and executive function: Developmental trajectories and mediation. Developmental Science, 18(5), 686-702.

Haidt, J., Seder, J. P., \& Kesebir, S. (2008). Hive psychology, happiness and public policy. The Journal of Legal Studies, 37(2), 133-156. http://doi.org/10.1086/529447

Hair, E., Halle, T., Terry-Humen, E., Lavelle, B., \& Calkins, J. (2006). Children's school readiness in the ECLS-K: Predictions to academic, health, and social outcomes in first grade. Early Childhood Research Quarterly, 21(4), 431-454.

Hamilton, K. \& Catterall, M. (2005). Towards a better understanding of the low-income consumer. In G. Menon, \& A. R. Rao (Eds.), Advances in Consumer Research (vol. 32) (pp. 627-632). Duluth, MN: Association for Consumer Research. 
Handa, S., Peterman, A., Seidenfeld, D., \& Tembo, G. (2016). Income transfers and maternal health: Evidence from a national randomized social cash transfer program in Zambia. Health Economics, 25(2), 225-236.

Hanson, T. L.; McLanahan, S.; \& Thomson, E. (1997). Economic resources, parental practices and children's well-being. In G. J. Duncan, \& J. Brooks-Gunn (Eds.), Consequences of growing up poor (pp. 190-238). New York, NY: Russel Sage Foundation.

Hart, B., \& Risley, T. (2003). The early catastrophe. American Educator, 27(4), 6-9.

Hastings, G., \& Domegan, C. (2007). Social marketing: Why should the devil have all the best tunes? New York, NY: Routledge.

Haskins, R. (2016). American policy on early childhood education \& development: Many programs, great hopes, modest impacts. Behavioral Science \& Policy, 2(1), 1-8.

Haveman, R.; Wolfe, B.; \& Wilson, K. (1997). Childhood poverty and adolescent schooling and fertility outcomes: Reduced-form and structural estimates. In G. J. Duncan, \& J. Brooks-Gunn (Eds.), Consequences of growing up poor (pp. 419-17). New York, NY: Russel Sage Foundation.

Hawe, P., Shiell, A., \& Riley, T. (2009). Theorising interventions as events in systems. American Journal of Community Psychology, 43(3-4), 267-276.

Heckman, J. J., Moon, S. H., Pinto, R., Savelyev, P. A., \& Yavitz, A. (2010). The rate of return to the HighScope Perry Preschool Program. Journal of Public Economics, 94, 114128.

Heckman, J. J. (2013). Giving kids a fair chance. Cambridge, MA: The MIT Press.

Helliwell, J. F., \& Putnam, R. D. (2004). The social context of well-being. Philosophical Transactions of the Royal Society B: Biological Sciences, 359, 1435-1446.

Helliwell, J., Layard, R., \& Sachs, J. (2012). World happiness. Retrieved from http://eprints.lse.ac.uk/47487/

Henrich, N., \& Henrich, J. P. (2007). Why humans cooperate: A cultural and evolutionary explanation. Oxford, UK: Oxford University Press.

Hernandez, D. J. (1997). Poverty trends. In G. J. Duncan, \& J. Brooks-Gunn (Eds.), Consequences of growing up poor (pp. 18-34). New York, NY: Russel Sage Foundation.

Heyman, J., \& Ariely, D. (2004). Effort for payment: A tale of two markets. Psychological Science, 15(11), 787-793.

Hick, R. (2012). The capability approach: Insights for a new poverty focus. Journal of Social Policy, 41(2), 291-308.

Hick, R. (2016). Material poverty and multiple deprivation in Britain: The distinctiveness of multidimensional assessment. Journal of Public Policy, 36(2), 277-308.

Hidalgo, C. (2017). Why information grows: The evolution of order, from atoms to economies. New York, NY: Basic Books. 
Hirsch, G. B.; Levine, R.; Miller, R. L. (2007). Using system dynamics modeling to understand the impact of social change initiatives. American Journal of Community Psychology, 39(3-4), 239-253.

Hoff, E., Laursen, B., \& Tardif, T. (2002). Socioeconomic status and parenting. In M.H. Bornstein (Ed.), Handbook of parenting (pp. 231-252). Mahwah, NJ: Erlbaum.

Holladay, R. (2015). Telling your story: Narratives in complex adaptive systems. Retrieved from http://www.hsdinstitute.org/resources/telling-your-story-narratives-incomplex-adaptive-systems-blog.html

Holland, P., \& Beer, M. (1990). People Express Airlines: rise and decline. Harvard Business School, case 9-490-12.

Holz, N. E., Boecker, R., Hohm, E., Zohsel, K., Buchmann, A. F., Blomeyer, D., ... \& Laucht, M. (2015). The long-term impact of early life poverty on orbitofrontal cortex volume in adulthood: Results from a prospective study over 25 years. Neuropsychopharmacology, 40(4), 996-1004. http://doi.org/10.1038/npp.2014.277

Homel, P., \& Carroll, T. (2009). Moving knowledge into action: Applying social marketing principles to crime prevention. Retrieved from http://www.aic.gov.au/media_library/publications/tandi_pdf/tandi381.pdf

Homer, J. B. (1993). A system dynamics model of national cocaine prevalence. System Dynamics Review, 9(1), 49-78.

Hovland, C. I., Lumsdaine, A. A., Sheffield, F. D. (1949). Experiments on mass communication. Princeton, NJ: Princeton University Press.

Hunt, S. D. (1976). The nature and scope of marketing. Journal of Marketing, 40(3), $17-$ 28.

Hurst, J. E., \& Kavanagh, P. S. (2017). Life history strategies and psycopathology: The faster the life strategies, the more symptoms of psycopathology. Evolution and Human Behavior, 38(1), 1-8.

IBGE (2006). Estatisticas do Século XX. Retrieved from http://biblioteca.ibge.gov.br/visualizacao/monografias/GEBIS\%20-\%20RJ/seculoxx.pdf

IBGE (2015a). Pesquisa Nacional por Amostra de Domicílios. Retrieved from http://biblioteca.ibge.gov.br/visualizacao/livros/liv98887.pdf

IBGE (2015b). Aspectos dos cuidados das crianças de menos de 4 anos de idade. Retrieved from https://biblioteca.ibge.gov.br/visualizacao/livros/liv100137.pdf

IBGE (2015c). Tábuas completas de mortalidade. Retrieved from https://www.ibge.gov.br/estatisticas-novoportal/todos-os-produtos-estatisticas/2050demografia-e-estatisticas-sociais/populacao/componentes-da-dinamica-demografica-eestatisticas-vitais/np-tabua-completa-de-mortalidade/9126-tabuas-completas-demortalidade.html

IBGE (2016). Sintese de indicadores sociais. Retrieved from https://biblioteca.ibge.gov.br/visualizacao/livros/liv98965.pdf 
IBGE (2017). Sintese dos indicadores sociais. Retrieved from https://biblioteca.ibge.gov.br/visualizacao/livros/liv101459.pdf

IBGE (n.d.). Séries históricas e estatísticas. Retrieved from https://seriesestatisticas.ibge.gov.br

Innocenti Research Centre (2012). Measuring child poverty: New league tables of child poverty in the world's rich countries. Retrieved from https://www.unicefirc.org/publications/pdf/rc10_eng.pdf

INPAD - Instituto Nacional de Ciência e Tecnologia para Políticas Públicas do Álcool e Outras Drogas (2014). II Levantamento Nacional de Álcool e Drogas. Retrieved from http://inpad.org.br/wp-content/uploads/2014/03/Lenad-II-Relat\%C3\%B3rio.pdf

Instituto Igarapé (n.d.). Homicide monitor. Retrieved from http://homicide.igarape.org.br/

International Social Marketing Association. (2013). The iSMA, ESMA and AASM consensus definition of social marketing. Retrieved from http://www.isocialmarketing.org/assets/social_marketing_definition.pdf

IPEA - Instituto de Pesquisa Econômica Aplicada (2008). World study on poverty and disparities in childhood. Retrieved from http://www.unicef.org/socialpolicy/ files/Childhood_and_Poverty_in_Brazil.ppt

Ipeadata (n.d.). Ipeadata social. Retrieved from http://www.ipeadata.gov.br/Default.aspx

IPM - Instituto Paulo Montenegro (2016). Indicador de analfabetismo funcional-INAF: Estudo especial sobre alfabetismo e mundo do trabalho. Retrieved from http://acaoeducativa.org.br/wp-content/uploads/2016/09/INAFEstudosEspeciais_2016 Letramento_e_Mundo_do_Trabalho.pdf

Isee Systems (2016). Stella Architect (Version 1.6.1) [Software]. Available from http://www.iseesystems.com/

Jaitman, L., Caprirolo, D., Ochoa, R. G., Keefer, P., Leggett, T., Lewis, J. A., Guerra, J. A. M., Mello, M., Sutton, H., \& Torre, I. (2017). The costs of crime and violence: New evidence and insights in Latin America and the Caribbean. Retrieved from: https://publications.iadb.org/handle/11319/8133

Janiszewski, C., Labroo, A. A., \& Rucker (2016). A tutorial in consumer research: Knowledge creation and knowledge appreciation in deductive-conceptual consumer research. Journal of Consumer Research, 43(2), 200-209.

Justus, M., Kahn, T., \& Cerqueira, D. (2016). O “mistério de São Paulo" e o papel do PCC na redução de homicídios nos anos 2000. Retrieved from $\mathrm{http}: / / \mathrm{www}$.eco.unicamp.br/docprod/downarq.php?id=3471\&tp=a.

Kahneman, D., \& Deaton, A. (2010). High income improves evaluation of life but not emotional well-being. Proceedings of the National Academy of Sciences of the United States of America, 107(38), 16489-16493. http://doi.org/10.1073/pnas.1011492107

Kahneman, D., Diener, E. and Schwarz, N. (Eds.) (1999). Well-being: The foundations of hedonic psychology. New York, NY: Russell Sage Foundation. 
Kamakura, W. A., \& Mazzon, J. A. (2013). Estratificação socioeconômica e consumo no Brasil. São Paulo, Brazil: Blucher.

Kellerman, B. (2012). The end of leadership. New York, NY: Harper Collins.

Kennedy, A., \& Parsons, A. (2012). Macro-social marketing and social engineering: A systems approach. Journal of Social Marketing, 2(1), 37-51. http://doi.org/10.1108/20426761211203247

Kennedy, A. M., Kapitan, S., Bajaj, Bakonyi, A., \& Sands, S. (2017). Uncovering wicked problem's system structure: Seeing the forest for the trees. Journal of Social Marketing, $7(1), 51-73$.

Kettl, D. F. (2000). Public administration at the millennium: The state of the field. Journal of Public Administration Research and Theory, 10(1), 7-34.

Keynes, J. M. (1935). The general theory of employment, interest and money. New York, NY: Macmillan Cambridge University Press.

Kidd, C., Palmeri, H., \& Aslin, R. N. (2013). Rational snacking: Young children's decision-making on the marshmallow task is moderated by beliefs about environmental reliability. Cognition, 126(1), 109-114.

Kidwell, B., Farmer, A., \& Hardesty, D. M. (2013). Getting liberals and conservatives to go green: Political ideology and congruent appeals. Journal of Consumer Research, 40(2), 350-367.

Kindra, G., \& Stapenhurst, R. (1998). Social marketing strategies to fight corruption. Retrieved from http://siteresources.worldbank.org/INTWBIGOVANTCOR/Resources/ socialmktg.pdf

Knack, S. (2001). Trust, associational life and economic performance. HRDC-OECD International Symposium on the Contribution of Investment in Human and Social Capital to Sustained Economic Growth and Well-Being. Retrieved from: http://www.oecd.org/innovation/research/1825662.pdf

Korenman, S., \& Miller, J. E. (1997). Effects of long-term poverty on physical health of children in the national longitudinal survey of youth. In G. J. Duncan, \& J. Brooks-Gunn (Eds.), Consequences of growing up poor (pp. 70-99). New York, NY: Russel Sage Foundation.

Kotler, P. (2015). Confronting capitalism: Real solutions for a troubled economic system. New York, NY: Amacon.

Kotler, P. (2017). Philip Kotler: Some of my adventures in marketing. Journal of Historical Research in Marketing, 9 (2), 203-208.

Kotler, P., \& Lee, N. R. (2009). Up and out of poverty: The social marketing solution. Upper Saddle River, NJ: Wharton School Publishing.

Kotler, P., \& Lee, N. R. (2016). Social marketing: Changing behaviors for good (5th ed.). Thousand Oaks, CA: Sage. 
Kotler, P., \& Roberto, E. L. (1989). Social marketing: Strategies for changing public behavior. New York, NY: The Free Press.

Kotler, P., Roberto, N., \& Lee, N. (2002). Social marketing: Improving the quality of life. Thousand Oaks, CA: Sage Publications.

Kotler, P.; Roberto, N.; \& Leisner, T. (2006). Alleviating poverty: A macro/micro marketing perspective. Journal of Macromarketing, 26(2), 233-239.

Kotler, P., \& Zaltman, G. (1971). Social marketing: An approach to planned social change. Journal of Marketing, 35(3), 3-12.

Kraus, M. W., Piff, P. K., \& Keltner, D. (2009). Social class, sense of control, and social explanation. Journal of Personality and Social Psychology, 97(6), 992-1004.

Kubinski, J. S.; Chopik, W. J.; \& Grimm, K. J. (2017). Change across the lifespan in a psychological measure of life history strategy. Evolution \& Human Behavior, 38(4), 434441.

Kumkale, G. T., \& Albarracín, D. (2004). The sleeper effect in persuasion: A metaanalytic review. Psychological Bulletin, 130(1), 143-172.

Kuzawa, C. W. (2010). Beyond feast-famine: Brain evolution, human life history, and the metabolic syndrome. In M. P. Muehlenbein (Ed.), Human evolutionary biology. Cambridge, UK: Cambridge University Press.

Lade, S. J.; Haider, L. J.; Engström, G.; \& Schlüter, M. (2017). Resilience offers escape from trapped thinking on poverty alleviation. Science Advances, 3(5), e1603043.

Lajolo, M. (2017). Trânsito no Brasil mata 47 mil por ano e deixa 400 mil com alguma sequela. Retrieved from http://www1.folha.uol.com.br/seminariosfolha/ 2017/05/1888812-transito-no-brasil-mata-47-mil-por-ano-e-deixa-400-mil-comalguma-sequela.shtml

Lagi, M., Bertrand, K. Z., \& Bar-Yam, Y. (2011). The food crises and political instability in North Africa and the Middle East. Retrieved from: https://arxiv.org/pdf/1108.2455

Laland, K.N. (2017). Darwin's unfinished symphony. Princeton, NJ: Princeton University Press.

Larson, C. P. (2007). Poverty during pregnancy: Its effects on child health outcomes. Paediatrics and Child Health, 12(8), 673-677

Latinobarómetro (2016). Informe 2016. Retrieved from: http://www.latinobarometro.org Laurin, K. (2018). Inaugurating rationalization: Three field studies find increased rationalization when anticipated realities become current. Psychological Science, 29(4), 483-495. https://doi.org/10.1177/0956797617738814.

Layton, R. A., \& Grossbart, S. (2006). Macromarketing: Past, present, and possible future. Journal of Macromarketing, 26(2), 193-213. http://doi.org/10.1177/ 0276146706294026

Lefebvre, R. C. (2011). An integrative model for social marketing. Journal of Social Marketing, 1(1), 54-72. http://doi.org/10.1108/20426761111104437 
Lerner, M. J., \& Simmons, C. H. (1966). Observer's reaction to the" innocent victim": Compassion or rejection? Journal of Personality and Social Psychology, 4(2), 203-210.

Leventhal, T., \& Brooks-Gunn, J. (2002). Poverty and child development. The International Encyclopedia of the Social and Behavioral Sciences, 3(14), 11889-11893.

Levine, R. L.; Fitzgerald, H. (1992). Analysis of dynamic psychological systems: Basic approaches to general systems, dynamic systems, and cybernetics (Vol. 1). New York, NY: Plenum Press.

Levine, R. L. (2000). System dynamics applied to psychological and social problems. Proceedings of the 18th International Conference of the System Dynamics Society. Bergen, Norway: System Dynamics Society.

Lewin, K. (1948; 2010). Resolving social conflicts and field theory in social science [Kindle version]. Retrieved from Amazon.com.

Lewin, K. (2015). Principles of topological psychology. Eastford, CT: Martino Fine Books.

Liesen, L. T. (2011). The state's response to parental divestment. In S. A. Peterson, \& A. Somit (Eds.), Biology and politics (pp.11-27). Bingley, UK: Emerald.

Lipman, E. L.; \& Offord, D. R. (1997). Psychosocial morbidity among poor children in Ontario. In G. J. Duncan, \& J. Brooks-Gunn (Eds.), Consequences of growing up poor (pp. 239-287). New York, NY: Russel Sage Foundation.

Lisboa, M. B.; \& Latif, Z. A. (2013). Democracy and growth in Brazil. Retrieved from https://www.insper.edu.br/wp-content/uploads/2013/07/Democracy_and_Growth_in_ Brazil.pdf

Lisboa, M. B.; Pessôa, S. A.; \& Almeida, M. F. (2015). O Ajuste inevitável. Folha de São Paulo. Retrieved from https://www.insper.edu.br/conhecimento/conjuntura-economica /o-ajuste-inevitavel/

Little, T. D., Hawley, P. H., Heinrich, C. C., \& Marsland, K. W. (2002). Three views of the agentic self: A developmental synthesis. In E. L. Deci \& R. M. Ryan (Eds.), Handbook of self-determination research (pp. 389-404). Rochester, NY: The University of Rochester Press.

Lobel, F.; \& Pagnan, R. (2016). 2 em 3 menores infratores não têm pai dentro de casa. Folha de São Paulo. Retrieved from http://www1.folha.uol.com.br/cotidiano/ 2016/06/1786011-2-em-3-menores-infratores-nao-tem-pai-dentro-de-casa.shtml

Loewenstein, G., \& Small, D. A. (2007). The scarecrow and the tin man: The vicissitudes of human sympathy and caring. Review of General Psychology, 11(2), 112-126.

Loewenstein, G. (2009). That which makes life worthwhile. In A. B. Krueger (Ed.), Measuring the subjective well-being of nations: National accounts of time and well-being (pp. 87-106). Chicago, IL: University of Chicago Press.

Loman, M. M., \& Gunnar, M. R. (2010). Early experience and the development of stress reactivity and regulation in children. Neuroscience \& Biobehavioral Reviews, 34(6), 867876. 
Ludwig, J., Sanbonmatsu, L., Gennetian, L., Adam, E., Duncan, G. J., ... \& McDade, T. W. (2011). Neighborhoods, obesity and diabetes: A randomized social experiment. The New England Journal of Medicine, 16, 1509-1519.

Lustig, R. (2017). The hacking of the American mind: The science behind the corporate takeover of our bodies and brains. New York, NY: Penguin Random House.

Maccoby, E., \& Martin, J. (1983). Socialization in the context of the family: Parent-child interaction. In P. H. Mussen (Ed.), Handbook of child psychology: Socialization, personality, and social development (pp. 1-101). New York, NY: Wiley.

Maia, G. (2017). PMDB foi o partido que perdeu mais filiados em 2017. Retrieved from https://noticias.uol.com.br/politica/ultimas-noticias/2017/12/19/pmdb-foi-o-partido-queperdeu-mais-filiados-em-2017.htm

Mani, A., Mullainathan, S., Shafir, E., \& Zhao, J. (2013). Poverty impedes cognitive function. Science, 341(6149), 976-980.

Manson, J. H. (2017). Are extraversion and openness indicators of a slow life history strategy? Evolution and Human Behavior, 38(4), 552-560.

Marmot, M. (2004). The status syndrome: How social standing affects our health and longevity. New York, NY: Holt Paperbacks.

Martin, R. L. (2013). Our self-inflicted complexity. Retrieved from https://hbr.org/2013/09/our-self-inflicted-complexity

Martin, R. L. (2016). M\&A: The one thing you need to get right. Retrieved from https://hbr.org/2016/06/ma-the-one-thing-you-need-to-get-right

Mayer, S. E. (1997). Trends in economic well-being and life chances of America's children. In G. J. Duncan, \& J. Brooks-Gunn (Eds.), Consequences of growing up poor (pp. 49-69). New York, NY: Russel Sage Foundation.

McEwen, B. S., \& Gianaros, P. J. (2010). Central role of the brain in stress and adaptation: Links to socioeconomic status, health, and disease. Annals of the New York Academy of Sciences, 1186, 190-222. http://doi.org/10.1111/j.1749-6632.2009.05331.x

McEwen, B. S. (2012). Brain on stress: How the social environment gets under the skin. Proceedings of the National Academy of Sciences, 109(Supplement 2), 17180-17185.

McLanahan, S. S. (1997). Parent absence or poverty: Which matters more? In G. J. Duncan, \& J. Brooks-Gunn (Eds.), Consequences of growing up poor (pp. 35-48). New York, NY: Russel Sage Foundation.

McLeroy, K. R., Bibeau, D., Steckler, A., \& Glanz, K. (1988). An ecological perspective on health promotion programs. Health Education Quarterly, 15(4), 351-377.

McLoyd, V. C. (1990). The impact of economic hardship on black families and children: Psychological distress, parenting, and socioemotional development. Child Development, 61(2), 311-346. http://doi.org/10.1111/j.1467-8624.1990.tb02781.x 
Mead, N. L., Patrick, V. M., Gunadi, M. P., \& Hofmann, W. (2016). Simple pleasures, small annoyances, and goal progress in daily life. Journal of the Association for Consumer Research, 1(4), 527-539. http://doi.org/10.1086/688287

Meadows, D. H., Meadows, D. L., Randers, J., \& Behrens III, W. W. (1972). The limits to growth. New York, NY: New American Library.

Meadows, D. H. (1999). Leverage points: Places to intervene in a system. Retrieved from: http://donellameadows.org/archives/leverage-points-places-to-intervene-in-a-system/

Meadows, D. H. (2002a). Controlling growth by controlling attractiveness. System Dynamics Review, 18(2), 137-138.

Meadows, D. H. (2002b). Dancing with systems. Systems Thinker, 13(2), 2-6.

Meadows, D. H., \& Wright, D. (2008). Thinking in systems: A primer. London, UK: Earthscan.

Meadows, D., Randers, J., \& Meadows, D. (2004). Limits to growth: The 30-year update. White River Junction, VE: Chelsea Green.

Medeiros, M.; \& Sousa, P. (2013). Gasto público, tributos, e desigualdade de renda no Brasil. Retrieved from http://www.en.ipea.gov.br/agencia/images/stories/PDFs/TDs/ td_1844.pdf

Mendes, M. (2014). Por que o Brasil cresce pouco? Desigualdade, democracia e baixo crescimento no país do futuro. Rio de Janeiro, Brazil: Elsevier.

Menezes Filho N. A.; \& Oliveira, A. P. (2014). A contribuição da educação para a queda na desigualdade de renda per capita no Brasil. Retrieved from https://www.insper.edu.br/wp-content/uploads/2012/05/PolicyPaper_Educacao_

Desigualdade.pdf

Miller, J. H. (2015). A crude look at the whole: The science of complex systems in business, life, and society. New York, NY: Basic Books.

Mitchell, M. (2011). Complexity: A guided tour. Oxford, UK: Oxford University Press.

Mitnik, P. A.; \& Grusky, D. B. (2015). Economic mobility in the United States. Retrieved from http://www.pewtrusts.org/ /media/assets/2015/07/fsm-irs-report_artfinal.pdf

Mittal, C., \& Griskevicius, V. (2016). Silver spoons and platinum plans: How childhood environment affects adult health care decisions. Journal of Consumer Research, 43(4), 636-656.

Moore, D. (2014). Trauma runs deep for Romania's children adopted in Canada. Retrieved from https://www.thestar.com/news/canada/2014/02/27/trauma_runs_deep _for_romanias_lost_children_in_canada.html

Morecroft, J. D. W. (2015). Strategic modelling and business dynamics: A feedback systems approach (2nd ed.). Chichester, UK: John Wiley and Sons.

Morison, S. J.; Ames, E. W.; \& Chisholm, K. (1995). The development of children adopted from Romanian orphanages. Merrill-Palmer Quarterly, 41, 411-430. 
Morris, A. S., Robinson, L. R., Hays-Grudo, J., Claussen, A. H., Hartwig, S. A., \& Treat, A. E. (2017). Targeting parenting in early childhood: A public health approach to improve outcomes for children living in poverty. Child Development, 88(2), 388-397.

Mossakowski, K. N. (2008). Is the duration of poverty and unemployment a risk factor for heavy drinking? Social Science \& Medicine, 67(6), 947-955.

Moura Jr., J. F. (2015). Pobreza multidimensional e bem-estar pessoal: Um estudo acerca da vergonha $e$ da humilhação (Doctoral dissertation). Retrieved from https://www.lume.ufrgs.br/bitstream/handle/10183/140913/000991608.pdf

Mullainathan, S., \& Shafir, E. (2013). Scarcity: Why having too little means so much. New York, NY: Time Books.

Murray, J., Cerqueira, D. R., \& Kahn, T. (2013). Crime and violence in Brazil: Systematic review of time trends, prevalence rates and risk factors. Aggression and Violent Behavior, $18,471-483$.

Mustard, F.; \& Young, M. E. (2007). Measuring child development to leverage ECD policy and investment. In M. E. Young (Ed.). Early child development - from measurement to action: A priority for growth and equity (pp. 193-218). Washington, DC: World Bank Publications.

National Scientific Council on the Developing Child (2007). The science of early childhood development: Closing the gap between what we know and what we do. Retrieved from: www.developingchild.harvard.edu

Naudeau, S., Kataoka, N., Valerio, A., Neuman, M. J., \& Elder, L. K. (2011). Investing in young children: An early childhood development guide for policy dialogue and project preparation. Retrieved from http://www.educationinnovations.org/sites/default/files/Investing\%20in $\% 20$ Early $\% 20$ Childhood\%20Development.pdf

Neff, D. (2009). The satisfied poor: Evidence from South India. Retrieved from www.manchester.ac.uk/bwpi

Negriff, S., Saxbe, D. E., \& Trickett, P. K. (2015). Childhood maltreatment, pubertal development, HPA axis functioning, and psychosocial outcomes: An integrative biopsychosocial model. Developmental Psychobiology, 57(8), 984-993. https://doi.org/10.1002/dev.21340

Noble, K. G.; McCandliss, B. D.; Farah, M. J. (2007). Socioeconomic gradients predict individual differences in neurocognitive abilities. Developmental Science, 10(4), 464480 .

Noble, K. G., Houston, S. M., Brito, N. H., Bartsch, H., Kan, E., Kuperman, J. M.,..., Sowell, E. R. (2015). Family income, parental education and brain structure in children and adolescents. Nature Neuroscience, 18(5), 773-778.

Noble, K. G. (2017, March 1). Brain trust. Scientific American, 46-49.

North, D. C. (2005). Understanding the process of economic change. Princeton, NJ: Princeton University Press. 
Nowotny, H. (2013). The embarrassment of complexity. Retrieved from https://hbr.org/2013/10/the-embarrassment-of-complexity

Nyborg, K., Anderies, J. M., Dannenberg, A., Lindahl, T., Schill, C., Schlüter, M., ... \& Zeeuw, A. (2016). Social norms as solutions. Science, 354(6308), 42-43.

Olson, G., \& Schober, B. L. (1993). The satisfied poor. Social Indicators Research, 28, 173-193. http://doi.org/10.1007/BF01079657

OECD - Organization for Economic Cooperation and Development (2017a). How's Life in Brazil? Retrieved from https://www.oecd.org/brazil/Better-Life-Initiative-countrynote-Brazil.pdf

OECD - Organization for Economic Cooperation and Development (2017b). Education at a glance 2017. Retrieved from http://www.keepeek.com/Digital-AssetManagement/oecd/education/education-at-a-glance-2017_eag-2017-en

Osborne, C. (2016). Home visiting programs: Four evidence-based lessons for policymakers. Behavioral Science \& Policy, 2(1), 29-36.

OXFAM (2017). A distância que nos une: Um retrato das desigualdades brasileiras. Retrieved from https://www.oxfam.org.br/sites/default/files/arquivos/Relatorio_A_ distancia_que_nos_une.pdf

Panko, B. (2017). Where did the FDA come from, and what does it do? Retrieved from https://www.smithsonianmag.com/science-nature/origins-FDA-what-does-it-do180962054/

Pareglio, S.; Vaglio, A.; Grasso, M.; Migliavacca, S.; \& Di Giulio, E. (2005). Modelling sustainable human development in a capability perspective. Retrieved from https://econpapers.repec.org/paper/wpawuwppe/ 0504008.htm

Patrick, M. E., Wightman, P., Schoeni, R. F., \& Schulenberg, J. E. (2012). Socioeconomic status and substance use among young adults: A comparison across constructs and drugs. Journal of Studies on Alcohol and Drugs, 73(5), 772-782.

Pechmann, C., Biglan, A., Grube, J. W., \& Cody, C. (2012). Transformative consumer research for addressing tobacco and alcohol consumption. In D. G. Mick, S. Pettigrew, C. Pechmann, \& J. L. Ozanne (Eds.), Transformative consumer research for personal and collective well-being (pp. 353-389). New York, NY: Routledge.

Perkins, D. (1995). Outsmarting IQ: The emerging science of learnable intelligence. New York, NY: Free Press.

Peters, B. G., \& Hogwood, B. W. (1985). In search of the issue-attention cycle. The Journal of Politics, 47(1), 238-253.

Peters, B. J. (1998). The Head Start mother: Low-income mothers' empowerment through participation (children of poverty). New York, NY: Garland.

Pew Research Center (n.d.). Social trends. Retrieved from http://www.pewresearch.org/.

Pianka, E. R. (1970). On r- and K-selection. American Naturalist, 104, 592-596. 
Piff, P. K., Stancato, D. M., Côté, S., Mendoza-Denton, R., \& Keltner, D. (2012). Higher social class predicts increased unethical behavior. Proceedings of the National Academy of Sciences, 109(11), 4086-4091.

Piff, P. K. (2014). Wealth and the inflated self: Class, entitlement, and narcissism. Personality and Social Psychology Bulletin, 40(1), 34-43.

Pinker, S. (2012). The better angels of our nature: Why violence has declined. Westminster, UK: Penguin Books.

PISA - Programme for International Student Assessment (2016). PISA 2015 results in focus. Retrieved from: http://www.oecd.org/pisa/pisa-2015-results-in-focus.pdf

Poletto, M., \& Koller, S. H. (2008). Contextos ecológicos: Promotores de resiliência, fatores de risco e de proteção. Estudos de Psicologia, 25(3), 405-416.

Prilleltensky, I. (2008). The role of power in wellness, oppression, and liberation: The promise of psychopolitical validity. Journal of Community Psychology, 36(2), 116-136.

Qureshi, M. A.; \& Davidsen, P. I. (2012). Conceptualizing human centered development: The case Pakistan. Proceedings of the 30th International Conference of the System Dynamics Society. St. Gallen, Switzerland: System Dynamics Society.

Radianti, J. (2004). Modeling government external debt and sustainability of fiscal policy. Proceedings of the 22nd International Conference of the System Dynamics Society. Oxford, UK: System Dynamics Society.

Radzicki, M. J., \& Sterman, J. D. (1994). Evolutionary economics and system dynamics. In R. W. England (Ed.), Evolutionary concepts in contemporary economics (pp. 61-89). Ann Arbor, MI: The University of Michigan Press.

Ramey, C.; \& Ramey, S. (1998). Prevention of intellectual disabilities: Early interventions to improve cognitive development. Preventive Medicine, 27(2), 224-232.

Raphael, D. (2011). Poverty in childhood and adverse health outcomes in adulthood. Maturitas, 69(1), 22-26.

Randers, J. (1973). Conceptualizing dynamic models of social systems: Lessons from a study of social change (Doctoral dissertation). Retrieved from https://dspace.mit.edu/bitstream/handle/1721.1/13813/24563662-MIT.pdf

Randers, J. (2012). 2052: A global forecast for the next forty years. White River Junction, VE: Chelsea Green Publishing.

REDE NOSSA SÃO PAULO (2016). Mapa da desigualdade 2016. Retrieved from http://www.nossasaopaulo.org.br/arqs/mapa-da-desigualdade-completo-2016.pdf

Repenning, N., Kieffer, D., \& Astor, T. (2017). The most underrated skill in management. Retrieved from https://sloanreview.mit.edu/article/the-most-underrated-skill-inmanagement/

Richardson, G. P. (1996). Problems for the future of system dynamics. System Dynamics Review, 12(2), 141-157. 
Richardson, G. P. (1999). Feedback thought in social science and systems theory. Waltham, MA: Pegasus Communications.

Rieckhoff, K., \& Maxwell, J. R. (2017). How the public sector can remain agile beyond times of crisis. Retrieved from http://www.mckinsey.com/industries/public-sector/ourinsights/how-the-public-sector-can-remain-agile-beyond-times-of-crisis

RIO GRANDE DO SUL - Secretaria Estadual da Saúde (n.d.). Programa Primeira Infância Melhor. Retrieved from http://www.pim.saude.rs.gov.br

Rittel, H. W. J., \& Webber, M. M. (1973). Dilemmas in a general theory of planning*. Policy Sciences, 4, 155-169.

Roberto, N. (2012). How to change the world: A manual for social marketers - using insighting to change social behavior to solve social problems. Quezon City, Philippines: FlipSide Publishing Services.

Rogers, E. M. (1983). Diffusion of Innovations (3rd ed.). New York, NY: Free Press.

Rolnick, A. J., \& Grunewald, R. (2007). The economics of early childhood development as seen by two Fed economists. Community Investments, 19(2), 13-15.

Ryan, R. M., \& Deci, E. L. (2002). Self-determination theory: An organismic dialectical perspective. In E. L. Deci \& R. M. Ryan (Eds.), Handbook of self-determination research (pp. 3-33). Rochester, NY: University of Rochester Press.

Sachs, J. (2005). The end of poverty : Economic possibilities for our time. London, UK: Penguin Books.

Saeed, K. (1987). A Re-evaluation of the effort to alleviate poverty and hunger. Socioeconomic Planning Sciences, 21(5), 291-304.

Saeed, K. (1994:2016a). Development planning and policy design: A system dynamics approach (2nd ed.) [Kindle version]. Retrieved from Amazon.com.

Saeed, K. (2016b). Systems thinking metaphors for illuminating fundamental policy dilemmas. Retrieved from http://digitalcommons.wpi.edu/cgi/viewcontent.cgi? article $=1004 \&$ context $=$ ssps-papers

Safra, L., Algan, Y., Tecu, T., Grèzes, J., Baumard, N., \& Chevallier, C. (2017). Childhood harshness predicts long-lasting leader preferences. Evolution and Human Behavior, 38(5), 645-651.

SÃO PAULO - Secretaria da Saúde (n.d.). Programa São Paulo Pela Primeiríssima Infância. Retrieved from http://portal.saude.sp.gov.br/ses/perfil/profissional-dasaude/areas-tecnicas-da-sessp/saude-da-crianca/sao-paulo-pela-primeirissima-infancia

Sarkar, C., \& De, A. (2015). The ecosystem of poverty: Lessons learned from the $\$ 300$ house project. Retrieved from https://thinkers.in/the-ecosystem-of-poverty-lessonslearned-from-the-300-house-project/

Schein, E. H. (2010). Organizational culture and leadership (4th ed.). San Francisco, CA: John Wiley \& Sons. 
Schlomer, G. L., \& Cho, H. J. (2017). Genetic and environmental contributions to age at menarche: Interactive effects of father absence and LIN28B. Evolution and Human Behavior, 38(6), 761-769.

Schwarz, N., Newman, E., \& Leach, W. (2016). Making the truth stick \& the myths fade: Lessons from cognitive psychology. Behavioral Science \& Policy, 2(1), 85-95.

Schweinhart, L. J. (2003). Benefits, costs, and explanation of the High/Scope Perry Preschool Program. 2003 biennial meeting of the Society for Research in Child Development. Tampa, FL: Society for Research in Child Development.

Seligman, M. E. P. (1972). Learned helplessness. Annual Review of Medicine, 23(1), $407-$ 412. http://doi.org/10.1146/annurev.me.23.020172.002203

Seligman, M. E. P. (2011). Flourish : A visionary new understanding of happiness and well-being. New York, NY: Free Press.

Sellitto, M.; Ciaramelli, E.; \& di Pellegrino, G. (2011). The neurobiology of intertemporal choice: Insight from imaging and lesion studies. Review of Neuroscience, 22(5), 565-574.

Sen, A. (1999). Development as freedom. New York, NY: Anchor Books.

Senge, P. M., \& Forrester, J. W. (1980). Tests for building confidence in system dynamics models. System dynamics, TIMS studies in management sciences, 14, 209-228.

Senge, P. M. (1990). The fifth discipline: The art and practice of the learning organization. New York, NY: Doubleday.

Senge, P. M., Hamilton, H., \& Kania, J. (2015). The dawn of system leadership. Stanford Social Innovation Review, 1-17.

Sethi, A., Mischel, W., Aber, J. L., Shoda, Y., \& Rodriguez, M. L. (2000). The role of strategic attention deployment in development of self-regulation: Predicting preschoolers' delay of gratification from mother-toddler interactions. Developmental Psychology, 36(6), 767-777.

Shonkoff, J.P.; Garner, A.S.; \& Committee on Psychosocial Aspects of Child and Family Health; Committee on Early Childhood, Adoption, and Dependent Care (2012). The lifelong effects of early childhood adversity and toxic stress. Pediatrics, 129(1), e232e246.

Simpson, J. A.; Griskevicius, V.; Kuo, S. I. -C; Sung, S.; \& Collins, W. A. (2012). Evolution, stress, and sensitive periods: The influence of unpredictability in early versus late childhood on sex and risky behavior. Developmental Psychology, 48(3), 674-686.

SINASC - Sistema de Informação sobre Nascidos Vivos (n.d.). Sistema de Informação sobre Nascidos Vivos. Retrieved from http://sinasc.saude.gov.br/default.asp

Sinclair, U. (1906:2014). The jungle. Charleston, SC: Millennium Publications.

Singer, P. (2011). The expanding circle: Ethics, evolution, and moral progress. Princeton, NJ: Princeton University Press.

Smith, J. R.; Brooks-Gunn, J.; \& Klebanov, P. K. (1997). Consequences of living in poverty for young children's cognitive and verbal ability and early school achievement. 
In G. J. Duncan, \& J. Brooks-Gunn (Eds.), Consequences of growing up poor (pp. 132189). New York, NY: Russel Sage Foundation.

Smith, W. K., \& Lewis, M. W. (2011). Toward a theory of paradox: A dynamic equilibrium model of organizing. Academy of Management Review, 36(2), 381-403.

Só, B., Franco, E. F., Carvalho, H. C., Santos, J. R. D., \& Armenia, S. (2018). Nobody deserves this fate: The vicious cycle of low human development in Guinea-Bissau. Kybernetes, 47(2), 392-408.

Soares, R. R., \& Naritomi, J. (2010). Understanding high crime rates in Latin America: The role of social and policy factors. In: R. D. Tella, S. Edwards, \& Schargrodsky, E. (Eds.), The economics of crime: Lessons for and from Latin America (pp. 19-55). Chicago, IL: University of Chicago Press.

SOBRAL - Secretaria de Educação (n.d.). Sobral tem a melhor rede pública de educação no Brasil. Retrieved from http://seducsobral.blogspot.com.br/p/blog-page_2.html

Souza, E. R. (1994). Homicídios no Brasil: O grande vilão da saúde pública na década de 80. Cadernos de Saúde Pública, 10(1), S45-S60.

Spears, D. (2011). Economic decision-making in poverty depletes behavioral control. The B.E. Journal of Economic Analysis \& Policy, 11(1), 1-42.

Stannard, D. E. (1993). American holocaust: The conquest of the new world. Oxford, UK: Oxford University Press.

Stanovich, K. E. (2005). The robot's rebellion: Finding meaning in the age of Darwin. Chicago, IL: University of Chicago Press.

Stanovich, K. E. (2010). What intelligence tests miss: The psychology of rational thought. New Haven, CT: Yale University Press.

Stanovich, K. E. (2011). Rationality and the reflective mind. New York, NY: Oxford University Press.

Starmans, C., Sheskin, M., \& Bloom, P. (2017). Why people prefer unequal societies. Nature Human Behaviour, 1(4), 0082.

Sterman, J. D. (2000a). Business dynamics : Systems thinking and modeling for a complex world. Boston, MA: Irwin/McGraw-Hill.

Sterman, J. D. (2000b). The 2000 Jay W. Forrester Award. System Dynamics Review, 16(4), 321-323.

Sterman, J. D. (2002). All models are wrong: Reflection on becoming a systems scientist. System Dynamics Review, 18(4), 501-531.

Sterman, J. D. (2006). Learning from evidence in a complex world. American Journal of Public Health, 96(3), 505-514.

Sterman, J. D. (2012). Sustaining sustainability: Creating a systems science in a fragmented academy and polarized world. In M. Weinstein and R.E. Turner (Eds), Sustainability science: The emerging paradigm and the urban environment (pp. 21-58). New York, NY: Springer. 
Strach, P. (2016). Hiding politics in plain sight: Cause marketing, corporate influence, and breast cancer policymaking. New York, NY: Oxford University Press.

Strauss, V. (2013a). Research on preschool: Setting the record straight. Retrieved from https://www.washingtonpost.com/news/answer-sheet/wp/2013/02/28/research-onpreschool-setting-the-record-straight/

Strauss, V. (2013b). Does Head Start work for kids? The bottom line. Retrieved from https://www.washingtonpost.com/news/answer-sheet/wp/2013/03/05/does-head-startwork-for-kids-the-bottom-line/

Stroh, D. P. (2015). Systems thinking for social change: A practical guide to solving complex problems, avoiding unintended consequences, and achieving lasting results. White River Junction, VT: Chelsea Green Publishing.

Suframa News (2014). Zona Franca de Manaus: Não dá pra ser contra [Video file]. Retrieved from https://www.youtube.com/watch?v=rtv6sCqWePw

Swanson, A. (2015). Why trying to help poor countries might actually hurt them. Retrieved from https:/www.washingtonpost.com/news/wonk/wp/2015/10/13/whytrying-to-help-poor-countries-might-actually-hurt-them/

Takahashi, F. (2018). Escola não muda educação sozinha, diz chefe de faculdade de NY. Retrieved from https:/www1.folha.uol.com.br/educacao/2018/03/escola-nao-mudaeducacao-sozinha-diz-chefe-de-faculdade-de-ny.shtml

Taleb, N. N. (2012). Antifragile: Things that gain from disorder. New York, NY: Random House.

Tank-Nielsen, C. (1980). Sensitivity analysis in system dynamics. In J. Randers (Ed.), Elements of the system dynamics method (p.. 226-242). Cambridge, MA: Productivity Press.

Teachman, J. D.; Paasch, K. M.; Day, R. D.; Carver, K. P. (1997). Poverty during adolescence and subsequent educational attainment. In G. J. Duncan, \& J. Brooks-Gunn (Eds.), Consequences of growing up poor (pp. 382-418). New York, NY: Russel Sage Foundation.

Teece, D. J. (2009). Dynamic capabilities and strategic management: Organizing for innovation and growth. Oxford, UK: Oxford University Press.

Teodorescu, K., \& Erev, I. (2014). Learned helplessness and learned prevalence: Exploring the causal relations among perceived controllability, reward prevalence, and exploration. Psychological Science, 25(10), 1861-1869.

Thaler, R. H. (2015). Misbehaving: The making of behavioral economics. New York, NY: W.W. Norton.

The American Presidency Project (n.d.). Radio address to the nation on welfare reform, February 15, 1986. Retrieved from: http://www.presidency.ucsb.edu/ws/?pid=36875

The Conference Board. (2015). Total economy database. Retrieved from https://www.conference-board.org/data/economydatabase/ 
The Economist (2015). Latin America: The loss of El Dorado. Retrieved from http://www.economist.com/news/leaders/21656185-after-commodity-boom-regionneeds-new-formula-growth-loss-el-dorado

The Economist (2016). Poverty in Latin America: Don't look down. Retrieved from http://www.economist.com/news/americas/21700677-escaping-poverty-was-easyenough-staying-out-it-looks-harder-dont-look-down

The Economist (2017). Why the war on poverty is about to get harder. Retrieved from https://www.economist.com/blogs/economist-explains/2017/05/economist-explains-1

The Guardian (2016). Biggest US coal company funded dozens of groups questioning climate change. Retrieved from https://www.theguardian.com/environment/2016/ jun/13/peabody-energy-coal-mining-climate-change-denial-funding

The Guardian (2017). The future of São Paulo sleeps in an improvised shack. Retrieved from https://www.theguardian.com/cities/2017/nov/27/sao-paulo-future-inequalityoccupations-homeless-movements-mtst-workers

The New York Times (2014). Repeal prohibition, again. Retrieved from https:/www.nytimes.com/interactive/2014/07/27/opinion/sunday/high-time-marijuanalegalization.html

The NICHD Early Child Care Research Network (1997). Poverty and patterns of child care. In G. J. Duncan, \& J. Brooks-Gunn, (Eds.), Consequences of growing up poor (pp. 100-131). New York, NY: Russel Sage Foundation.

The White House (2015). Remarks by the president in conversation on poverty at Georgetown University. Retrieved from https://obamawhitehouse.archives.gov/thepress-office/2015/05/12/remarks-president-conversation-poverty-georgetown-university

Thompson, V. A., Turner, J. A. P., \& Pennycook, G. (2011). Intuition, reason, and metacognition. Cognitive Psychology, 63(3), 107-140.

Thomson, A. (2010). "Tortilla riots" give foretaste of food challenge. Retrieved from https://www.ft.com/content/a0aa9ef0-d618-11df-81f0-00144feabdc0

TIME (2016). The story behind the 'Napalm Girl' photo censored by Facebook. Retrieved from http://time.com/4485344/napalm-girl-war-photo-facebook/

Tottenham, N; Hare T.A.; Quinn, B.T.; McCarry, T.W.; Nurse, M.; Gilhooly, T.; Milner, A.; Galvan, A.; Davidson, M.C.; Eigsti, I.M.; Thomas, K.M.; Freed, P.; Booma, E.S.; Gunnar, M.; Altemus, M.; Aronson, J.; \& Casey, B.J. (2010). Prolonged institutional rearing is associated with atypically large amygdala volume and difficulties in emotion regulation. Developmental Science, 13(1), pp.46-61.

Tremblay, R. E. (1999). When children's social development fails. In D. P. Keating, \& C. Hertzman (Eds.), Developmental health and the wealth of nations: Social, biological, and educational dynamics (pp. 55-71). New York, NY: The Guilford Press.

Trevor-Roper, H. R. (1969). The European witch-craze of the sixteenth and seventeenth centuries and other essays. New York, NY: Harper. 
Trochim, W. M., Cabrera, D. A., Milstein, B., Gallagher, R. S., \& Leischow, S. J. (2006). Practical challenges of systems thinking and modeling in public health. American Journal of Public Health, 96(3), 538-546. http://doi.org/10.2105/AJPH.2005.066001

Tsukayama, H. (2017). It takes more than social media to make a social movement. Retrieved from https:/www.washingtonpost.com/news/the-switch/wp/2017/01/31/ittakes-more-than-social-media-to-make-a-social-movement/

Tully, S. M., Hershfield, H. E., \& Meyvis, T. (2015). Seeking lasting enjoyment with limited money: Financial constraints increase preference for material goods over experiences. Journal of Consumer Research, 42(1), 59-75.

Turchin, P. (2007). War and peace and war: The rise and fall of empires. New York, NY: Plume.

Turchin, P. (2016). Ages of discord: A structural-demographic analysis of American history. Chaplin, CT: Beresta.

UNICEF (2016). Ending extreme poverty: A focus on children. Retrieved from https://www.unicef.org/publications/index_92826.html

UNICEF (2017). Mais de 80\% crianças ouvidas pela Unicef no Brasil temem violência. Retrieved from https://news.un.org/pt/story/2017/11/1601472-mais-de-80-de-criancasouvidas-pelo-unicef-no-brasil-temem-violencia

United Nations (2015). The Millenium Development Goals report. Retrieved from http://www.un.org/millenniumgoals/2015_MDG_Report/pdf/MDG\%202015\%20rev\%2 0(July\%201).pdf

United Nations Development Programme (n.d.a). Human development reports. Retrieved from http://hdr.undp.org/en

United Nations Development Programme (n.d.b). Multidimensional Poverty Index (MPI). Retrieved from http://hdr.undp.org/en/content/multidimensional-poverty-index-mpi

United Nations World Food Programme. (2016). The Republic of Haiti: Current issues and what the World Food Programme is doing. Retrieved from https://www.wfp.org/countries/haiti

van Brummen-Girigori, O., \& Buunk, A. (2016). Intrasexual competitiveness and nonverbal seduction strategies to attract males: A study among teenage girls from Curaçao. Evolution and Human Behavior, 37(2), 134-141. http://doi.org/10.1016/ j.evolhumbehav.2015.09.007

Velasco, C. (2017). Saneamento melhora, mas metade dos brasileiros segue sem esgoto no pais. Retrieved from https://g1.globo.com/economia/noticia/saneamento-melhoramas-metade-dos-brasileiros-segue-sem-esgoto-no-pais.ghtml

Velasquez-Manoff, M. (2013). The great divide: Status and stress. Retrieved from https://opinionator.blogs.nytimes.com/2013/07/27/status-and-stress/

Vignoles, V. L. (2009). The motive for distinctiveness: A universal, but flexible human need. In S. J. Lopes \& C. R. Snyder (Eds.), The Oxford handbook of positive psychology (pp. 679-687). New York, NY: Oxford University Press. 
Warren, K. (2008). Strategic management dynamics. West Sussex, UK: John Wiley \& Sons.

Weiland, C. (2016). Launching Preschool 2.0: A road map to high-quality public programs at scale. Behavioral Science \& Policy, 2(1), 37-46.

Wentzel, (2017). O preço da violência: Quanto os brasileiros pagam por não viverem em paz? Retrieved from http://www.bbc.com/portuguese/brasil-38852816

Werner, E. E.; Smith, R. S. (2001). Journeys from childhood to midlife: Risk, resilience, and recovery. Ithaca, NY: Cornell University Press.

Wiebe, G. D. (1952). Merchandising commodities and citizenship on television. Public Opinion Quarterly, 15(4), 679-691.

Williams, L. E.; \& Poehlman, T. A. (2017). Conceptualizing consciousness in consumer research. Journal of Consumer Research, 44(2), 231-251.

Williamson, O. E. (2000). The new institutional economics: Taking stock, looking ahead. Journal of Economics Literature, 38(3), 595-613.

Wittenborn, A. K., Rahmandad, H., Rick, J., \& Hosseinichimeh, N. (2015). Depression as a systemic syndrome: Mapping the feedback loops of major depressive disorder. Psychological Medicine, 46(3), 551-562.

World Bank Institute (2005). Introduction to poverty analysis. Retrieved from http://siteresources.worldbank.org/PGLP/Resources/PovertyManual.pdf

World Bank (2011a). The state of the poor: Where are the poor and where are they poorest? Retrieved from http://www.worldbank.org/content/dam/Worldbank/ document/State_of_the_poor_paper_April17.pdf

World Bank (2011b). Investing in young children: An early childhood development guide for policy dialogue and project preparation. Retrieved from http://documents.worldbank.org/curated/pt/691411468153855017/pdf/578760REPLAC EM053783B09780821385265.pdf

World Bank (2012). Teenage pregnancy and opportunities in Latin America and The Caribbean - on teenage fertility decisions, poverty and economic achievement. Retrieved from https://openknowledge.worldbank.org/bitstream/handle/10986/16978/831670 v20REVIS00Box385190B00PUBLIC0.pdf

World Bank (2017). Um ajuste justo: Análise da eficiência e equidade do gasto público no Brasil. Retrieved from http://documents.worldbank.org/curated/en/ 884871511196609355/pdf/121480-REVISED-PORTUGUESE-Brazil-PublicExpenditure-Review-Overview-Portuguese-Final-revised.pdf

World Bank (n.d.a). Measuring poverty. Retrieved from http://www.worldbank.org/ en/topic/measuringpoverty

World Bank (n.d.b). World development indicators. Retrieved from https://data.worldbank.org/products/wdi 
Wymer, W. (2011). Developing more effective social marketing strategies. Journal of Social Marketing, 1(1), 17-31. http://doi.org/10.1108/20426761111104400

Yoshikawa, H., \& Hsueh, J. (2001). Child development and public policy: Toward a dynamic systems perspective. Child Development, 72(6), 1887-1903. doi:10.1111/14678624.00384

Yunus, M., Moingeon, B., \& Lehmann-Ortega, L. (2010). Building social business models: Lessons from the Grameen experience. Long Range Planning, 43(2), 308-325.

Zagonel, A. A.; Rohrbaugh, J.; Richardson, G. P.; \& Andersen, D. F. (2004). Using simulation models to address "what if" questions about welfare reform. Journal of Policy Analysis and Management, 23(4), 890-901.

Zachrisson, H. D., Dearing, E., Lekhal, R., \& Toppelberg, C. O. (2013). Little evidence that time in child care causes externalizing problems during early childhood in Norway. Child Development, 84(4), 1152-1170. doi:10.1111/cdev.12040

Zachrisson, H. D., \& Dearing, E. (2015). Family income dynamics, early childhood education and care, and early child behavior problems in Norway. Child Devevelopment, 86(2), 425-440. doi:10.1111/cdev.12306

Zak, P.J. (2014). Why your brain loves good storytelling. Retrieved from https://hbr.org/2014/10/why-your-brain-loves-good-storytelling

Zaltman, G. (2003). How customers think: Essential insights into the mind of the market. Boston, MA: Harvard Business School Press.

Zanetic, A. (2005). A questão da segurança privada: Estudo do marco regulatório dos serviços particulares de segurança (Masters thesis). Retrieved from http://www.teses.usp.br/teses/disponiveis/8/8131/tde-14062007-154033/pt-br.php

Zolli, A., \& Healy, A. M. (2012). Resilience: Why things bounce back. New York, NY: Simon and Schuster. 